\title{
Numerical Calculation of Impurity Charge State Distributions
}

\author{
E. C. Crume \\ D. E. Arnurius
}




\section{DISCLAIMER}

This report was prepared as an account of work sponsored by an agency of the United States Government. Neither the United States Government nor any agency Thereof, nor any of their employees, makes any warranty, express or implied, or assumes any legal liability or responsibility for the accuracy, completeness, or usefulness of any information, apparatus, product, or process disclosed, or represents that its use would not infringe privately owned rights. Reference herein to any specific commercial product, process, or service by trade name, trademark, manufacturer, or otherwise does not necessarily constitute or imply its endorsement, recommendation, or favoring by the United States Government or any agency thereof. The views and opinions of authors expressed herein do not necessarily state or reflect those of the United States Government or any agency thereof. 


\section{DISCLAIMER}

Portions of this document may be illegible in electronic image products. Images are produced from the best available original document. 


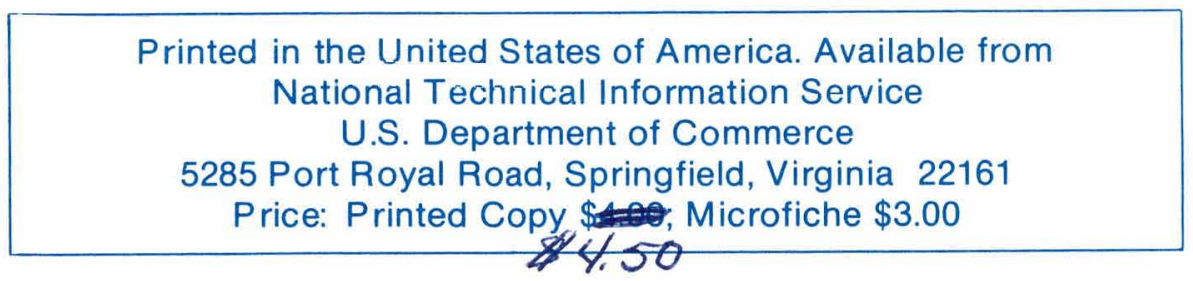

This report was prepared as an account of work sponsored by the United States Government. Neither the United States nor the Energy Research and Development Administration/United States Nuclear Regulatory Commission, nor any of their employees, nor any of their contractors, subcontractors, or their employees, makes any warranty, express or implied, or assumes any legal liability or responsibility for the accuracy, completeness or usefulness of any information, apparatus, product or process disclosed, or represents that its use would not infringe privately owned rights. 
Contract No. W-7405-eng-26

FUSION ENERGY DIVISION

NUMERICAL CALCULATION OF IMPURITY CHARGE STATE DISTRIBUTIONS

E. C. Crume and D. E. Arnurius

Date Published - September 1977

This report was prepared as an account of Weither

sponsoled Sistes nor the Uninistration, nos any of

the Uliled Development Ad of theis contes any

Researcentoyces, not any employees. makes legal

their entors, or implied, or assumes anpleteness

suberanty, express or in for the accuracy, cous, product or

Tiphility or respor any information, appa its use would nor

or usefuiness of and iepresents

process disclosed, oumed rights.

infringe privin -

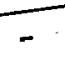

\author{
Prepared by the \\ OAK RIDGE NATIONAL LABORATORY \\ Oak Ridge, Tennessee 37830 \\ operated by \\ UNION CARBIDE CORPORATION \\ for the \\ ENERGY RESEARCH AND DEVELOPMENT ADMINISTRATION
}

DISTRIBUTION OE. IHIS DOCUAAENT IS UNLIMITED 


\section{THIS PAGE}

\section{WAS INTENTIONALLY LEFT BLANK}




\section{ABSTRACT}

The numerical calculation of impurity charge state distributions using the computer program IMPOYN is discussed. The time-dependent corona atomic physics model used in the calculations is reviewed, and general and specific treatments of electron impact ionization and recombination are referenced. The complete program and two examples relating to tokamak plasmas are given on a microfiche so that a user may verify that his version of the program is working properly. In the discussion of the examples, the corona steady-state approximation is shown to have significant defects when the plasma environment, particularly the electron temperature, is changing rapidly. 


\section{THIS PAGE}

WAS INTENTIONALLY

LEFT BLANK 
CONTENTS

ABSTRACT ..............................

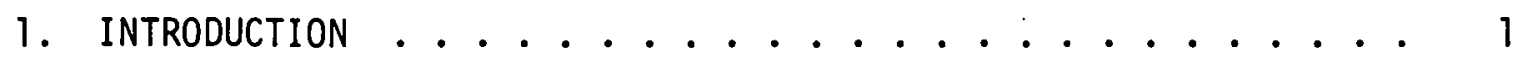

2. THE CORONA MOdel RATE EqUATIONS ............. 3

2.1 THE CORONA MODEL ..................... 3

2.2 THE RATE COEFFICIENTS ............. 5

2.2.1 General .................... 5

2.2.2 Ionization Rate Coefficients . . . . . . 6

2.2.3 Recombination Rate Coefficients ........ 7

3. NUMERICAL SOLUTION OF THE RATE EQUATIONS ......... 11

3.1 THE NORMALIZED CHARGE STATE DISTRIBUTION VECTOR .... 11

3.2 A REDUCED CHARGE STATE DISTRIBUTION SYSTEM AND ITS ASSOCIATED ERROR ................... 13

3.3 PROPAGATION OF THE CURRENT ERROR ........... 18

3.4 A STRATEGY FOR MONITORING THE ERROR AND ALTERING

THE SET OF ACTIVE EQUATIONS ............ . . 19

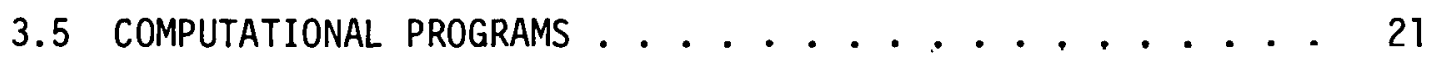

4. EXAMPLES ............................. 27

4.1 EXAMPLE I: CORONA EQUILIBRIUM ............ 27

4.2 EXAMPLE II: TIME-DEPENDENT $\mathrm{T}_{\mathrm{e}}$ AND $\mathrm{n}_{\mathrm{e}} \ldots \ldots . \ldots . . . . .29$

5. SUMMARY AND CONCLUSIONS ................ 33 


\section{INTRODUCTION}

It is well known that unwanted ions, called impurities, are found in magnetically confined plasmas created for controlled thermonuclear fusion research. The role of impurities in the transport and in the balance of both particles and energy in one of the most promising types of plasma confinement devices, the tokamak, 1 is a topic of intense and widespread current research, both theoretical and experimental. Knowledge of the ionic state (charge state) of a given impurity, or, more generally, of the distribution of charge states of a given impurity element as a function of position in a plasma is critical to such research and its application. For example, the Coulombic friction among various ions and with the electrons which determines classical (i.e., nonturbulent) particle and heat transport depends on the magnitudes of the charge states of the interacting species. ${ }^{2}$ Also, as is well known from atomic physics, the quantity and character of the electromagnetic radiation emitted by ions interacting with electrons depend on the ionic charge, and the amount of such radiation lost from a plasma can be an important part of the plasma energy balance. ${ }^{3}$ Tokamak plasmas are considered to be "steady state" from the standpoint of equilibrium and stability, but the density and temperatures of the plasma constituents are functions of position in the plasma. Even this "steady-state" plasma must be created from a neutral gas by ionization, and also during the "steady state" there are more or less significant changes in plasma density and temperature as a function of time.

In order to study the temporal evolution of impurity charge states in such plasmas, we have created the computer program IMPDYN 4 (from IMPurity DYNamics) which can be used either alone with proper input or as a subroutine of another program, such as a tokamak transport code, 5 which supplies the necessary input. The atomic physics model we use is the time-dependent corona mode 1,6 although the code will trivially generate steady-state corona model (corona equilibrium) ionic distributions. The set of coupled first order differential equations describing the model, the rate equations, is integrated in time using an adaptation of a "stiff" equation solver. 7 The number of possible equations to be 
integrated for a given high-Z impurity such as tungsten (atomic number 74 - therefore 75 equations including the neutral species) may itself be large, and there are usually several impurities present, which may yield a large number of equations even if the impurities have low or intermediate atomic numbers.

Thus, the number of equations to be integrated may be cumbersomely large and their integration excessively time consuming, especially if the rate equation solver is being used as a subroutine of another program which already may require a large amount of computer core and/or computation time. Consequently, we have implemented in IMPDYN a scheme by which the program decides which equations govern the evolution of the species present in significant quantities at a given time and integrates only these equations. Because rarely as many as half the possible ionic states of an impurity are likely present in significant quantities at a given point in a plasma at a given time, and frequently much fewer, this scheme can more than halve computation time. Because the level of significance is in input quantity, the user can decide how detailed (or crude) an analys is is to be made.

In Sect. 2, the corona atomic physics model is briefly reviewed, and the sources of the rate coefficients we have used are noted. The mathematics of solution of the rate equations, the scheme for integrating only the "significant" cquations, and the current version of IMPnYN are discussed in Sect. 3. Two examples illustrative of the use of the program, an approach to corona equilibrium and a neutral injection heating experiment in a tokamak, are given in Sect. 4 . In Sect. 5 the conclusions are summarized. A complete program listing with numerous comment cards and the two detailed examples are given on the microfiche enclosed in a pocket on the inside back cover of the report. 


\section{THE CORONA MODEL RATE EQUATIONS}

\subsection{THE CORONA MODEL}

The corona model in both its steady-state and time-dependent forms is discussed in detail by McWhirter, 6 so we only summarize here. The time-dependent corona model was evolved from the steady-state corona model, an atomic model proposed to explain certain spectral features of the solar corona. ${ }^{8,9}$ The atomic processes involved are electron col1 isional ionization, radiative recombination, and excitation and spontaneous decay of excited atomic and fonic states. Jordan 10 has more recently included the additional collisional electronic processes of auto-ionization and dielectronic recombination. For plasmas with electron densities and temperatures in the range of interest, 1 we may decouple the radiation problem (i.e., collisional excitation and spontaneous decay) from the ionic distribution problem and consider only the ground states of the ions (and atoms) involved. 6 (In fact, we will not consider the radiation problem any further here, except to remark that by applying the appropriate coefficients one can determine the radiation from the ionic distributions and the recombination rates calculated by IMPDYN.) The time-dependent corona model was first used to analyze laboratory plasmas by Breton 11 and by Hobbs et al.; 12 $^{12}$ the latter workers also coupled the model to a plasma.transport model. The steady-state model follows from the time-dependent model by setting all the time derivatives of the ion densities equal to zero, so we treat the steadystate model as a special case.

We may state the assumptions of the time-dependent corona model as follows:

(1) It is assumed that the plasma electron velocity distribution can always be adequately approximated by a Maxwellian distribution of temperature $T_{e}$, where $T_{e}$ may, however, be a function of both time and position within the plasma. This assumption has two aspects. First, thermalization of the distribution following changes in plasma conditions is assumed to occur on a much faster time scale than the time scale of the problem we are considering. ${ }^{6}$ Also, perturbations to the 
Maxwellian due to electric currents and to magnetic geometry effects ${ }^{1}$ are neglected as being of too high an order. No assumptions as to the form of the ion (or atom) velocity distribution need to be made other than that its "temperature" must be low enough $\left(T_{i} \lesssim T_{e}\right)$ that the relative electron-ion (-atom) velocity may be approximated by the electron velocity.

(2) It is assumed that all atomic processes result from two-body collisions between electrons and atoms or ions in their ground states. This is straightforward for collisional ionization and radiative recombination, but any auto-ionization and dielectronic recombination rate coefficients used must be related to ground state populations. There are also other perturbative corrections, which are summarized in Ref. 10.

(3) It is assumed that any atomic radiation emitted escapes entirely from the plasma (the optically thin approximation).

We may then write the differential equation governing the time evolution of the density $n_{j}(\vec{r}, t)$ of the ground state of an ion of charge $j$,

$$
\frac{d n_{j}}{d t}=n_{e}\left[n_{j-1} S_{j-1}+n_{j+1} \alpha_{j+1}-n_{j}\left(S_{j}+\alpha_{j}\right)\right],
$$

where $n_{e}(\vec{r}, t)$ is the electron density. The ionization rate coefficient $S_{j}\left(T_{e}\right)$ for the ion of charge $j$ is the moment of the product of the ionization cross section $\sigma_{j}(|\vec{v}|)$ with the relative velocity $|\vec{v}|$, which we here take to be the electron velocity, over the assumed Maxwellian electron distribution

$$
S_{j}\left(T_{e}\right)=\frac{1}{n_{e}} \int d^{3} v \sigma_{i}(|\vec{v}|)|\vec{v}| f_{e o}\left(T_{e}\right)
$$

The recombination rate coefficient $\alpha_{j}\left(T_{e}\right)$ is a similar moment of the recombination cross section $\sigma_{r}(|\vec{v}|)$. We reiterate that auto-ionization, dielectronic recombination, or other effects to be included must have rate coefficients which apply to ground state populations. (Otherwise, obviously, we would have to have an enormously increased number of equations - one for each excited state.) For a given element, there are 
$Z+1$ such coupled equations where $j$ ranges (in integral steps) from $j=0$ (atoms) to $j=Z$ (fully ionized ion, $i . e .$, the bare nucleus). Although analytic solutions of this set are possible if $T_{e}$ is constant, 6 such solutions are of limited value for real plasmas, and we are led to numerical solutions such as those accomplished by IMPDYN. If the lefthand sides of the $z+1$ equations for an element are set equal to zero, the well-known steady-state corona model solution,

$$
\frac{n_{j}}{n_{j+1}}=\frac{\alpha_{j+1}}{S_{j}}
$$

is obtained, expressing the balance between ionization and recombination rates.

Before discussing the sources of the ionization and recombination rate coefficients, we draw attention to the fact that equations of the form of Eq. (1) obviously do not account for sources and sinks which may arise from particle transport or externally, such as from wall sources of neutral atoms. To account for particle transport in a simple manner, one can add a term $-n_{j} / \tau_{j}$ to Eq. (1) where $\tau_{j}(\vec{r}, t)$ is an appropriate decay time. If $\tau_{j}$ is positive the term represents a sink; if negative, a source. We have not included such terms in IMPDYN because of its planned use with tokamak transport codes for problems in which the transport occurs on time scales such that alternating computation of atomic physics processes and transport can be made. We also do not include external source terms. Such terms may have arbitrary forms, and, in any event, we would try to treat them on the same time scale as the transport; i.e., we consider only weak external source terms.

\subsection{THE RATE COEFFICIENTS}

\subsubsection{General}

The selection of the coefficients to use in the solution of the coupled equations of the form of Eq. (1) is decidedly problem-dependent. It might occur, especially for low atomic number elements, that the 
ionization and recombination rate coefficients are known as accurately as the changing electron temperature and density environment in the problem. On the other hand, it is probably more likely, at least for tokamak research, that there are insufficient experimental data and/or theoretical calculations to determine the desired rate coefficients to within a factor of two or more. If the rate coefficients are entirely obtained from theory, it may be that the overall problem is such that some or all of the theoretical calculations may be done at the same time as the solution of the rate equations. However, if the atomic physics aspect of the problem is only part of the calculation - say, for example, if one is including impurity atomic physics in a tokamak discharge simulation - such theoretical calculations may be too cumbersome and/or time consuming to include. It is not our purpose here to assess the merits of rate coefficients from different sources. Our own criterion for most of the calculations that we perform is that the coefficients include as much physics as possible while retaining a calculationally simple form. Because the rate coefficient calculations in IMPDYN are handled in subroutines, the user has the option of providing his own subinitines for that purpose. Besides the references to rate coefficients already listed and those to be given below, we refer the reader to the newsletter Atomic Data for Fusion ${ }^{13}$ for the most current references and summaries of new results. We now turn to a brief discussion of the rate coefficients included in the subroutines of IMPDYN.

\subsubsection{Ionization Rate Coefficients}

Wherever possible, for both ionization and recombination rate coefficients we use tabulations such as those of Jordan ${ }^{14}$ and Summers ${ }^{15}$ for two reasons. First, more physics went into such calculations (e.g., dielectronic recombination and auto-ionization) than can be put into simple expressions such as the ones we give below for use when such tables are not available. Also, on a computer, interpolation within a table is more rapid than evaluation of a complicated expression. However, when such tabulations are not available, and this is generally true for high atomic number impurities such as molybdenum and tungsten, 
we use H. J. Kunze's semiempirical expression for the ionization rate coefficient ${ }^{16}$ with the numerical coefficient reduced by a factor of two as he later suggested: 17

$$
\begin{aligned}
S_{j}\left(T_{e}\right)=3.75 \times 10^{-8} \frac{q_{j}}{E_{j}}\left[\left(\ln \frac{40 T_{e}}{E_{j}}\right)^{3}+40\right] \\
\times \frac{T_{e}^{1 / 2}}{E_{j}+3 T_{e}} \exp \left(-E_{j} / T_{e}\right) \mathrm{cm}^{3} \mathrm{~s}^{-1} .
\end{aligned}
$$

In Eq. (4), $q_{j}$ is the number of electrons in the outermost shell of the atom or ion, $T_{e}$ is the electron temperature of the plasma, and $E_{j}$ is the ionization energy obtained either experimentally 18 or from the theoretical calculations of Carlson et al. ${ }^{19}$. When no experimental values are available. We note that we also use Eq. (4) to fill the uncompleted portions of tabulations such as those referred to above.

There are two exceptions to the above discussion, carbon and oxygen. For these two elements we have used unpublished work by Dory 20 based on the results of Beigman et al.,21 who give

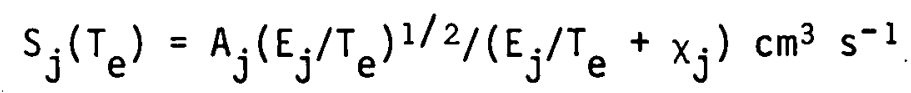

where the values of $A_{j}$ and $x_{j}$ are given in Table 1 .

\subsubsection{Recombination Rate Coefficients}

The calculation of the dielectronic recombination contribution to the total recombination rate coefficient is generally so complicated that we do not calculate it. Consequently, when tabulations of total recombination rate coefficients are not available, except for the cases of carbon and oxygen, we calculate only the radiative recombination rate with a few minor corrections along the line pursued by Jordan. 10 For radiative recombination from the charge state $j$ we use the expression of Burgess and Seaton, 22

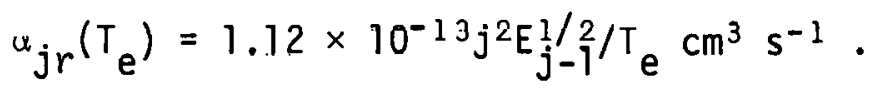


Table 1. Parameters for ionization and recombination rate coefficients of carbon. and oxygen

\begin{tabular}{lccll}
\hline $\begin{array}{c}\text { Spectroscopic } \\
\text { state }\end{array}$ & $\begin{array}{c}\mathrm{A}_{j} \\
\left(\times 10^{8}\right)\end{array}$ & $x_{j}$ & $\begin{array}{c}\mathrm{B}_{j} \\
\left(\times 10^{12}\right)\end{array}$ & $\psi_{j}$ \\
\hline CI & 13.0 & 0.36 & & \\
CII & 3.6 & 0.40 & 0.165 & 0.1 \\
CIII & 2.4 & 0.73 & 0.287 & 0.5 \\
CIV & 0.83 & 0.78 & 0.576 & 0.87 \\
CV & 0.104 & 0.62 & 0.73 & 0.9 \\
CVI & 0.037 & 0.62 & 0.38 & 0.64 \\
CVII & & & 0.56 & 1.0 \\
OI & 11.0 & 0.285 & & \\
OII & 3.35 & 0.285 & 0.088 & 0.1 \\
OIII & 1.42 & 0.33 & 0.255 & 0.15 \\
OIV & 0.9 & 0.38 & 0.412 & 0.53 \\
OV & 0.43 & 0.42 & 0.583 & 0.75 \\
OVI & 0.17 & 0.44 & 0.777 & 0.82 \\
OVII & 0.034 & 0.62 & 0.925 & 0.93 \\
OVIII & 0.013 & 0.62 & 0.46 & 0.74 \\
OIX & & & 0.65 & 1.0 \\
\hline
\end{tabular}

To this we add the correction due to Wilson ${ }^{23}$ for radiative decay from bound levels above the thermal principal quantum number limit $n_{t}$ to those below

$$
\alpha_{j b}\left(T_{e}\right)=9.60 \times 10^{-13 j^{4}} \exp \left(x_{t j} / T_{e}\right) / n_{t j} j^{1 / 2} e^{2 m^{3}} s^{-1},
$$

where Wilson ${ }^{23,24}$ gives

$$
x_{t j}=1.29 \times 10^{-4}\left(E_{j} / T_{e}\right)^{1 / 7 n_{e}^{2 / 7}}
$$


and Griem ${ }^{25}$ gives

$$
n_{t j}=1.26 \times 10^{2}\left(\frac{j^{12} T_{e}}{n_{e}^{2} E_{H}}\right)^{1 / 17} \exp \left(\frac{4 j^{2} E_{H}}{17 n_{t j}^{3} T_{e}}\right),
$$

where $E_{H}$ is the ionization energy of the hydrogen atom. Two further corrections by Wilson 23 are included but are generally negligible for tokamak plasmas. The first is for three-body recombination from the continuum,

$$
\alpha_{j c b}=4.45 \times 10^{-29} n_{e} /\left(j T_{e}\right)^{2} \mathrm{~cm}^{3} \mathrm{~s}^{-1},
$$

and the second is for collisional de-excitation from levels above the thermal limit $n_{t j}$,

$$
\alpha_{j c c}=1.48 \times 10^{-28} n_{e} \exp \left(x_{t j} / T_{e}\right) /\left(j n_{t j} T_{e}\right)^{2} \mathrm{~cm}^{3} \mathrm{~s}^{-1} .
$$

For carbon and oxygen recombination we use the expression

$$
\alpha_{j}\left(T_{e}\right)=B_{j}\left(E_{j} / T_{e}\right)^{3 / 2} /\left(E_{j} / T_{e}+\psi_{j}\right) \mathrm{cm}^{3} \mathrm{~s}^{-1}
$$

where Dory's 20 values for $B_{j}$ and $\psi_{j}$ are given in Table 1 . 
THIS PAGE

WAS INTENTIONALLY

LEFT BLANK 


\section{NUMERICAL SOLUTION OF THE RATE EQUATIONS}

\subsection{THE NORMALIZED CHARGE STATE DISTRIBUTION VECTOR}

It is advantageous to work with the normalized form of Eq. (1), so we define the normalized density or concentration of the $(j-1)$ st charge state of an impurity element as

$$
y_{j} \equiv n_{j} / \sum_{j=1}^{z+1} n_{i}
$$

where $1 \leqslant j \leqslant z+1$. Thus $j=1$ corresponds to the neutral atom and $j=$ $Z+I$ corresponds to the fully ionized $i$ on where $Z$ is the atomic number of the impurity element. The indexing is seen to be different from that in Sect. 2 and has been changed from the more physical notation used there to simplify computer programming. We denote by $y=y(t)$ the complete normalized charge state distribution vector of which $y_{j}=y_{j}(t)$ is one component. The normalization of the vector $y$ is expressed in matrix notation as

$$
e^{\top} y(t)=1
$$

where

$$
e^{\top}=(1,1, \ldots, 1)
$$

and the superscript $T$ is used to indicate the transpose of a matrix.

The vector $y$ is the solution of an initial value problem associated with a system of $n$ linear ordinary differential equations of the form taken by Eq. (1) upon normalization. We designate the ionization rate coefficient for the ion of charge $j-1$ by $I_{j}$, which corresponds to $S_{j-1}$ of Sect. 2. We designate the recombination rate coefficient for the ion of charge $j$ by $R_{j}$, corresponding to $\alpha_{j}$ of Sect. 2 . If we define

$$
\begin{aligned}
& \beta_{j}=n_{e}\left(R_{j} y_{j+1}-I_{j} y_{j}\right) ; \quad j=1,2, \ldots, n-1, \\
& \beta_{0}=\beta_{n}=0,
\end{aligned}
$$


- then $y$ satisfies the linear, homogeneous system of ordinary differential equations

$$
y_{j}^{\prime}=-\beta_{j-1}+\beta_{j}, \quad j=1, \ldots, n,
$$

where the prime indicates a time derivative and time dependence usually will not be indicated explicitly. The initial condition is given at $t=$ $t_{s}$ and satisfies

$$
e^{\top} y\left(t_{s}\right)=1, \quad y\left(t_{s}\right) \geqslant 0 .
$$

Equation (17) may be expressed in vector-matrix notation as

$$
y^{\prime}=n_{e} A y
$$

where $A$ is the tridiagonal matrix

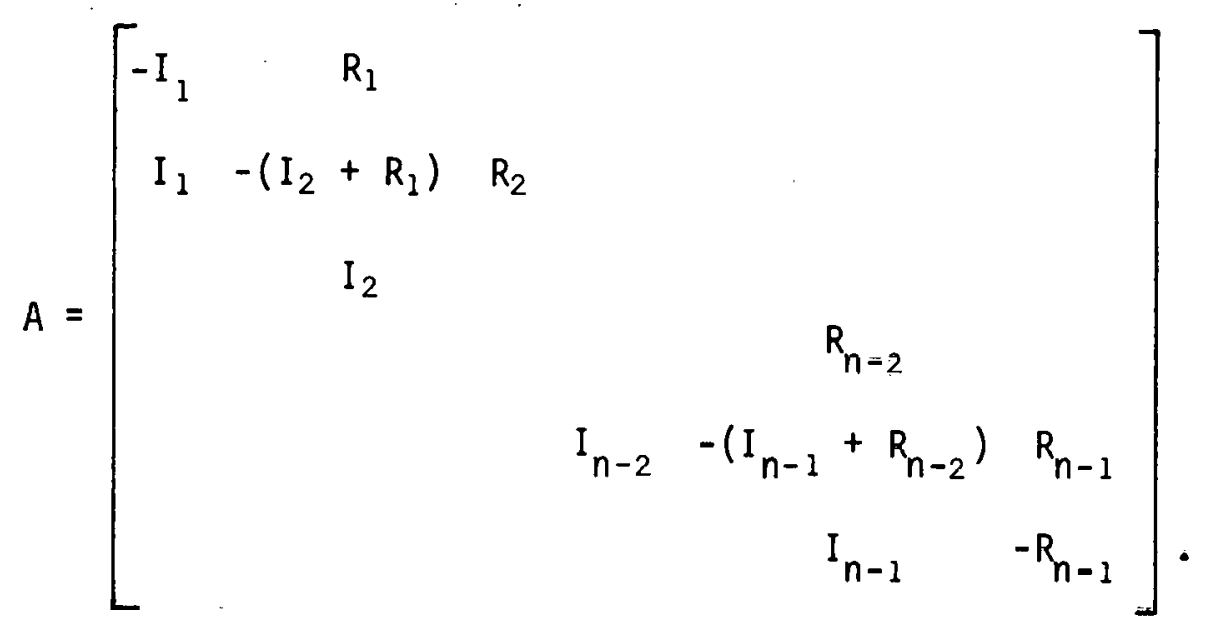

Because $e^{\top} A=0$, zero is an eigenvalue of the matrix $A$. Moreover, it can be shown that the eigenvalues of $A$ are simple, real, and nonpositive. The system of differential equations that $y$ satisfies is called a stiff system because there are some large magnitude negative eigenvalues of the matrix $n_{e} A$. If a nonstiff numerical integration procedure (e.g., RungeKutta or Adams-Moulton) is used to approximate $y$, a small step size is required to ensure the stability of the integration method, even when the terms associated with the negatively large eigenvalues have become 
relatively insignificant. For this reason, an integration procedure designed for stiff systems ${ }^{7}$ is used to approximate the solution $y$.

It is characteristic of the charge state distribution vector that a significant number, often one-third to one-half, of its components are negligibly small at any given time. However, the components that are negligible vary with time. The computational time required to solve a stiff system as described in Eqs. (19) and (20) is proportional to $n$, the number of equations in the system. If Eq. (19) can be replaced by a reduced system that adequately describes the significant components of the charge state distribution vector, then a marked saving in computational time can be realized. This approach is discussed in Sect. 3.2.

\subsection{A REDUCED CHARGE STATE DISTRIBUTION SYSTEM AND ITS ASSOCIATED ERROR}

The elimination of some equations from each end of the homogeneous system of differential equations described in Eq. (19) yields a reduced system with an inhomogeneous term. Let the reduced system comprise equations $l$ through $k$ and define

$$
\tilde{y}^{\top} \equiv\left(y_{\ell}, y_{\ell+1}, \ldots, y_{k}\right) \text {. }
$$

Then the reduced system may be expressed as

$$
\tilde{y}^{\prime}=n_{e} \tilde{A} \tilde{y}+b
$$

where

$$
b^{\top}=\left(-\beta_{\ell-1}, 0, \ldots, 0, \beta_{k}\right)
$$

and 


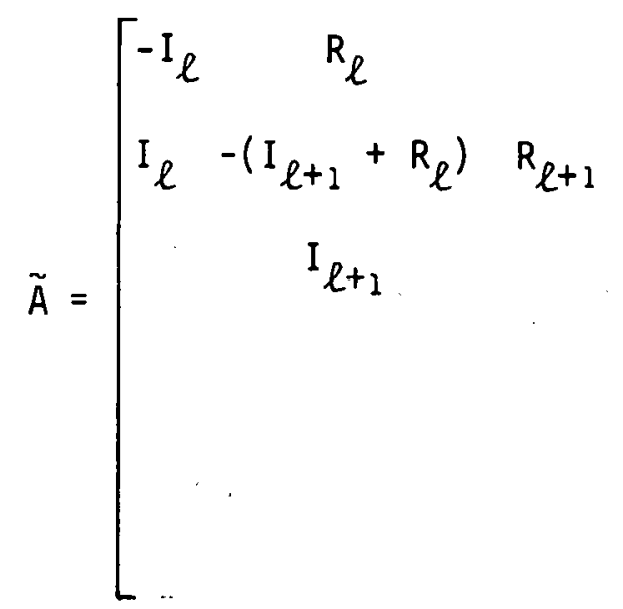

$$
\left.\begin{array}{ccc} 
& \\
I_{k-2} & -\left(I_{k-1}+R_{k-2}\right) & \\
& R_{k-1} \\
& & -R_{k-1}
\end{array}\right] \text {. }
$$

An analytical representation for the solution to the inhomogeneous problem of Eq. (22) is given by

$$
\tilde{y}(t)=\Phi(t) \Phi^{-1}(\tau) \ddot{y}(\tau)+\int_{\tau}^{t} \Phi(t) \Phi^{-1}(s) b(s) d s,
$$

where

$$
\dot{y}_{h}(t) \equiv \Phi(t) \Phi^{-1}(\bar{\tau}) \varphi(\tau)
$$

is the solution to the associated homogeneous problem with the same inilial condition at $t=\tau$. Moreover, $\Phi$ is the malrix solution to the matrix initial value problem

$$
\Phi^{-}=n_{\rho} \ddot{A}^{\Phi}, \quad \Phi(\tau)=I,
$$

where $I$ is the identity matrix of order $k-l+1$.

Define the vector $e_{j}$ to be that vector whose $j$ th component is unity, whose other components are zero, and whose dimension is to be inferred from the context, and let

$$
E_{f} \equiv-\int_{\tau}^{t} \beta_{l-1}(s) \Phi(t) \Phi^{-1}(s) e_{1} d s
$$

and 


$$
E_{b} \equiv \int_{\tau}^{t} \beta_{k}(s) \Phi(t) \Phi^{-1}(s) e_{k-\ell+1} d s
$$

Then

$$
\tilde{y}(t)-\tilde{y}_{h}(t)=E_{f}(t)+E_{b}(t) .
$$

Define the function []$^{+}$by

$$
[x]^{+} \equiv\left\{\begin{array}{l}
x \text { whenever } x \geqslant 0 \\
0 \text { otherwise }
\end{array} .\right.
$$

Let

$$
\begin{aligned}
& E_{f}^{+}(t)=\int_{\tau}^{t}\left[-\beta_{\ell-1}(s)\right]^{+} \Phi(t) \Phi^{-1}(s) e_{1} d s \geqslant 0, \\
& E_{f}^{-}(t)=\int_{\tau}^{t}\left[\beta_{\ell-1}(s)\right]^{+} \Phi(t) \Phi^{-1}(s) e_{1} d s \geqslant 0, \\
& E_{b}^{+}(t)=\int_{\tau}^{t}\left[\beta_{k}(s)\right]^{+} \Phi(t) \Phi^{-1}(s) e_{k-\ell+1} d s \geqslant 0, \\
& E_{b}^{-}(t)=\int_{\tau}^{t}\left[-\beta_{k}(s)\right]^{+} \Phi(t) \Phi^{-1}(s) e_{k-\ell+1} d s \geqslant 0 .
\end{aligned}
$$

With these functions, $\tilde{y}$ may be expressed as

$$
\tilde{y}(t)=\tilde{y}_{h}(t)+\left[E_{f}^{+}(t)+E_{b}^{+}(t)\right]-\left[E_{f}^{-}(t)+E_{b}^{-}(t)\right] .
$$

Because

$$
\left[-\beta_{\ell-1}\right]^{+} \leqslant n_{e} I_{\ell-1} y_{l-1}
$$

and 


$$
\left[\beta_{\ell-1}\right]^{+} \leqslant n_{e} R_{l-1} y_{l},
$$

it follows that

$$
E_{f}^{+}(t) \leqslant \int_{\tau}^{t} n_{e} I_{\ell-1} y_{\ell-1} \Phi(t) \Phi^{-1}(s) e_{1} d s
$$

and

$$
E_{f}^{-}(t) \leqslant \int_{\tau}^{t} n_{e} R_{l-1} y e^{\Phi(t) \Phi^{-1}(s) e_{1} d s .}
$$

Also, the components of $\Phi(t) \Phi^{-1}(s)$ are nonnegative and $e^{\top} \Phi(t)=e^{\top}$ for $t \geqslant$ $\tau$; rnnsequently

$$
\left\|E_{f}^{+}(t)\right\|_{1} \leqslant \int_{\tau}^{t} n_{e} I_{\ell-1} y_{\ell-1} d s
$$

and

$$
\left\|E_{f}^{-}(t)\right\|_{1} \leqslant \int_{\tau}^{t} \|_{e} R_{l-1} y_{l}^{d s}
$$

where $\|v\|_{1}$ denotes the $\ell_{1}$-norm of the vector $v^{\top}=\left(v_{1}, \ldots, v_{k-\ell+1}\right)$. That is,

$$
\|v\|_{1}=\left|v_{1}\right|+\ldots+\left|v_{k-\ell+1}\right| .
$$

In a similar fashion,

$$
\left\|E_{b}^{+}(t)\right\|_{1} \leqslant \int_{\tau}^{t} n_{e} R_{k} y_{k+1} d s
$$

and 


$$
\left\|E_{b}^{-}(t)\right\|_{1} \leqslant \int_{\tau}^{t} n_{e} I_{k} y_{k} d s \text {. }
$$

The reduced system to be used is not the inhomogeneous system described in Eq. (22), which is exact, but the associated homogeneous system

$$
\tilde{y}_{h}^{\prime}=n_{e} \tilde{A} \tilde{y}_{h}, \quad \tilde{y}_{h}(\tau)=\tilde{y}(\tau) .
$$

It follows from Eq. (33) that the approximation $\tilde{y}_{h}$ is low by at most the vector $E_{f}^{+}+E_{b}^{+}$and high by at most the vector $E_{f}^{-}+E_{b}^{-} \cdot E_{f}^{+}(t)$ is associated with the gain into the reduced system from the equations eliminated at the front (low index equations) and $E_{f}^{-}(t)$ is associated with the loss from the reduced system to those same equations. But the magnitude of the gain at the front over the time interval $[\tau, t]$ is bounded by the magnitude of the loss to the front over the same time interval plus the sum of the concentrations discarded by the truncation at time $\tau$. Thus,

$$
\left\|E_{f}^{+}(t)\right\|_{1} \leqslant\left\|E_{f}^{-}(t)\right\|_{1}+\sum_{j=1}^{l-1} y_{j}(\tau)
$$

and

$$
\left\|E_{f}^{+}(t)+E_{b}^{+}(t)\right\|_{1} \leqslant\left\|E_{f}^{-}(t)+E_{b}^{-}(t)\right\|_{1}+\sum_{j=1}^{l-1} y_{j}(\tau)+\sum_{j=k+1}^{n} y_{j}(\tau) .
$$

From Eqs. (36b) and (38b) it follows that

$$
\left\|E_{f}^{-}(t)+E_{b}^{-}(t)\right\|_{1} \leqslant \int_{\tau}^{t} n_{e}\left(R_{\ell-1} y_{l}+I_{k} y_{k}\right) d s .
$$

Equations (40) and (41) are used in Sect. 3.4 as the basis for the strategy to alter (add to or delete from) the set of active equations and to monitor the error arising from the use of a truncated set. 


\subsection{PROPAGATION OF THE CURRENT ERROR}

Let us assume that at $t=\tau$ the exact solution of the reduced system is denoted by $y(\tau)$ and that $y(\tau)$ is decomposed into

$$
y(\tau)=y_{a}(\tau)+E^{+}(\tau)-E^{-}(\tau)
$$

where

$$
E^{+}(\tau) \geqslant 0, E^{-}(\tau) \geqslant 0,\left[E^{+}(\tau)\right]^{\top} E^{-}(\tau)=0
$$

and $y_{a}(\tau)$ is the computed approximation to $y(\tau)$. From the linearity of the problem it follows that.

$$
\begin{aligned}
\Phi(t) \Phi^{-1}(\tau) y(\tau)= & \Phi(t) \Phi^{-1}(\tau) y_{a}(\tau)+\Phi(t) \Phi^{-1}(\tau) E^{+}(\tau) \\
& -\Phi(t) \Phi^{-1}(\tau) E^{-}(\tau),
\end{aligned}
$$

where $\Phi$ is the matrix solution to the problem described in Eq. (27) with $\ell=1$ and $k=n$. Because $\Phi(t) \Phi^{-1}(\tau) \geqslant 0$ and because $e^{\top} \Phi(t) \Phi^{-1}(\tau)=e^{\top}$, it follows that

$$
\left\|\Phi(t) \Phi^{-1}(\tau) E^{+}(\cdot)\right\|_{1}-\left\|E^{+}(\tau)\right\|_{1}
$$

and

$$
\left\|\Phi(t) \Phi^{-1}(\tau) E^{-}(\tau)\right\|_{1}=\left\|E^{-}(\tau)\right\|_{1} .
$$

Thus, the $\ell_{1}$-norm of each vector term on the right-hand side of Eq. (45) is constant. The accuracy of most integration procedures is expresscd in Leruls of a local lrunciation error hound, so it would be beneficial if some cancellation in the vector difference in Eq. (45) occurred with time.

Qualitatively there are two basic types of reduced systems. In the first, the reduced system is such that $I_{j} / R_{j}$ is large (small) for all $j$ within the reduced system. In this case the tendency is for the distribution to move toward the higher (lower) charge states. This is also true for the associated error vectors. In the second, the reduced system is 
such that $I_{j} / R_{j} \geqslant 1$ for some $j$ and $I_{j} / R_{j} \leqslant 1$ for some $j$. In this situation there is a tendency for the distribution to move toward or reside mainly in the components $j+1$ for which $I_{j} / R_{j}$ is near one. Again, the error vectors have the same tendency. In this second type with the central tendency we would expect good cancellation in the vector difference in Eq. (45). In fact, in the case of constant temperature and density the three vector terms on the right-hand side of Eq. (45) become proportional to the equilibrium charge state distribution vector as time increases. Hence, in this case, maximal cancellation occurs.

If $y^{\top}\left(t_{s}\right)=(1,0, \ldots, 0)$ or $(0, \ldots, 0,1)$, then a significant number of integration steps are often required with the first type of reduced system. Although some cancellation is to be expected with the first type, its degree is indeterminant.

\subsection{A STRATEGY FOR MONITORING THE ERROR AND ALTERING THE SET OF ACTIVE EQUATIONS}

The results of Sects. 3.2 and 3.3 need to be combined in order to monitor the error more closely on a time interval $(\tau, t)$. We let the set of active equations be equations $\ell$ through $k$ and in Eq. (43) let the components of $y_{a}(\tau)$ that correspond to deleted equations be zero. Define $\tilde{E}^{+}(t)$ to be the vector comprising the $l$ through $k$ components of the vector $\Phi(t) \Phi^{-1}(\tau) E^{+}(\tau)$ appearing in Eq. (45) and define $\tilde{E}^{-}(t)$ in the obvious way. Then

$$
\left\|\tilde{E}^{+}(t)\right\| \leqslant\left\|E^{+}(\tau)\right\|_{1},\left\|\tilde{E}^{-}(\tau)\right\|_{1} \leqslant\left\|E^{-}(\tau)\right\|_{1}
$$

Thus, the representation

$$
\tilde{y}(t)=\tilde{y}_{h}(t)+\left[\tilde{E}^{+}(t)+E_{f}^{+}(t)+E_{b}^{+}(t)\right]-\left[\tilde{E}^{-}(t)+E_{f}^{-}(t)+E_{b}^{-}(t)\right]
$$

includes the error due to an initial error at time $\tau$, as described in Eq. (43), but with the above alteration as well as the error due to using the reduced system of equations.

With the introduction of zeros into $y_{a}(\tau)$ it follows that 


$$
\left\|E^{+}(\tau)\right\|_{1}=\left\|\tilde{E}^{+}(\tau)\right\|_{1}+\sum_{j=1}^{l-1} y_{j}(\tau)+\sum_{j=k+1}^{n} y_{j}(\tau)
$$

and

$$
\left\|E^{-}(\tau)\right\|_{1}=\left\|\tilde{E}^{-}(\tau)\right\|_{1}
$$

Define

$$
L(\tau, t)=\int_{\tau}^{t} n_{e}\left(R_{l-1} y_{l}+I_{k} y_{k}\right) d s .
$$

Then on the interval $[\tau, t]$,

$$
\left\|\tilde{E}^{+}(t)+E_{f}^{+}(t)+E_{b}^{+}(t)\right\|_{1} \leqslant\left\|E^{+}(\tau)\right\|_{1}+L(\tau, t)
$$

and

$$
\left\|\tilde{E}^{-}(t)+E_{f}^{-}(t)+E_{\underline{b}}^{-}(t)\right\|_{1} \leqslant\left\|\tilde{E}^{-}(\tau)\right\|_{1_{d}}+L(\tau, t) .
$$

Let us assume that at the initial time $t=t_{s}$ the initial value is exact. Thell on the interval $\left(t_{s}, t\right)$

$$
\left\|\tilde{E}^{+}(t)+E_{f}^{+}(t)+E_{b}^{+}(t)\right\|_{1} \leqslant L\left(t_{s}, t\right)+p(t)
$$

and

$$
\left\|\tilde{E}^{-}(t)+E_{f}^{-}(t)+E_{b}^{-}(t)\right\|_{1} \leqslant !\left(t_{s}, t\right) .
$$

where $p(t)$ is the cumulative sum of the values of the deleted components through time $t$.

The components of the approximation, $\tilde{y}_{h}$, may be used in $L$ and $p$ with the result that Eq. (52) remains valid. The functions $L$ and $p$ provide a computationally simple means to monitor the error associated with the current set of active equations and to alter the set of active 
equations. In fact, except at points where the set of active equations is altered, the time derivative of the bounds on the right-hand side of Eq. (52) is

$$
n_{e}\left(R_{l-1} y_{l}+I_{k} y_{k}\right)
$$

The function $L$ may be effectively restrained by requiring the time derivative in Eq. (53) to be bounded. Indeed, if the value of the expression in Eq. (53) becomes too large, then equations should be added to the back of the current system whenever $I_{k} y_{k} \geqslant R_{\ell-1} y_{l}$ or to the front of the system whenever $R_{\ell-1} y_{l}>I_{k} y_{k}$.

A criterion for deleting equations must take two things into account. First, the proposed new set of active equations must have a sufficiently small value for the time derivative given by Eq. (53). Second, the sum of the components associated with the proposed newly deleted equations must be bounded so that the function $p$ does not become too large.

\subsection{COMPUTATIONAL PROGRAMS}

A collection of subroutines has been compiled from which it is possible to form two separate computer programs. One program, PROGTI, requires that the temperature and density be constant. Here the suffix (and elsewhere the "argument") II indicates time independence. The other program, PROGTD, allows the temperature and density functions to be time-dependent. The suffix (and elsewhere "argument") TD indicates time dependence.

Program PROGTI is designed for equilibrium calculations. In this case, the system of linear ordinary differential equations describing the normalized charge state distribution vector

$$
y^{\prime}=n_{e} A y, \quad y\left(t_{s}\right)=y_{0}
$$

has a constant coefficient matrix $n_{e} A$. PROGTI may be requested to: determine the equilibrium vector associated with Eq. (53), (NCH.NE.0); (2) approximate the eigenvalues of the coefficient matrix $n_{e} A$ in Eq. (54), (NROOTS.GT.0); (3) integrate Eq. (54) over the time interval $\left(t_{s}, t_{f}\right)$ 
with $y_{0}$ specified in subroutine YINIT; or (4) integrate Eq. (54) until the current $y(t)$ first becomes within EPSCC of the equilibrium vector associated with Eq. (54), where subroutine CONEQU contains the two criteria for measuring closeness.

Fundamentally, the equilibrium vector associated with Eq. (54) is determined from the relationship

$$
y_{j+1}=\left(I_{j} / R_{j}\right) y_{j}
$$

However, measures are followed to exclude the occurrence of machine underflows or overflows and to handle zero values for $I$ and $R$ reasonably. The equilibrium vector is approximated within subroutine EQU. Program PROGTD is designed only to integrate Eq. (54) over the interval $\left(t_{s}, t_{f}\right)$ where the temperature and density are time-dependent. Subroutines DENTMP(TD), DTDATA, and DTINIT provide for the definition of the temperature and density profiles.

Subroutine MAINI(TD) is the basic control routine for program PROGTD; subroutine MAINI(TI) is the basic control routine for program PROGTI. Subroutine DRIVES controls the numerical integraion of Eq. (54). Logic schematics of these three subroutines dre yiven in the flow charts in Figs. 1, 2, and 3 .

The subroutines, including numerous comment cards, are 11sted un the accompanying microfiche lexicographically except that the block data routines come first. The block data routine BDPARM comes first, followed by the set of block data routines BDEL, ordered according to the atomic number of the associated impurity element. The parameter EL is replaced by the chemical symbol for the element. The data within BDEL is for use with the rate coefficient routines, SVIONZ and SVRECZ, but NZ, the atomic number of the element, is used in several other routines. The block data routine BDPARM contains descriptions of all the control parameters that may be used in the definition of the problem to be solved with the computer program. All input to the program is through the block data routine BUPARM for the program PROGTI. For program PROGTD, the additional data describing the time-dependent temperature and density profiles are found within subroutine DTDATA in data statements. 


\section{FLOW CHART I \\ SUBR. MAINI (TD)}

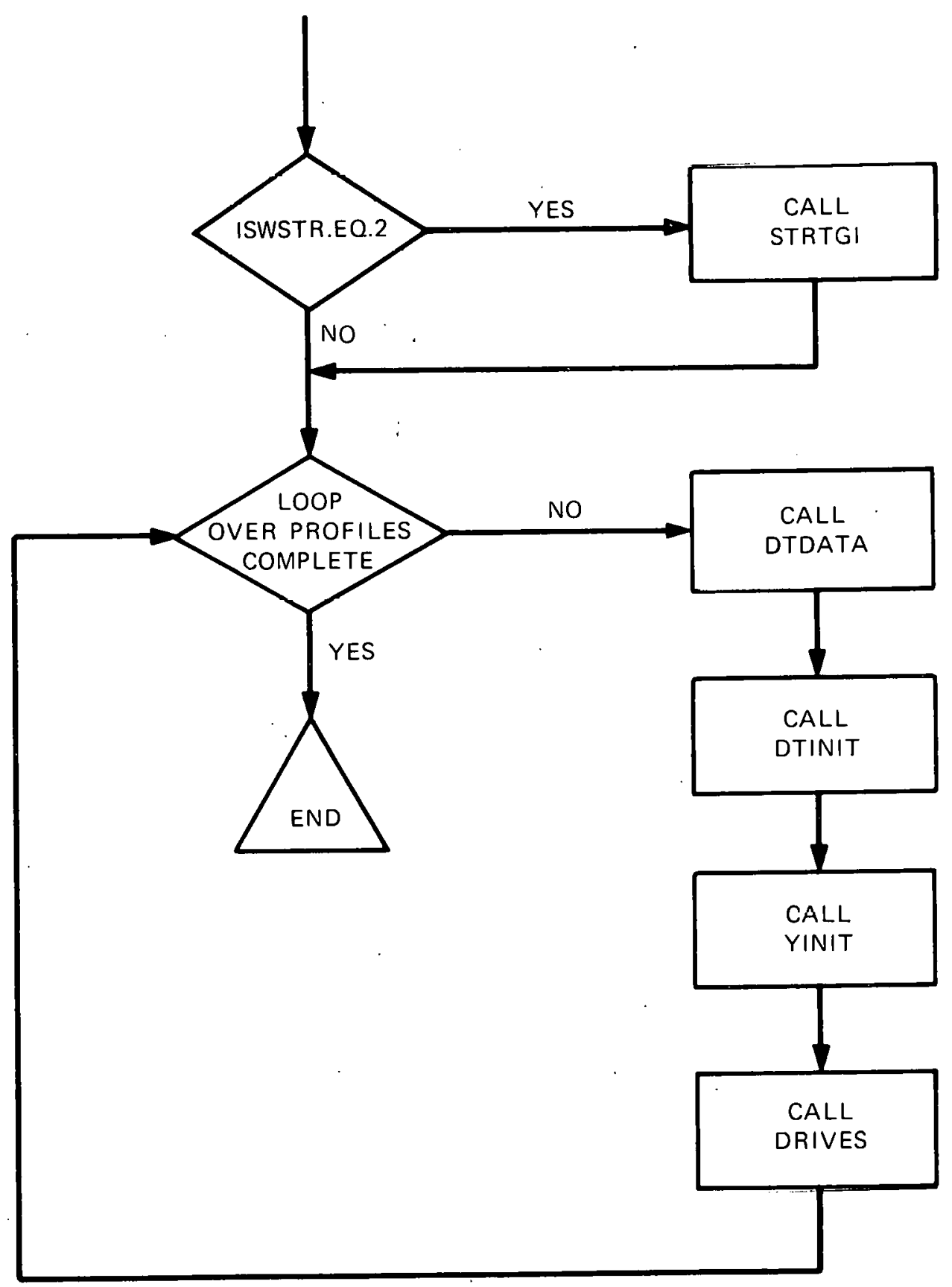

Fig. 1. Logic schematic of IMPDYN program subroutine MAINI(TD) used when the electron density and temperature are time-dependent. 


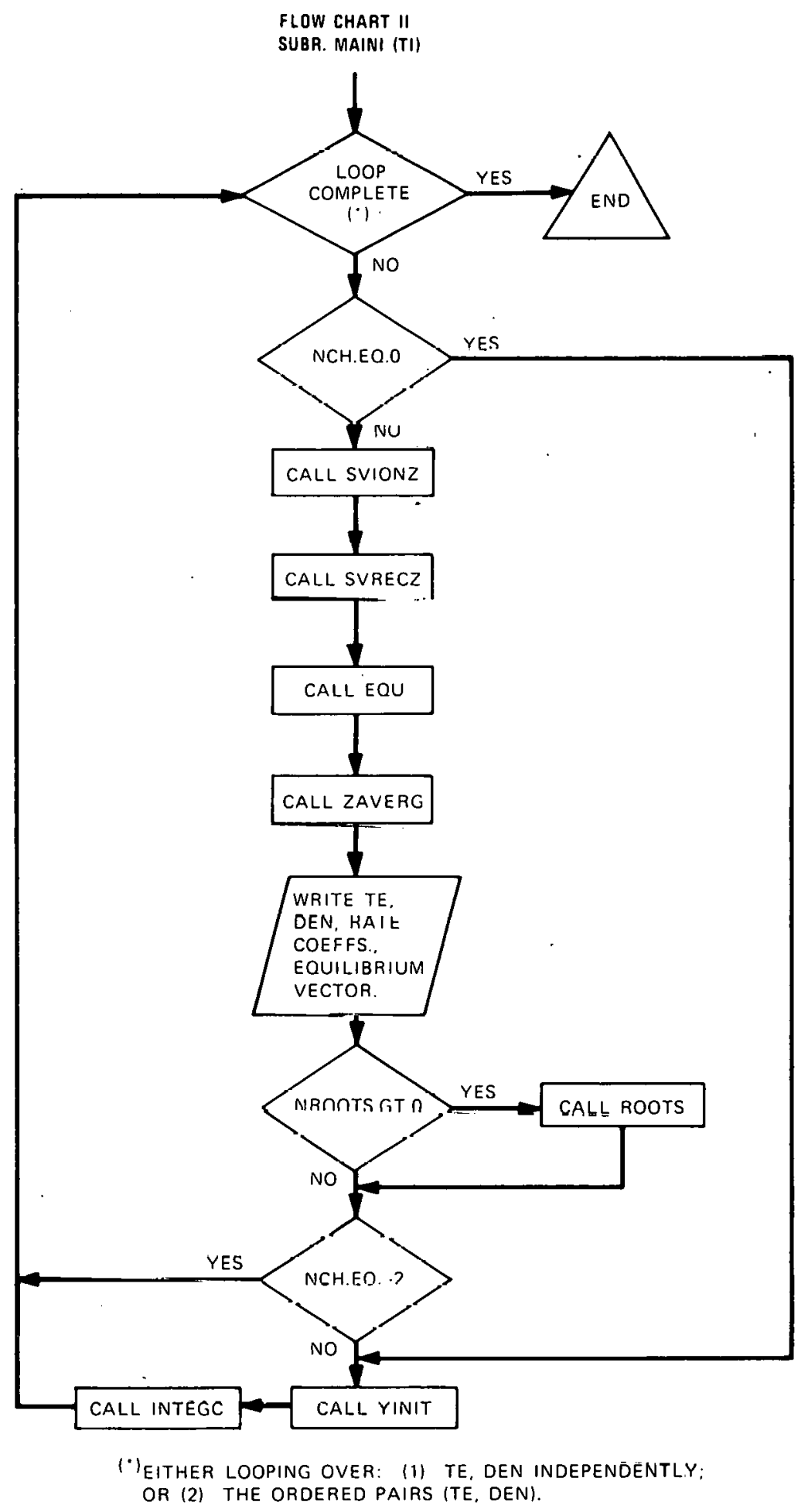

Fig. 2. Logic schematic of IMPDYN program subroutine MAINI(TI) used when the electron density and temperature are constant (timeindependent). 


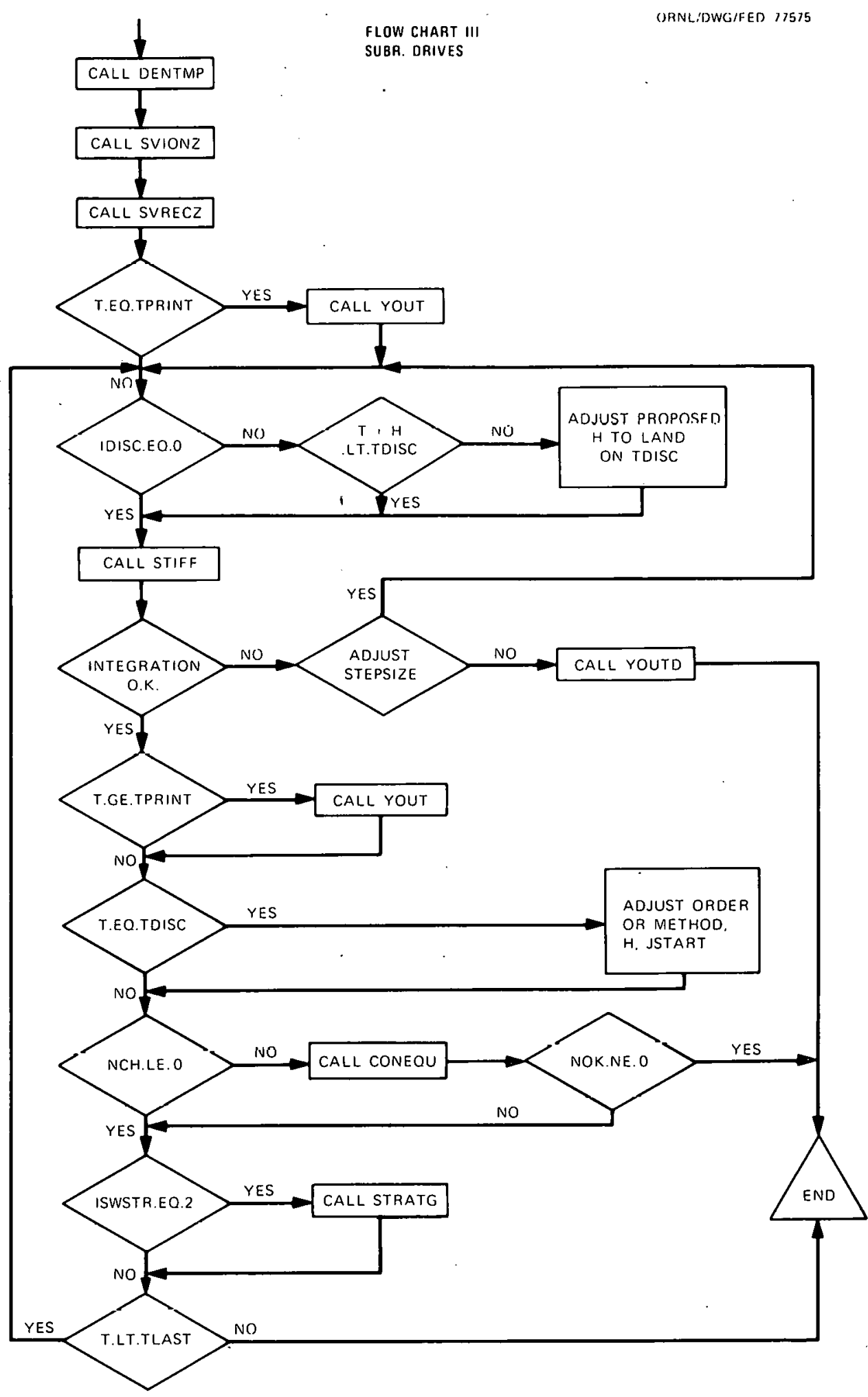

Fig. 3. Logic schematic of IMPDYN program subroutine DRIVES. 
Besides describing in the comment cards the kinds of problems the programs PROGTD and PROGTI can solve, the main routine, MAIN, contains two tables that help to reveal the structural organization of the programs and the layout of the labeled commons. 


\section{EXAMPLES}

In this section we discuss the two examples that are included on the microfiche. These examples were chosen to illustrate the use of IMPDYN in its most recent version, to provide benchmarks for checkout of IMPDYN at other installations, and to illustrate some points of physics. Because considerable discussion of input and output for the examples is given on the comment cards associated with the examples on the microfiche, few of the programming details are discussed here and the emphasis is on physics.

\subsection{EXAMPLE I: CORONA EQUILIBRIUM}

The first example concerns the corona equilibrium charge state distribution of iron in constant plasma conditions where $T_{e}=500 \mathrm{eV}$, $n_{e}=10^{13} \mathrm{~cm}^{-3}$. For the simple general models of ionization and recombination used, in which auto-ionization and dielectronic recombination are neglected, the equilibrium vector is essentially independent of $n_{e}$, al though there are small corrections which depend on $n_{e}$ [see Eqs. (7)(11)]. However, the time required for the charge state vector to approach to within a specified approximation to the equilibrium vector is directly proportional to $n_{e}$. This follows directly from Eq. (1), where the time rate of change of a given charge state is seen to be directly proportional to $n_{e}$. On page 3 of the Example I part of the microfiche, the normalized equilibrium vector calculated using Eq. (55) [cr. alsu Eq. (14)] is listed. Only components with concentrations of $\geqslant 10^{-6}$ are included in the vector. Components with smaller concentrations are neglected and the vector renormalized. This lower bound is set in the data statement card EQU 18 of subroutine EQU. The eigenvalues of $n_{p} A$ are also listed on page 3 . Note that the known zero eigenvalue is not calculated numerically by this single precision proyrall to vanish identically; however, its computed value is about five orders of magnitude smaller than the next larger eigenvalue.

On page 4 of this example, an approach to equilibrium is illustrated. At time $t=0$, neutral iron atoms are subjected to the plasma 
conditions listed above. Printouts of the distribution have been requested for convergence criteria $E P S E=0.5,0.1$, and 0.01 , corresponding to the three values of EPSCC in the block data, card EX.I 50, and at intermediate values controlled by the information on card EX.I 47 . The convergence criterion used, NCRIT = 1 (cf. cards BD̄PARM 35-42, page 2 of program listing), is that the $\ell_{1}$-norm, defined in Eq. (37), of the vector difference between the charge state vector $\tilde{y}_{h}(t)$ calculated at a given time and the equilibrium vector $y_{e q}$ be less than a prescribed amount. From the listing it is seen that nearly $57 \mathrm{~ms}$ are required for $\left\|\tilde{y}_{h}-y_{y}\right\|_{1}<0.5$. Although this value of EPSE is adequate to get the average charge of the distribution within $23.5 \%$ of its equilibrium value, the concentrations of important states may be incorrect by as much as a factor of two, with possible significant effects on transport and radiation. As would be expected, the lower charge states are overpopulated and the higher states are underpopulated. We alsu riote that 12 equations are current $(K-L+1)$, those for $\mathrm{Fe}^{13+}$ through $\mathrm{Fe}^{24+}$, down from the 14 equations needed at the time $t=0.5 \mathrm{~ms}$ of the first printout. The integration step size $H$ is between 2 and $4 \mathrm{~ms}$ ( $H$ is isted in seconds), up from the initial step size of 5 ns (input quantity HO) needed at the beginning of the integration when the distribution was farthest from equilibrium. It takes nearly $64 \mathrm{~ms}$ more to satisfy the next convergence criterion, EPSE $=0.1$, at which time the average $z$ is within less than a percent of its equilibrium value. The dominant charge states are within $10 \%$ or so of their equilibrium values at this time. In fact, at $t=110 \mathrm{~ms}$ the dominant charge states were within $15 \%$ or so, and even at $t=80 \mathrm{~ms}$, within $25 \%$ or so. Nevertheless, it is apparent that for this electron density, tens of milliseconds are required for the charge distribution to approach reasonably near to corona equilihrium. These times are on the order of transport times in a tokamak, 24 so the effects of transport should be taken into account, as discussed in Sect. 2. We recall, however, that these times are also inversely proportional to the electron density. For the electron temperature chosen for the example, realistically, the electron density should probably be on the order of a factor of two to three higher. 24 
Consequently, the time estimates should be reduced by the same factor. Such a reduction would still leave the time estimates on the order of transport times, thus leaving open the question of whether corona equilibrium distributions for iron can exist in tokamak plasmas. We address this point further in the next example. We also point out that including auto-ionization and dielectronic recombination in the rate coefficients would change the results for these examples quantitatively (e.g., increase the proportions of the lower charge states) but not qualitatively (i.e., relatively long times are still needed for the approach to corona equilibrium).

\subsection{EXAMPLE II: TIME-DEPENDENT $T_{\mathrm{e}}$ AND $\mathrm{n}_{\mathrm{e}}$}

In the second example, we study the evolution of the charge state distribution of iron in a plasma environment representative of the central plasma region of the Oak Ridge Tokamak (ORMAK) during electron heating experiments. 24 Laser electron temperature and density data were available for seven times within the discharge period studied, starting at $20 \mathrm{~ms}$, and these are listed at the top of page 4 of the Example II part of the microfiche. In the period before data were available, simple models of the density and temperature evolution were used, and these are listed following the data. As is also indicated on the microfiche, linear interpolation is used to obtain necessary density and temperature information between data points. At each printout time, as chosen in the data statements for TPRNT, DTPRNT, and NPRNT, the distribution of charge states is given, along with other information similar to that given for Example I.

We first note that the time step $H$ in this case, in which the electron temperature is evolving with time, exceeds $1 \mathrm{~ms}$ only when the temperature is changing very slowly and never exceeds $2.6 \mathrm{~ms}$. This is in contrast to Example $I$, in which the temperature was constant and $H$ eventually exceeded $10 \mathrm{~ms}$. In order to best illustrate some of the things that can be learned from this example, we have plotted some of the results of the calculations in Fig. 4. In the upper part of Fig. 4, the evolution of the electron density and temperature is illustrated. 

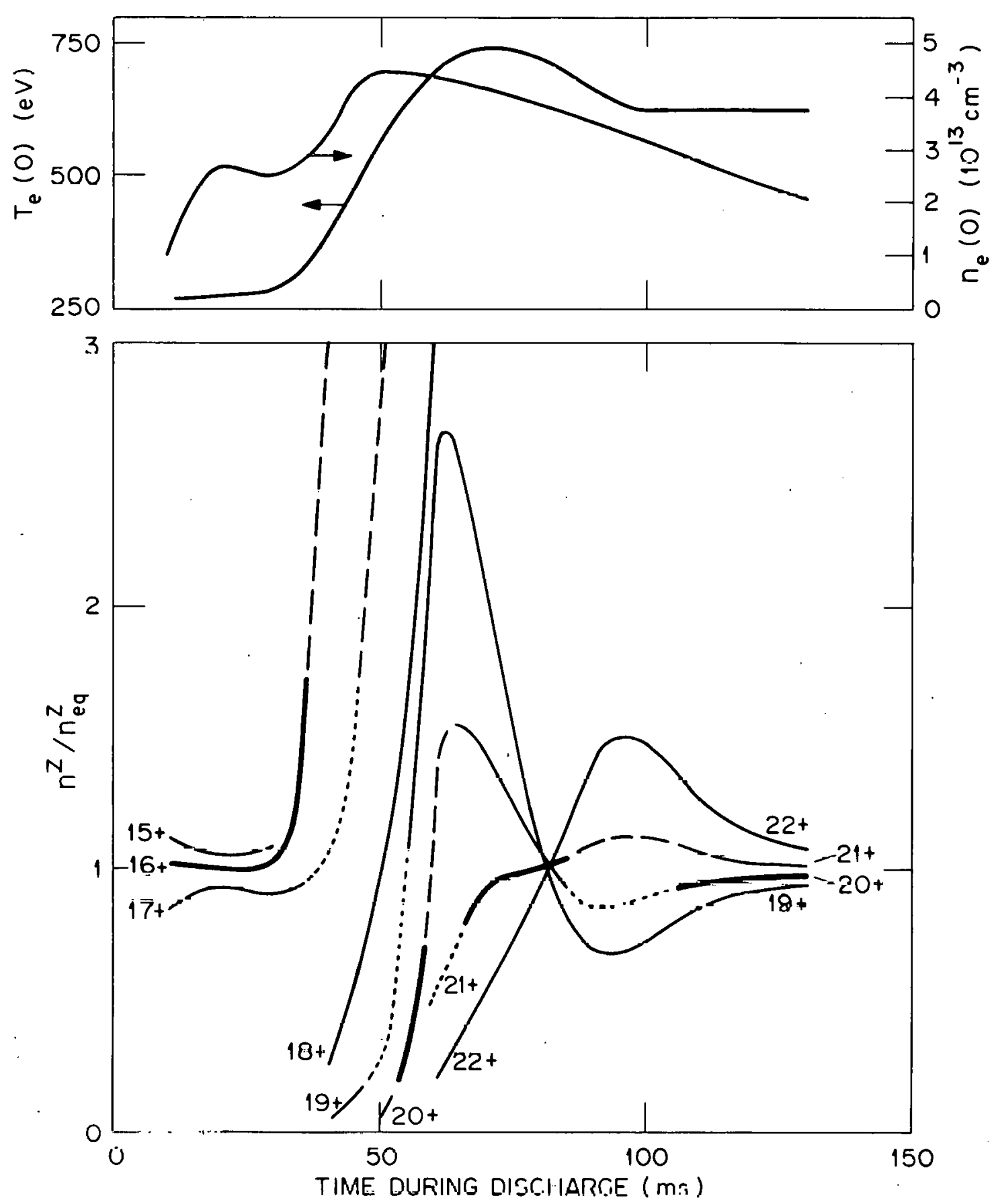

Fig. 4. Ratios of time-dependent to corona steady-state densities of iron ions as functions of time in an ORMAK experiment. In the upper part curves showing the evolution of the central plasma electron density and temperature are given. In the lower part curves are given only for ions with concentrations at least $10 \%$ of the total iron density at a given time. The following coding is used for the dominant (greatest fraction of total) ion: (1) heavy line - dominant for both time-dependent and steady-state, (2) broken line - dominant for time-dependent only, (3) dotted line - dominant for steady-state only. 
In the lower part of the figure, the evolution of charge states comprising more than $10 \%$ of the total impurity at the time of plotting is shown in the following way. The curves plotted are the ratios of the densities (concentrations) calculated using PROGTD, i.e., the concentrations given on the microfiche, to densities (concentrations) for coronal steady state calculated using PROGTI (not given on the microfiche). When a curve is at or near unity, the steady-state approximation is good for that species. Another criterion for the validity of the steadystate approximation is whether it would predict the same dominant (highest concentration) charge state as the time-dependent model. In Fig. 4, the heavy solid line indicates when this is true. When it is not true, the dominant species are indicated as described in the figure caption. As would be expected, the steady-state approximation is worst when the electron temperature is changing relatively rapidly, e.g., in the intervals $30-70 \mathrm{~ms}$ and $80-100 \mathrm{~ms}$. Although in the vicinity of $80 \mathrm{~ms}$ all the curves are near unity, they have large slopes, so the ratios are changing rapidly. At the end of the calculation, where the temperature has been essentially constant for about $30 \mathrm{~ms}$, the curves are approaching unity. Note that when the temperature is increasing, the time-dependent distribution is weighted toward lower charge states than the equilibrium; when the temperature is decreasing, the opposite is true. Because the excitation rate coefficient for a given species is strongly dependent on the electron temperature, ${ }^{25}$ this can have the effect of enhancing the intensity of the radiation emitted when the electron temperature is rising but diminishing it when the temperature is falling. Finally, as was also noted in the discussion of Example I, the atomic physics processes are occurring on time scales comparable to plasma transport time scales, so they must generally be treated time-dependently in transport modeling along with the diffusion processes. 


\section{THIS PAGE}

WAS INTENTIONALLY

\section{LEFT BLANK}




\section{SUMMARY AND CONCLUSIONS}

In this report, we have discussed a computer program, IMPDYN, that we have found very useful in the study of the evolution of impurities in tokamak plasmas. The program has a number of desirable features, such as minimizing the number of rate equations that need to be solved at any time and allowing any models of ionization and recombination to be used, provided they can be put in a form compatible with the rest of the program. The program has been designed to make this latter step relatively easy by having.ionization handled by one subprogram, SVIONZ, and recombination handled by another, SVRECZ, either or both of which may be replaced by equivalent subroutines. The entire program, including two examples which are valuable for checking that the program is working properly, is listed on a microfiche so that the program may be put on any machine. The program is also available from the authors via the National Magnetic Fusion Energy Computer Center.

In the examples we have basically tried to point out that (1) the corona steady-state approximation can be poor when plasma conditions, especially electron temperature, are changing rapidly, and (2) in timedependent modeling of tokamak discharges there must be interplay between the calculations of the atomic physics processes and the diffusion in order to get them both correct. 
THIS PAGE

\section{WAS INTENTIONALLY \\ LEFT BLANK}




\section{REFERENCES}

1. L. A. Artsimovich, Nuc7. Fusion 12, 215 (1972), H. P. Furth, Nucl. Fusion 15, 487 (1975), S. 0. Dean et al., Status and objectives of Tokamak Systems for Fusion Research, WASH-1295, United States Atomic Energy Commission, Washington, D.C. (1974).

2. L. Spitzer, Physics of Fully Ionized Gases, 2nd ed., Wiley (Interscience), New York and London, 1962.

3. R. F. Post, J. Nucl. Energy C $\underline{3}, 273$ (1961), Equipe TFR, Nucl. Fusion 15, 1053 (1975).

4. Thermonuclear Division Annual Progress Report for Period Ending December 31, 1974, ORNL-5053, p. 38; Thermonuclear Division Annual. Progress Report for Period Ending December 31, 1975, ORNL-5154, p. 90; and Fusion Energy Division Annual Progress Report for Period Ending December 31, 1976, ORNL-5275, p. 135; Oak Ridge National Laboratory, Oak Ridge, Tennessee.

5. J. T. Hogan, Methods in Computational Physics 16, 131 (1976).

6. R.W.P. McWhirter in Plasma Diagnostic Techniques, ed. by R. H. Huddlestone and S. L. Leonard, Academic Press, New York, 1965. 7. A. C. Hindmarsh, UCID-30001, Lawrence Livermore Laboratory, Livermore, California (December 1974).

8. R.v.d. Wooley and D.W.N. Stibbs, The Outer Layers of a Star, Oxford Univ. Press (Clarendon), London and New York, 1953.

9. G. Elwert, Z. Naturforsch. 7a, 432 (1952).

10. C. Jordan, Mon. Not. R. Astron. Soc. 142, 501 (1969).

11. C. Breton, Euratom Report No. 94, Centre d'Etudes Nucleaires, Fontenay-aux-Roses; Proc. 5th Intz. Conf. on Ionization Phenomena in Gases, Vol. 2, p. 2247 (1962).

12. G. D. Hobbs, R.W.P. McWhirter, W. G. Griffin, and T.J.L. Jones, Proc. 5th Int2. Conf. on Ionization Phenomena in Gases, Vol. 2, p. 1965 (1962).

13. A bulletin from the Controlled Fusion Atomic Data Center of Oak Ridge National Laboratory and the National Bureau of Standards, edited by C. F. Barnett and W. L. Weise. 
14. C. Jordan, Mon. Not. R. Astron. Soc. 148, 17 (1970); private communication, 1975.

15. H. P. Summers, Tables and Graphs of Collisional Dielectronic Recombination and Ionization Coefficients and Ionization Equilibria of $H$-like to A-like Ions of Elements, Appleton Laboratory Internal Memo 367, Culham Laboratory, Abingdon, 0xon (1974).

16. H.-J. Kunze, Phys. Rev. $\underline{A 3}, 939$ (1971).

17. H. -J. Kunze, Space Science Reviews 13, 565 (1972).

18. W. Finkelnberg and W. Humback, Naturwissenschaften $\underline{42}, 35$ (1955).

19. T. A. Carlson, C. W. Nestor, Jr., N. Wasserman, and J. D. McDowe11, Atomic Data 2, 63 (1970).

20. R. A. Dory (Oak Ridge National Laboratory), private communication, 1973.

21. I. G. Beigman et al., Astron. Zh. [Sov. Astron.-AJ] 46, 985 (1969).

22. A. Burgess and M. J. Seaton, Mon. Not. R. Astron. Soc. 127, 355 (1964).

23. R. Wilson, Plasmas in Space and in the Laboratory, ESRO SP-20, p. 373, European Space Research Organization, Paris (1967).

24. Fusion Energy Division Annual Progress Report for Period Ending December 31, 1976, ORNL-5275, pp. $20 \mathrm{ff}$., Oak Ridge National Laboratory, Oak Ridge, Tennessee.

25. Equation (23) in R.W.P. McWhirter in Plasma Diagnostic Techniques, ed. by R. H. Huddleston and S. L. Leonard, Academic Press, New York, 1965. 
INTERNAL DISTRIBUTION

ORNL/TM-6050

1. J. D. Callen

2. J. F. Clarke

3. R. A. Dory

4. G. G. Kelley

5. 0. B. Morgan

6. M. W. Rosenthal

7-31.: E. C. Crume

32-34. Laboratory Records Department

35. Laboratory Records, ORNL - RC

36. $y-12$ Document Reference Section

37-38. Central Research Library

39. Fusion Energy Division Library

40. Fusion Energy Division Reports Office

41. ORNL Patent Office

\section{EXTERNAL DISTRIBUTION}

42. Plasma Physics Library, Plasma Physics Laboratory, Princeton Univ., Forrestal Campus, P.0. Box 451, Princeton, NJ 08540

43. Controlled Thermonuclear Research Library, Lawrence Livermore Laboratory, P.0. Box 808, Livermore, CA 94550

44. Q Division Library, Los Alamos Scientific Laboratory, P.0. Box 1663, Los Alamos, NM 87544

45. Controlled Thermonuclear Research Library, c/o Weston M. Stacey, Jr., Argonne National Laboratory, 9700 S. Cass Ave., Argonne, IL 60439

46. CTR Computer Center, c/o Dr. John Killeen, Lawrence Livermore Laboratory, P.0. Box 808, Livermore, CA 94550

47. Librarian, Culham Laboratory, U.K. Atomic Energy Authority, Abingdon, 0xon, 0X14 3DB, United Kingdom

48. Ruth Lengye, Bibliothek, Max-Planck Institut für Plasmaphysik, 8046 Garching bei München, Federal Republic of Germany

49. Library, Centre de Recherches en Physique des Plasmas, 21 Avenue des Bains, 1007, Lausanne, Switzerland

50. A. M. Dupas, Documentation S.I.G.N., Départment de la Physique du Plasma et de la Fusion Controlée, Association EURATOM-CEA sur la Fusion, Centre d'Etudes Nucleaires, BP 85 Centre Du TRI 38041 Grenoble Cedex (France)

51. Bibliothèque, Service du Confinement des Plasmas, C.E.A., B.P. No. 6, 92, Fontenay-aux-Roses (Seine) France

52. Library, International Centre for Theoretical Physics, Trieste, Italy

53. Library, Laboratorio Gas Ionizzati, Frascati, Italy

54. V. E. Ivanov, Physical-Technical Institute of the Ukranian Academy of Sciences, Sukhumi, U.S.S.R.

55. L. M. Kovrizhnikh, Lebedev Institute of Physics, Academy of Sciences of the U.S.S.R., Leninsky Prospect 53, Moscow, U.S.S.R.

56. Prof. Dshumber G. Lominadze, Academy of Sciences of the Georgian SSR, 8 Dzerzhinski St., 38004, Tbilisi, U.S.S.R.

57. Library, Inst. for Plasma Physics, Nagoya Univ., Nagoya, Japan 464 
58. Library, FOM-Institut voor Plasma-Fysica, Rijnhuizen, Jutphaas, Netherlands

59. Plasma Physics Group, Department of Engineering Physics, Australian National University, P.0. Box 4, Canberra A.C.T. 2600, Australia

60. Thermonuclear Library, Japan Atomic Energy Research Institute, Tokai, Naka, Ibaraki, Japan

61. Dr. D. G. McAlees, Exxon Nuclear Co., Inc., Research \& Technology Laser Enrichment Department, 2955 George Washington Way, Richland, WA 99352

62. CTR Reading Room, c/o Prof. D. W. Kerst, Dept. of Physics, Sterling Hal1, Univ. of Wisconsin, Madison, WI 53706

63. CTR Reading Room, c/o Prof. I. B. Bernstein, Yale Univ., 200 Mason Laboratory, Dept. of Engineering \& Applied Science, New Haven, CT 06510

64. Center for Plasma Physics and Thermonuclear Research, c/o D. W. Ross, Physics Dept., Univ. of Texas, Austin, TX 78712

65. CTR Reading Room, c/o Prof. B. D. Fried, Physics Dept., Univ. of Cal ifurnia, Lus Allyeles, CA 90024

66. CTR Reading Room, C/o Prof. David C. Montgomery, Physics \& Astronomy Dept., Univ. of Iowa, Iowa City, IA 52240

67. Magneto-Fluid-Dynamics Library, c/o Dr. Harold Grad, Courant Inst. of Math. Sci., New York Univ., 251 Mercer St., New York, NY 10012

68. CTR Reading Room, c/o Prof. Allan N. Kaufman, Physics Dept., Univ. of California, Berkeley, CA 94720

69. Dr. David A. Dingee, Fusion Programs, Battelle-Northwest, Battelle Boulevard, Richland, WA 99352

70. CTR Reading Room, c/o Prof. C. S. Liu, Dept. of Physics and Astronomy, Univ. of Maryland, College Park, MD 20742

71. CTR Reading Room, c/o Prof. T. Kammash, 103 Research Ädmin. Bildg., N. Campus, Univ. of Michigan, Ann Arbor, MI 48105

72. CTR Reading Room, c/o Dr. Ravi N. Sudan, Phillips Hall, Cornell Univ., Ithaca, NY 14850

73. Prof. Marshall N. Rosenbluth, Institute for Advanced Study, Princeton, NJ 08540

74. CTR Reading Room, c/o Prof. R. Gross, Plasma Research Lab., Columbia Univ. , New York, NY 10027

75. CTR Reading Room, c/o Prof. Roy Gould, California Inst. of Tech., M.S. 116-81, Pasadena, CA 91125

76. Dr. Nicholas A. Kral1, Science Applications, Inc., P.0. Box 2354, 1200 Prospect St., La Jolla, CA 92037

77. CTR Reading Room, c/o Dr. Jay P. Boris, Plasma Physics, Naval Research Laboratory, Washington, D.C. 20390

78. Professor A. Simon, Dept. of Mechanical \& Aerospace Sciences, University of Rochester, Rochester, NY 14627

79. CTR Library, c/o Dr. Alan. F. Haught, United Technologies Research Labs, East Hartford, CT 06108

80. Dr. H. K. Forsen, Exxon Nuclear Co., Inc., 777-106th Avenue, NE, C-000777, Bellevue, WA 98009

81. Dr. George Vahala, Physics Dept., College of William \& Mary, Williamsburg, VA 23185

82. Dr. Robert E. Price, Division of Magnetic Fusion Energy, G-234, Energy Research and Development Administration, Washington, D.C. 20545 
83. Dr. R. C. Davidson, Division of Magnetic Fusion Energy, G-234, Energy Research and Development Administration, Washington, D.C. 20545

84. Dr. Oscar P. Manley, Division of Magnetic Fusion Energy, G-234, Energy Research and Development Administration, Washington, D.C. 20545

85. Mr. E. E. Kintner, Division of Magnetic Fusion Energy, G-234, Energy Research and Development Administration, Washington, D.C. 20545

86. Dr. L. D. Pearlstein, L-388, Lawrence Livermore Laboratory, P.0. Box 808, Livermore, CA 94550

87. Dr. J. P. Friedberg, Los Alamos Scientific Laboratory, Los Alamos, NM 87544

88. Dr. David J. Rose, Dept. of Nuclear Engineering, MIT, Cambridge, MA 02139

89. Dr. Gareth E. Guest, General Atomic Co., P.0. Box 81608, San Diego, CA 92138

90. Dr. Claude Mercier, Service du Theorie des Plasmas, Centre d'Etudes Nucléaires, Fontenay-aux-Roses (Seine) France

91. Dr. J. B. Taylor, Cul,ham Laboratory, UKAEA, Abingdon, Oxon, 0xi4 3DB, United Kingdom

92. Dr. D. Pfirsch, Institute for Plasma Physics, 8046 Garching bei München, Federal Republic of Germany

93. Dr. V. D. Shafranov, I. V. Kurchatov Inst. of Atomic Energy, 46 Ul itsa Kurchatova, P.0. Box 3402 , Moscow, U.S.S.R.

94. Dr. A. Rogister, Institute for Plasma Physics, KFA, Postfach 1913, D-5170, Julich 1, Federal Republic of Germany

95. Dr. J. G. Cordey, Culham Laboratory, UKAEA, Abingdon, Oxon, $0 \times 14$ 3DB, United Kingdom

96. Dr. David Baldwin, L-388, Lawrence Livermore Lab., P.O. Box 808, Livermore, CA 94550

97. CTR Reading Room, c/o Prof. Bruno Coppi, Dept. of Physics, MIT, Cambridge, MA 02138

98. Dr. Harold P. Furth, Princeton Plasma Physics Lab., Princeton Univ., P.0. Box 451, Princeton, NJ 08540

99. Dr. Paul H. Rutherford, Princeton Plasma Physics Lab., Princeton Univ.. P.0. Box 451, Princeton, NJ 08540

100. Research \& Technical Support Div., Oak Ridge Operations, Energy Research and Development Administration, P.0. Box E, Oak Ridge, TN 37830

101-127. Technical Information Center, P.0. Box 62, Oak Ridge, TN 37830 
NUMERICAL CALCULATION OF IMPURITY CHARGE STATE DISTRIBUTIONS

E. C. Crume and D. E. Arnurius

\section{MICROFICHE ENCLOSED}

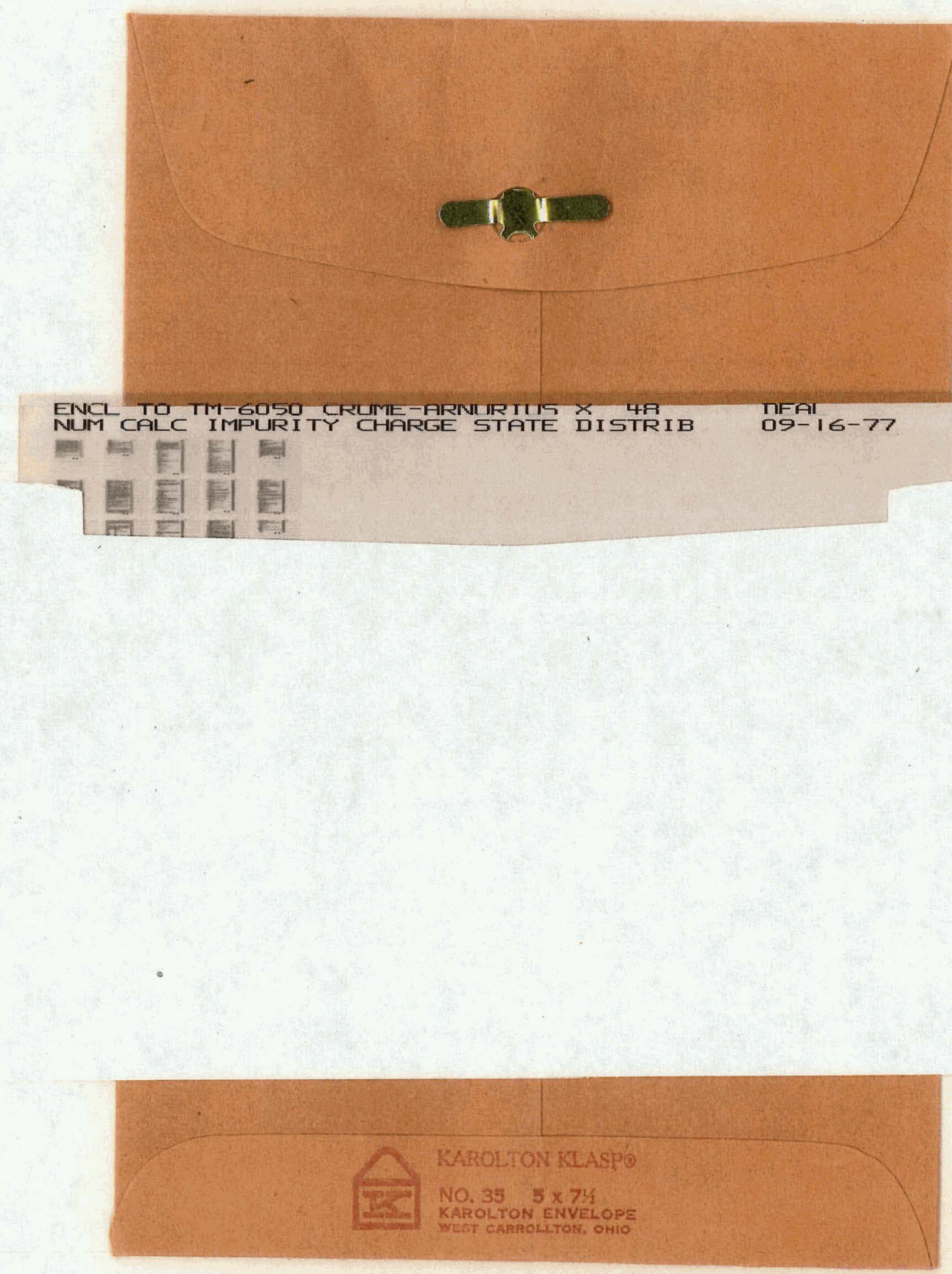


MICROFICHE ENCLOSURE 


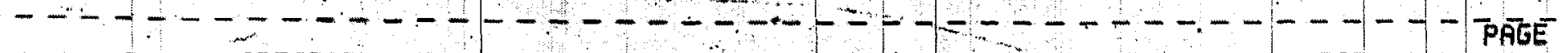

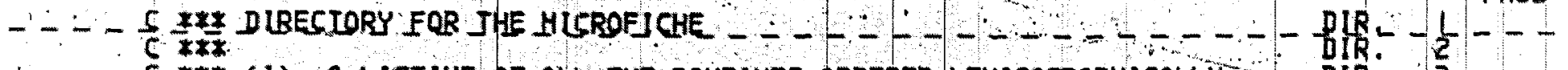
5 X** (1) A LISTING OF ALL THE ROUTINES ORDERED LEXICOURAPHICALLY Y DIR

E * * EXCEPT THAT THE BLOCK DATA BDPARH COMES FIRST AND THEN THE COLL.

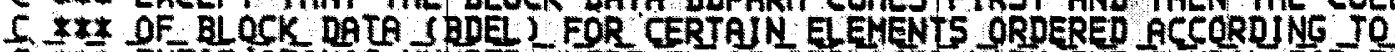

C. XFE THEIR 'ATOHIC MUMBER HHERE EL IS REPLACED WITH THE SYMBOL FOR THE

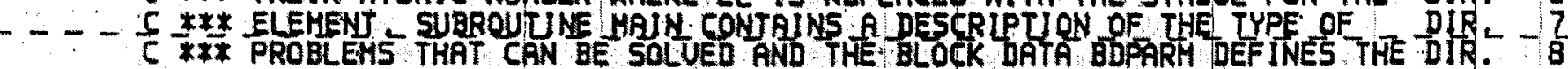

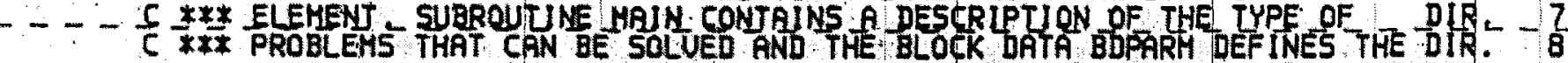

C *** PARAMETERS THAT NEED TO BE DEFINER BY THE USER, THE CURRENT SPACE DIR, 9

DIR.

DIR 5

5 : \pm HANDLED THE SPACE ALLOCAUION MAY BE CHANGED BY REDEF INING NDM IN DIR IL

$C$ NXF MAIN TO THE DESIRED UALUE AND ALTER THE SIZE OF THE COMMON ARRAYS DIR: IT

5 * $*$ DEF LNED JN MAIN ACCORDING JQ THE FORMULAS INDLCATED THERE

C $\$$ KF MOREOUER, SUBROUTINE SURECZ, THE MODIFIED CAROLE JORDAN ROUTINE - DIR. T4

C *** FOR APPROXIMAFING THE RECOHBINATION RATE COEFF HAS THREE LOCAL DIR 15

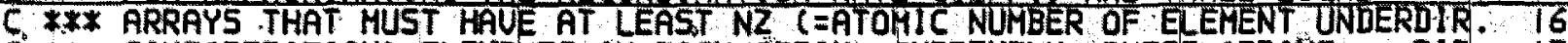

5 XXX CONSI DERAU ON 2 EL EHENTS IN EACH ARRAY L GURRENLL IHESE ARRAYS - DIR 17

C $75 \%$ HAVE NOH=74 ELEMENTS EACH.

5 * Z* JHE ORDER OF THE ROUT INES 15 EDPARH BDC BDO BDAL, BDFE, BDNL BDCUL DIR

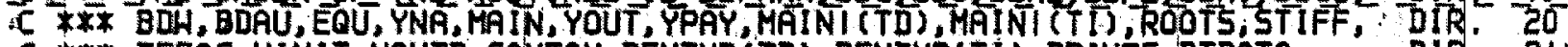

C *X* TESOC YINIT, YOUTD, CONEOU, DENTHP(TD), DENTMPITI) DRIUES, DTDATA, DIR

C *** DTINIT, IHTOL I, INTEGC, STRATG, STRTEI, SUIONZ, SURECZ, ZAVERG. . . DIR.

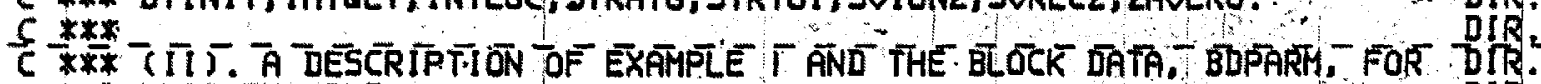

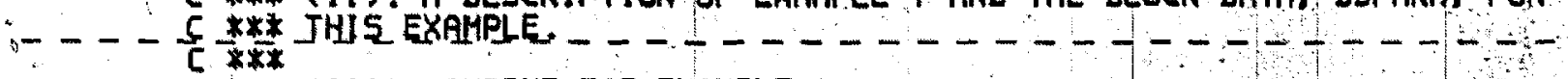

C *** (III). OUTPUT FOR EXAHPLE 1 .

24

C ***

$----\frac{C}{C} \frac{* * *}{* * *}$ THIS EXAMPLE.

$---\frac{C}{C} \frac{* * *}{* * *}-(\bar{U})$. OUTPUT FOR EXAMPLE. 2 ;

bIR.
DIR

हारि. 


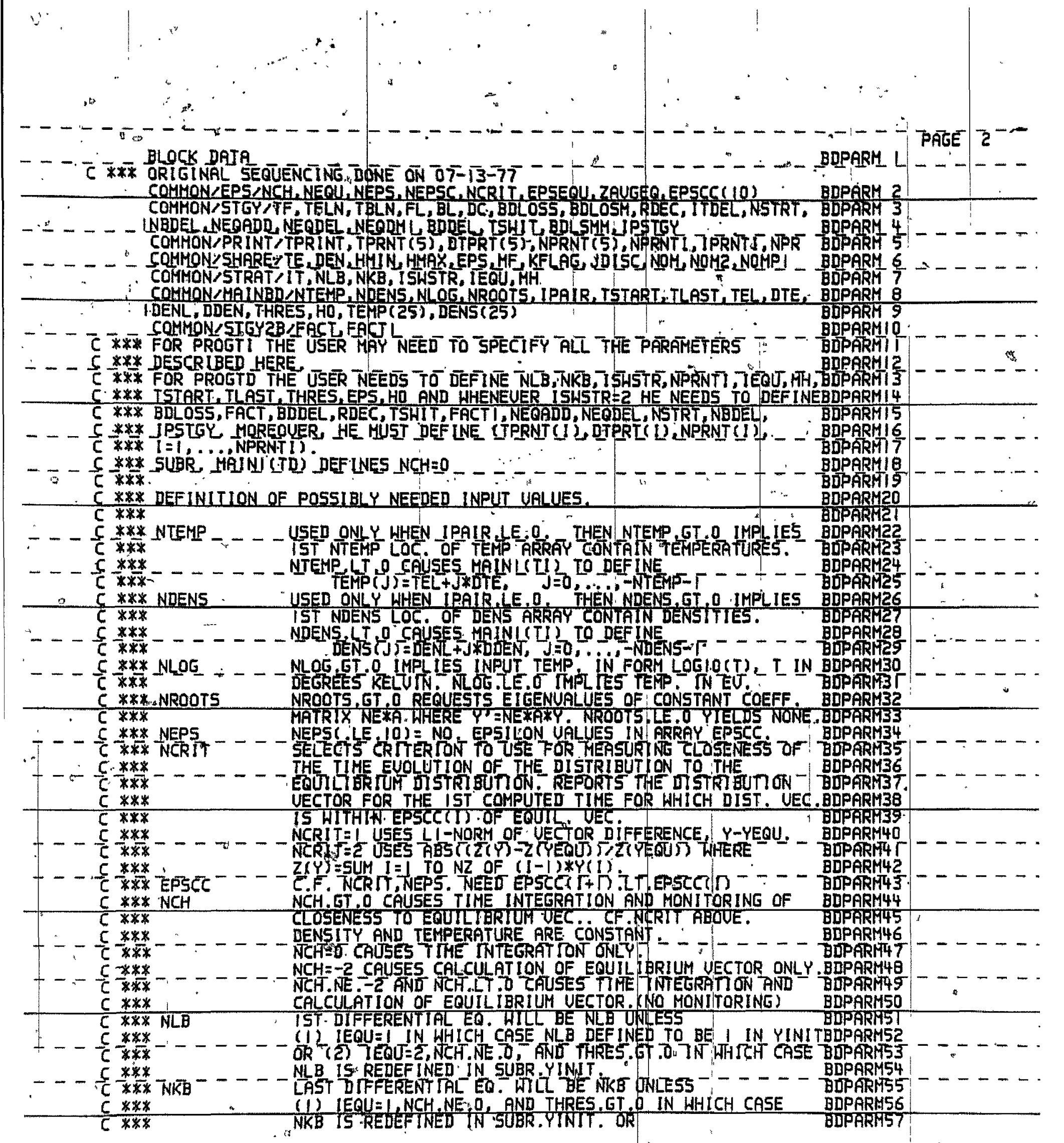





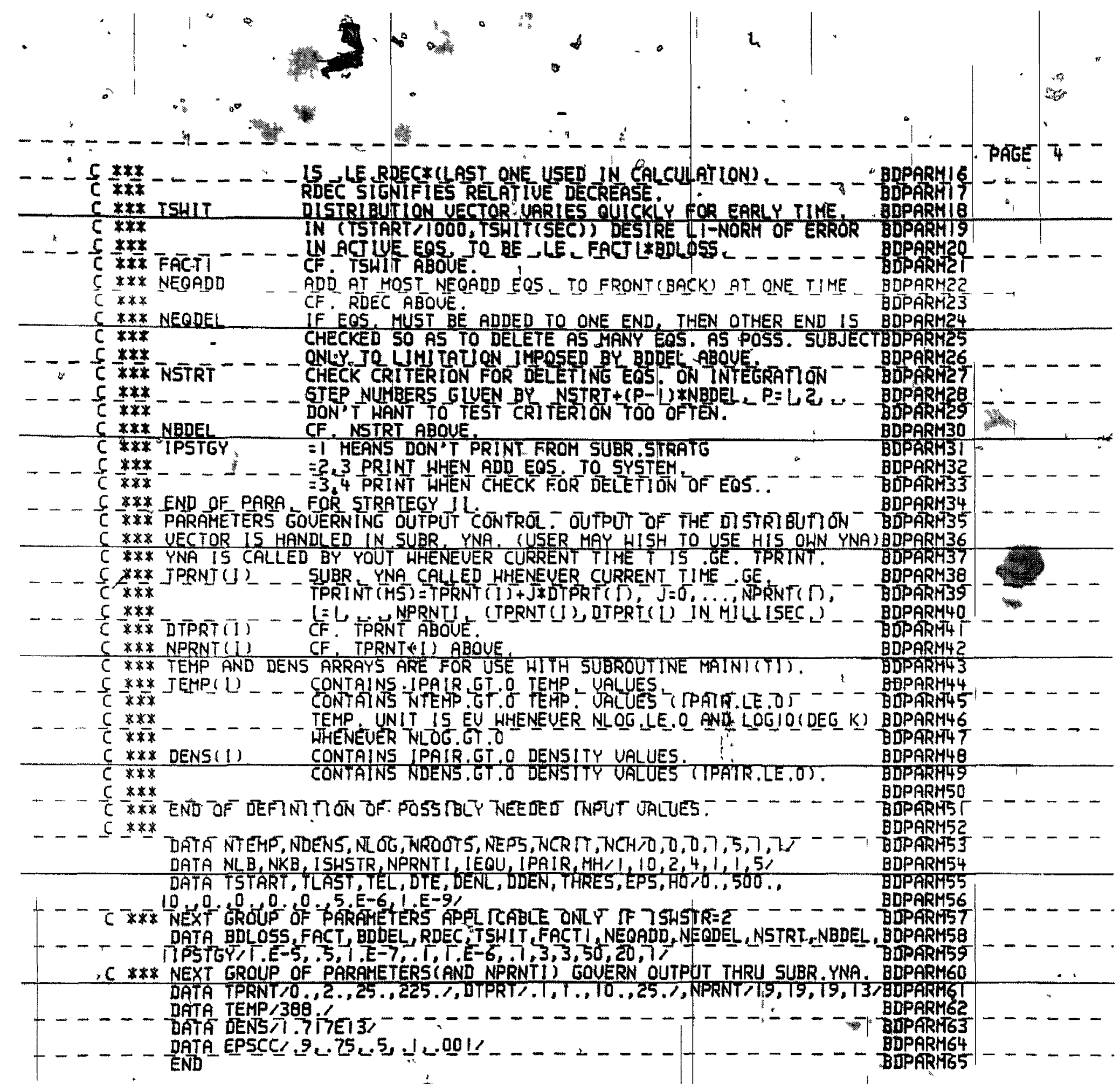
i 
$\bar{C} \bar{x} \times \bar{F}$ OLLCK DAIR

C XXX EAPI.CHI USED IN SUIONR BY DORY

$C$ *** E, APR, CHR USED IN SURECZ BY DORY.

- - S \#\# USE E'S AND O'S IN SURONZ FQR, KUNZE JONLZAT LN AS HELLL AS JNFQ,

C XXF IN COMHONAXCION

- - 5 IXE USE E'S IN SURECZ FOR HODIF LER C JORDAN RECLMBINATHON

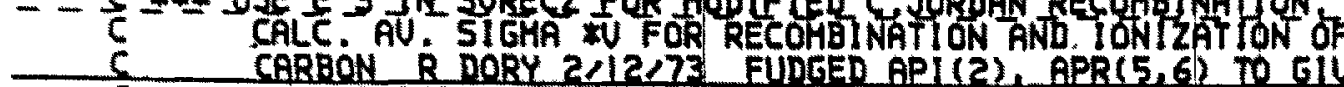

C

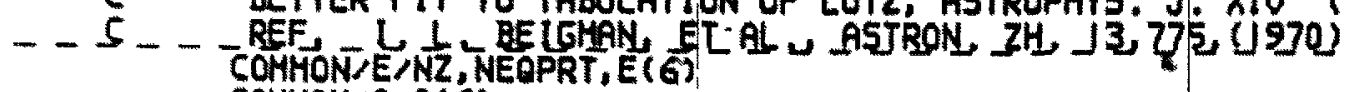
SOHHON<Q/Q(6)

$*-1$
COHHON/AP I/API $\overline{6}(\overline{6})$
COMHON,APR

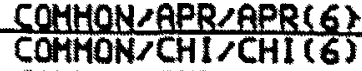

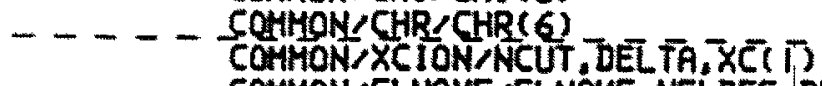

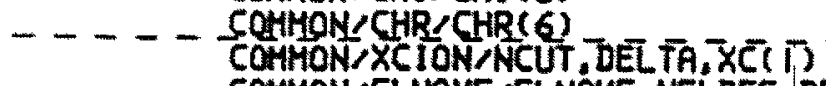

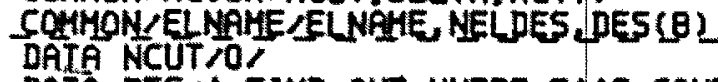

DATA DES " EIND OUT HHERE E''S CAME FROH, "

DATA NELDES/B/

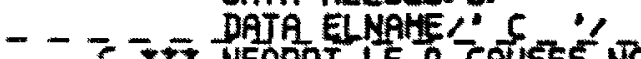

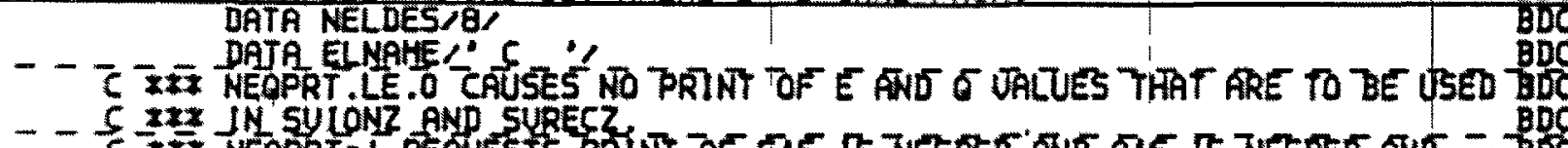

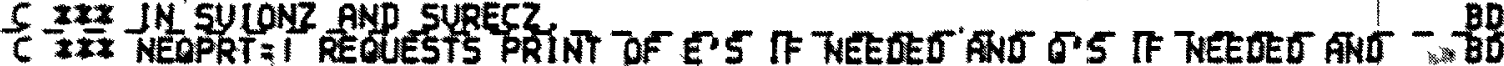

$C$ XXX DESCRIPTIUE INFO IN DES ARRAY

C IXX NEOPRT HAY BE ALTERED HTTHIN SUIDKL, SURECZ.

- - - - WUTEEER NZ $/ 6 /$ NEOPRTLL

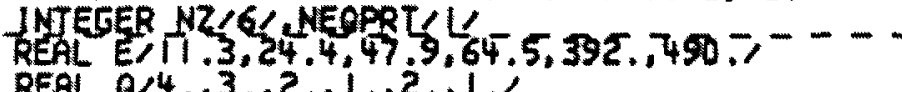

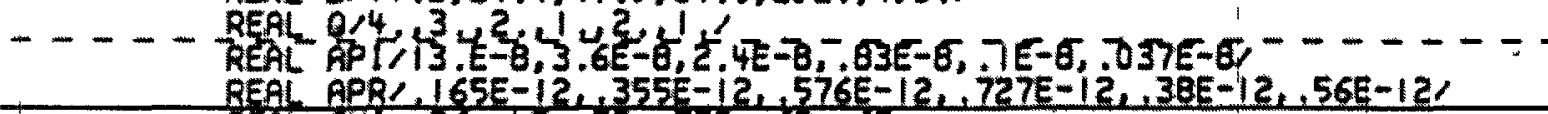

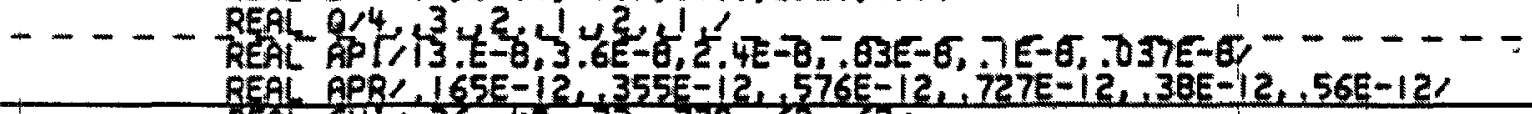

REAL CHI $.36, .40, .73, .778, .62, .627$

END

- - - - RE

$-$ EAL CHR I U S Bं 9 264 I L 


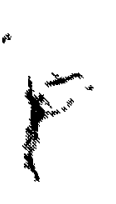

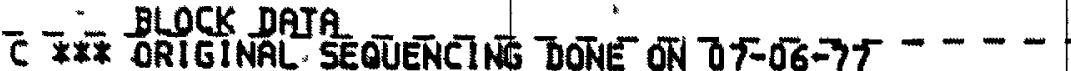

C XXX E.APL CHI USED IN SUIONZ BY DORY.

C $\times$ XX E, APR, CHR USED IN SURECZ BY DORY.

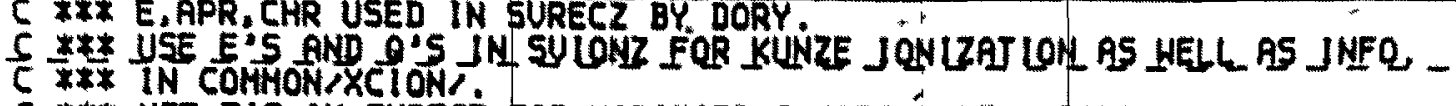

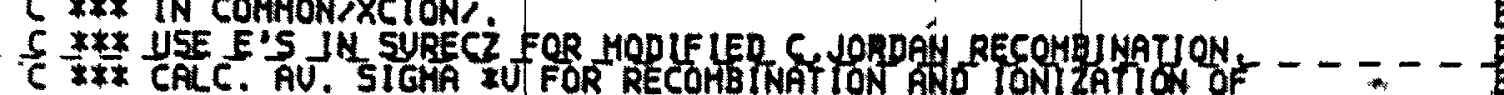

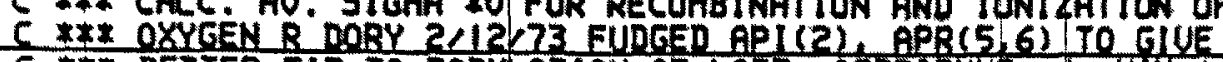

$C$ IFX BETTER FIT TO TABULATION OF LOTZ, ASTROPHYS. J. XVO (1967).

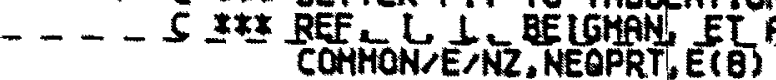

- . - . - - cothon

COAMON, Q

COHHON $\angle A P R / A P R(B)$

COHHON/CHI/CHI(B)

COHMONCHRYCHRCB

ASJRON, IH, J 3775 (1970)

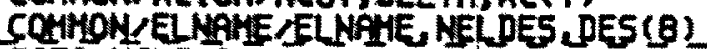

DATA NCUT 10 ;

DAIA DES " EIND OUI HHERE E'S CAME FROM

DATA NELDES/ 8 ;

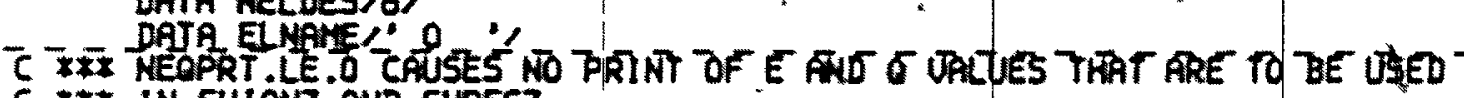

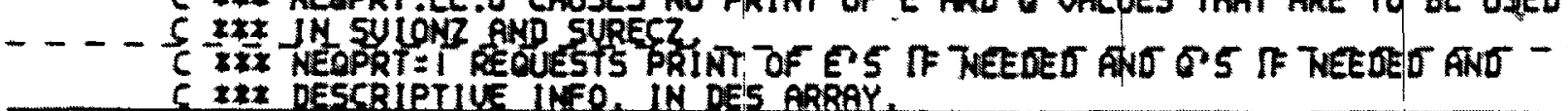

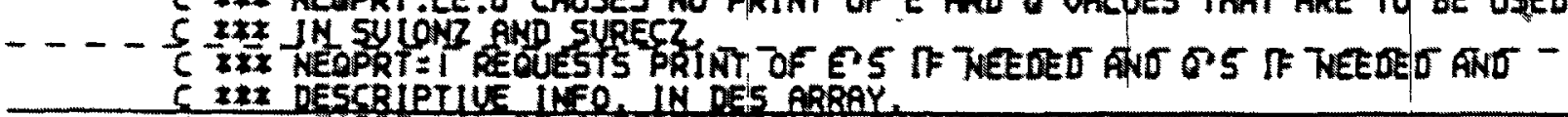

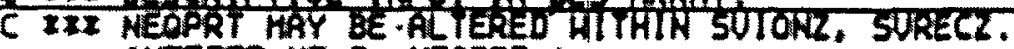

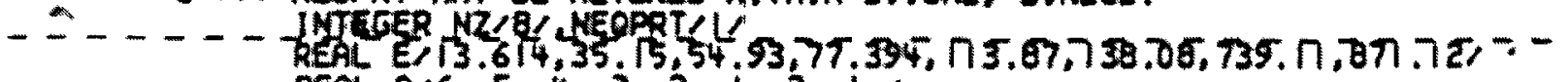

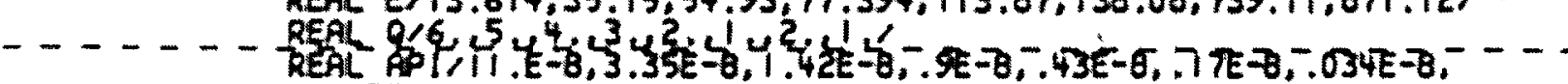

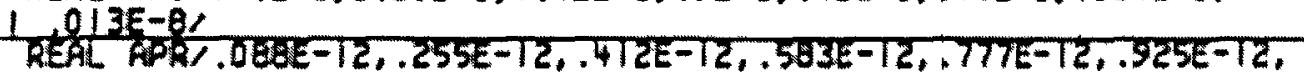

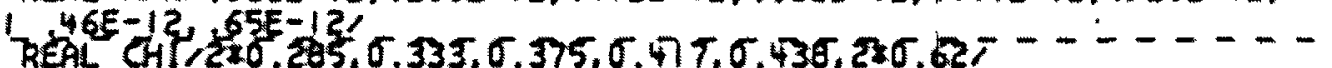

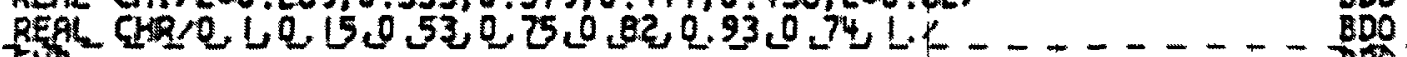

- - - - - ENó 
$\bar{C} \times \bar{*}$ OLOCK DRIG

- PATE

C *** USE E'S AND O'S IN SUIONZ FOR KUNZE IONIZATION AS WELL AS INFO.

C *** IN COMMONIXCION/

COMHON $10 / 0(13)$

SOHMON $\angle E$ N NZ NEOPRT E (13)

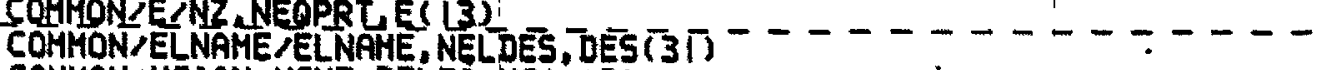

COHHON $X X C 1 O N / N C U T, D E L T A, X C(13)$

DATA NCUT, DELTA / I, I.E-20/

5 *** NCUT:OU L MEANG ARRAY XC UNAUAJLABLE (AUAJLARLE)

C XX* XC RERE RRE. FOR TONIZATION BY KUNZE. IF X XE(T), TE. TE. XC (I),

5 * $*$ JHEN LONI ZAU ON RATE COEFF, -LT L DELTA

DATA XC'

$\frac{1}{2} 29.27,27,18,25,89,25,81,25,31,24,84,24,31,23,85,23,35$,

DATA DES, O. '

$L 1970$, E' 'S FROM DIE NAUURH ISSEN SCHAEIEN UOL 2 L 1955 BY FINKLEMBUBDAL

DATA ELNAME $/ A L$ '"

C * NEQPRT. LE.O CAUSES NO PRINT OF E AND $Q$ UALUES THAT ARE TO BE USED

- 5 \& $*$ IN IN SULONZ AND. SURECZ

C X XX NEOPRT = I REQUESTS PRINT OFF E'S JF NEEDED AND 6.5 IF NEEDED AND -

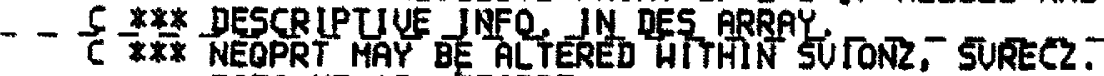

DATA NZ 13, NECPRT 1 ,

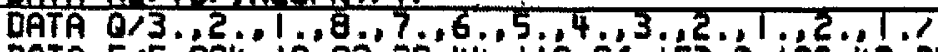

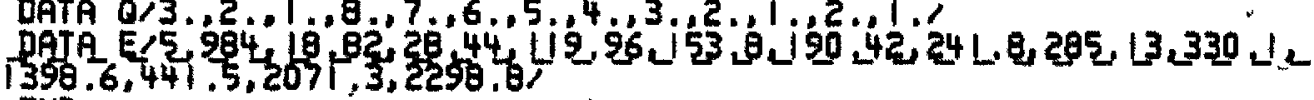
END

$\mathrm{HI}$

BDAL

BDAL

BDAL

BDAL 5

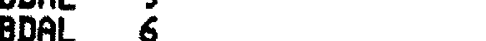

GoAL

BDA

BDAL 10

GDAL Ti

BDAL $-\frac{1}{1}$

Bn

菂的

14

$-16$

BDAL

BDAL

DAL

BDAL

BDAL

BDAL

BDAL

UDAL

BDAL

BDAL 30

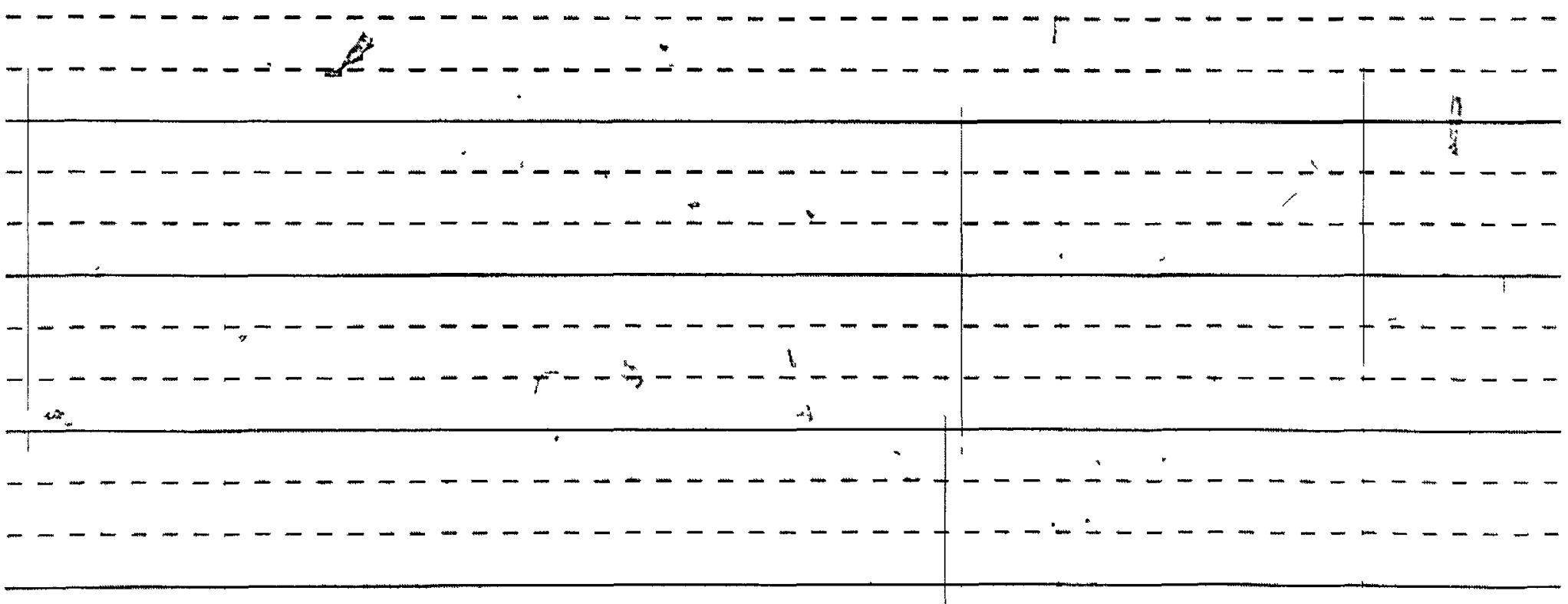


C X* USE E'S AND O'S IN SUIONZ FOR KLNAZE IONIZATION AS HELLL AS INFO,

C *** IN COMMON XXCION:

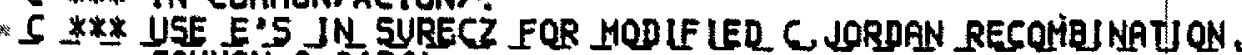
COMMON $>0 / O(26)$

COMMONZE 1 NZ. NEOPRT E(26)

COMMON, E MAME, ELNAME, NELDES, DEST(3)

COMMON XXCLON JNCUT, DELTA, XC( 26$)$

DATA NCUT', DELTA I I I.E-20/

5 F*K NCUT:OC MEANS ARRAY XC UNAUALLABLE AUAILABLE

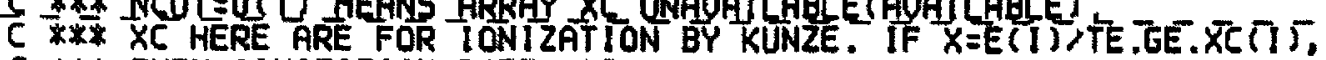

5 X DATA XC/

$128,46,26,72,28,37,27,37,26,75,26,27,25,87,25.51,24,78$,

$224.47,24.16,23.63,23.45,23.05,22.42,21.64,22.45,22.18$,

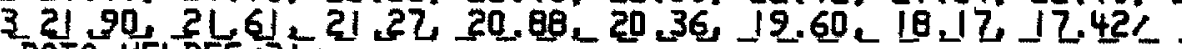
DATA MELDEST3T,

DATA DES $\nearrow^{\prime} Q$ "'S AND SOME E''S FROM CARLSON ATOMIC DATR, UOL $2, P, 63 B D F E$

1970 . E' 2RE

DATA ELNAME/'FE '"

5 * * NEQPRT LE D CAUSES NO PRINT OF_E AND Q UALUES IHAL ARE TO BE USED

C *** IN SUIONZ AND SURECZ:

5 X** NEOPRI $=L$ REQUESTS PRINT OF E'S IF NEEDED AND Q'S IF NEEDED AND -

C * * DESCRIPTIUE INFO. IN DES ARRAY'.

C *** NEQPRT MAY BE ALTERED WITHIN SUIONZ, SURECZ.

\section{DATA NZ/26/,NEQPRT/1/}

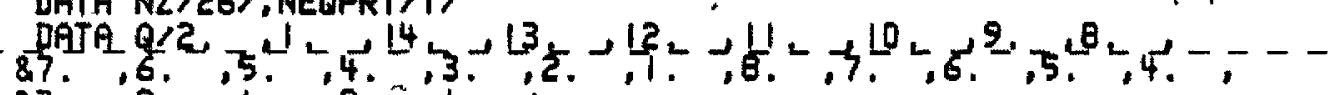

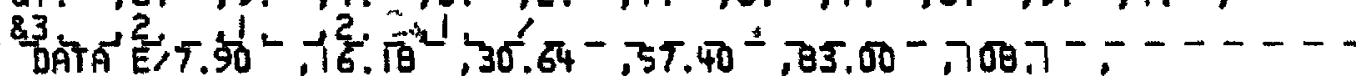

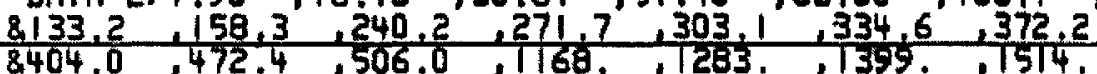

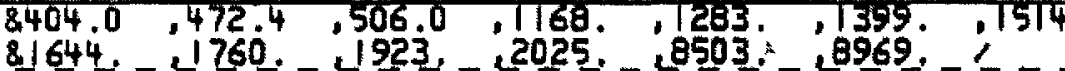
$\frac{81}{E N D}$

BDEF

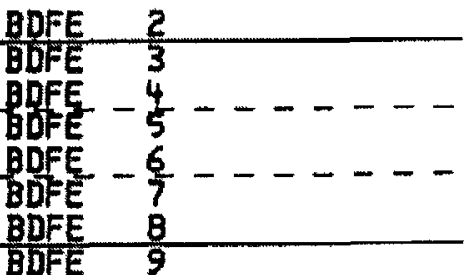

$-2-18$

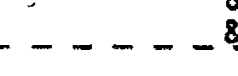




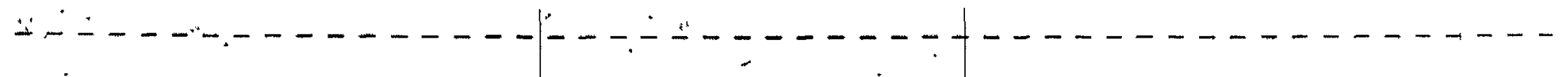

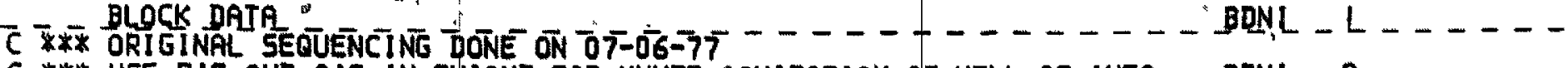
C WKX USE E'S AND O'S IN SUIONZ FOR KUNZE IONIZATION AS WELL AS INFO.

C *** IN COHHON/XCION/,

- 5 X*Z USE E'S JN SURECZ FOR HQDLF LER C JORDAN RECOHBJ NAUON

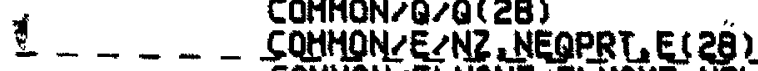

COMMON/ SWNAME/ELNAHE, NELDES,DES(3T) - - - - - - - - -

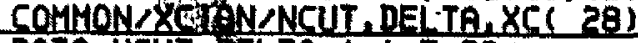

C DATA NCUT, DELTAII, I E-20

5 **Z NCUT $=O C U$ MEANS ARRAY XC UNAUALLARLE (AUAJLABLE)

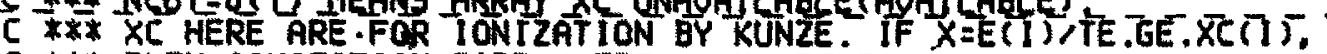

C * * IHEN LONI ZAUION RATE COEFF, LU _ DELTA DATA XC,

$128,51,26,55,28,26,27,35,26.75,26,29,25,89,25.55,25.24$,

2 $24.94,24.31,24.03,23.75,23.45,23.10,22.71,22.10,21.33$,

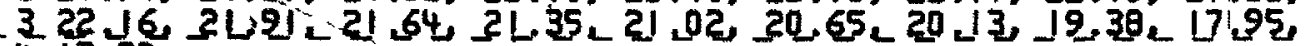

417.20

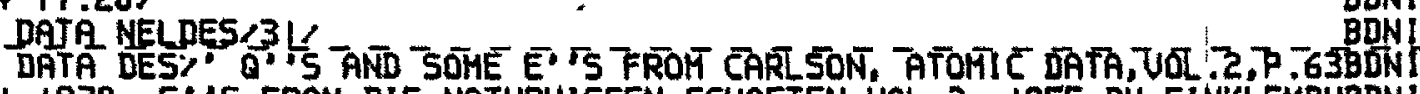

1 1970. E*'S FROM DIE NATURHISSEN SCHAFTEN, UOL. 2 , 1955 BY FINKLEMBUPDN

2RG. '’

DAIA ELNAME $\because M$

D BDN

C

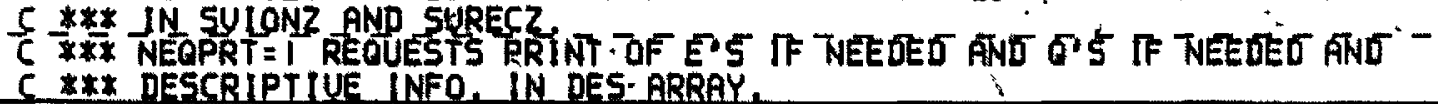

$C$ *** NEOPRT MAY BE ALTERED HITHîN SUTONZ, SURECZ.

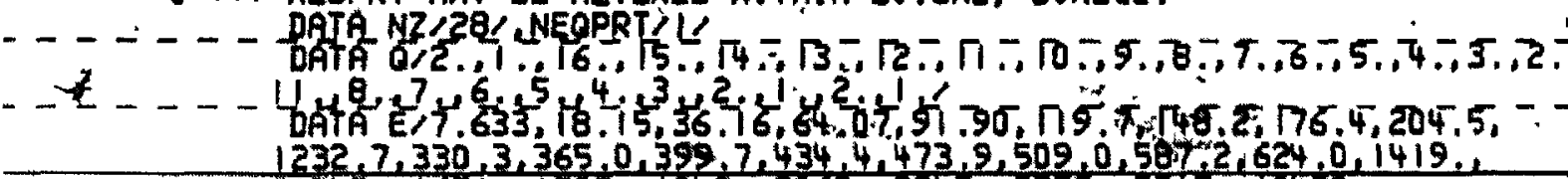
$\frac{1232,7,330,3,365,0,399,7,434,4,473,9,509,0,569,2,624,0,1419.1}{21545.1671 .01797 ., 1942 . .2069 .02547 ., 2358, .955 .10420 .1}$ END

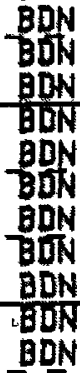

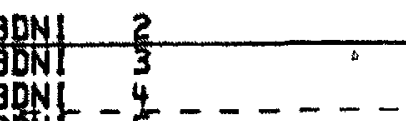

5

BDN

BDN

BDNL 10

BDN

GoNT 73

BDint 15

BDNI 16

18

19
20

21

$-5--$

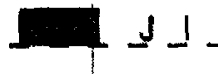




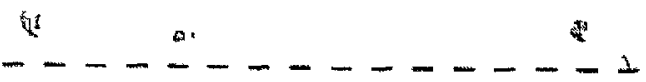

$\bar{C}$ X*F OLOCK DRTR

C ** USE E'S AND O'S IN SUIONZ FOR KUNZE IONIZATION AS HELL AS INFO.

C *** IN COMMON/XCION/.

5 **Z USE E'S JN SURECZ FQR MODIF IER C JORDAN RECOMBINATION COMMONTOROC (29)

COMMON $\angle E>N Z$ NEOPRT E (29)

COMMON/ELNAME ELLNAME, NELDES, DEST TO

COMMON XCION NCUT, DELTA XC( 29$)$

DATA NCUT, DELTA I, I,E-ZD,

C $X$ * NEUTZQCU MEANS ARRAY XC UNAUAILABLE ( AUAILABLE)

C *** XC HERE ARE FOR IONIZATION BY KUNZE. IF X XE (I), tE. TEE. XC

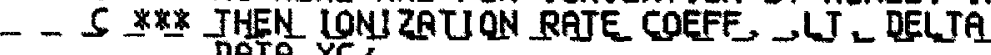

DATA XC

$127.81,29.23,28,29,27,17,26.66$,

$225.01,24.74,24.14,23.87,23.59,23.30,22.97,22.56,21.98$,

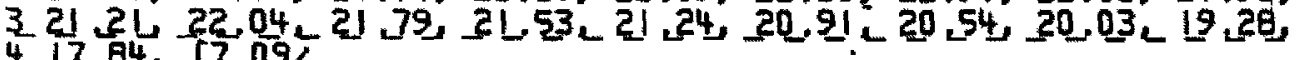

DATA ELNAME COS

DATA DES" Q"'S AND SOME E'"S FROM CARLSON, ATOMIC DATA, UOL, $2, P, 63 B D C U$

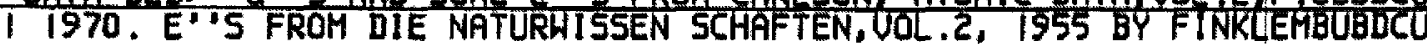

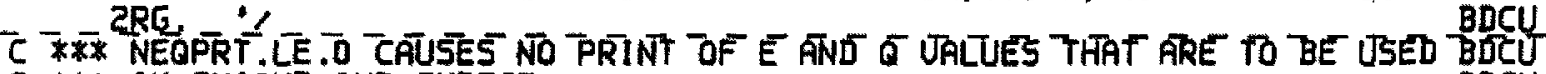

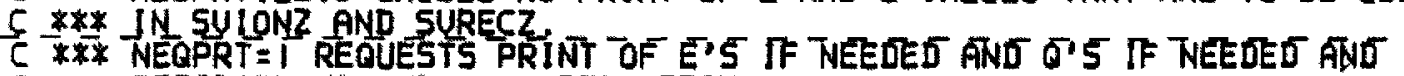

C *** DESCRIPTIUE INFO IN DES ARRAY

C ** NEQPRT MAY BE ALTERED HITHIN SUIDN2, SUREC?.

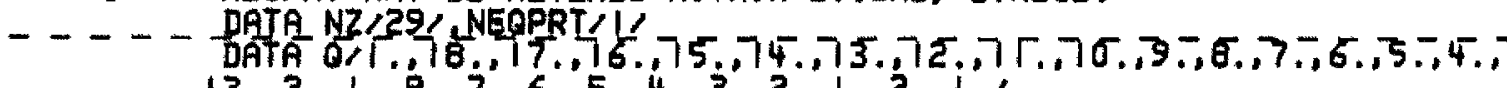

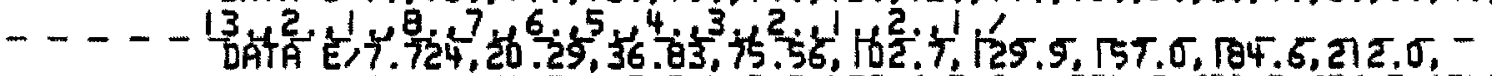
$1239,5,266,9,371,7,407,7,443,7,479,6,510,4,554,9,639,3,676,5,1542$,

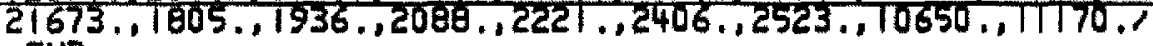
END

k I 


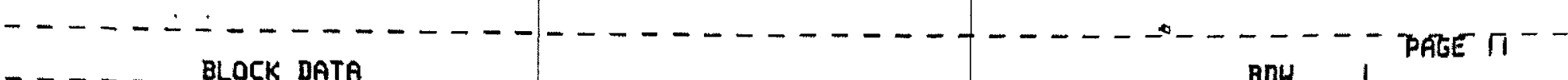

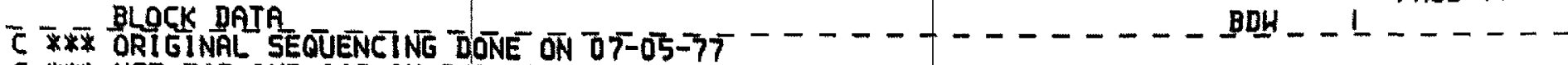

C *** USE E'S AND O'S IN SUIONZ FOR KUNZE IONLZATION AS WELL AS INFO, BDH

C *** IN COMMONIXCION/.

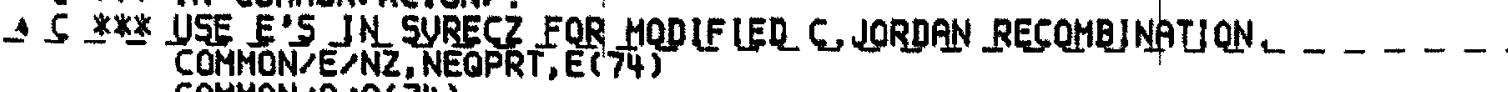
SOMHON $\angle Q \angle Q(24)$

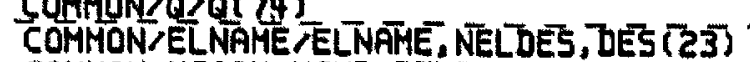

COMHON XCION NCUT, DELTA, XC ( 74)

DATA NCUT, DELTA I, 1.E-20'

$5 * * *$ NCYT=0(U) MEANS ARRAY XC UNAUAILABLE (AUAILAELE)

$C$ XXX XC HERE ARE FOR IONIZATION BY KUNZE. IF X

5. *** IHEN IONIZAUION RATE COEFF, . LT L DELTA

DATA XC,

$128,45,26,59,28,50,27,77,27,23,26,79,27,18,25,57,25,23$,

$224.90,24.56,24.10,23.68,25.81,25.57,22.76,22.01,25.17$,

$324.92,24.82,24,66,24.51,24,36,24.22,24.09,23,95^{\prime}, 23,82$,

$423.70,23.26,23.14,23.02,22.90,22.77,22.64,22.50,22.36,-60 H$

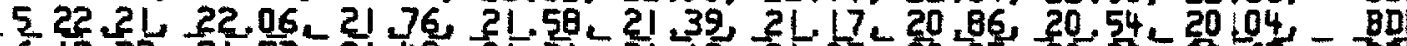

6 19.32, 21.53, 21.42, 21.31, 21.19, 21.07, $20.95,20.60,20,67,-$

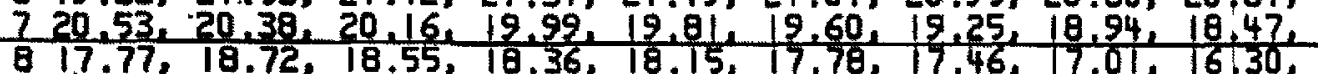

$87.77,18.72$,

DATA RELDEST3,

DATA DES

C $* * *$ NEPPRTY $\$$ F $O$ CAUSES NO PRINT OF E AND O UALUES THAT ARE TO BE USED BDW

C $*$ *\% IN SUTONZ AND SURECZ.

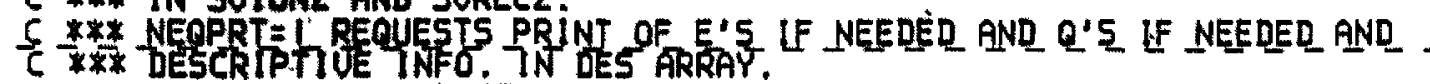

C X*Z NERPRT MAY BE ALIERED HITHIN SUIONZ, SURECZ

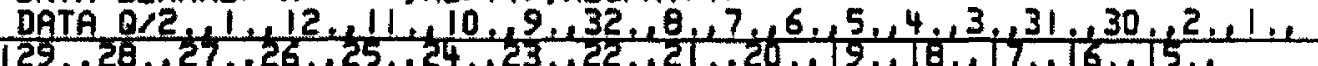

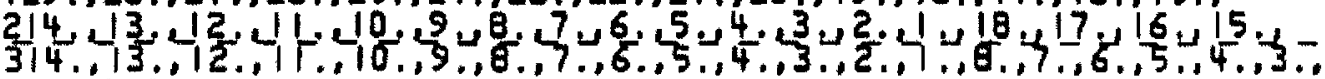

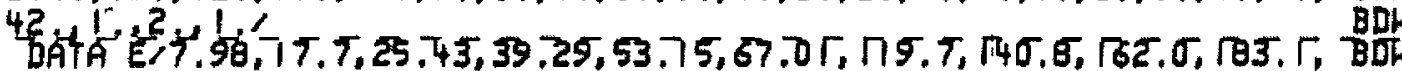

$1204,2,240,5,263,1,294,6,339,9,369,9,395.0,435.5,480,0,526,1,571,4, \mathrm{BDH}$

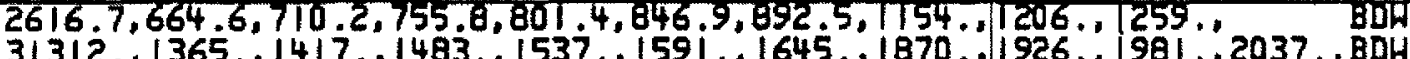

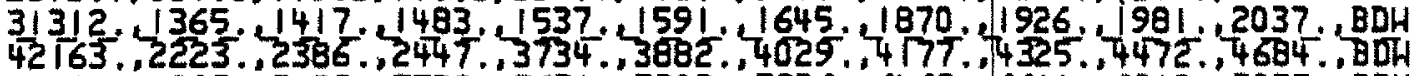

54036.4987 .5139 .5538 .5671 .5803 .55936 .6468 .6611 .6919 .7055 . . BDW

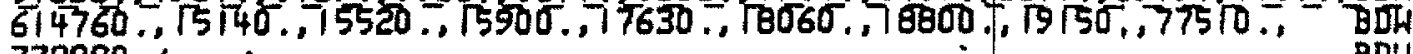
778990.1 END 


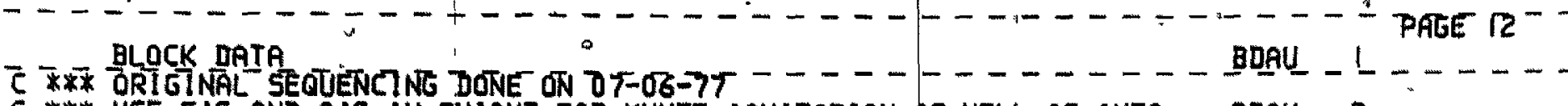
C *** USE E'S AND Q'S IN SUIONZ FOR KUNZE IONIZATION AS WELL AS INFO:

C *** UN COHE'S IN SURECZ FOR MOD IF IED C. JORDAN RECOMBINATION.

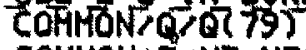

COMMON $>$ E NZ, NEQPRT, E (79)

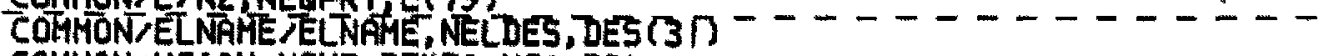

COMMON $X C$ CION/NCUT, DELTA, XC ( 79)

DATA NCUT, DELTA/, I.E-ZD'

5 ***. NCUT $=0(1)$ MEANS ARRAY XC UNAUAILARLE (AUAILABLE).

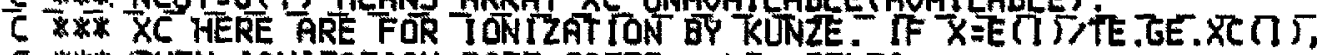
C * * THEN LONI ZATION RATE COEFF, .LT - DELTA

$127.55,29.22,28.27,27.66,27.20,26.82,26.49,26.17,25.89$,

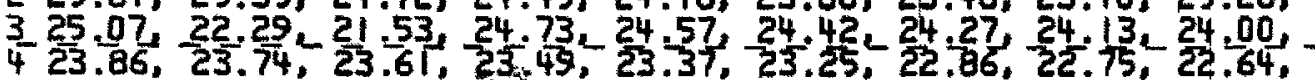

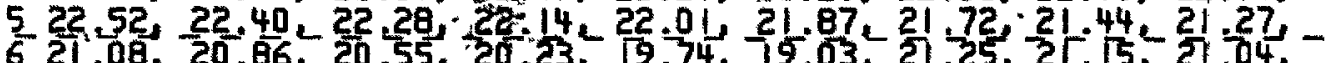
$720,93,20,81,20,70,20,55,20,42,20,29,20,14,19,92,19,76$, BDAU

$819.58,19.37,19.01,10.70 .18 .24,17.54,18.50,18.34,18.15$, $917.94,17,55,17.24,16.79216 .00,14.22,14.02,-X_{-}-\ldots-\frac{B D A U}{\text { BDAU }}$

DATA DES'' Q'S AND SOME E''S FROM CARLSON ATOMIC DATA UOL , 2,P.63BDAU

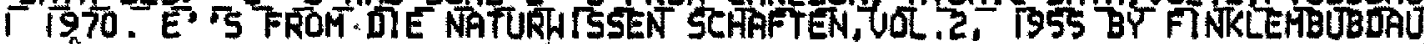
SRE, 1

DATA ELNAME $\nearrow^{\top}$ AU 'I

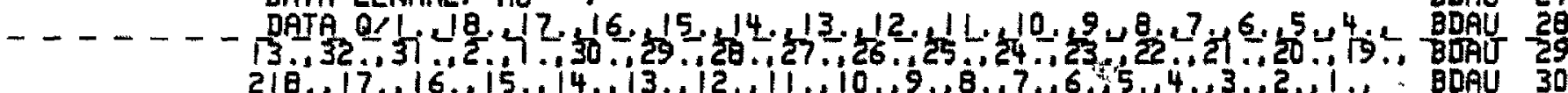

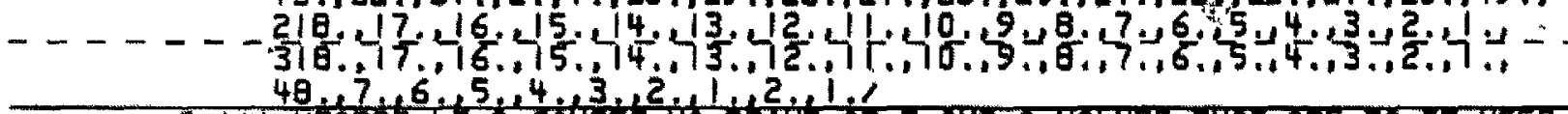

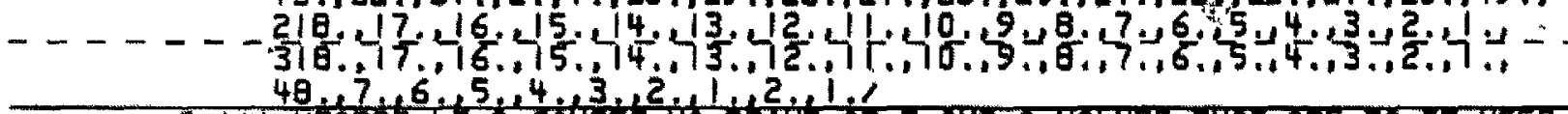

BDAU

BluAL

C *** NEQPRT.LE.O CAUSES NO

C *** IN SUIONZ AND SURECZ.

C *** DESCRIPTIUE INFO. IN DES ARRAY.

C $\times$ WEOPRT MAY EE AGTERED WTTHIN SUTONZ, SURECZDATA NZ 79, NEOPRT/I,

DATA E $19,223,20$.

8104.6,

8432.9

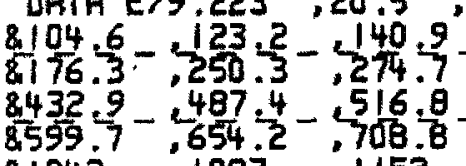

81042

81207.

\&1 948.

$82065-2009$

82991.

84637.

86500 .

$37.37, .54 .18,70.99,87.81$

$86931 ;, 7615 ; .7772$

$.259 .6-323.5-, 365.7-, 391.7-$

$.763 .3-.877 .9-.872 .7-.930 .9-.986 .2^{-}-$

$1097 ., 1152$.

BDAL

DAU 2

BDAU -4

BDAU $-\frac{6}{7}-\ldots$

BUAU

9

BDAU

BDAU

BDAU 14

BDIU 15

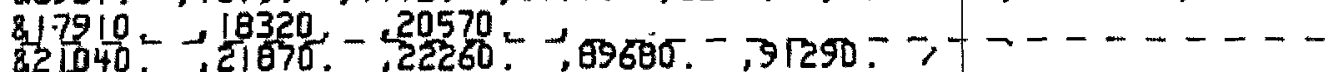

BUAL

DRUU

BDAU

BUAU

BDAU

BDAU

BDAL

BDRU 42

BDAU

BDAU

BDAU

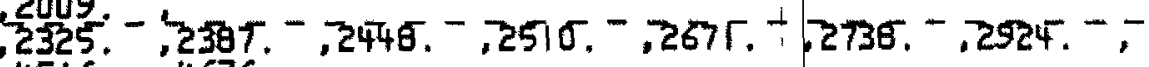

4516.4676. END

$.5316 .-.5566 .-.573 \Gamma .+15896 .-.7065 \Gamma^{-}-$

BDAU 48

BDAU 45

BDAU 50

BDAU 51

BDAU $\frac{52}{53}$

BDAU 54 
SUBROUT INE EQUIYEQU, SUIZ, SURZ, NZ, D)

$\bar{C}$ **F ORIGINAL SEQUENCING DONE ON $07 \overline{7}-12-75$

EQU -1 PAGE B $^{-}$

DIMENSION YEQU(1), SUIZ(1), SURZ(1),D(1)

C *** NEED DIM. YEQU(NZ+1), SU1Z(NZ), SURZ (NZ),D(NZ)

S * * D J 5 Q SCRATCH ARRAY

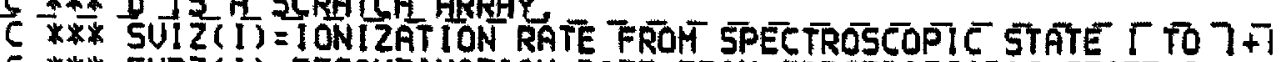

5 *** SURZ ( ) =RECOMBINATION RATE FROH SPECTROSCOP IC STATE I +I JO

C * YEQU, THE EQUIL IBRIUM DISTRIBUTION UECTOR, IS NORPALTZED SO THAT

C *** SUM OF ITS COMPONENTS = I.

$C$ *** YEQU IS IN THE NULL SPACE OF THE COEFF. HATRIX, A,

5 * * LET RHO( 1$)=5$ IZ (I) /SURZ (I) AND ASSUME SURZ (I) NE. O. MOREOUER LET EO

C *** THE I-TH COHPONENT OF THE NORHALIZED EQUILIBRIUM VECTOR, YEOU, BE EQU

c *** ETA(1)

C X* DETERHINE INDEX OF LARGEST COMPONENT, ETAC(I), BY USING LOGS IN

*** ORDER TO AUOID UNDERFLOWS OR OUERFLOHS, THEN FORH YEQU NORHALI LED EQL

5 * SQ US LARGEST COMPONENT HAS UALUE I. IHEN NORMAL IZE YEQU SO THE

DATA EPSEOU

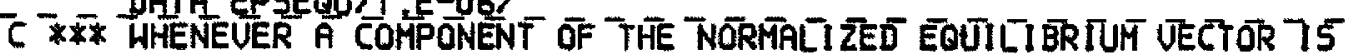

$C$ *** LE.EPSEOU TIMES THE LARGEST COMPONENT SET IT TO 0

C *** COMPUTATIOMALLY SOME OF THE COMPUTED RATE COEFF. MAY BE 0.

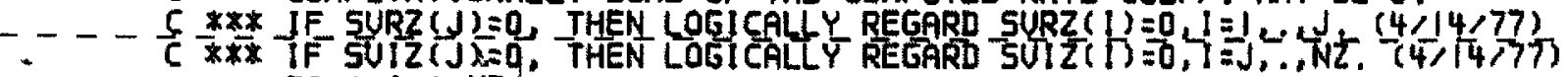

EOU

E⿰冫U

EQU

E⿺辶.

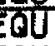

oul

E⿺辶寸

GU

EQU

EQU

EOU

EOO

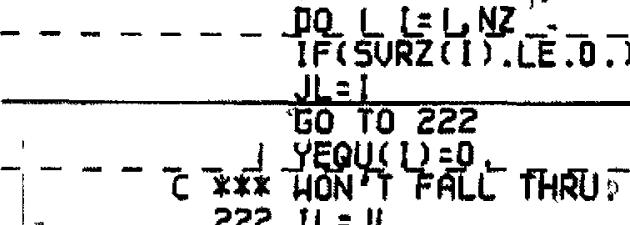

$222-14=4$

Do $\Pi I=I L, N 2$

IF(SURZ (i).GT, 0 , GO TO 11

$J L=1$

1 CONTINUE

TFI $\pi . E S . \pi 560$ To

2 YO 13$]=i L 4$

$J L=J L+1$

2 IHFNZ

22. IF (SUIZ(IH) GT.O.) 60 IO 33

YEQU $(I H+1)=0$.

$1 \mathrm{H}=\mathrm{IH}-1$

33) IZ $=I \mathrm{H}$

$\mathrm{I}=\mathrm{IH}-\mathrm{I}$

35 IF (SUIZ(1).GT .0.) EO TO 34

$i z=i$

$34 \quad I=I-1$

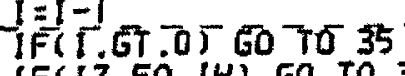

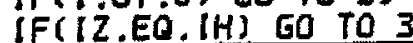

D0 $36 \mathrm{~J}=12$, IH

36 YEOU $(J+1)=0$

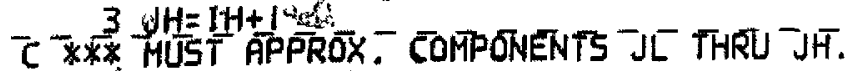
ANUMMX $=-1, E B$

$5=0$.
EQU

EQU

EOU

EOU

EOU

Equ

EQU

EOU

EOU

EOOU

EQU

EUU

EQU

EQU

EOU

EQU

EQU

EGU

EOU

EQU

EQU 46

- 47

EQU

EOU

EQO

EQU

EGU

EQU

EUU

EQU 


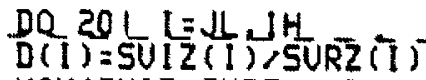

C $* * *$ MAX (SUIZ, SURZ), LT, I, IF NEITHER Ó, THEN SUIZ,LT, SUIZ SURZ,LT

$5=5+A L O C(D(1))$

IF (S.LE.ANUMMX) GO TO $20 \overline{1}$

ANUMHX $=5$

IMAX = !

201 CONIINUE

YEQU $(1 \mathrm{MAX}+1)=1$

¿ $*$ X

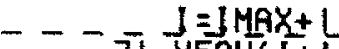

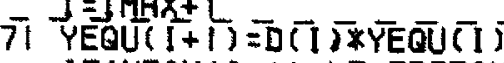

IF (YEQU $(I+1)$. LE, EPSEQU) GO TO 80

$I=I+1$

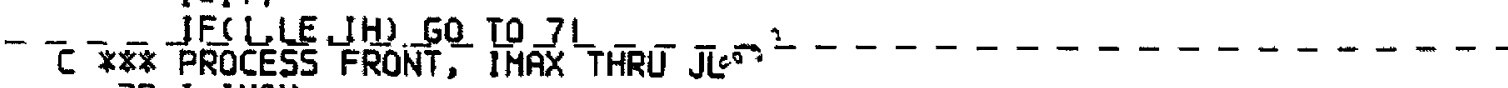

- $-2 Z$ I $=1 \mathrm{MAX}$

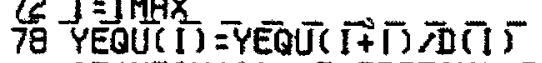

IF (YEOU(I).LE.EPSEOU) GO TO I80

$i=1-1$

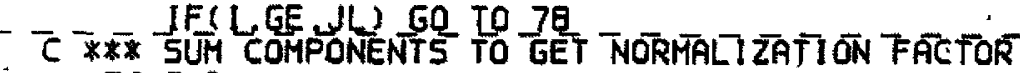

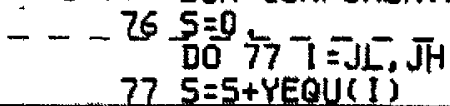

$C$ *** NORMALIZE EQUILIBRIUM VECTOR

- -74 DQ 24 J

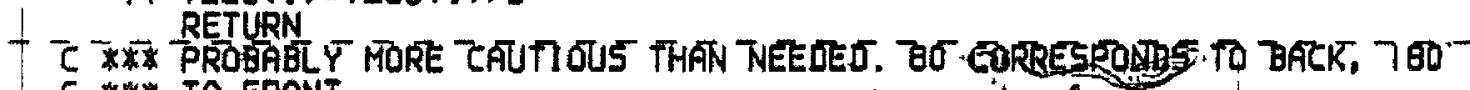
$C * * *$ TO FRONT.

80 S=YEOU $(1+1)$

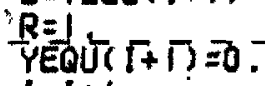

Q1 $1=I+1$

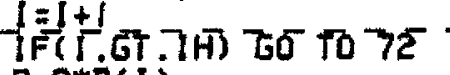

$R=R * D(I)$

IF(R.LE. I.E-4) G0 TO 75

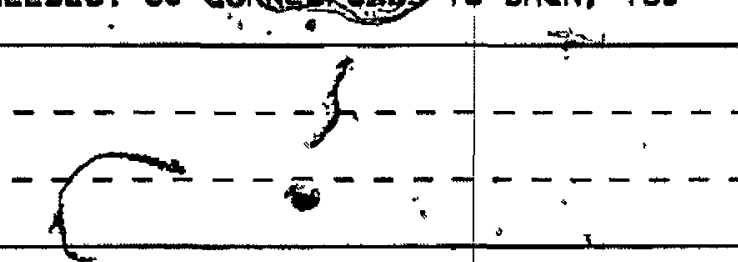

IF (R,LE, I $)$ GO TD 73

YEQUUC

50 TO 8

73 YEQUT) GO TO BI

75 YEOU $(1+1)=0$.

$-2-\frac{1}{150}+1$ IF! [LE,TH 70 TO 75

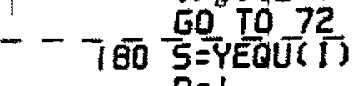

$R=1$.

YEQUं $(1)=0$.

$\ldots-181]$

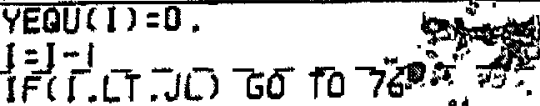

$$
\text { - }
$$

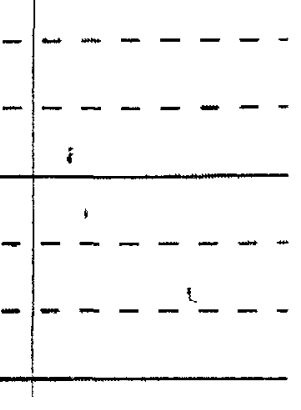

EOU 00

EOU

EQU - 82

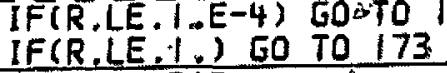
YEQU $(7)=R \times 5$ 
50 To $18 \mid$

175 YEQU $(1)=0$.

- - - - J J I 50 T0 76

END

F
EOU

EQU

EQUU

Egi

EQQU

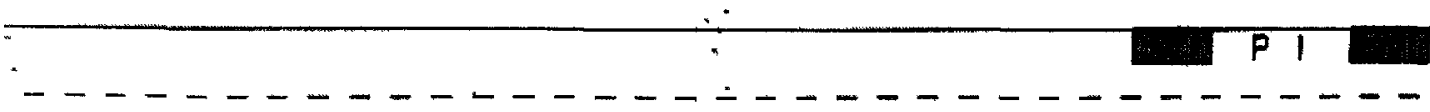

PALEE 15- 18

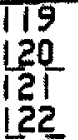

(1) 1

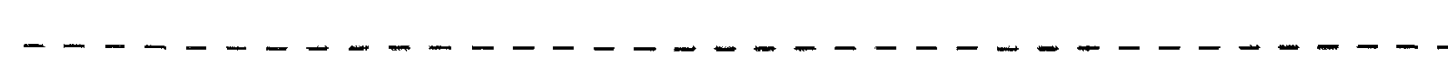
. - - - - - - - - - - - - - - - - - - - - - - - - - - - - - - - - - - - - - - - - - - - - - - - - - - - - - - - - - - - - - -

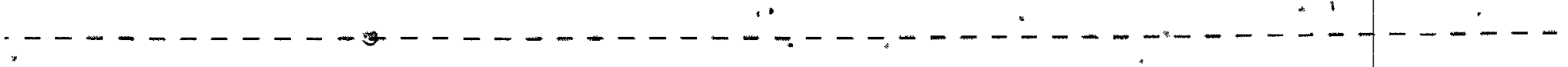
c. $+$

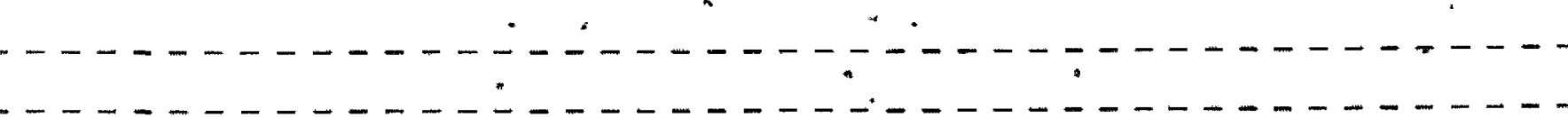

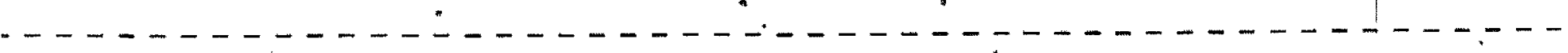

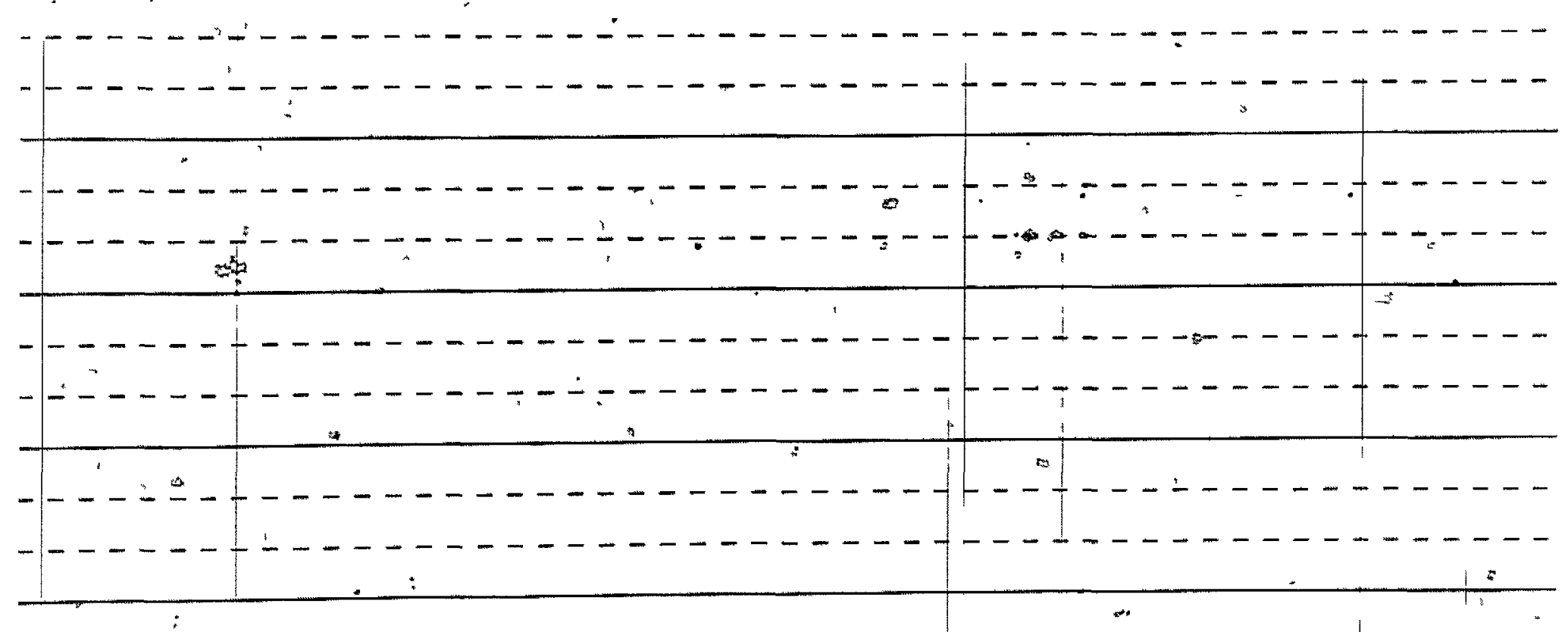

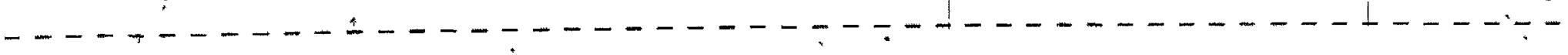

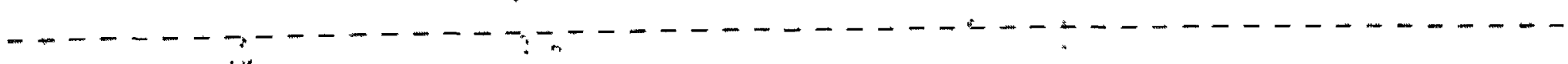

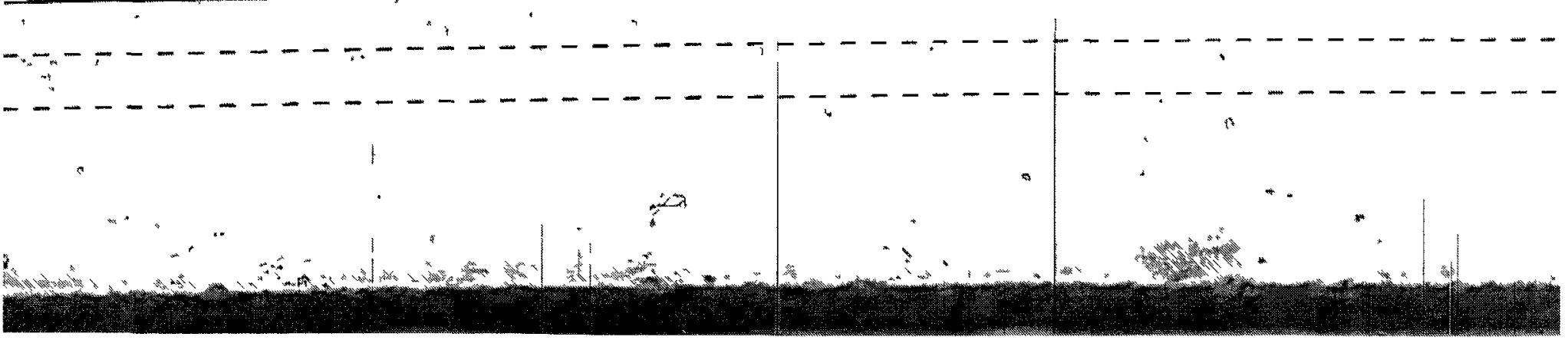




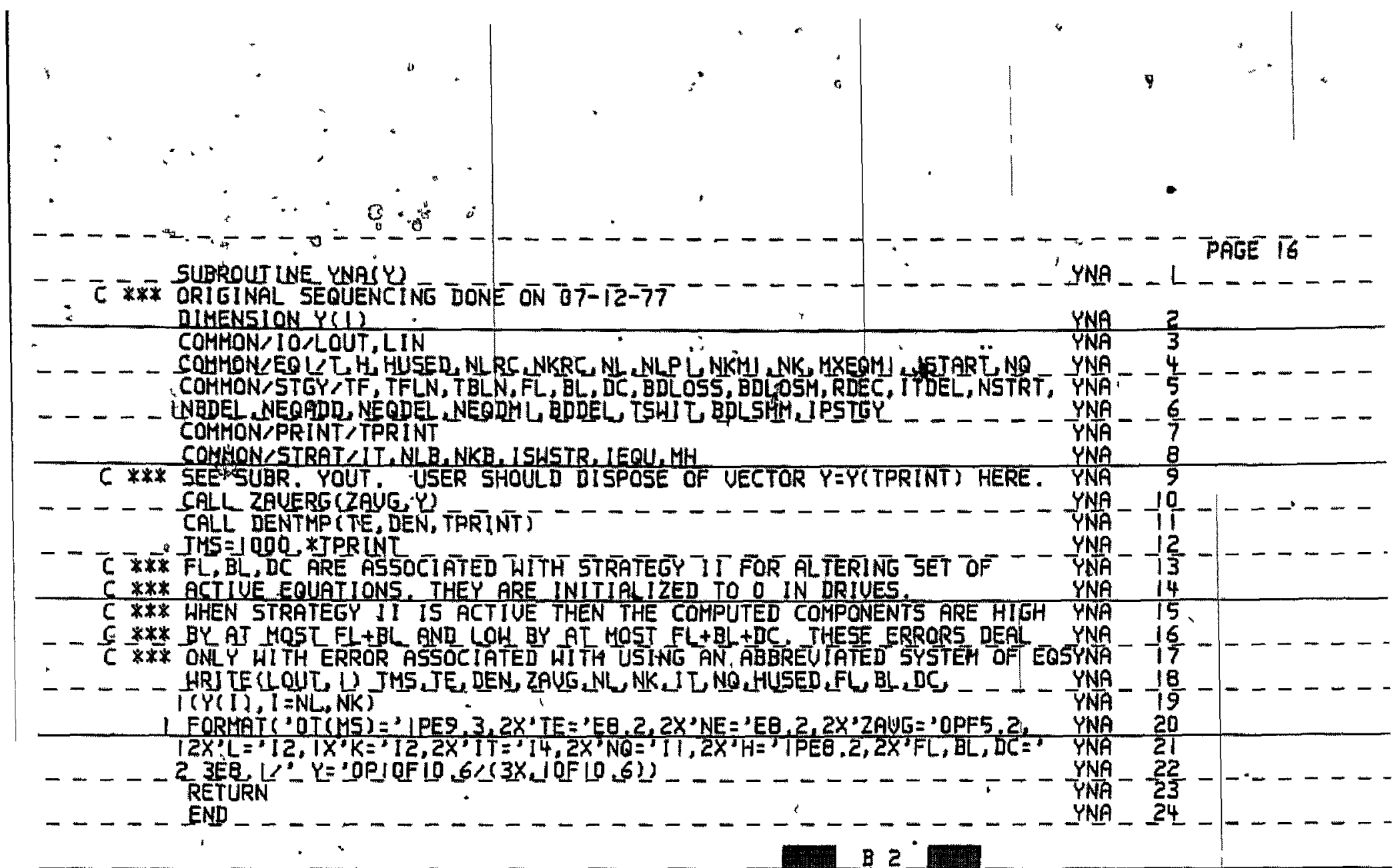

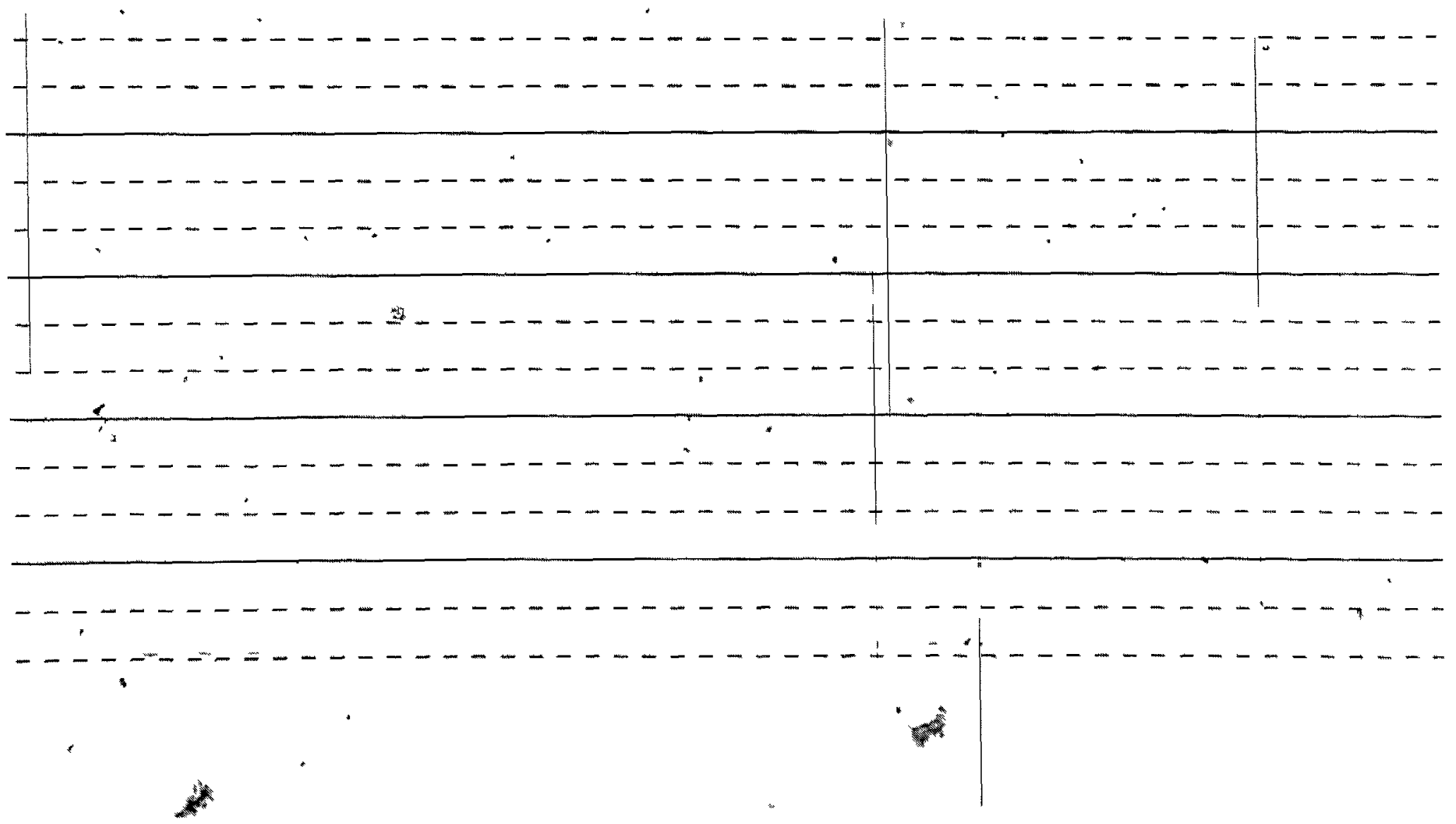



5 * $*$ *** THESE RQUUTUNES HAUE

BEEN ALTERED TO TAILOR THE INTEGRATION TO THE MAIN 50

PATEE TB-

OHE LINEAR SYSTEM OF DIFF.

$C$ *** N UECTOR. IN THIS CASE, THE SYSTEY IS (i) LINEAR, (2) HAS A

MAIN

(1)

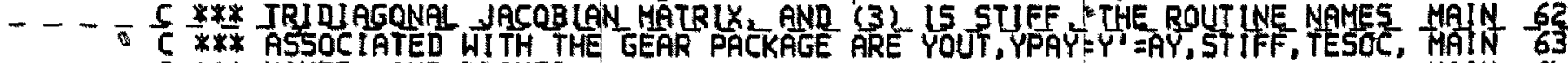

- 5 X** YOUTD. AND DRIUES

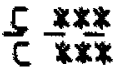

C***

MAIN 64

C *** THE SUBROUTINES APPEARING IN THE PROGRAM LISTING ARE DRDERED ${ }^{2}$ MAIN 67

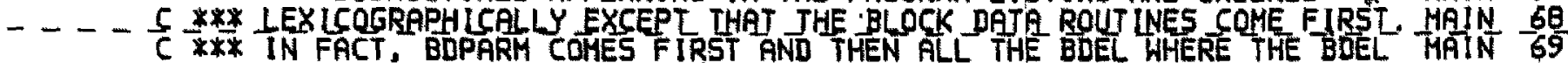

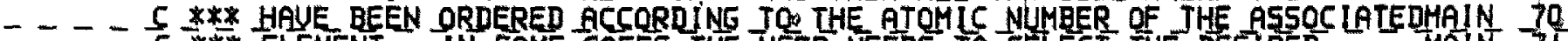

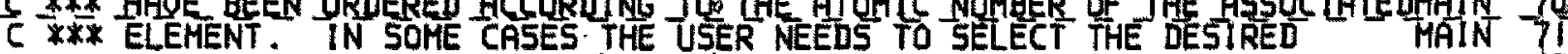

C * * ROUTINE HHEN SEUERAI ARE OFFERED.

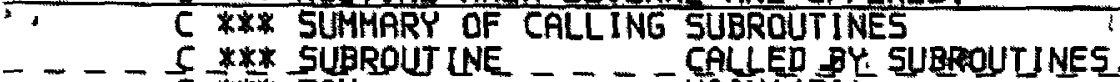

c $\frac{* * *}{* * *}$ EOU

5 * \$* YNA

MAINT(T)

C XX* MAIN

C *** YOUT

DRIUES

C *** MAINI (TTO) - - - STIFF

$f$ X** MAINIUU _ . . . MAIN

$\frac{C}{C}+$ ROOTS

C *** STIFF

MAINT(T)

C *** TESOC

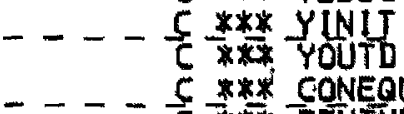

DRIUES

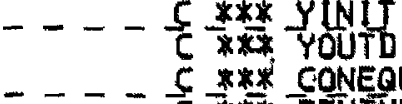

STIFF

MAINI(U), MALNL(TD)

C $\bar{X} \times \bar{X}$ DENTMP(TD)

C *** DENTMP

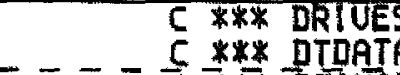

C *** DTDATA

DRTUES

DRIUES TRESTPAY, YNA

DRIUES, YPAY, YNA

---
$-\ldots$
$-\ldots$
$-\ldots$

C *** IMTOL

X*X. INTEGC

*** STRTGI

INTEGC, MAINT (TD)

MAINI (TD)

MATNF( D

ROOTS

MATNT
DRIUES

C कxस STRTLI

C *** SUIONZ

MAINT(T) HAINT(TO)

MAIN

72

C *** ZAUERG

MAINI(TI), DRIUES, YPAY, STRATS

MATNTETS, DRTUES, YPAY, STRATO

MAIN: 74

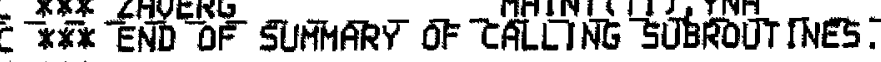

C ****

MAINI TI I) YNA

MAIN

C *** BOEL=BLOCK DATA FOR ELERENT, EL. E.G., BDC=BLOCR DATA.FOR CARBON. MAIN TOS

C $* * *$ BDPARHF BLOCK DATA HHERE USER SPECIF IES PROGRAM CONTROL PARAMETERS MAIN IOH

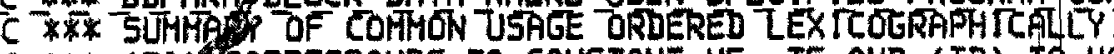

C ** ITI CORRESPONDS TO CONSTANT NE TE AND (TD) TO UARIABLE NE, TE. MAIN 106

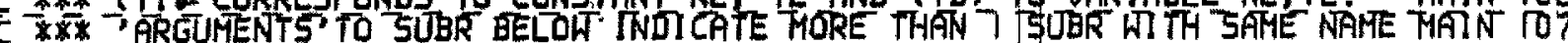

C * *E CE BDEL, MAIN, MAINI (TD, TI), STRTGI, SUIONZ (DORY, KUNZE),

C *** SURECZ (DORY, MOD.C.JORDAN)

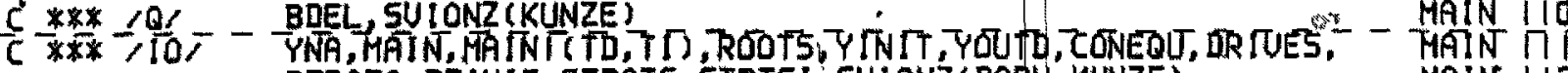

C * * - - DTDATA DTINIT, STRATG STRTGI, SUI ONZ (DORY, KUNZE)

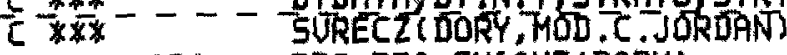

C K** $/ A P L / B D C$, BDO, SUIONZ(DORY)

C X** /APR/ BDC, BDO, SURECZ (DORY)

MAIN 1 I

TALN TIS

MAIN 114

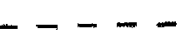

.

- - - -

- - - -

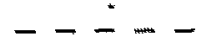

MAIN 75

MAIN 80

MAIN 63

MAIN 85

MAIN 86

MAIN 90

MAIN 92

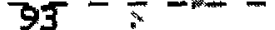

MAIN 96

MAIN 99

MAIN 100 


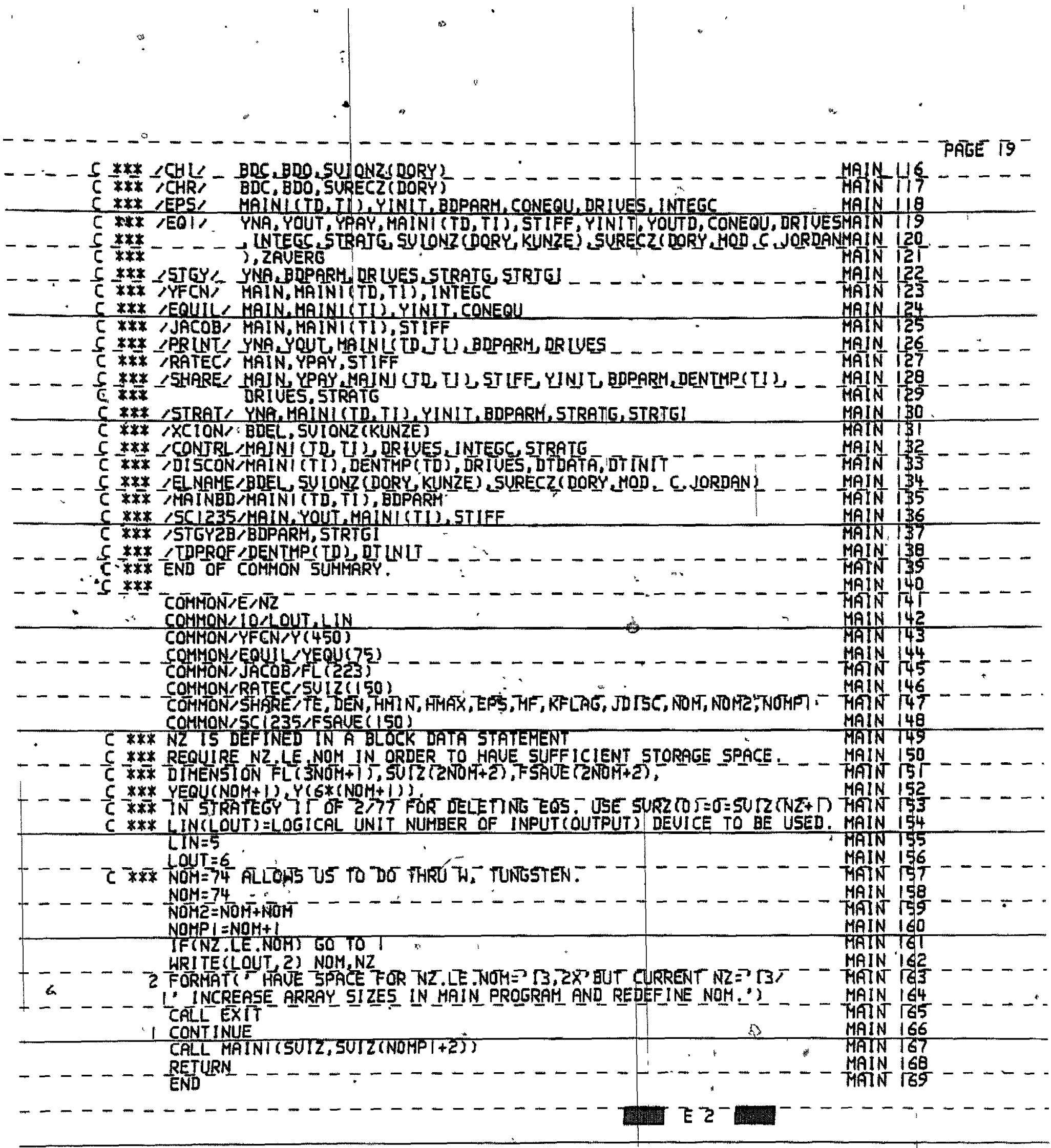


- - - - - - - - - - - - - - - - - - - - - - - -

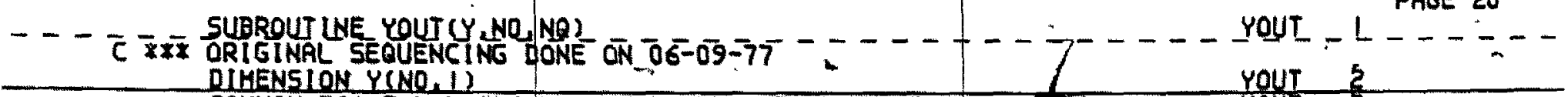

COMHON/EO IIT,H, HUSED, ,NLRC, NKRC, NL, NLPI, NKHI,NK O YOUT

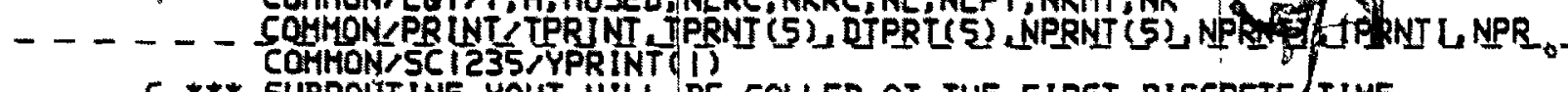

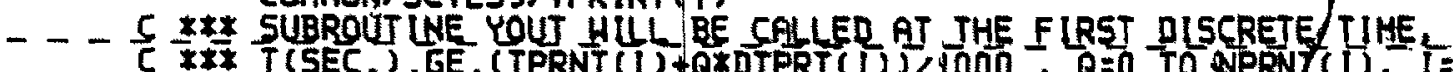

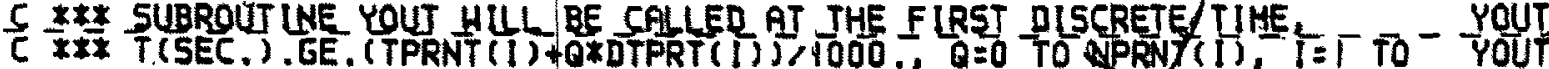

C *** NPRNTI. THE SYSIEM OF ODE'S IS EXPRESSED IN SECONES I AND TPRINT YOUT

C *** ARE IN SEC.. HOHEUER ARRAYS TPRNT ANB DTPRT ARE IN MILLISEC.

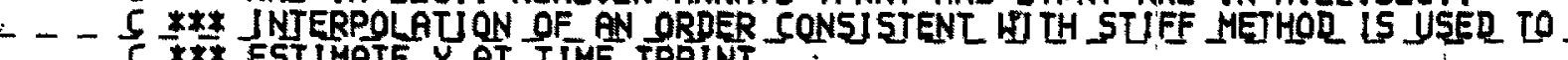

$C$ X $\times$ ESTIMATE Y AT TIME TPRINT

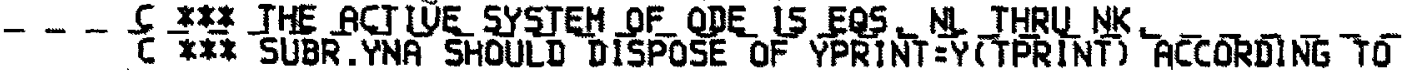

$5 \times * *$ THE USER'S HISHES.

C *A* NPR =0, IPRNTI $=1$, TPRINT = TPRNT (1)/1000 ARE DEFINED AT BEGINNINE OF

5 *** DRIUES - TPRNL U DTPRTU I NPRNTS U NPRNT L NEED TO BE DEFINED

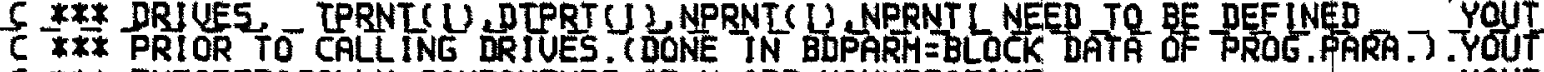

5 *** THEORETICALLY COMPONENTS OF Y ARE NONNEGATIUE,

Yout

\section{-}

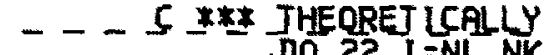

2R CONTINUE
-5 SONTINUE

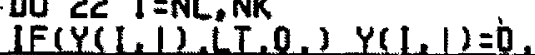

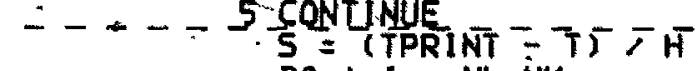

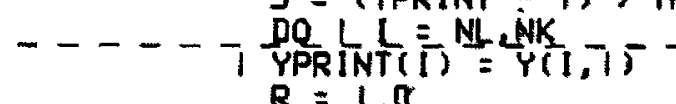

$R=1,0$

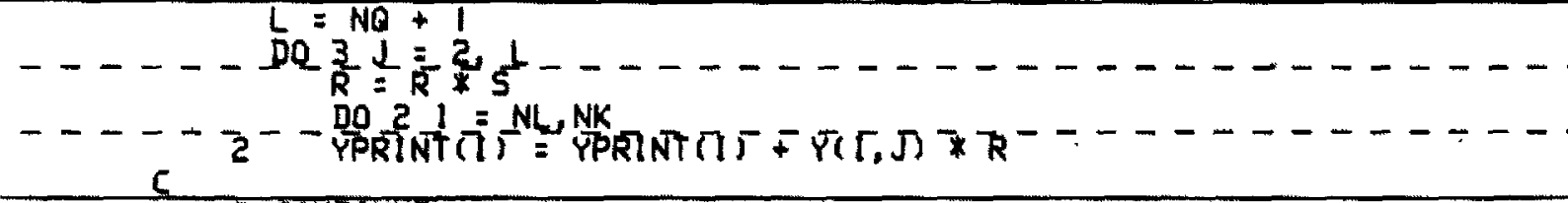

3 CONTINUE

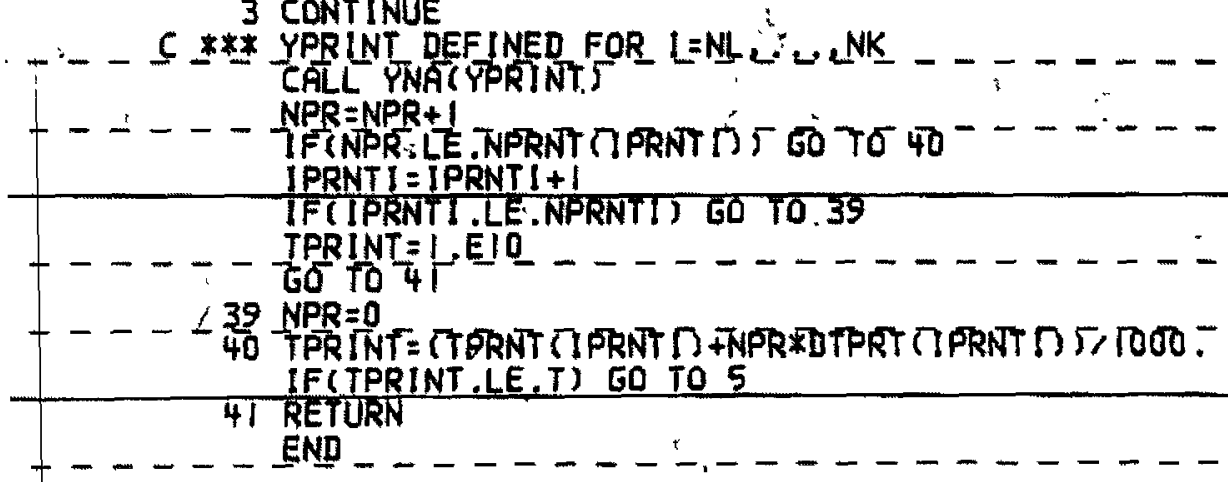


G $\bar{X}$ XF SURROUT LNE YPAY CYDOL Y

DIHENSION Y (1), YDOT(1)

COMHON/EOI T, H, HUSED, MLRC, NKRC, NL, NLPI, NKMI, NK

COHMON $\angle R A T E C, S U L Z(J)$

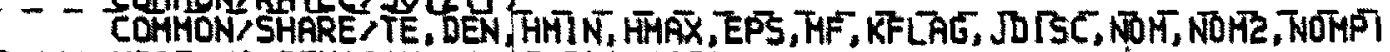

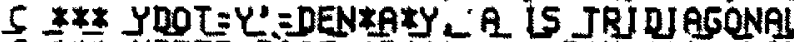

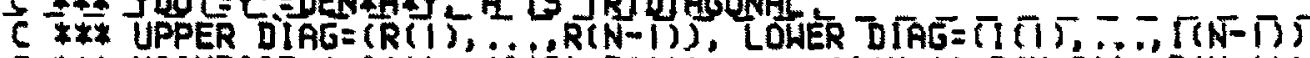

$5 \times x *$ HAINDIAG $=(-1(1),-(i(2)+R(1)), \ldots,-(1(N-1)+R(N-2)),-R(N-1))$

$C$ *X* BIAG DISPLAY FOR $N=1$ AND NK $=N$.

C $\overline{\text { XXF }}$ SULLR. DENTHP UE, REN T

5 *** JHE GUEN J WE, L, TE, DENS

CALL SURECZ (SUIZ (NOMPIIZ), TE, DEN)

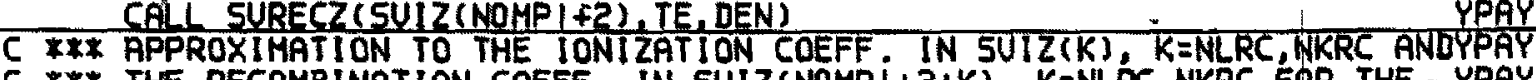

YPAY - L

PAGE टा -

C * K* JWE RECOMBINATION COEFF, IN SUIZ CNOMPL L

S *** JHE SYSTEM OF ODE'S IS EXPRESSED IN TIME UNLT OF SEC

C * R* RATE COEFF. ARE IN UNITS OF CM*X3/SEC

YDOT $(N L)=$ DEN* (SUIZ $(N O M+N L+2) * Y(N L+1)-5 U / 2(N L) * Y(N L))$

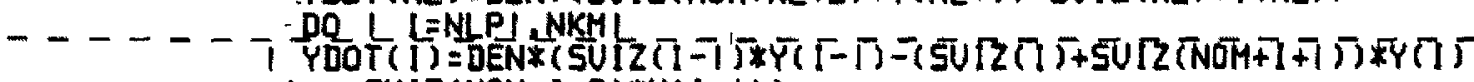

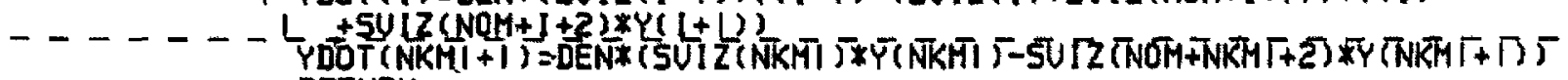
RETURN END

YPAY

YPAY

YPAY

YPAY

YPAY

YPAY

YPAY

.11

YPAY

YPAY

YPAY -1.

YPAY 18

YPAY 19

YPAY

YPAY

YPAY

YPAY

YPAY

YPAY

YPAY
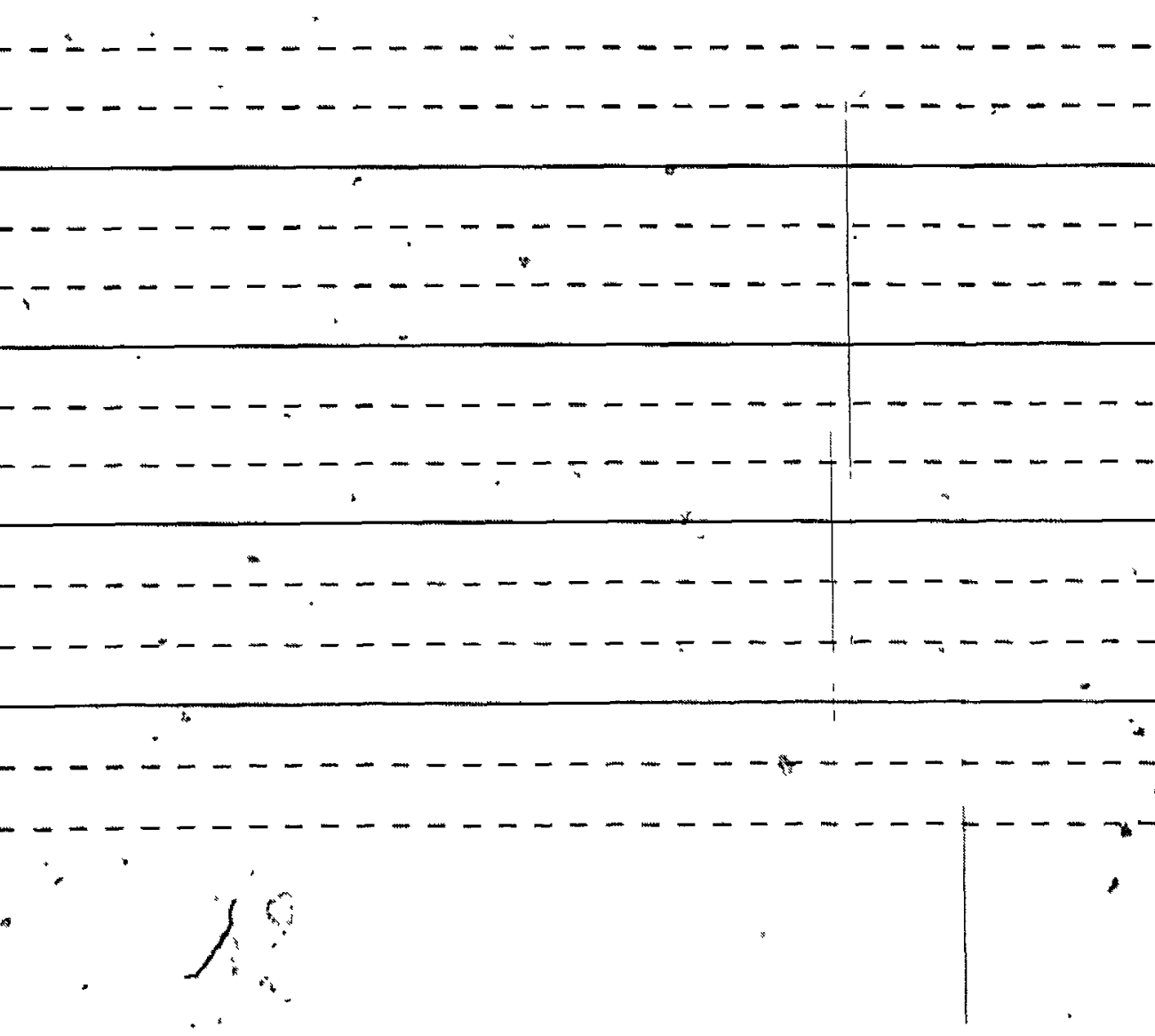


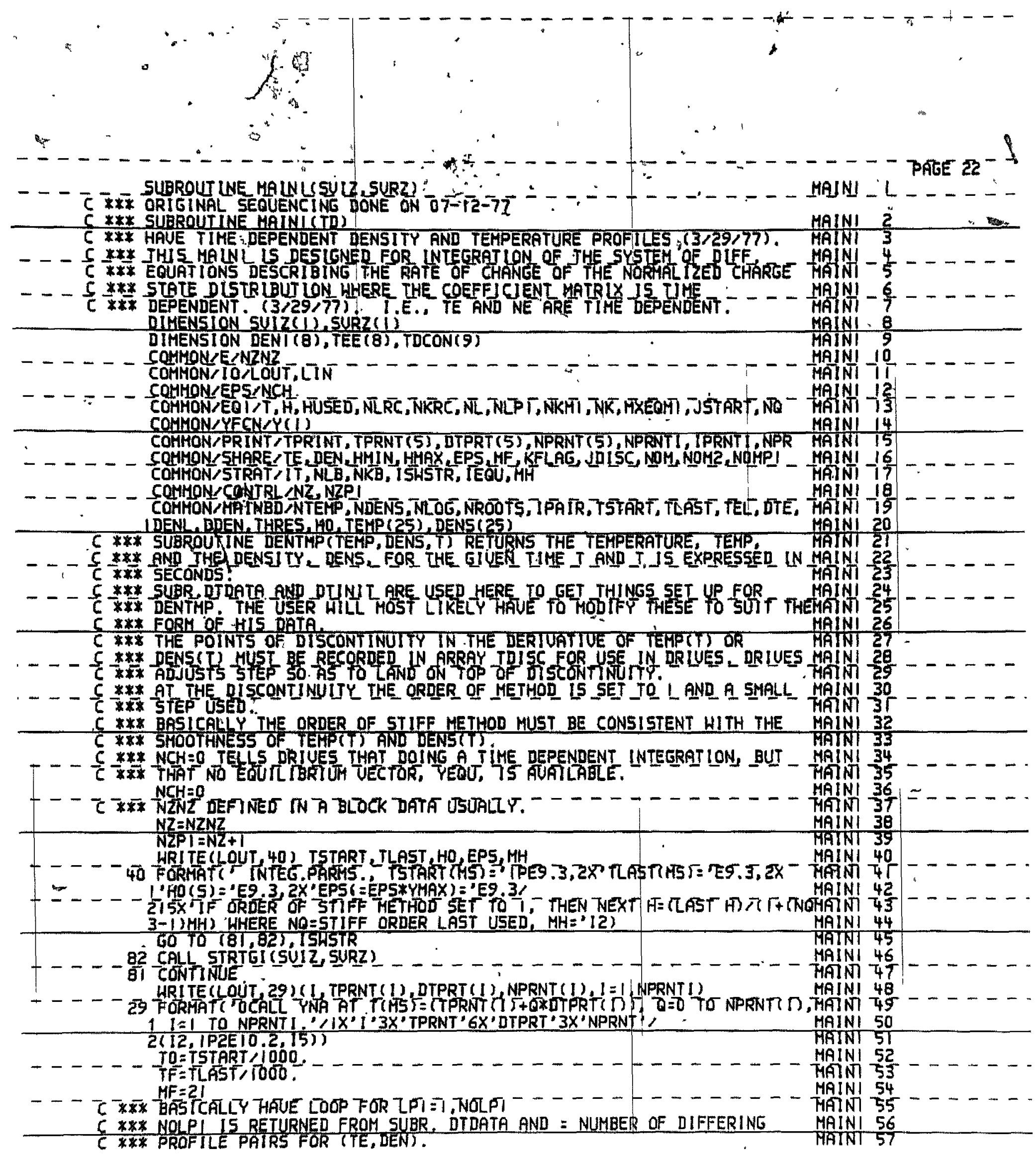

C *** PROFILE PAIRS FOR (TE, DEN). MAINI 5 T 


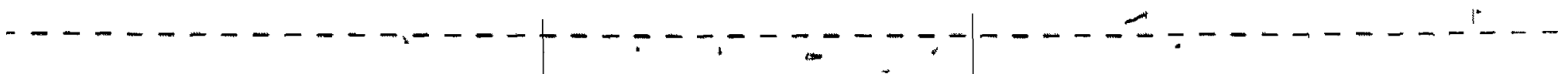

C *** GENERALLY NOLPJ ENUHAER OF RADLAL POLNTS AT WHLCH EXPERIMENTAL MAINI 58

C * F* UALUES FOR TE, DEN ARE DBTAINED FROH A LASER SHOT. HENCE LOOP OUER MAIN DFS

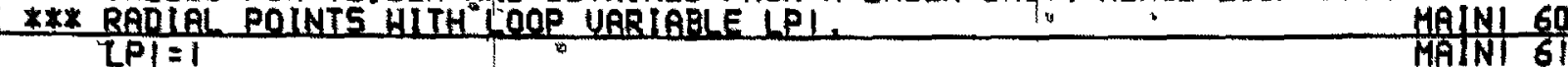
$L P \mid=1$

140 SALL DTDATACLPI NQLP JENL TEE TDEON NTLAS, NDEN DNI L DNLZ DNI 3 1 DN21, DNE2, TP II, TPIZI

MAIN 62

CALL DT LNIT DENL TEE TDCON, NDEN,DN L DNIZ, DNU 3 DNZI DNZZ TPL L TP(2,NTLAS)

CALL YINITIY NZPI THRES)

CALL DRIUES (NZP), TO, TF, $Y, H O, E P S, M F$, IGFLAG, SUIZ, SURZ)

5 * $*$ KFLAG $=0$ MEANS EQUAT LONS INTEGRATER TO DESIRED END. IF(KFLAG.EQ.0) GO TO $113^{\prime}$

HRI TE (LQUT I I ) KFLAG

12 FORMAT "DODE-PACKAGE DI DNTT DELIUER OUR REOUEST, KFLAG $D$ TB G0 TO 222

113 CONTINUE

222 CONUINUE

$L P I=L P I+1$

JFCLPLLLE NOLPI) GO TO L4O END

$\ldots-\cdots-\ldots-\ldots-\ldots-\ldots \ldots$ 



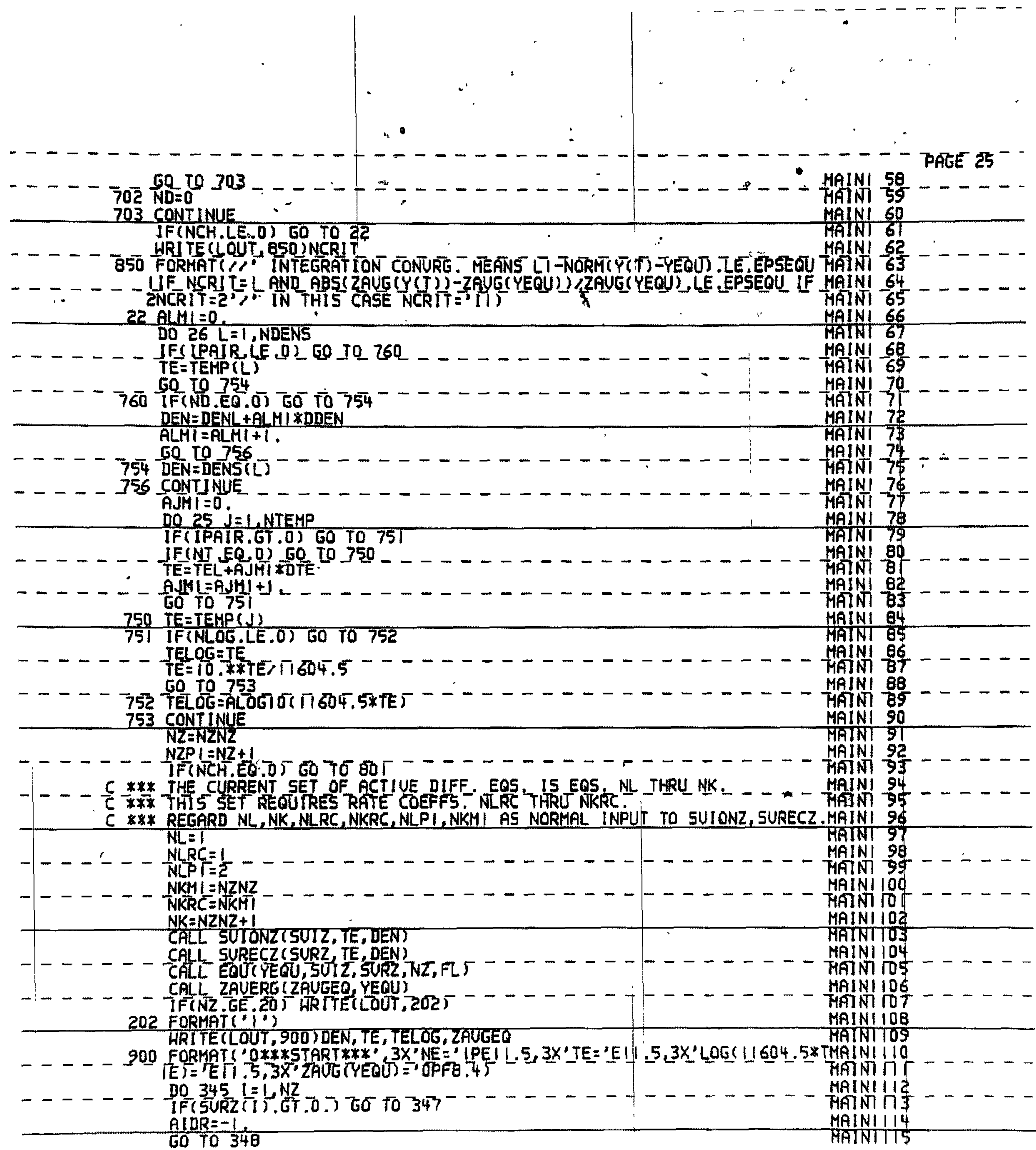




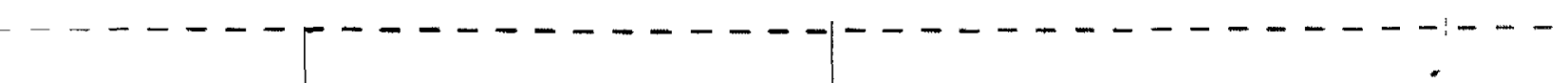

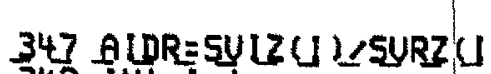

$348 \quad|M|=1-1$

IF (1, GT, I) G0 TO 223

WRITE(LOUT, 200)

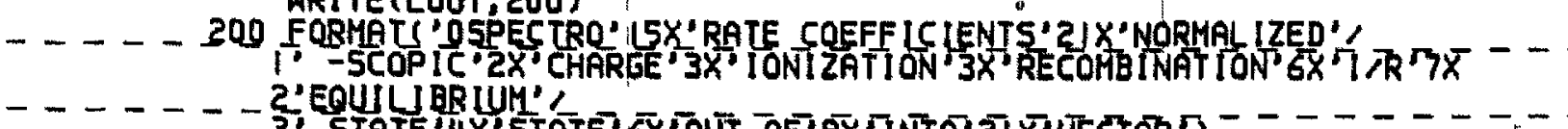

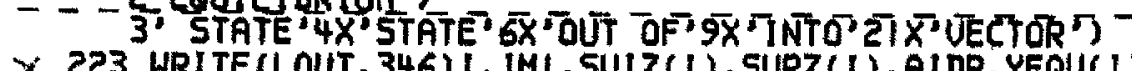

346 FORMAT $(15,6 \mathrm{X}, 13,1 \mathrm{X}, 1 \mathrm{PZE} 14,4,5 \mathrm{X}, \mathrm{E} 10.4,3 \mathrm{X}, 0 \mathrm{PFE}, 6)$

345 CONTINUE

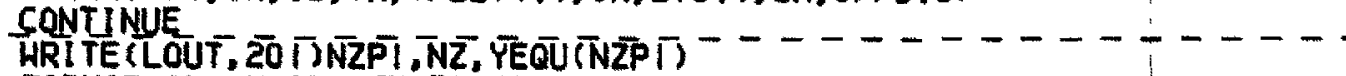

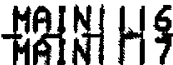

PAGE $\overline{26}$

201 FORMPTS $5.6 \times$ L $13.47 \times, F 8,6)$

IF(NROOTS.GT, D) CALL ROOTS(SU[Z, SURZ, NZPT, DEN, FL, FSAUET)

IFCMCH, EQ, -2) 50 TO 222

NEPSC $=1$

- . - . - EPSEGU =EPSCCS U

IFINZ.GE. ¿OU) WRTTETLLOUT, $\overline{2025}$

801 CALL YINIT(Y, NZPI, THRES)

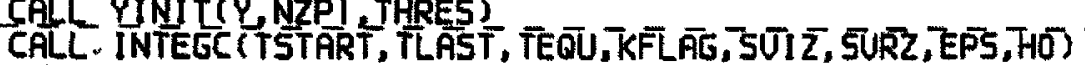
IEIKFLAE. EQ O) GO TO 113

HRI TE(LOUT, 12) KFLAG

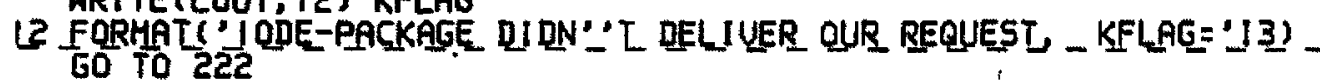

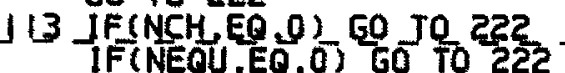
TOUT ETCONUT

HRI TE(LOUT, 15) TOUT

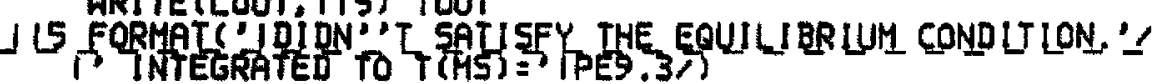

222 CONTINUE

¿25 continue

26 CONTINUE

RETURN

END

MAINIIIB

MAINIIS

MAINIIZO

सAीNITा

MAINIIZ2

TARINI हैड

MAINII 24

MAINIIZ5

MAINIIZ6

MAINIIIZT

MAINI 128

MAINI

MAINII30

MAाNI|31

MAINI 132

MAIN

MAIN 134

MAINI 35

MAINI 136

MAINII37

MAINI 138

MAINI 35

MAINI 140

HAiNI 145

MAINI 142

MAINIT43

MAINi 44

TAीN 145

MAINI 146

พAี NT 147

MAINI 148

HAINIT 49

MAIN NII 150

$$
\text { - }
$$

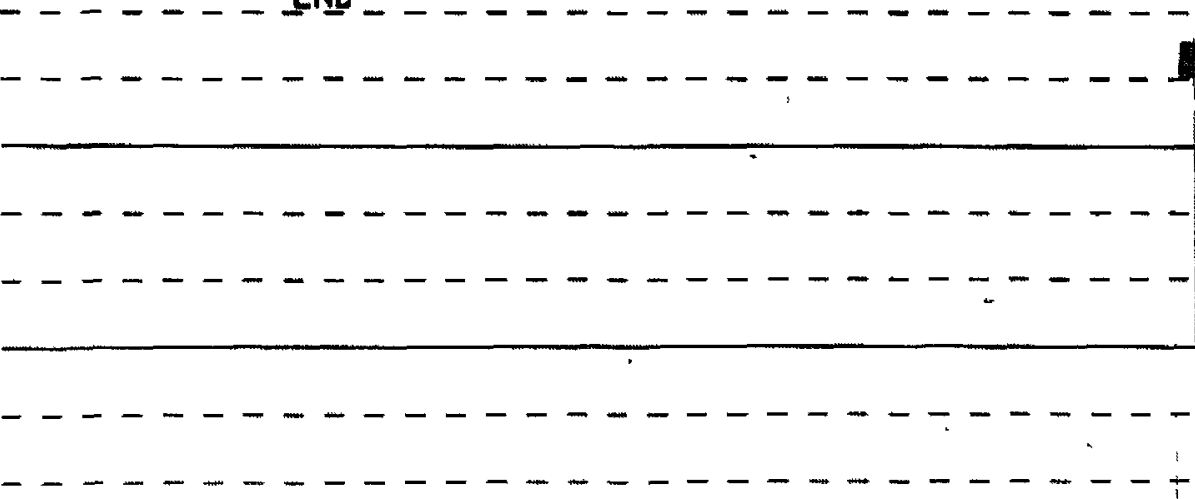

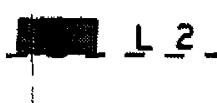



$\bar{C} \bar{X} \times \bar{X}$ SUBROUT LNE STIFF(Y, NO)

DEN $06-09-77$

MAUE TAILORED STIFF FOR DUR LINEAR SYSTEM

DIMENSION Y $(N O, 6), E L(6)$, TO(3)

- 5 I* DIMENSION Y $(N O, 13)$, EL (II), TQ(4) FOR NONSTIFF DIMENSIONING

C FTE OF MAX. ORDER.

5 \$ I RCT IUE EQUATIONS ARE NL THRU NK

C XXT THE CORRECTOR

C $\$ *$ ITSELF LINEAR

C \$** CF., "NURERICAL INITIAL UALUE PROBCEH IN ORUINARY DIFFERENTIAL

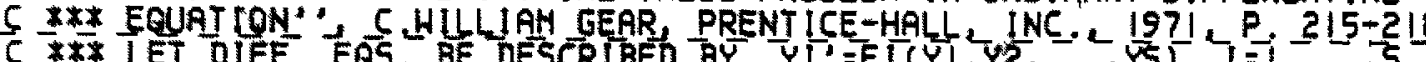

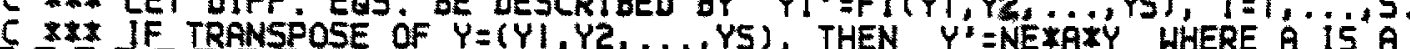

C $\times \bar{X}$ TRI DIRGONAL MATRIX HHOSE NONZERO ENTR IES ARE LINERR COHEINATIONS

$C$ $* * *$ OF IONIZATION AND RECOMBINATION RATE COEFFICIENTS. THE LETTERS

C XXX PRED FOLLOHING AN EXPRESSION IN PARENTHESES INDTCATES AN ESTIMATE

- 5 \$* OBTAINED FROH THE PREDICTOR STEP

C $\$$ XX USING $(11.8)$ ON P. 216 DEFINE

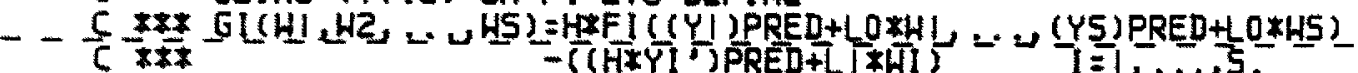

C *** HI . WS ARE DETERHINED FROH GI $=$ G2 = . =GS $=0$

C *** THIS IS EQUUIUALENT TO THE UECTOR-MATR'T $X$ EQUATIOK

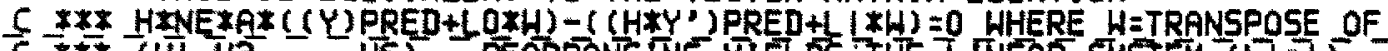

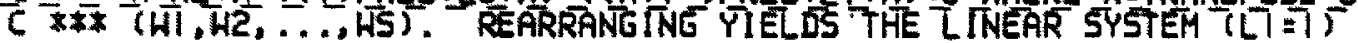

C * $* * *-L O Z H * N E * A) H=H *(N E * A *(Y) P R E D)-\left(H * Y^{\prime}\right)$ PRED

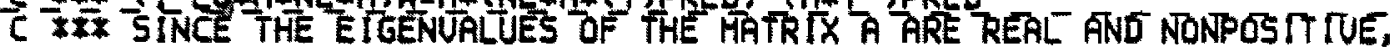

$C$ KXX THE COEFF, MATRIX IS NONSINGULAR, MOREOUER, IT CAN BE SHOLN THAT

C XXX GAUSSIAN ELIMINATION WITH PARTIAL PTUÓTING REQUIRES NO PIUOTINE

C $x \times x$ AT ALL

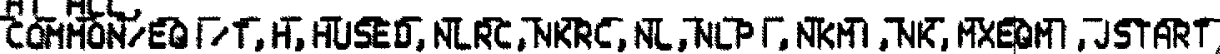

COMHON $/$ JPCOB $/ F L(1)$

COAHON/RATEC/SURП

COHMON, SHARE, TE, DEN, HMIN, HMAX, EPS, MF, KFLAG, JDISC, NOM, NOMZ, NOMP |

COHMON/SCI 235/F5AUE(T)

$C * * * 5 U I Z(N O M+Z+1)=5 U R Z(1), F L(N O M+1)=F U(1), F(N O M Z+1)=F D(1)$

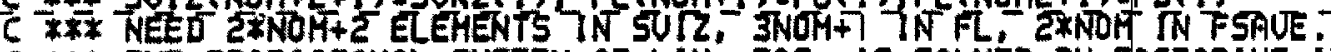

C \$** THE TRIDIAGONAL SYSTEM OF LIN. EQS. IS SOLUED BY FACTORING IT INTOSTIFF 36

作

$C * * *$ DIAG (U), FU $=$ IST UPPER DIAG OF U.

C $X$ WX HAVE SUH $Y(I)=1, Y(1), 6 E, 0$. CHOOSE YAAX TO BE CONSTANT

C XX* FEED IN EPS THE UALUE YHAXXEPS

CX STIFF PERF ORHS DNE STEP OF THE INTEGRATT ON DF AN TINITIAL UALUE

C* PROBLEM FOR A SYSTEM OF ORDINARY DIFFERENTIAL EQUATIONS.

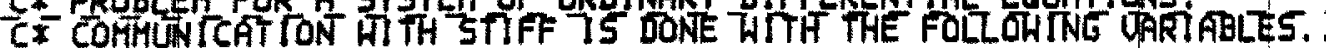

$c *$

$\frac{c}{c}$

cx

C*

$6 *$

$\mathcal{c} *$

C*

$\frac{C *}{c *}$

C*

\section{AN NO BY LHAX ARRRAY CONITAINING THE DEFENDENT UARIABLES} AND THEIR SCALED DERIUATIUES. LMAX IS QURRENTLY II FOR THE ADAMS METHODS ANN 5 FOR THE GEAR METHODS. ZMAX = IS MAXDER, THE MAXIMUM ORDER USED. SEE SUBROUTINE TESOC. Y $5, \mathrm{~J}+D$ CONTAINS THE $J-T H$ DERTUAT TUE OP YAS, SCALED BY HXXJ JFACTORIAL (J). ONLY Y $(J), I$. LE. I LE, N. NEED BE SET BY THE CALLINE PROGRAM ON THE FIRST ENTTRY IF IT IS DESIRED TO INTERPOLATE TO NON-MESH POINTS. IS $H$ AND THE UALUE AT T + E 15 NEEDED, FORM $5=E / H$, AND THEN COMPUTE NO

$Y(1)(T+E)=S U T H(1, J+1) \times 5 * X J$.
THE Y ARRAY CAN BE USED. IF THE CURRENT STEP SI ZE
PALE ZB

STIFF

STIFF

STIFF

STIFF

ST IFF

STIF

SfIF

STIFF 12

STIFF 13

STIFF 15

STIFF -16

SIIFF 18

STIFF 20

STIFF 21

STIFF $\frac{22}{3}$

5TIFF 24

STीF 25

STIFF 26

STIFF 27

STIFF 20

STIFF 30

STIFF 32

STIFF 33

STIFF 34

5 TFF 37

STIFF 38
StIFF 39

STIFF 40

5ñF $4 \Gamma$

STIFF $\frac{42}{43}$

STIFF 44

\section{STIF}

STIFF

STFF 4

STIFF 48

FF 4

STIFF 50

STIFF 51

STIFF 52

SnคF 53

STIFF 54

STFF 55

STIFF 56

STIFF 57

$-$

$-$

$-$

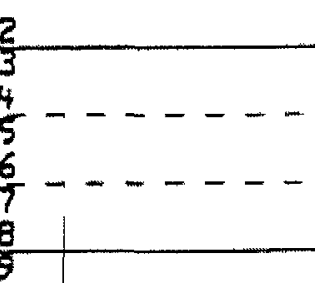




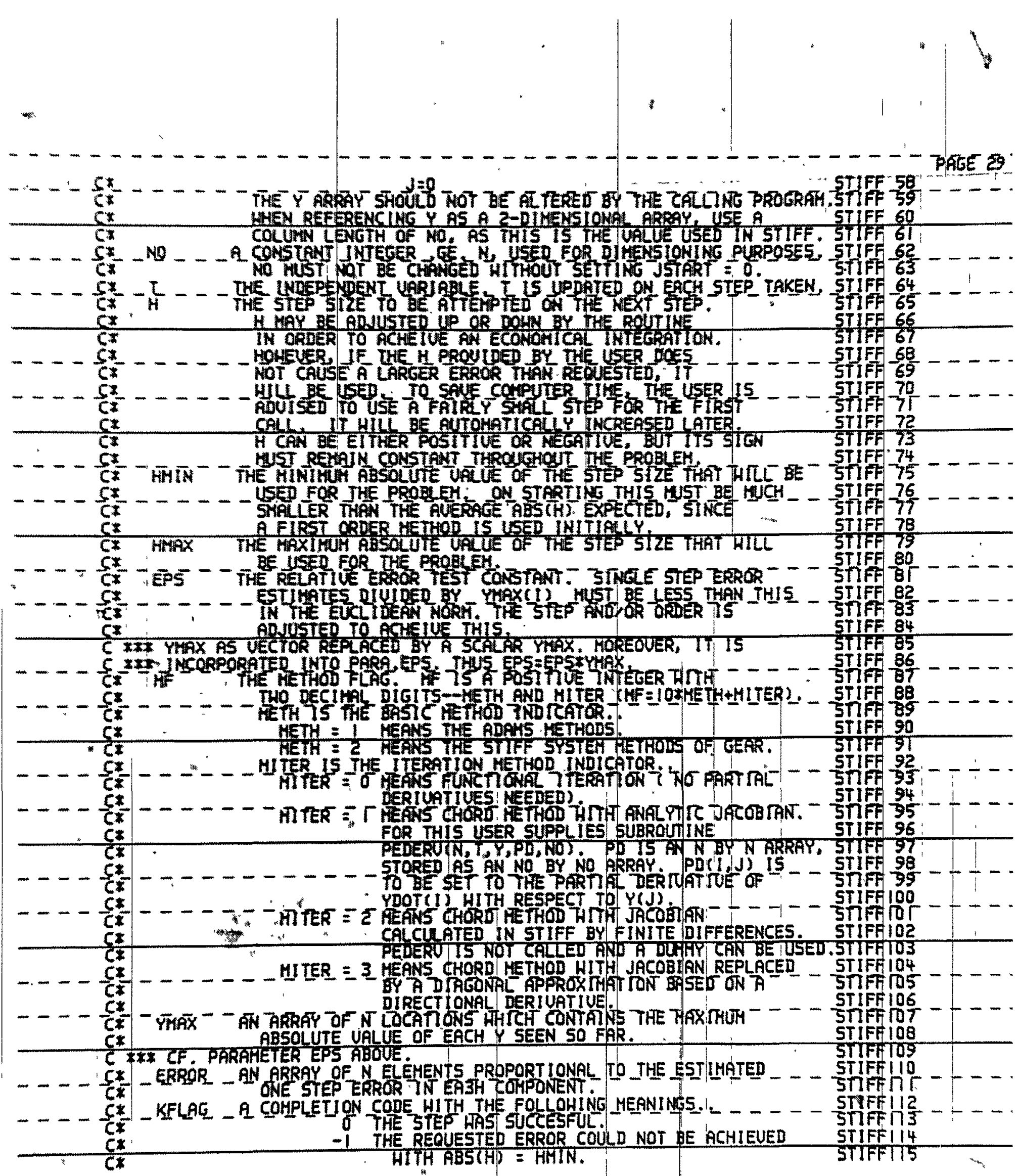




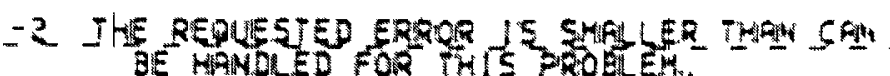

PAGE 30

5

-3 STRRECTOR CONUERG OMCE COULD NOT RE - ACMIEVED FOR ABS (H) GT, MHIT.

STIFFit

STIFFIIB

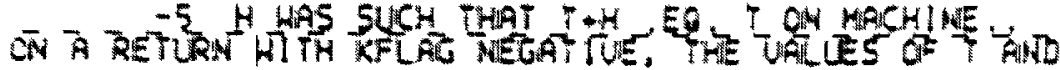

STIFF 115

THE $\angle$ ARRAY ARE AS OF THE BELINUJW OF THE LAST

STEP, AMD H IS THE LAST STES SDE ATTERP TED.

ISTART AM INTEEER USED ON INPUT AND OUTPUT

CN INPUT, IT HAS THE FOLLOHINE UALUES AND RERMINUS. Q PERFORH THE FIRST STEP. THIS UALUE ENAELES

THE SURROUTINE TO INAIIPRTZE TTSELF.

$5 x$

- - -

GLQ IAKE A NEH STR CQMTINULW FROM THE LAST USER HAS NOT CHAMEED ANY FARAMETERS.

.LT.O REPEAT THE LAST STEP WITH A WBH UALUE OF H RND OR EPS AND OR ME. THIS HAY BE

EITHER IN REDOINE A STEP THAT FAILED, OR

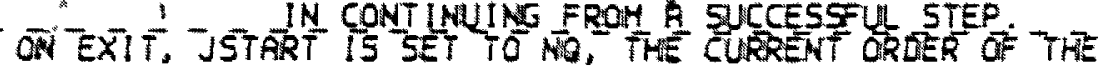

STIFFIIZO

हीFिए

STIFF 122

STIFFI

STIFICS

STIFFI26

STIFFा27

STIFFIZE

SHFFizS

STIFFI 30

c:

.$L T .0$

METHOD

IHIS IS ALSO THE OPO

ODER OF THE MRXIMUY DERIURTIUE

AUAILABLE IN THE Y RRRAT. AFTER A SUCCESSFUL STEF.

SIFFIII

$\frac{C_{x}}{C_{x}}-\cdots+\cdots$

C* THE PARAMETERS WHICH MUST BE INPUT BY THE USER RRE..

CI - $\mathrm{N}$ MO IL $Y$ HL HMINL HMAXL EPS ME, JSIRRT.

C. ADOITIONAL SURROUTINES REQUIRED ARE

C* TESOC(METH, NQ,EL, TO, MAXDER) SETS METHOD COEFFTCTENIS.

$5 T$ IFF I 32

STIFF 33

$5 T I F F 134$

STIFFI36

STIFF 138

STIFFI40

STFF

STIFFI42

SIIFT143

C* THE CALL INS PROURAD MUS THE PACKAGE

C* ABOUE, IN WHICH THE LENGTHS RRE AS GIUEN BY THE DESCRIPTIONS

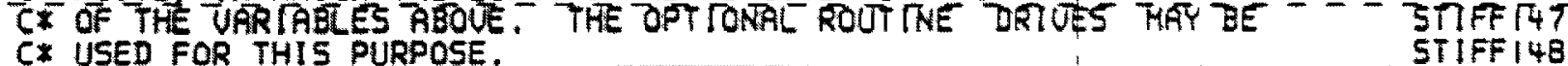

C*

C* THE QRIGINAL UERSION OF THIS PROGRAM HAS WRITTEN AT LLL BY A. C. - -

C* HINDHARSH FOR CDC COMPUTERS. THE CDC UERS ION HAS RODIFI ED FOR

C* USE ON I IBY COMPUTERS AI ARGONNE IN JUNE, I973.

C* LATEST REUISION SEPTEMBER, 1973 KFLAG $=0$

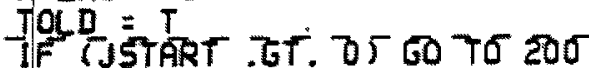

CE ON THE FIRST CALL, THE ORDER IS SET TD T RND THE TNT TRL

C* DERIUATIUES ARE CALCULATED.

CX

5 TIFFI49

STIFF 150

STIFTS

STIFFI52

STIFF 53

STIFFI54

STIFFT55

$5 T$ IFF I 56

STFF 57

STIFFI58

STIFF 59

STIFF 100

C* IN S SINGLE STEP IT IS INITIALLY I E4 TO COMPENSATE FOR THE SMALL STIFFI62

STIFFTO

C* OCCURS (IN CORRECTOR CONUERGENCE OR ERROR TEST), RHAX IS SET AT 2 STIFFI04

C* FOR THE NEXT INLREASE. EPSJ IS USED AS THE RELATUUE TNCREHENT - - STIFF 65

C* TO Y HHEN GETTING PARTIIALS BY FINITE DIFFERENCING.

STIFFI 60

C XFX STARTINE OR RESTARTING AT T. NEED NECT, TETI AND TONIZATTDN

STIFFT67

C * * AND RECOHBINATION COEFF.

CALL YPAY (FSAUE,Y)

DO III $1=\mathrm{NL}, \mathrm{NK}$

STIFF 168

STFF

泣 $\bar{Y}(1,2)=\overline{F S A U E}(\bar{T}) \overline{X H}$

STIFF 170

$\mathrm{NQ}=2$

STIFF 172

STFFTS 
C* IF JHE SALLER HAS CHANGED H Y MUST EE RESCALED

C* RC IS THE RATIO OF NEW TO OLD UALUES OF THE CDEFFICIENT LCOTKH.

C* HHEN RC DIFFERS FROM I BY MORE THAN 3D PERCENT, OR. THE CALLER HAS

C* CHANGED HITER, IWEUAL IS SET TO MITER TO FORCE THE PARTIALS TO BE

STIFF 186

S* UPDATED, IF PART IPLS ARE USED.

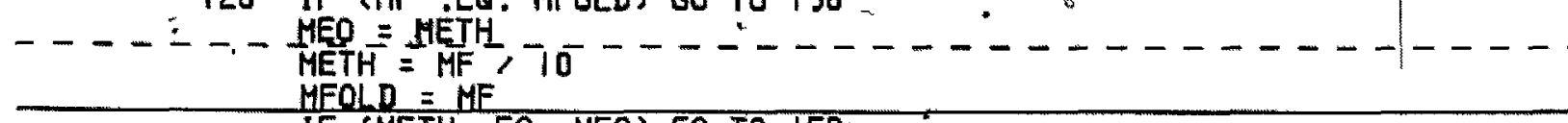

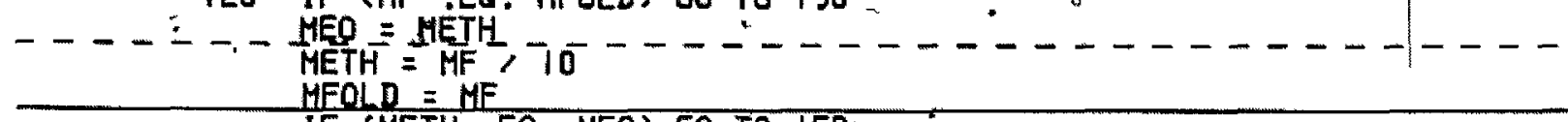

IF (METH .EQ. MEO) GO TO 150\%

STIFFI97

STIFFI89

STIFF 89

STFF I9I

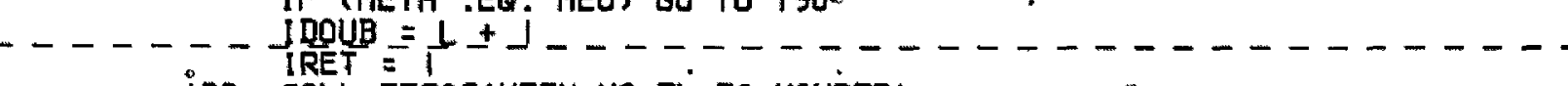

STIFF.192

STIFF I93

STIFF 194

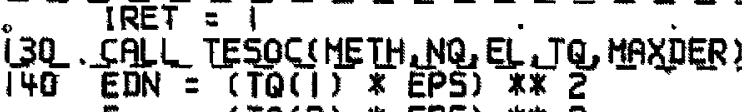
E $=(T Q(2) *$ EPS) $* * 2$

STIFFIS5.

- 140 EDN = (TQC(1) $*$ EPS) $\times \times 2-\ldots$

STIFFi96

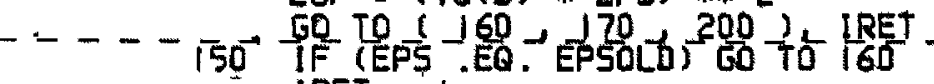

STIFF 198

StifF 99

$5 T$ IFF 200

$-\cdots-\ldots$ - RET $=\frac{1}{60}=$

160. LMAX $=$ MAXDER +

STIFFZOT

$----\frac{C}{* * *}$ JDISC IS A DISCONTINUITY SWITCH. IF . NE _ D TRYING TQ LAND

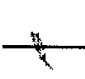
IF (JDISC.EQ.0) GO TO 169

. HSAUE $=H$

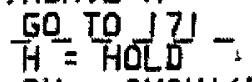

170

$----170$

RH = AMAXI(RH, HMIN/ABS $(H))$

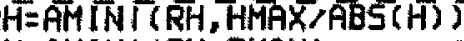

RH $=A M I N($ SRH, RMAX)

STIFFED2

STIFFZO 4

STिF=5

STIFF206

STIFFEOT

5TIFF208

STFF二S

STIFFCIO

STIFFZ1?

STIFFII3

STIFFE4 4

STIFFaí

STIFECT

STIFFZIA

$|7| R \mid=.1 .0$

SIIFF्वाS

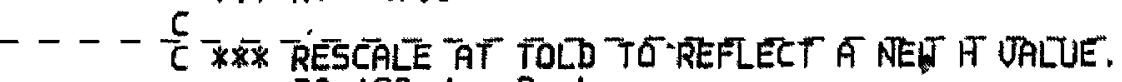

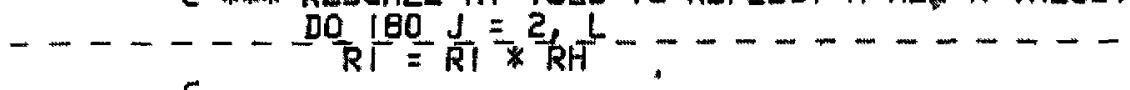

c DO $180 T=N L, N K$

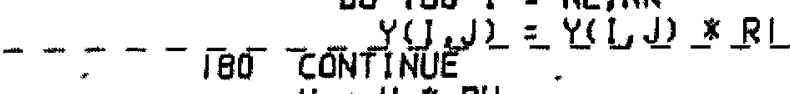

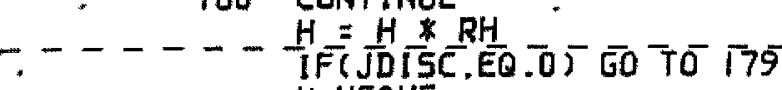

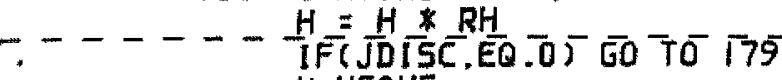
$H=H S A \cup E$

STIFFE2D

5TIFFE!

STIFFZ22

STFF2ट3

STIFF224

STIFF2 5

STIFF226

5TFFE2T

179 IDOUB $=\mathrm{L}+1$

STiFFes

STIFF230

STIFF23T 


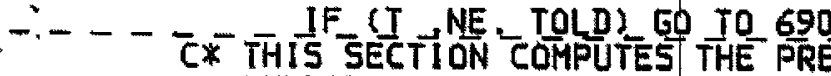

C* MUL TIPLYING THE Y ARRAY OY THE PASCAL TRIANGLE MATRIX 200 CONTINUE

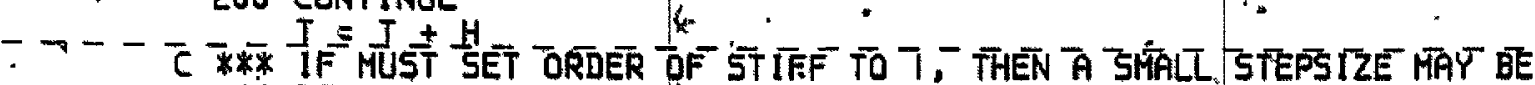

- - - - C $* * *$ REOURED TO MAINTAIN BOUND FOR LOCAL TRUNCATION ERROR EXPRESSED

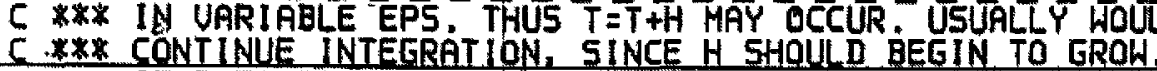

$\because$, IF (T.EQ.TOLD) 60 TO 685

IFCT TTEQ

DQ $210 \mathrm{JI}=7, \overline{\mathrm{NO}}$

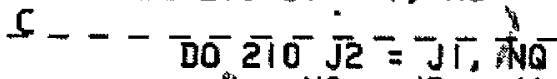

$y=N Q-\sqrt{2}+11$

C

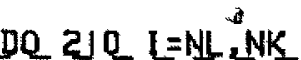

$Y(1, J)=Y\left(\frac{1}{1}, \bar{J}\right)+Y(I, J+1)$

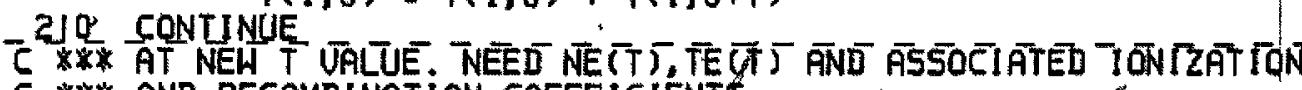

C $* * *$ AND RECOMBINATION COEFFICIENTS, CALL YPAY (FSAUE (NOMPI), Y)

$R=-E L(1) \times H \times D E N$

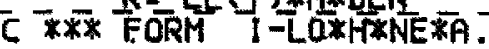

$+ \pm$

DQ 250 L $=N$ N, NKML

$F L(I)=R \times S U I Z(I)$

$250 \cdot F L(N D H+1)=R * 5 \cup 1 Z(N O M+1+2)$

$F L(N D M Z+N L)=1 .-F L^{2}(N L)$

$F L(N Q M Z+N K)=1-F L(N O M+N K M L$

DO $25 T$ T=NLPI, NRKA I

251 FL $(N O M 2+1)=1-(F L(1)+F L(N O M+I-1))$

C * F F FACTOR TR TDIRE. MATRIX

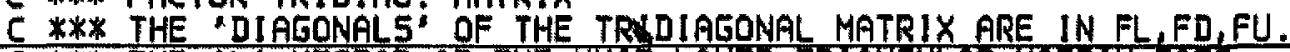

$C$ *** THE ' $L$ ' UECTOR OF THE UNIT LOWER TRIANGULAR MATRIX GOES

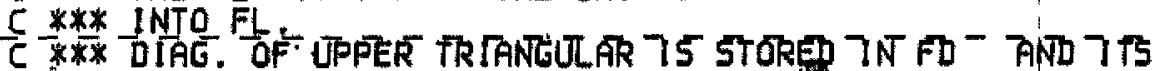

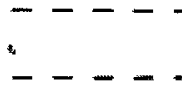

C X** SUPERDIAG IN FU N N. SUPERPS IS JUST FU ANYWAY

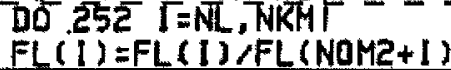

$252 \mathrm{FL}(\mathrm{NOH}+1+1)=F L(\mathrm{NOH} 2+1+1)-\mathrm{FL}(1) \times \mathrm{FL}(\mathrm{NON}+1)$

C X*X FORM HX(NEXAX (Y) PRED) $=\left(H * Y^{\prime}\right)$ PRED IN FSAUE $(N Q M+I)$. DO $370^{\circ}$ i $=N L, N K$

370 FSAUE $(I+N O M)=$ FSAUE $(1+N O M) \times H=Y(1,2)$ SOLUE Z FFACTOR TR TANGULLRR SYSTEM. FSAUE $(N L)=F$ SAUE $(N O M+N L)$ DO $90 \mathrm{~K}=\mathrm{NL}$, NKMI

90 FSAUE $(K+1)=F 5 A U E(K+N D M P \mid)-F L(K) * F S A U E(K)$

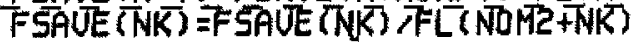

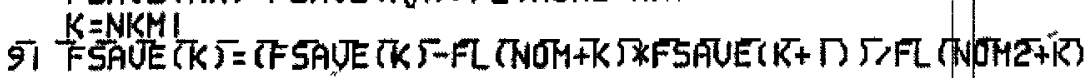
$K=K-1$

IF(K.GE.NL) GO TO 91

$\mathrm{D}=0.0$

DO $460^{\circ}-\bar{N} \mathrm{NL}, \mathrm{NK}$

$460 D \subseteq D+F 5 A U E(1) * * 2$

IF (D. ST. E) $6 \overline{0}$ TO 700

C* AFIER A SUCCESSFUL STEP, UPDATE THE Y ARRAY

STIFF232

PAEE 32-

$5 T$ IFF233

STIFF234

STIFF235

- . - -

5THFE36

STIFF238

STIFF 239

STIFF240

STIFF24I

STIFF 242

STIFF 244

STIFF 246

STIFF247

SIIFF 48

ड़ीFियद

STIFF250

STIFF

STIFFES2

STIFF253

STIFF 54

STIF" 55

STIFF256

STIF作5

STIFF258

STIFFC59

$5 T$ IFF $260^{\circ}$

STREE

STIFF262

5TFF 263

STIFF264

StगिF265

STIFF266

5TीF 267

STIFF268

STIFF 269

STIFF270

STIFF271

STIFF272

5 FF 73

$5 T$ FF 274

STFF 275

$5 T$ IFF 276

STIFF 77

STIFF278

STIFF 75

STIFF 280

STFF

ST IFF202

STIFF2B3

STIFF284

5TीFF 285

5 IFF286

STIFFe

STIFFE8B

C* CONSIDER CHANE ING H IF IDOUB $=1$. OTHERATSE DECREASE IDOUB BY T.

STIFF889 


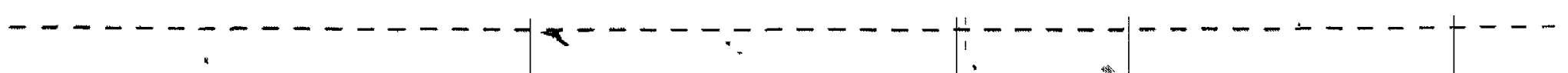

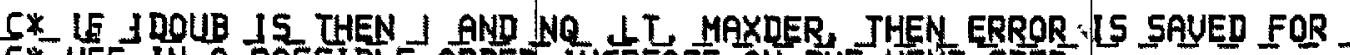

C* USE IN A POSSI LLE ORDER INCREASE ON THE NEXT STEP.

C* IF A CHANGE IN H IS CONSIDERED. AN INCREASE OR DECREASE IN ORDER

STIFF290

PATEE $3 \overline{3}$

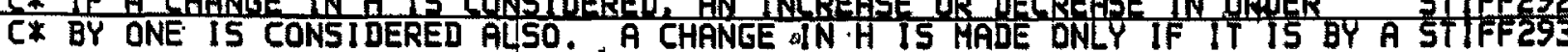

C* FACJOR OF AT LEASI J JF NOL JDOUB JS SEL TO JR TO PREUENT

C* TESTING FOR THAT MANY STEPS. KOL $470=5$

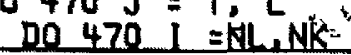

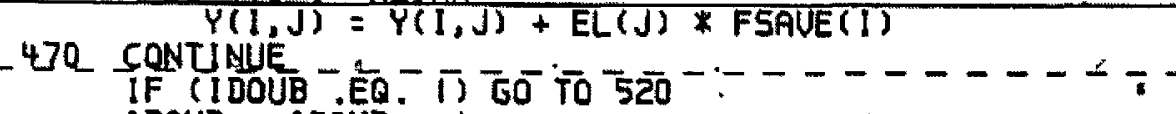

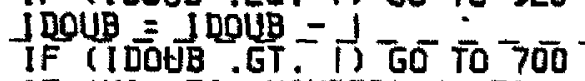

IF (NQ. EQ. MAXDER) GO TO 700

STHFF'

5 TIFF296

STIF 297

STIFF29日

STIFF299

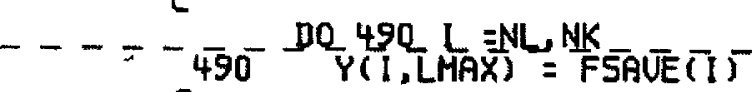

- - - 5 - $\overline{\mathrm{GO}} \overline{\mathrm{TO}} \overline{\mathrm{7}} \overline{\mathrm{OO}}$

C* THE ERROR TEST FAILED, KFLAG KEEPS TRACK OF MULTIPLE FAILURES

C* RESTORE T AND THE Y RRRAY TO THEIR PREUIOUS UALUES, AND PREPARE

5* TO TRY THE STEP ALAIN - COMPUTE THE QPTIMUM STEP SIZE FOR IHIS OR

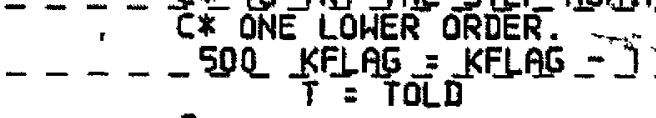

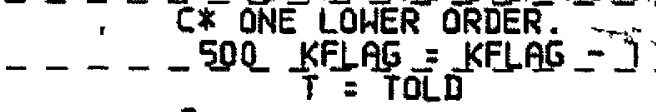

$c$

C $05510 \mathrm{JI}=1, \mathrm{NO}$

SUTF300

STIFF30

STIFF302

$5 T$ IFF $30 \mathrm{~s}$

STIFF 304

STIFF 305

S - - DO $510 \overline{\mathrm{DC}}=-J \Gamma, \bar{N} Q$

$\dot{\mathrm{c}}--$

$-J=N Q=\sqrt{2}+J 1$

$\begin{aligned} \text { DO } 5101 & =N L, N K \\ Y(1,0) & =Y(1, J)-Y(1, J+1)\end{aligned}$

510 CONTINUE

CONTINUE -

- $P R 3=1.0 E 20$

60 TO 540

C* REGARDLESS OF THE SUCCESS OR FAILURE OF THE STEP, FACTORS

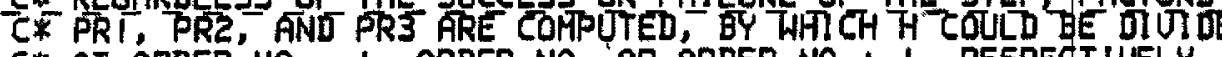

C* AT ORDER NQ - L ORDER NQ OR ORDER NQ + 1 RESPEOT IUEL $Y$

C* IN THE CASE OF FAILURE, PRS I. ODZD TO AUOID AN ORDER INCREASE.

C* THE SMALLEST OF THESE IS DETERMINED AND THE NEW ORDER CHOSEN

C* ACCORDINELY. TF THE ORDER IS TO BE INCREASED, WE COAPUTE ONE

C* ADDITIONAL SCALED DERIUATIUE.

520 PR3 $=1.0 \mathrm{E20}$

- . . . - IF (NQ EQ. MAXDER) GO TO 540

C

DO $530 I=N L, N K$

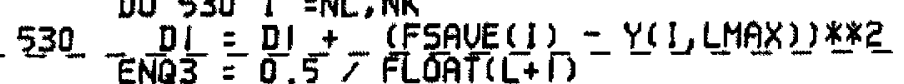

$P R 3=((D)$, EUP $) * *$ ENQ3) $* 1.4 \pm 1.4 E-06$

540 PROE $=\frac{(D)}{0.5} \rightarrow$ EUP $)$ FLA

$P R 2=((D, E) * E N O 2) * 1.2+1.2 E-D G$

PRI $=1.0$ E2O

STIFF306

STIFF30日

STIF何

STIFF310

डTIFF⿻

STIFF312

STIFF314

5ी FF 315

STIFF 316

STIFFST

STIFF31日

STif 315

STIFF320

STIFF32?

STIFF 323

5 TFF 324

5 TिF 325

STIFF326

5TFF 32 ?

STIFF32s

STIFF 330

STIFF 33

STIFF 33

STIFF33

STIFF 334

5TIFF 335

STIFF 336

STFF 33

STIFF 338

$5 T$ FF 335

STIFF340

STIFF341

ST IFF 342

STFF $34 / 3$

ST IFF 344

STFF 345

STIFF 346

STIFF347

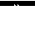

$---\cdots$

$--\cdots$

(2)

-

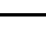

- - - - -

-

$--\cdots$

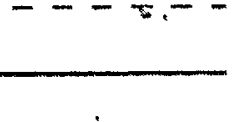

- - - -

$-7-$

- - . -

- - - - -

(1)




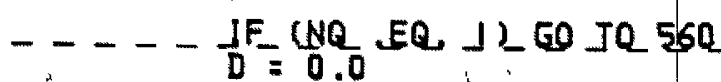
$D_{0}=550^{\circ},=N L^{\circ}$ NK

$550 \mathrm{D}=\mathrm{B}+\mathrm{Y}(1, L) \times * 2$

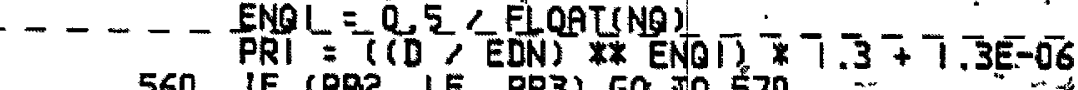

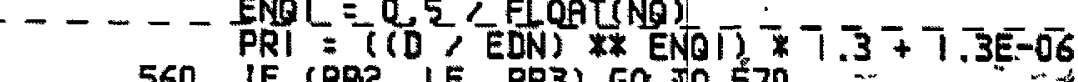

STIFF 348

STIFF 350

STIFF 35

STIFF 352

IF (PR3 .LT: PRI) GO TO 590

570 IF (PR? GT PRI) G0 TO 580

STIFF355

C *** PRZ=MIN(PRI,PRZ,PR3)

STIFF 356

NEHQ $=$ NO

$\mathrm{RH}=\overline{1} . \overline{\mathrm{P} R \overline{2}}$

STIFF357

GQ TO 620

$5 \overline{8} 0^{-}$NEWQ $=$NO $=-1$

$C * * *$ PRI $=M I N(P R I, P R 2, P R 3)$

RH $=1 . \prime$ PRI

STIFF 358

STIFF 359

STIFF 360

STIFF 361

STIFF362

GQ To 620

$590^{-} \cdot$ NEWO $=\mathrm{L}$

STIFF 363

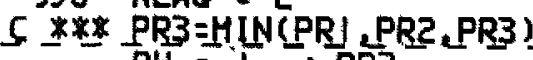

$\mathrm{RH}=1 ., \mathrm{PR} 3$

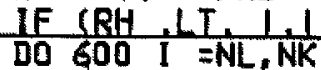

STIFF 364

STIFF 366

STIFF 367

STIFF368

\section{I =NL.NK}

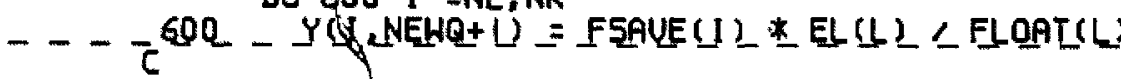

STIFF369

$---\frac{610}{100}$ T0 630

$610+10001070$

620 IF (KFLAG .EQ. 0).AND. (RH .LT. I.1DO) GO TO 610

C* IF GHERE IS A CHANGE OF ORDER RESET NQ L AND THE COEFICIENTS

C* IN ANY CASE HS RESET ACEOKOON NE TO RH AND THE Y ARRAY IS RESCALED,

S* THEN EXIT FROM 690 IF THE STEP WAS OK, OR REDO THE STEP OTHERWISE.

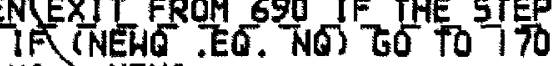

$630 \mathrm{NO} \perp$ NEHO

J

C* CONTROL REACHES THIS SECTION IF 3 OR MORE FAILURES HAUE OCCUIRED:

C* IT IS ASSUMED THAT THE DERTUAT TUES THAT HAUE ACCUMULATED TN THE

C* Y ARRAY HAUE ERRORS OF THE HRONG ORDER. HENCE THE FIRST

C* DERIUATTUE 15 RECOMPUTED, AND THE ORDER TS SET, TO I T THEN

C* H I5 REDUCED BY A FACTOR OF 10 . AND THE STEP IS RETRIED.

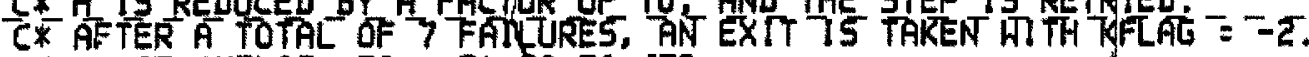

STIFF370

StIFF 37

STIFF 372

STIFF 374 .

StIFF 375

STIFF376

50 FF 377

SIFF379

$327=379$

STFF 380

STIFF3日

STIFF 392

STFF 393

STIFF 384

STFF 385

STIFF 386

STFF387

640 IF (KFLAG. EO - -7) 60 TO 670

$\mathrm{RH}=-\mathrm{T}$

RH = AMAXICHMIN/ABS (H), RH)

$\mathrm{H}=\mathrm{H} * \mathrm{RH}$

C * ** GOING BACK TO TOLD. NEED NE (TOLD), TE (TOLD) AND ASSOCIATED

$C$ *

C *** IF AFTER EACH SUCCESSFUL STEP THE ĖST IMATED Y' IS REPLACED

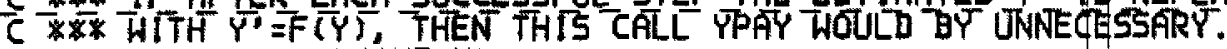
CALL : YPAY (FSAUE, Y)

C

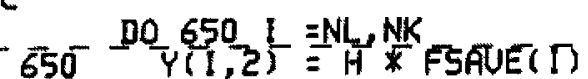

$C_{-}-\bar{T} \overline{\mathrm{DOU}} \overline{\mathrm{BB}}=-1 \overline{\mathrm{O}}$

IF (NO,EQ, 1) EO TO 200

TTFF 389

STIFF 390

STFF 39

STIFF392

STIFF393

STIFF394

STTFF 395

STIFF396

STIF 397

ST IFF 398

5TIFF395

STIFF400

STIFF40

STIFF402

5TनF40

STIFF404

STIFFप05 


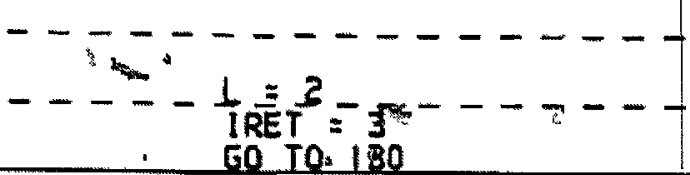

C* ALL RETURNS ARE MADE THROUGH THIS SECTION. H IS SAVED IN HOLD

S* TO ALLOH JHE SALLER TO CHANGE H ON JHE NEX் STEP

660 KFLAG $=-1$

$670^{-} \frac{60}{K F L C L}=300$

685 KFLAG $=-5$

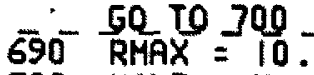

- 200 HOLD $=\mathrm{H}$

JSTART $=\overline{N O}$

RETURN

END

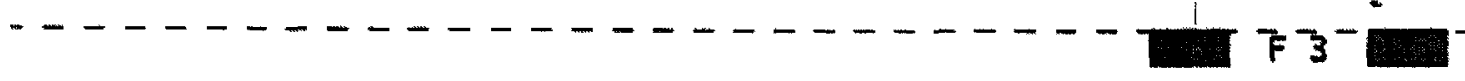

1

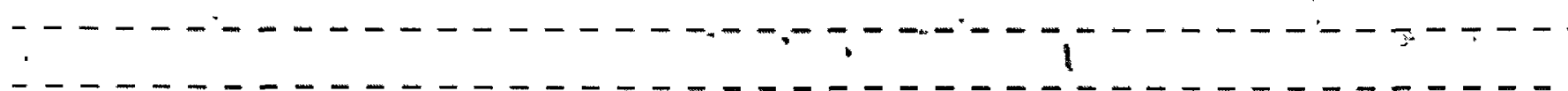

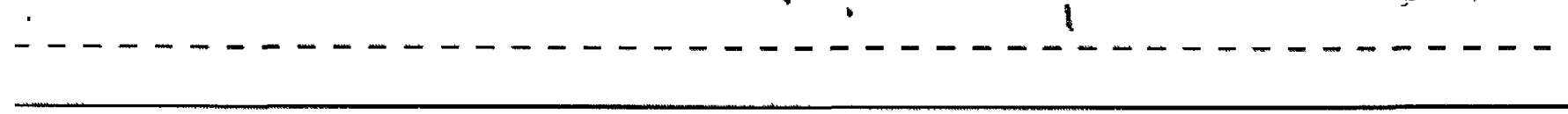

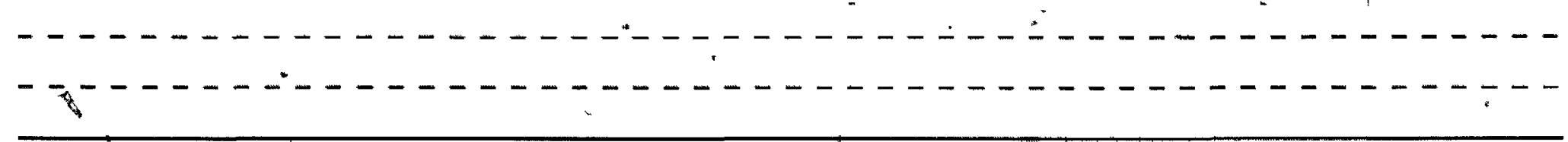

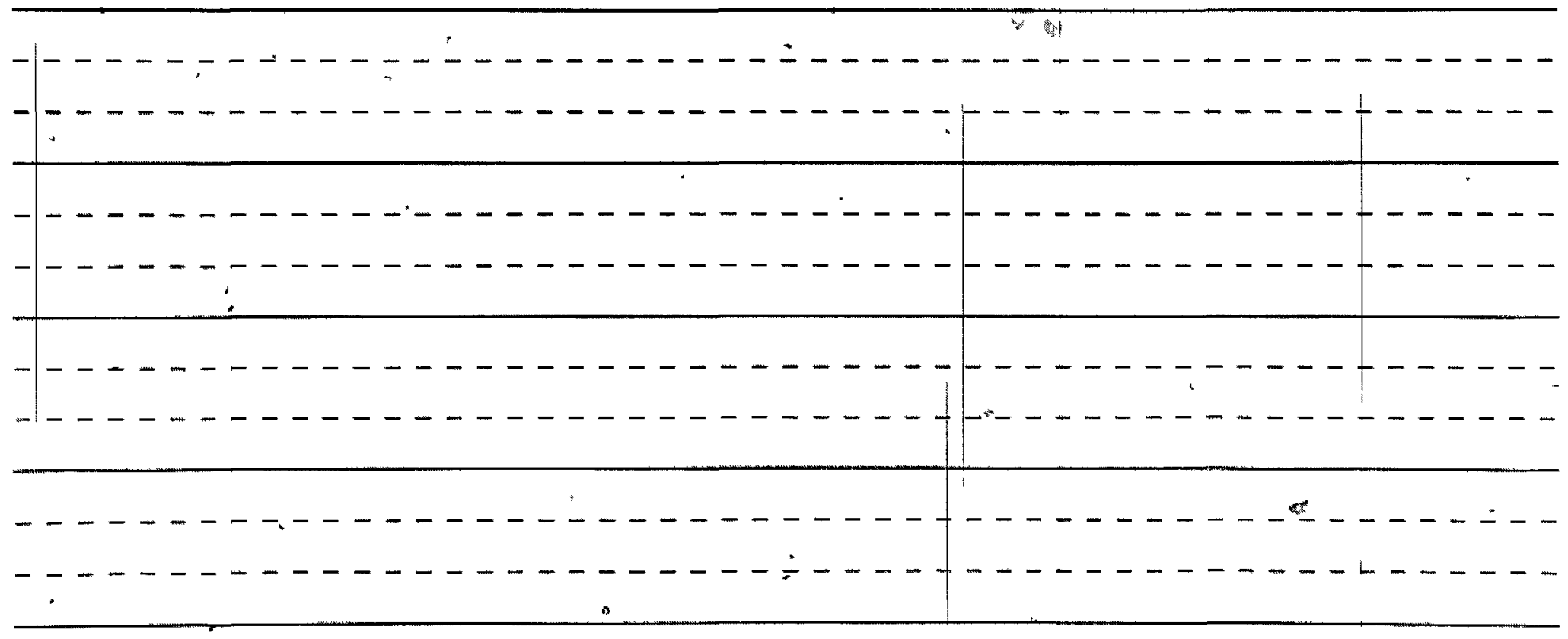

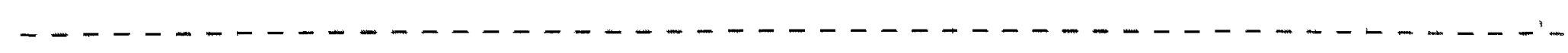

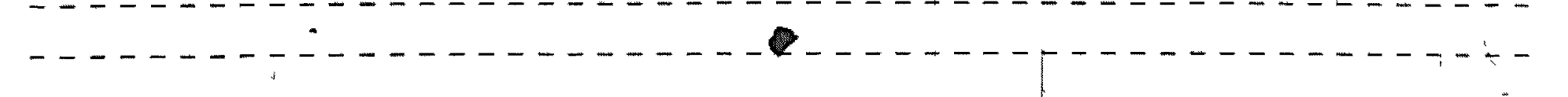


$---\bar{C} \bar{*}$ SE SUROUT LNE TESOC (METH, NQ, EL TQ MAXDER)

DIMENSION PERTSI $(12,2,3)$, EL $(13)$, TO (4)

C **A \{3/25/77) SELECTS STIFF OPTION ACTOMATICALLY, NONSTIFF

C* TESOC IS CALLED BY STIFF AND SETS COEFFICIENTS FOR USE THERE.

S* THE UECIQR EL OF LENG IH NQ + L DETERMINES THE BASIC METHOD

C* THE UECTOR TO, OF LENGTH 3 , IS INUOLUED IN ADJUSTING THE STEP SI ZE

C* IN RELATION TO TRUNCATION ERROR.

C* PERTST ARRAY.

5* THE UECTORS EL AND JQ DEPEND ON METH AND NQ.

C* TESOC ALSO SETS MAXDER, THE MAXIHUM ORDER OF THE METHOD AUATLABLE,

C* CURRENTL U IS L2 FOR THE ARAMS METHODS AND 5 FOR THE GEAR HETHODS

C* LMAX = MAXDER + I IS THE NUMBER OF COLUMNIS IN THE Y FRRAY.

C* THE HAXIMUH ORDER USED HAY BE REDUCED SIMPL $Y$. BY CHANGING THE

C* THE NUREERS IN STATEMENTS I AND 2 BELOW.

C* THE COEFFICIENTS IN PERTST NEED BE TIUEN TO ONLY ABOUT

C* QNE PERCENT ACCURACY THE ORDER IN WHLCH THE GROUPS APPEAR BELON

C* IS. COEFFICIENTS FOR ORDER NO - I, COEFFICIENTS FOR ORDER NQ.

C* COEFFICIENTS FOR ORDER NO +1 , WITHIN EACH GROUP ARE THE

C* COEFFICIENTS FOR THE ADAMS METHODS, FOLLOWED BY THOSE FOR THE

C* GERR METHODS -

C* THE ORIGUNAL UERSI ON OF THIS PROGRAM WAS WRI TTEN AT LUL BY A $C$ TH

C* USE ON IBY COMPUTERS AT ARGONNE IN JUNE: 1973.

- - - C C* $^{*}$ LATEST REULSLN SEPTEMBER L 1973

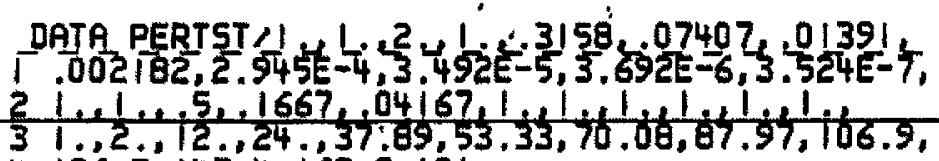

TESOC
TESOC

PATEE 36

\section{- - -}




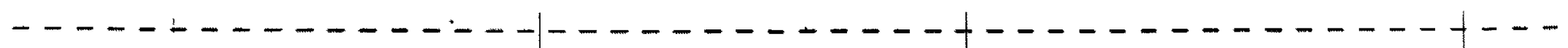

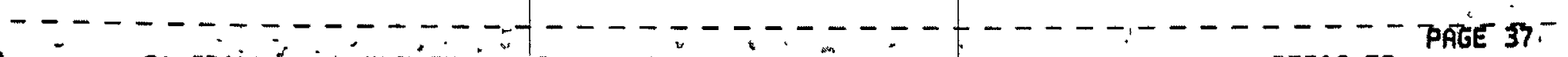

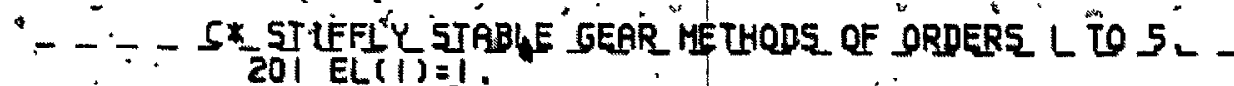

201 EL(T) TO $=100$

$202 \mathrm{EL}(1)=2.13$.

$-\therefore-1-\frac{E L}{60}(3)=1 \frac{1}{70}$

203 EL $(U)=6,1$

$E L(3)=E L(T)$

$E L(4)=1, \lambda 11$.

Go TO 900

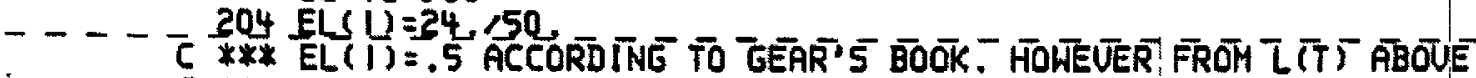

5 \&** EL $(U)=24<50$

$E L(3)=35.150^{\circ}$.

$E L(4)=10,150$.

$E L(5)=1.150$.

50 T0 900

205 EL( 1$)=120.1274$.

$E L(3)=225,1274$.

$E L(4)=85.1274$.

$E L(5)=15.1274$

$E L(6)=1.1274$.

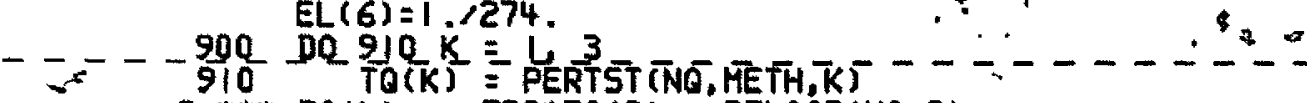

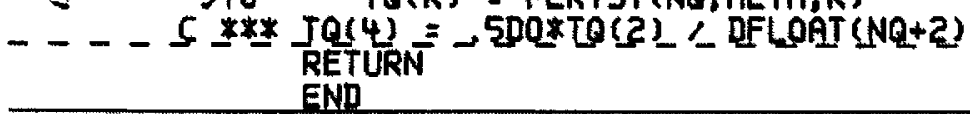

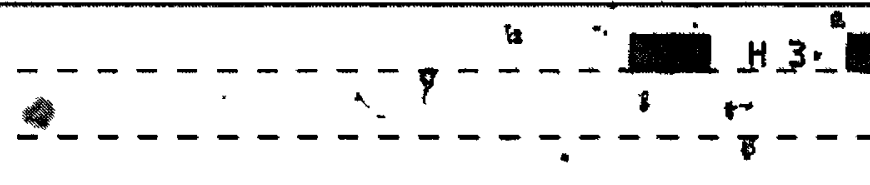

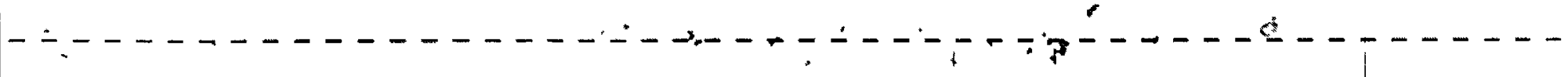
- - - - - - - - - - - - - - - - - - - - - - - - - - - - - - -

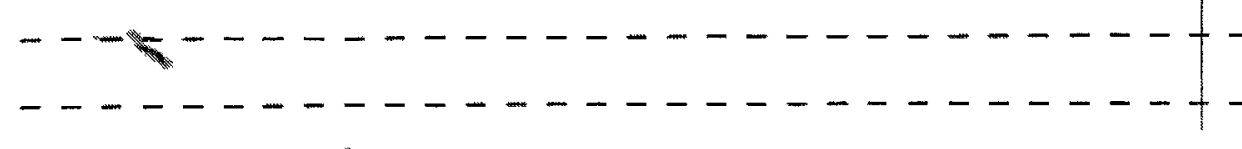
8 


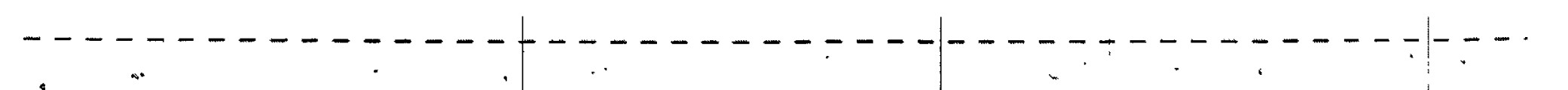
3. COMMON/IOJLUT, LIN

COMHONKEPS NCF

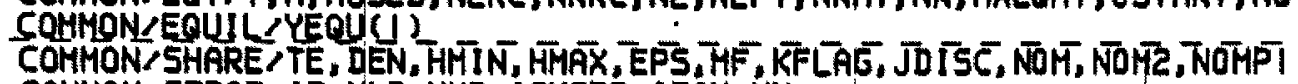

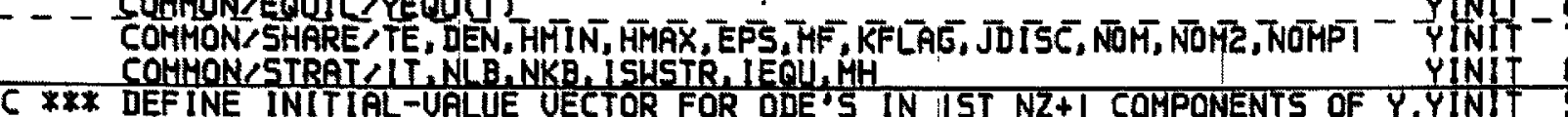

$C$ *** DEFINE INITIAL-UALUE UECTOR FOR DDE'S IN IIST NZ+I COMPONENTS OF Y.YINI 9

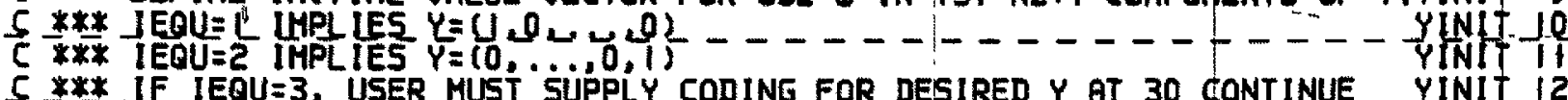

PÄGE 38

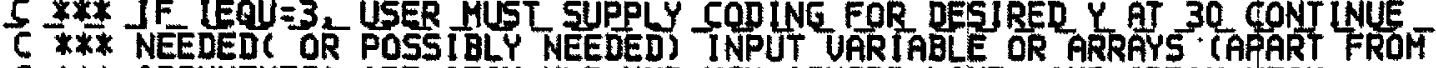

( * *** ARGUMENTS) ARE IEQU, NLB, NKB, NCH, ISHSTR, LOUT, AND ARRAY YEQU.

C *** IF YEQU IS USED, IT MUST CONTAIN EQUILIBRIUM, NORMALIZEE, CHARGE

- 5 * *** STATE DISTRIBUT LON UECTOR FOR FIXED IE AND NE DEN UNDER

C $\times \times \times$ CONSIDERATION.

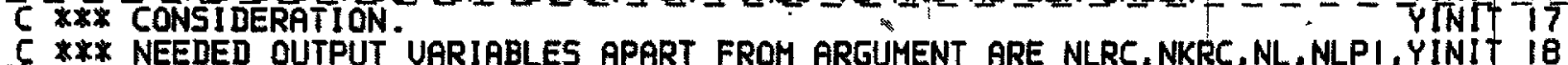

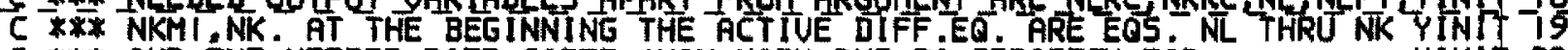

C X** AND THE NEEDED RATE COEFF. (MAY UARY DUE TO STRATEGY FOR TR YINIT 20

C *** ALTERING SET OF ACTIUE EOS.) ARE NLRC AND NKRC. OF COURSE NLPI =NL YINIT 21

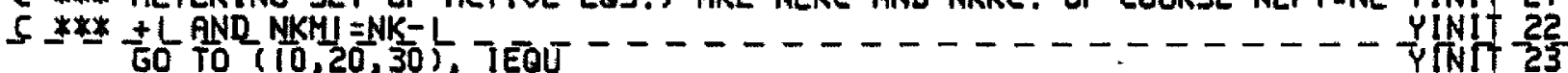

10 Y NLB =1 DO I I I Z, NZP

$1 Y(1)=0$.

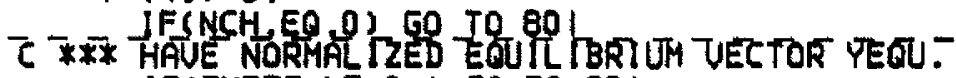

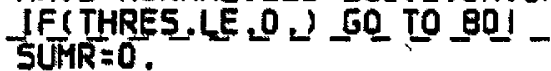
NKI $=N Z \dot{P}$ ।

800 IF( SUMR+YEOUTRKI). GE. THRES) 60.70802 $S U M R=S U M R+Y E Q U\left(N K C^{\prime}\right)$

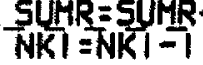

60 TO 800

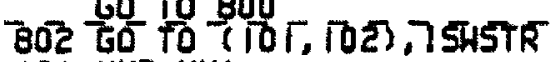

$101 \mathrm{NKB}=\mathrm{NKI}$

C * ** INITIAL SET OF ACTTOE EOS. NOT ALTERED DURING INTEGRATTON. HRI TE (LOUT 603) THRES, NKB 'SUMR

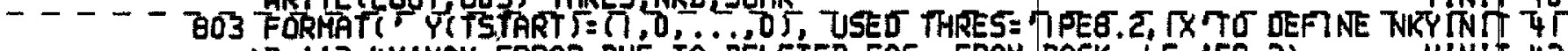
Yinit 24

Y $T$ NT 25 Yinit 26 पांगि 27

YINIT 2 I

YMINT 30

Yinit 35

Yासा 33

YINIT 34

Y

YINIT 36

Y

YINIT 38

YाNTा 35

YINIT 40

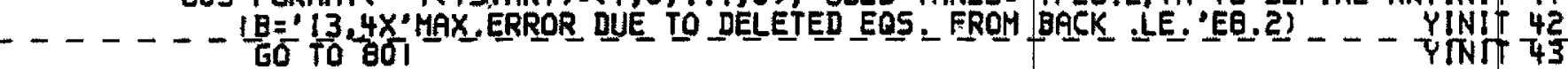

102 NKB=MINO (NKB, NKI)

ZC, \#** STRATESY II ALTERS ACTIUE EOS. DURING TIME INTEGRATION. GO TO BOI

20 Y $(N Z P D)=1$.

NKB $=$ NZPI

$N Z=N Z P \mid-1$

DO $21 \quad I=1, \mathrm{NZ}$

2) $Y(I)=0$.

IF(NCH,EO OO) GO TO 801

IF (THRES.LE.TO TÓ TO T001

YINIT 44

YINTा 45

YINIT 46

YINT 47

YINIT 48

YTIT 49

YINIT 50

YाNग 51

YINIT 52

SUML $=0$. . . . . . .

YTNT 53

$N L I=1$

YINIT 54

Y TiN 55

900 IF (SUHL+YEQU(NL1) GE. THRES) GO TO 902

YINIT 56 SUML $=$ SUML+YEQU (NL I)

YाNIT 57 


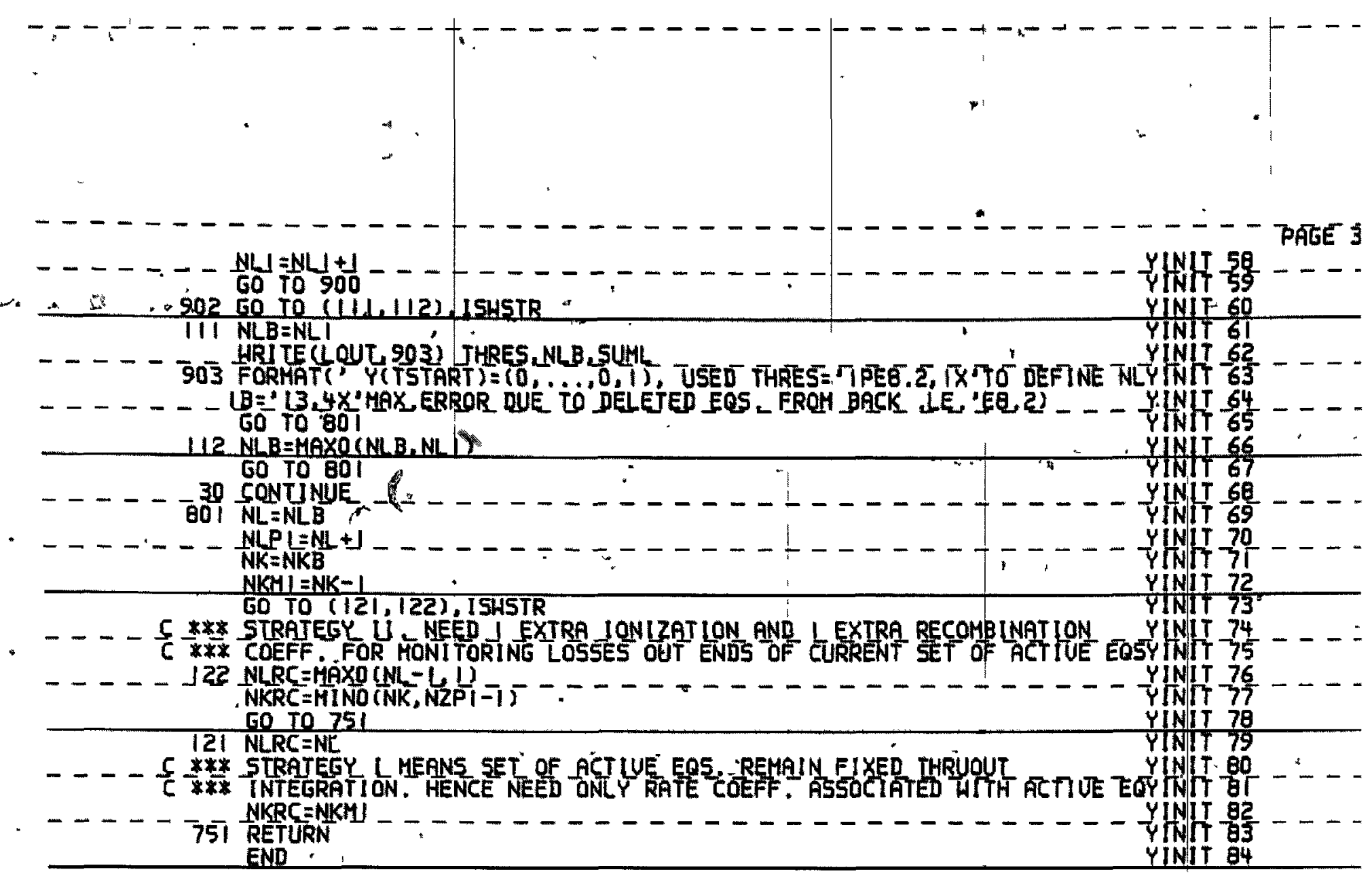

- - - - - - - - - - - - - - - 3

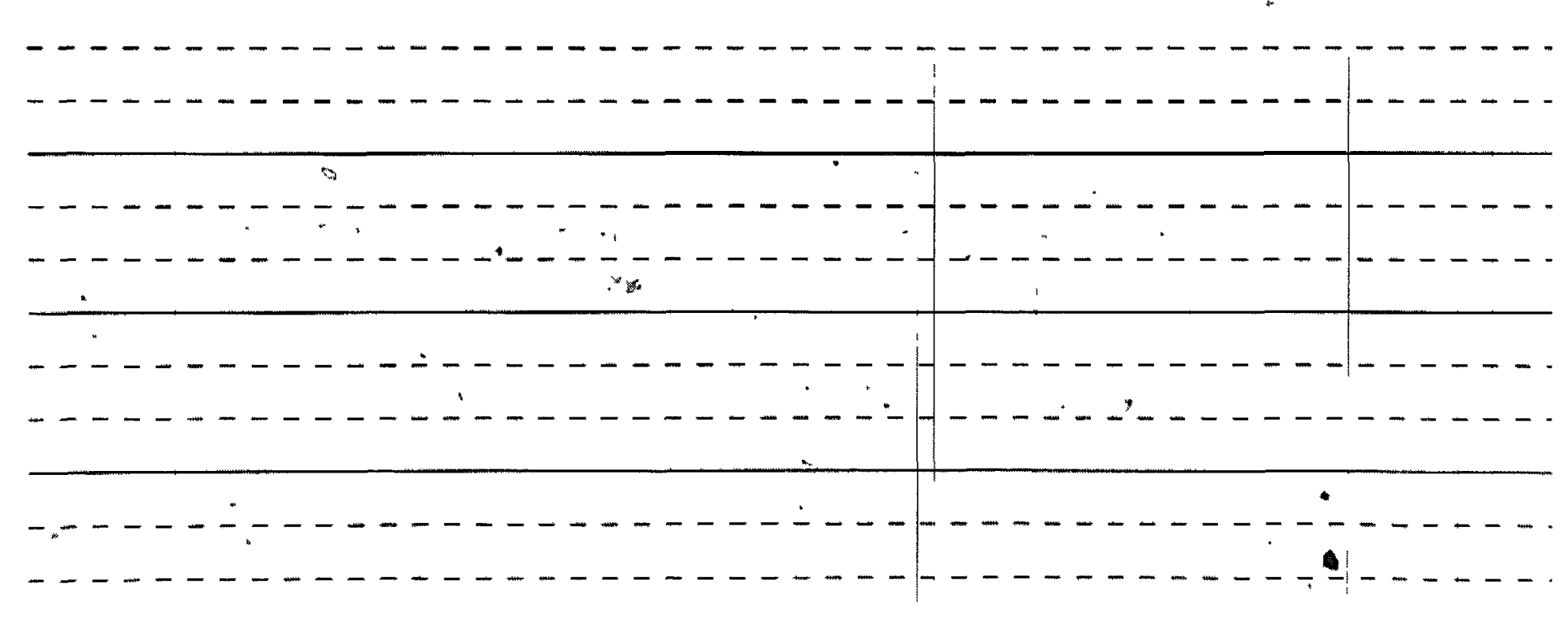

的 


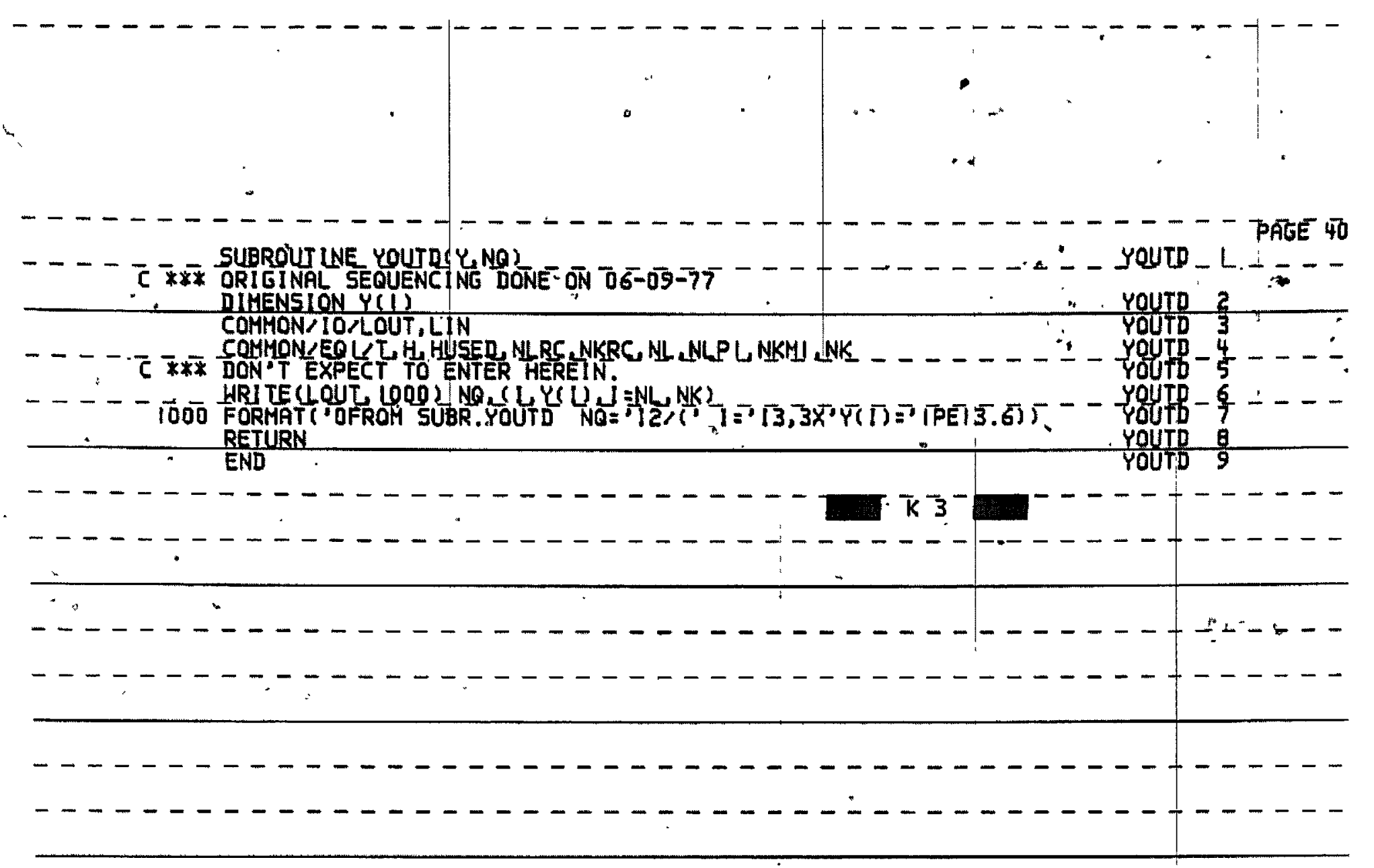

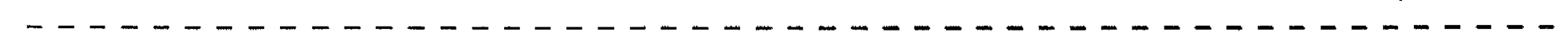
(2- - - - - - - - - - - - - - - - - - - - - - - - - - - - - -

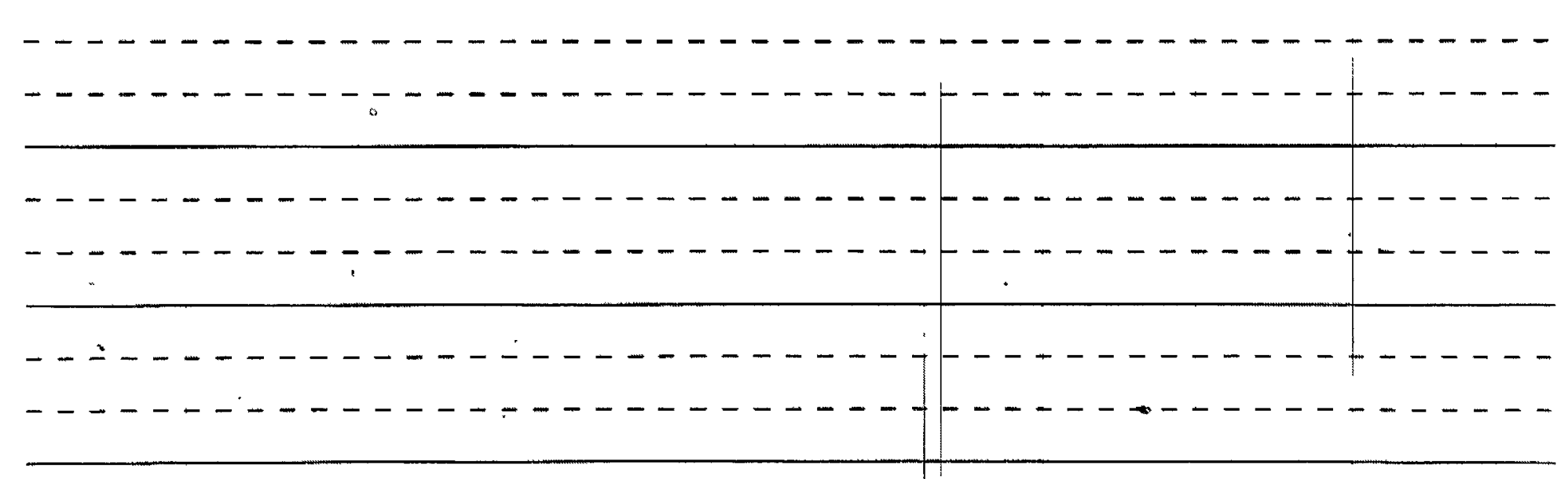

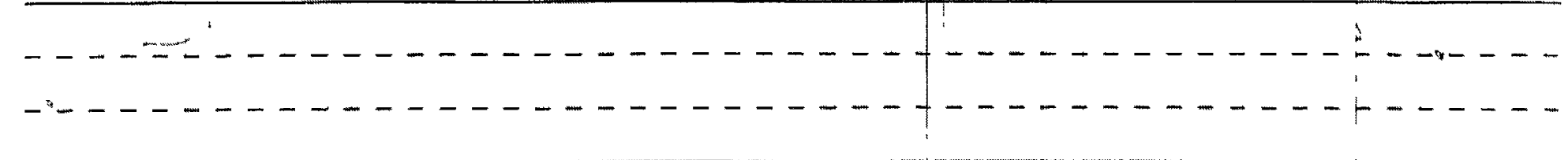

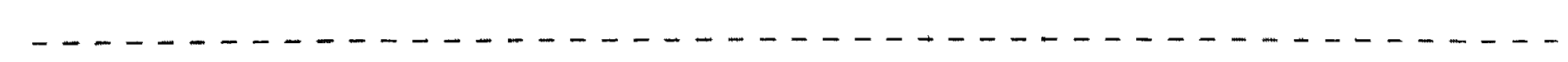
- - - - - - - - - - - - - - - - - - - - - - - - - - - - - 


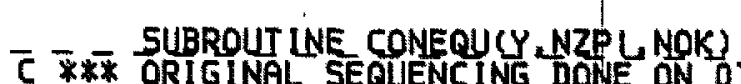

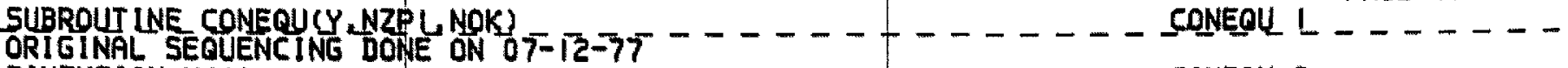

DIMENSION Y(I)

COMMON/IOTLOT, LIN

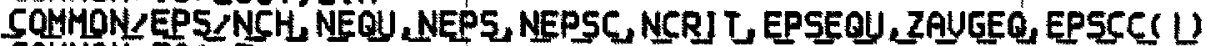

COMHONTEOTT

COHMONLEUILYYEQUU) - -

NOK $=0$

C X** HONITOR CLOSENESS OF DISTRIBUTION UECTOR, Y TO THE EQUILIBRIUM

C *** VECTOR, YEOU. 2 CLOSENESS CRITERIA. CORRESPOND TO NCRIT TI, 2 .

5 *** NCR U $=J$ HEASURES CLOSENESS OF Y TO YEQU IN TERHS OF LL-NORM OF

C *** Y Y YEQU.

C $\times * \times$ TO $Z$ TAU MEASURES

-C * C C OSENES5 LEUELS ARE GIUEN IN THE UECTOR EPSCC AND THE NUMBER OF

C *** LEUELS IS MEPS.

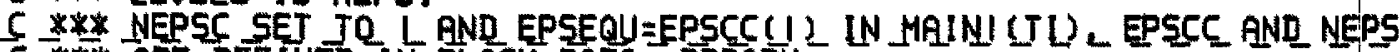

C XXX ARE DEFINED IN BLOCK DATA, BDPARM.

- - ALITLO

DZAUG $=0$

DO $901 \quad i=1, \mathrm{NZP} \mid$

$Y D I F F=Y(U)-Y E Q U(I)$

DZAUG =DZAULOAIMIXYDIFF

901 AIMT $=$ AIMT +AB

ZAUG =DZAUG ZZAUGEO

YDIFF=ABS (DZAUE)/ZAUGEO

GO TO 61000 , 100$)$, NCRLT

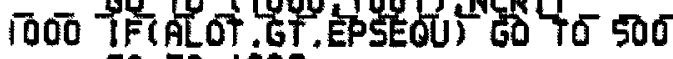

60 T0 1002

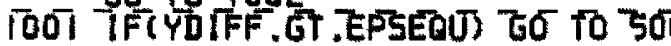

1002 TMS $=1000$, *T

HRITE (LOUT, 950) THS, YDIFF, ZAUG, ALOT, EPSEOU

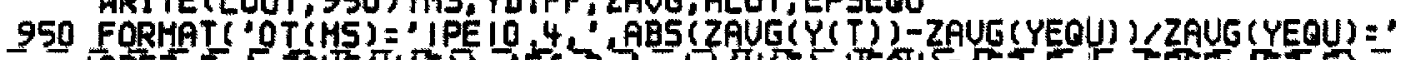

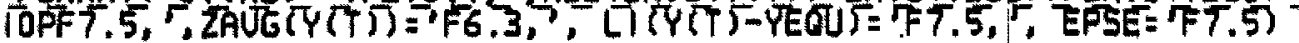

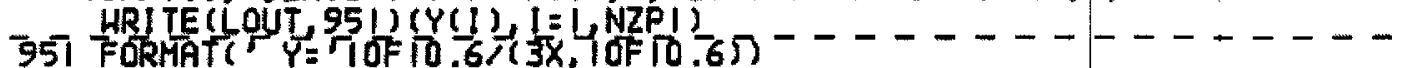
NEPSC $=$ NEPSC +1

IF (NEPSC. LE. NEPS) 60 TO 899

CONEOU

CONEQU 3

CONEOU 4

CONEOU 5

CONEQU 6

CONEROU 7

CONEQU $\mathrm{B}$

CONEOU 9

CONEQUIO

CONEGUIZ

CONEQUI 3

ONEQU 14

CONEOUIS

CONEOUIS

CoNÉOUI 7

CONEOUIB

CONEQUTIS

CONEQUZO

CONEQUZ

CONEQU2Z

CONEOUZ3

CONERUZ4

CONEOUZS

CONEQU26

CONEOU27

CONEOUZE

CONEQUZS

CONEOUZO

CONEOUS

CONEOUZZ

CONEQU33

CONEOU34

CONEQU35

CONEOU36

TONEDUST

CONEOU3B

CONEOU35

$C$ *** NOK $J(0)$ MEANS THAT CONUERGENCE CRITERIA IN CONEOU HAS(NOT) BEEN CONEQU4D

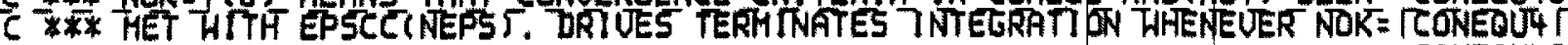

C *W* IS RETURNED

C *** MaINI(TI).

NEOU $=0$

CONEQU42

CONEOU 43

CONEQU44

NOK $=1$

CONEOU45

70 to 500

CONEQU46

899 EPSEQU $=$ EPSCC (NEPSC)

500 RETURN END

CONEOL48

CONEOUY

CONEQU50

13 


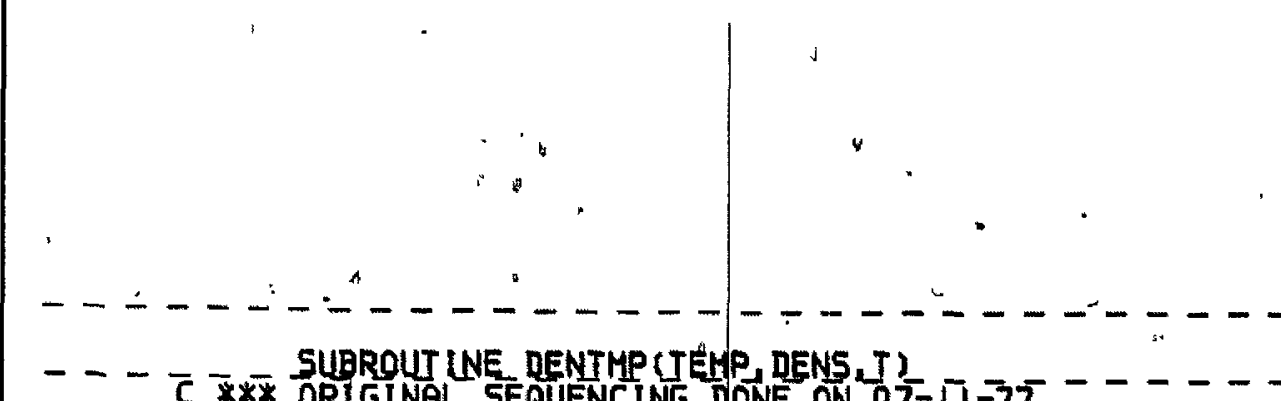

$\bar{C}$ F*X DRIGINAL SEQUENCING DONE ON $07-\pi 7-77-$

C *** SURROLITINE DENTHP (TD)

6 *** DENTMP (TD) AND DTDATA AND DTINIT NEED TO BE VIEWED TOCETHER.

- - - - - SOMMON COMMON

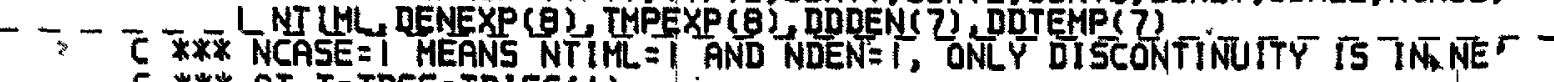

c *** QT $T=T D 55=T 015 C(1)$

C. *** NCASE $=2$ MEANS NTIML $=1$ AND NDEN $=2$, NO DISCONT INUITIES.

5 *** NCASE $=3$ MEANS NUIM GL L AND NDEN $=J_{2}$ LSL DI SOONUINUIY AT

C *** T T TDS $=$ TDISC ( I)

5 *** NCASE $=4$ MEANS NIIML GL L AND NDEN=2 L LST DJSCONUNUITL

C *** AT T $=S T S=T D I S C(2)$.

C *** NCASE 5 MEANS DENSITY AND TEMPERATURE ARE CONSTANT $(N D E N=0)$.

DATA TEO, DENO $/, 1,1, E 4 /$

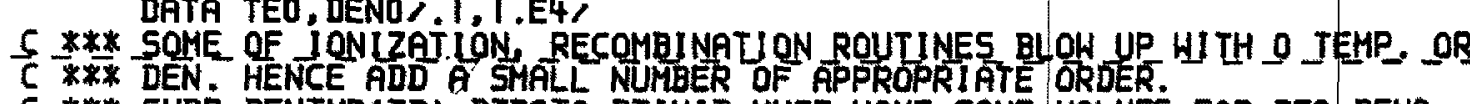

5 * $* *$ SUBR, DENTMP(TD),DTDATA, DTINLT MUST HAUE SAHE UALUES FOR IED DENO.

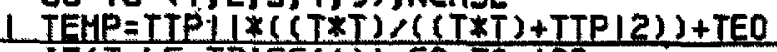

IF (T.LE.TDISC(I)) 60 TO 100

99 RETURN

JOQ DENSEDDNI L*T+DEND

GO TO 99

2. TEMP $=T T P|| *((T * T) /((T * T)+T T P \mid 2))+T E 0$

DENS=DDNEI* ( (T*T)/(T*T)+DDNES ) +DEND

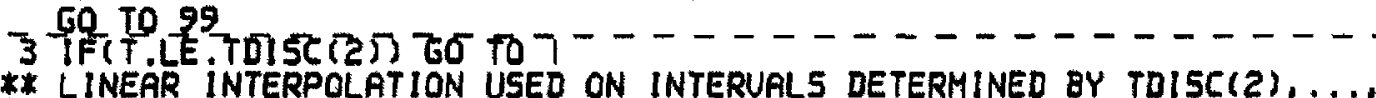

$C$ C** LINEAR INTERPQLAT ION USED ON INTERUALS DETERMINED EY TDISC(2)

101 DO $102 \quad 1=2$, NT IML

IF(T.ET Totsc(1+1) G0 To 102

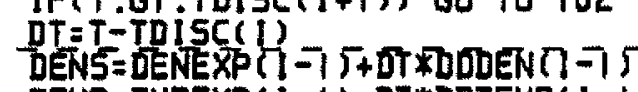

IEMP $=T M P E X P(I-1)+D T$ XDDTEMP $(I=1)$

tó to 99

102 CONTINUE

DENS=DENEXP(NTIRL)

TEMP $=$ TMPEXP (NTIML)

4 IF(T,LE TDJSC(2) ) GO TO Z

5 TEMP $=$ TMPEXP (1)

DENS DDENEXP(I)

GO TO 99

DENTHP L _ _ . . -

DEvTyP $\rightarrow$ DENTHP 3

DENTMP

DENTHF

DENTMP

DENTMP 7

DENTMP B

DENTHP 9

DENTMPIO

DENTHPI?

DENTMPI?

DENTHPI

DENTHPTS

DENTMPI 6

DENTHPI

DENTMPIB

DENTMPZO

DENTMPZI

DENTMP22

DENTHPZ3

DENTHP24

DENTMP26

DENTHPC?

DENTMP28

DENTHPCS

DENTMP 30

DENTMP3

DENTMP 32

DENTTP 3

DENTMP34

DENTHPSS

DENTMP36

DENTTPST

DENTMP3B

DENTHP 39

DENTMP4O

DENTTFY I

DENTMP4 Z

DENTMP4

DENTMP 44

DENTHP4 6

DENTAPY T

$\pi 3 \frac{1}{1}$ 


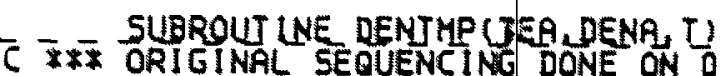

XXX SURROUTINE DENTMP (TI) TEMPERATURE, DENSITY CONSTANT

C *** T 15 . XME IN SECONDS (NCH.NE.0)

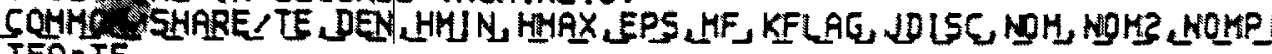
$T E A=T E$
END

$--$

(2)




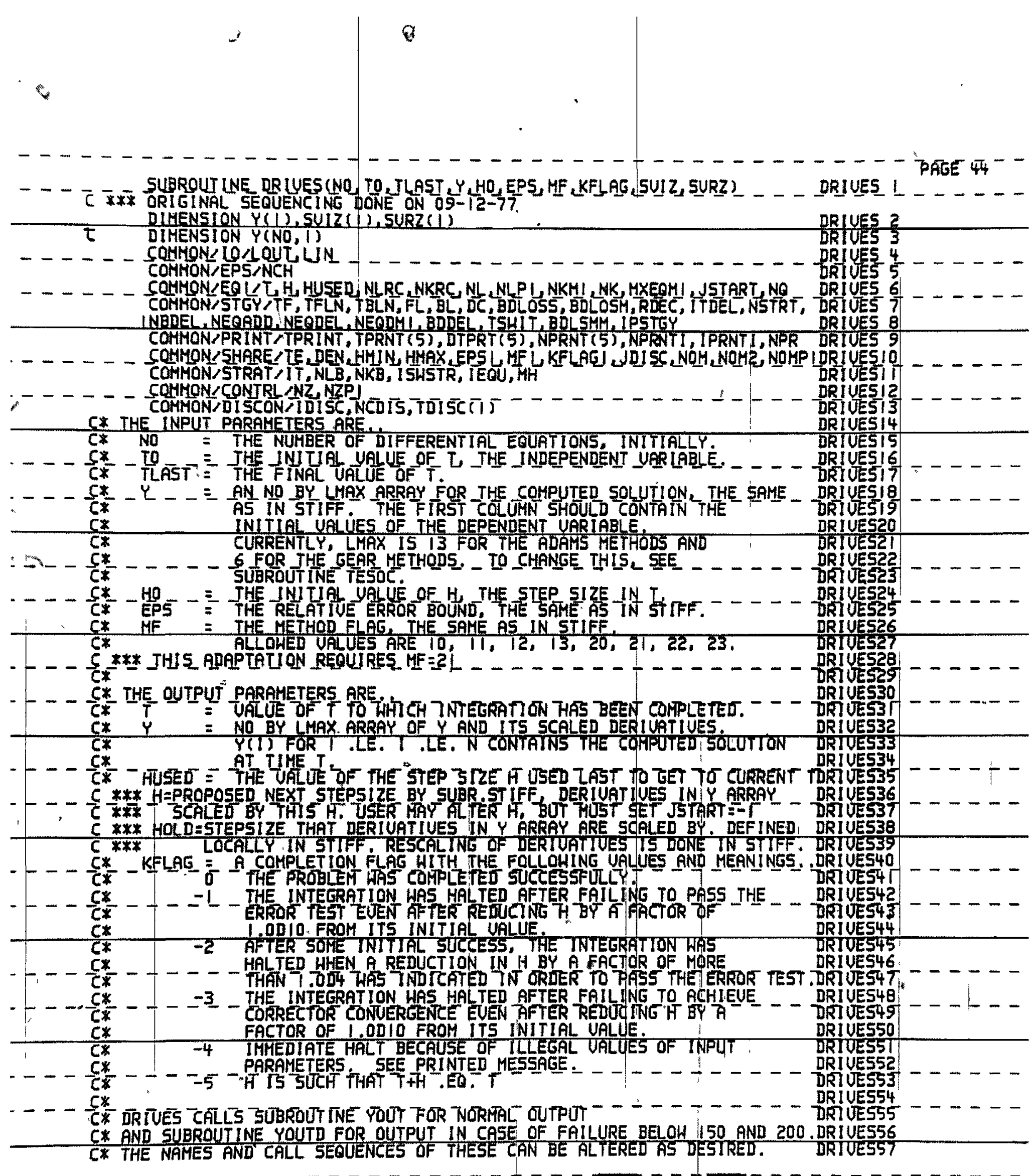
DRIGINAL SEQUENCING DONE ON OS-12-77.

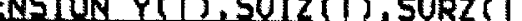

COMHON EPS NCH

SOMMON $1 E Q L L L H, ~ H U S E D, N L R C$ NKRC, NL NLPL, NKMI NK, MXEOMI JSTART, NO NBDEL NEQRDD NEODEL NEADYL BDDEL TSHIT BDL SHM IPSTTY

COHHON $P R$ RINT ITPRINT, TPRNT (5), DTPRT (5), NPRNT (5), NPRATI I TR COMMON, STRAT, IT, NLB, NKB, I SWSTR, JEQU, MH COHMON $C$ CONTRL NZ. NZP

C* THE INPUT PARAMETERS ARE

C* NO $=$ THE NUHBER OF DIFFERENTIAL EQUATIONS, INITIALLY

TRIUESIS

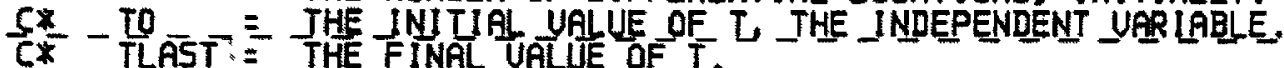

DRाÜ517

C* $-Y-$ - E AN NO BY LHAX ARRAY FOR

AS IN STIFF. THE FIRST COLUHN SHOULD CONTA IN THE

INITIAL UALUES OF THE DEPENDENT UARIABLE

URTY LMAX IS I3 FOR THE ADAMS METHODS AND

BRTUES?

C* 6 FOR THE GEAR METHODS. TO CHANGE THIS, SEE - DRIUES22

DRIUES24

C* - EPS - THE RELATIUE ERROR BOUND, THE SAME AS IN ST IFF.

C* MF = THE METHOD FLAG, THE SAME AS IN STIFF,

DRIUES26

5 *** JHIS ADAPTALION REQUIRES MF $=2$

C* THE OUTPUT PARAMETERS ARE

c. Y

Y

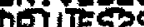

DRIUES30

c⿻一亅八.

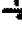

$C$ *** H=PROPOSED NEXT STEPSIZE BY SURR, ST IFF DERIUATIUES INIY ARRAY -

OF THE

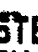

C *** H=PROPOSED NEXT STEPSIZE BY SURR ST IFF DERIUATIUES IN Y ARRAY

TAST

C *** HOLDESTEPSIZE THAT DERIUATIUES IN $Y$ ARRAY ARE SCALED BU. DEFINED,

C* - KFLAG $=A$ COMPLETION FLAG WITH THE FOLLOHING UALUES AND MEANINGS.

C* - - - THE INTEGRATION WAS HAL TED AFTER FAILING TO PASS THE _ -

ERROR TEST ZUEN AFFER REDUCTNG H BY A FACTOR OF I.ODIO. FROM ITS INITIAL UALUE.

HTER SOME INITIAL SUCCESS, THE TNTEGRATION WhS

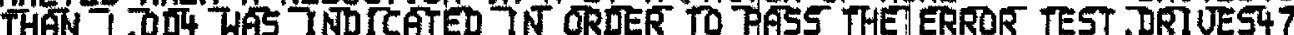

THE INTEGRAT ION WAS HAL TED AFTER FAILING TO ACHIEUE _ DRIUES48

CORRECTOR CONUERGENCE EUEN AFTER REDUC TNG H BY A

DRIUES50

C* $\quad-4$ IMMEDIATE HALT BECAUSE OF ILLEGAL UALUES OF INPUT

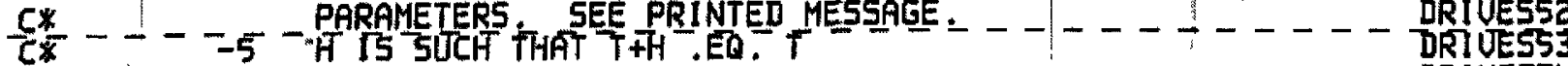

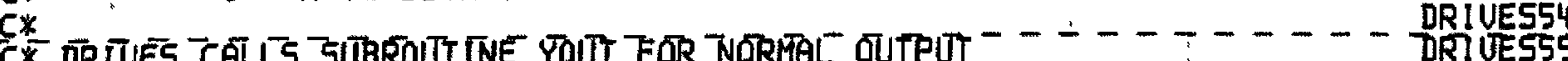

* AND SUBROUTINE YOUTD FOR OUTPUT IN CASE OF FAILURE BELOW 150 AND 200. DRIUES5G

C* THE NAMES AND CALL SEQUENCES OF THESE CAN BE ALTERED AS DESTRED. 


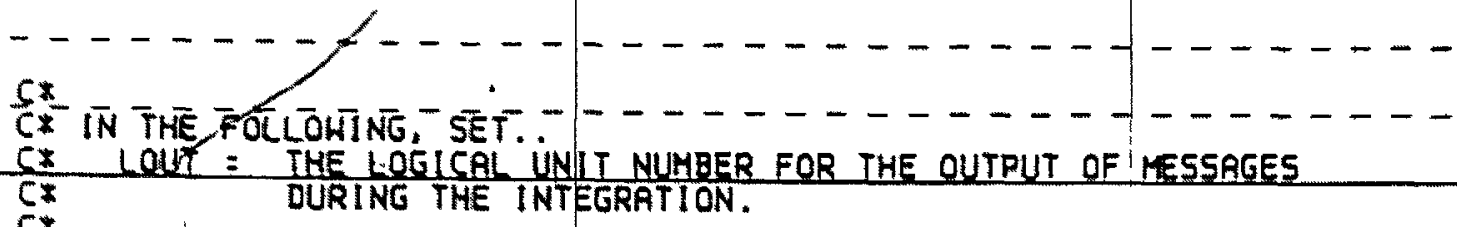

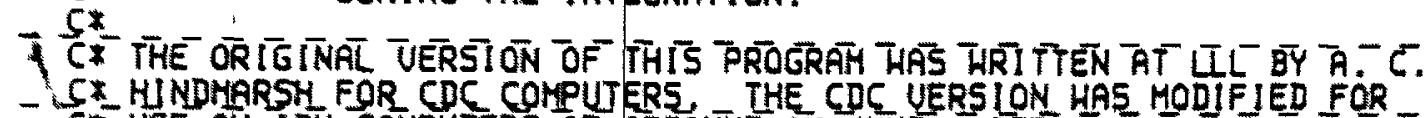

C. USE ON IBM COMPUTERS AT ARGONNE IN JUNE, 1973.

Cx

Cะ LATEST REUISION SEPTEMEER, 1973

5 I* DATE OF REULISLN FROM ARGONNE $15 \% 73$.

C X TF PROG. FROH ARGONNE TAILORED FOR THE LINEAR SYSTEM DESCR IEINE THE

5 * 5 CHARGE STATE DI STRI BUI ON UECTOR, DONE FOR E.C.CRLME OF

C $\$ * *$ THERHONUCLEAR. (FUSION ENERGY) (UERSTON DATE $=3 / 25 / 77$ ).

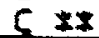

C $\$ 7 *$ TO, TF =TLAST, HO, TPRINT, TDISC(I) ARE IN UNITS OF SEC..

C $\$$ XX THE JIME UNU OF THE SYSTEM OF QDE'S IS SECONDS

C \$

C $\$ * *$ THIS IS SET IN SUBR. IESOC. MAY NEED TO DEFINE THIS LOHER FOR SOME DRIUESTY

$C$ N* APPROXIHATING FCNS. TO DEN AND TE:

- 5 \$\#\# JF IDLSC=0, FHEN FCNS, DEN AND TE ARE SUFFICIENTEY SHOOTH FOR THE DRIUESBD

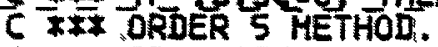

$S$ *** JF DISC,NE D THEN AT TDISC( I) JHE IST DISCONTINUITY IS

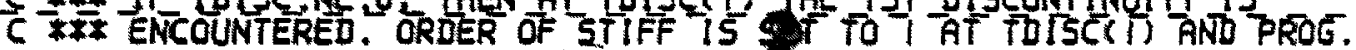

C *** CONTINUES, ON (TO, TDISC(1)) HILL ALLOH ORDER TO GO TO 5 AS HELL
C $\$$ ON ON (TDISC(I), TDISC(2)). IF HAVE J DISCONTINUITIES, THEN DEFINE

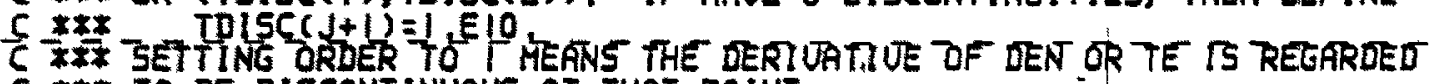

C $\times \times \times$ TO BE DISCONTINUDUS AT THAT POINT.

$\bar{C} \bar{x} \bar{x}$

C \#** PRIOR TO CALL DRTUES MUST DEFINE UARIABLES NZ,NZPI $=N Z+1$,

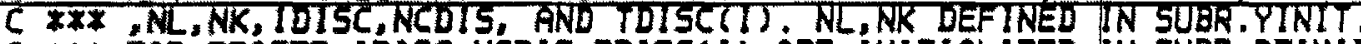

C $\times * *$ FOR PROGTD IDISC, NCDIS, TDISC (I) ARE INITIRLIZED IN SUBR. DTINIT

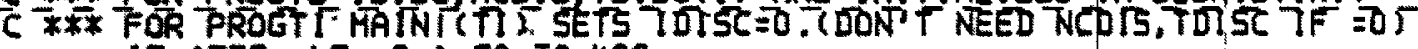

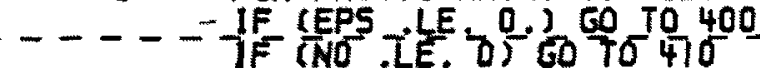

IF ( (TO-TLAST) *HD . GE. O.) GO TO 420

$T=0$

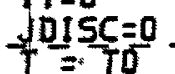

$H=H D$.

$-\overline{H I N}=\overline{A B S(H O)}$

C *** BEGIN INITIALIZATION FOR STRATEGY II, ISHSTR=2

C $\$ \times \times$ INCLUDES THAT FDR TSASTR=I SURZ $(0)=0$.

SUI $Z(N Z+1)=0$.

ITDEL =NSTRT

CALL DENTHP (TE, DEN, T)

CALL SUIONZ (SUIZ,TE, DEN)

CALL SURECZ (SURZ, TE, DEN)

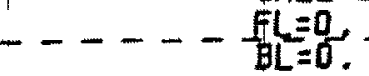

TCE =0: $\bar{N}=\overline{D E N *}$ SURZ (NLE- T) KY (NL)

$T B L N=D E N * S U I Z$ (NK) *Y (NK)

C *** END INITIALIZATION FOR STRATEGY II, ISWSTR $=2$

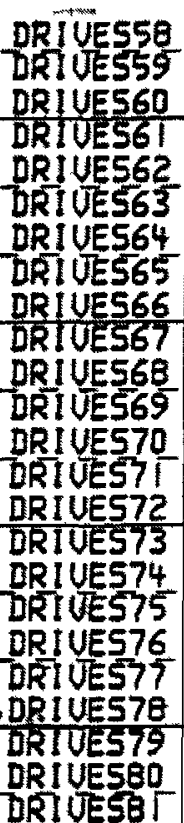

PATE $45^{--}$

DRIUESE2

DRIVESB3

SDRI UESB 4

DRIUESES

DRIUESE6

DRTUESB

ORIUESB8

DRIUESES

DR IUES90

DRTUES91

QRIUE592

DRTUES93

DRIUES94

DRिUE595

DRIUE596

DRTUE597

DRIUES98

DRT UES99

DRIUES 0

DRIUES ?

DRIVES 2

DRIUES 3

DRIUES 4

DRIUES 5

DRIUES 6

DRT UES T

DRIUES 8 !

DRTIUES 9

DRIUESIO

DRIUEST ।

DRIUESI?

DRUE์ 3

DRIUES 14

DRTIUESTS 


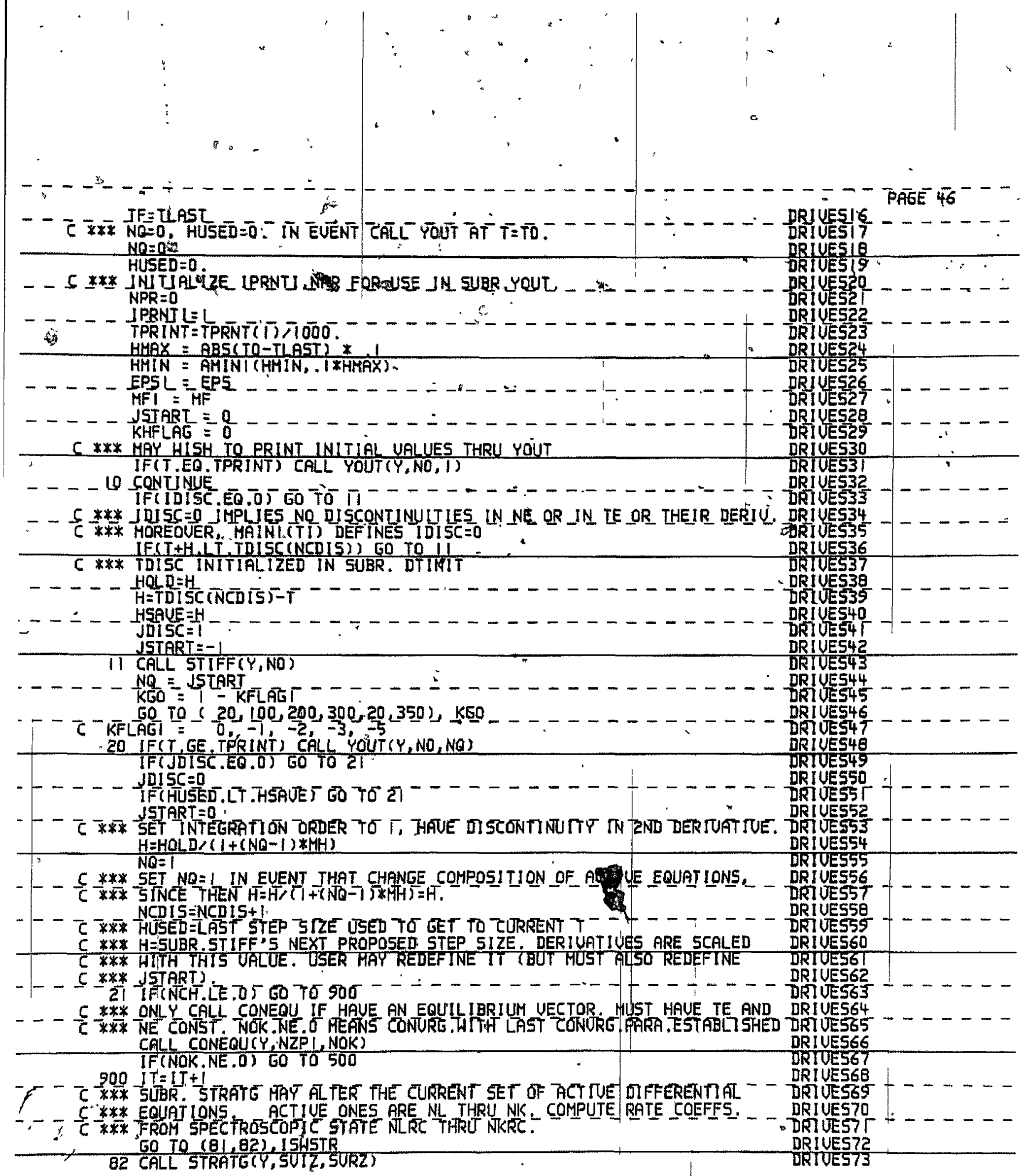
Q2 CALL STRATE (Y, SUI7, SURZ) 


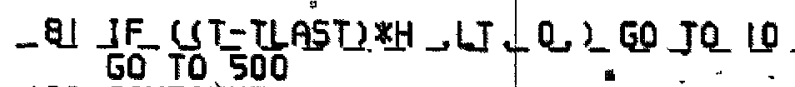

100 CONTINUE.

CIOD HRITE (LOUT, 105) T

CI05 FORMATS 130 HKFLAG = -1 FROM STIFF AT $=0$ DRIUE577

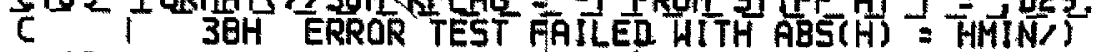

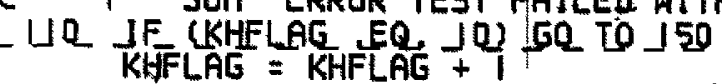

HMIN $=$ HMIN $\times$.

$H=H *=1$

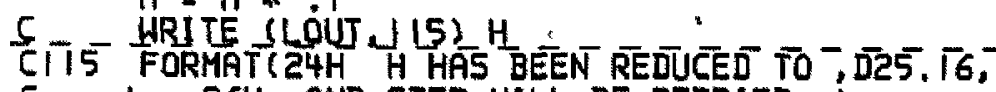

C - L 26H AND STEP WILL.BE RETRIEQ/S JSTART $=-1$

GO TO 10

1.50 HRI TE (LOUT, 155)

155 FQRHATC $\angle 44$ PROBLEM APPEARS UNSOLUABLE HITH GIUEN INPUT

C* HMIN HAS BEEN CUT BY 10 . ORDERS OF MAGN ITUDE HI TH NO SUCCESS.

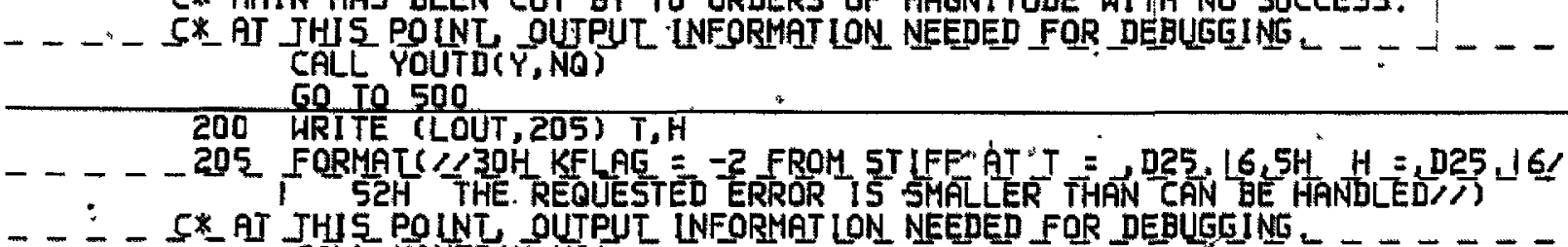

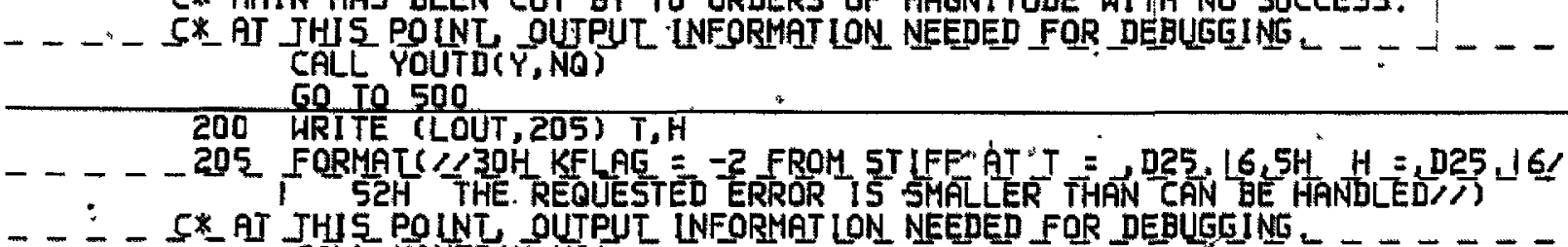

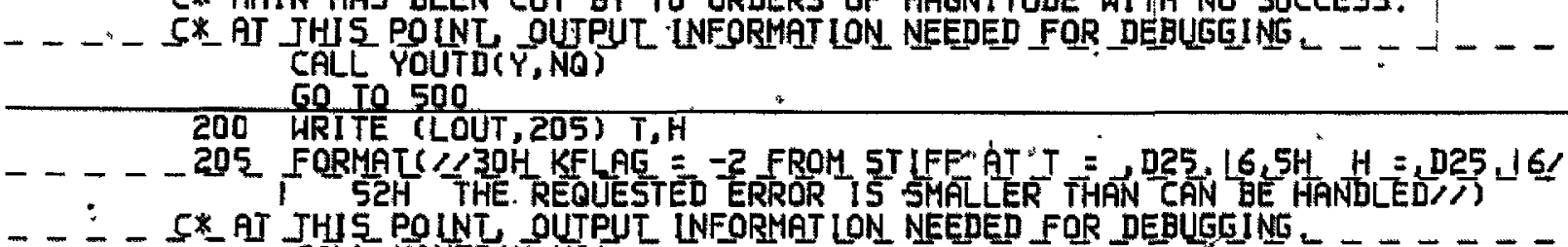

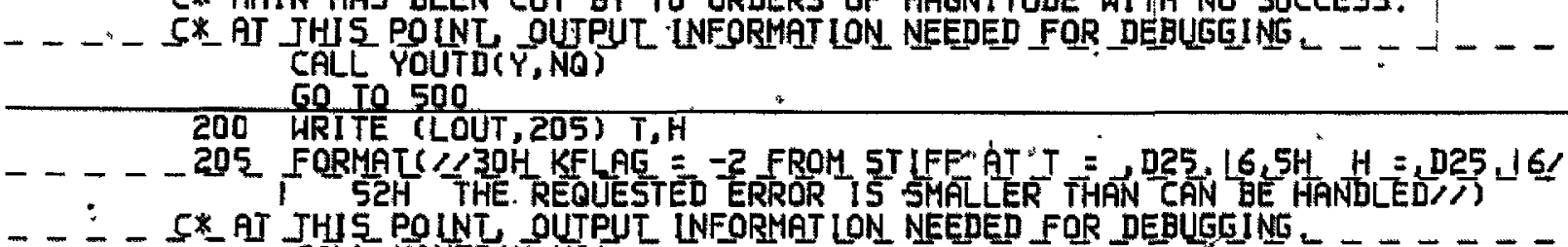

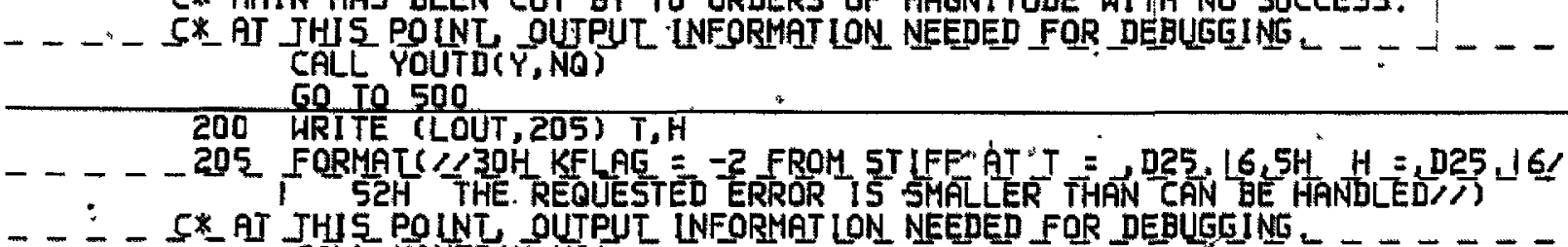

- - - S* AT JHIS POLNT OUTPU

60 TO 500

C *** SINCE SYSTEM IS LINEAR AND STIFF TAKES ADUANTACE OF THIS,

5 *** GORRECJOR CONUERGES IN L STEP. HENCE NEUER ARRIUE AT 300 .

$300^{\circ}$ WRI TE (LOUT, 305 ) I

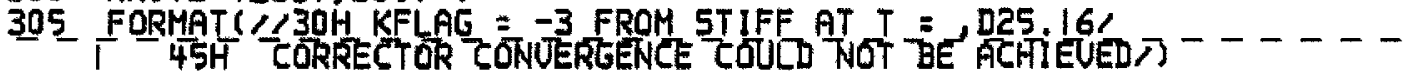
G0 To 110

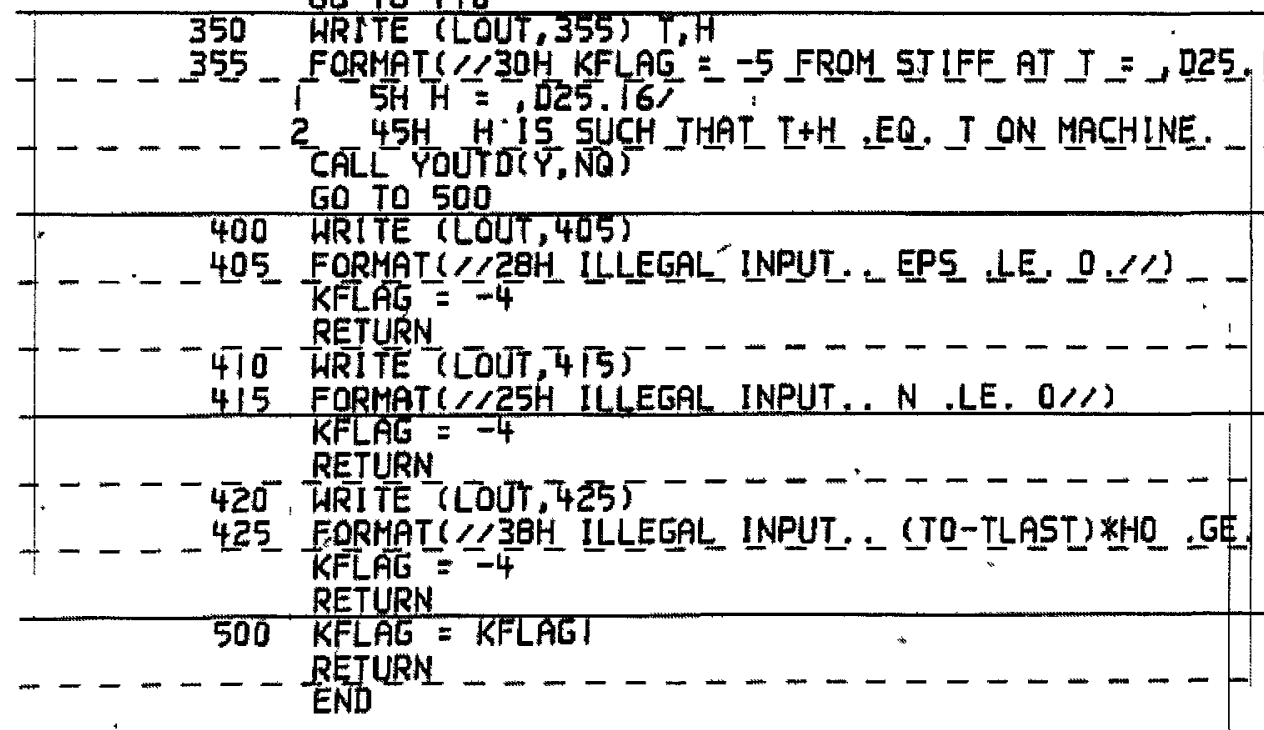

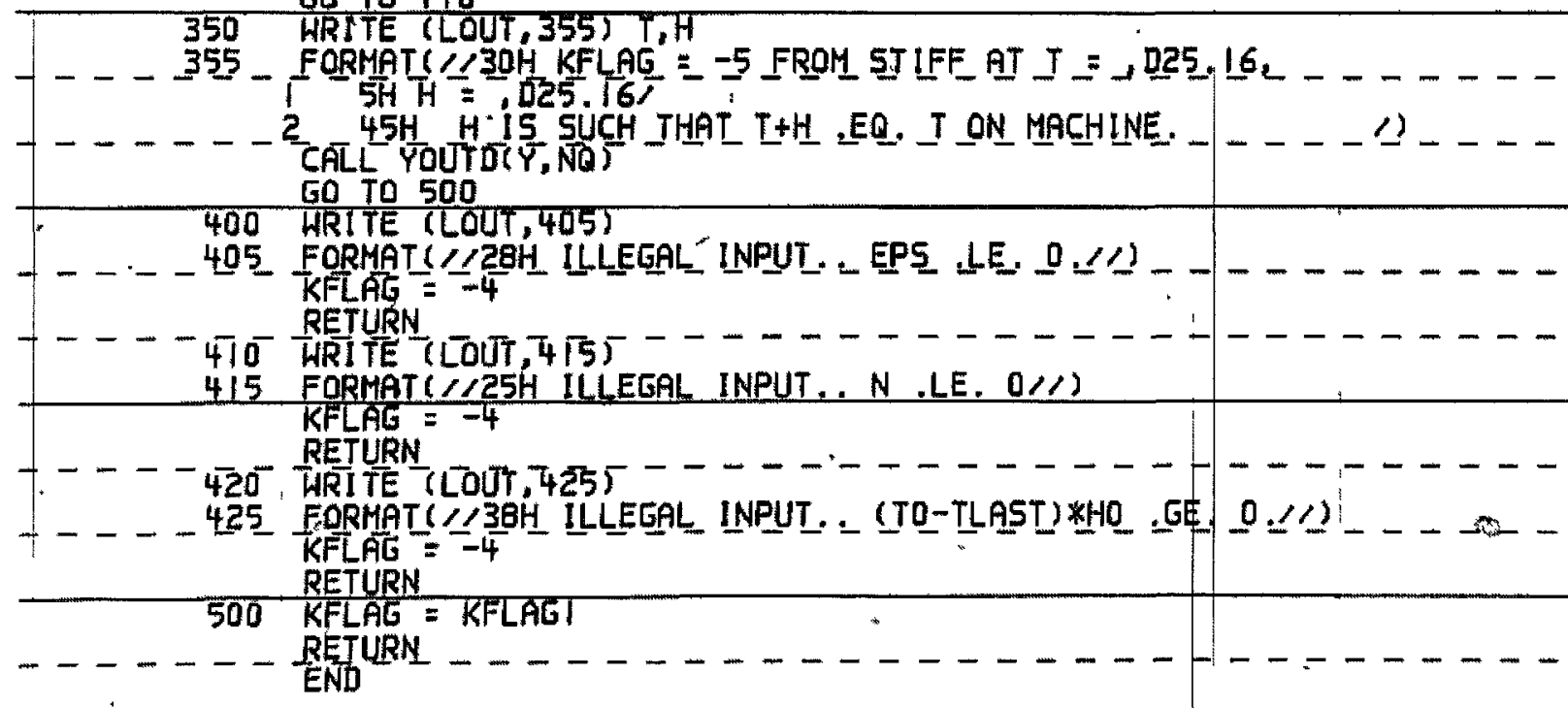

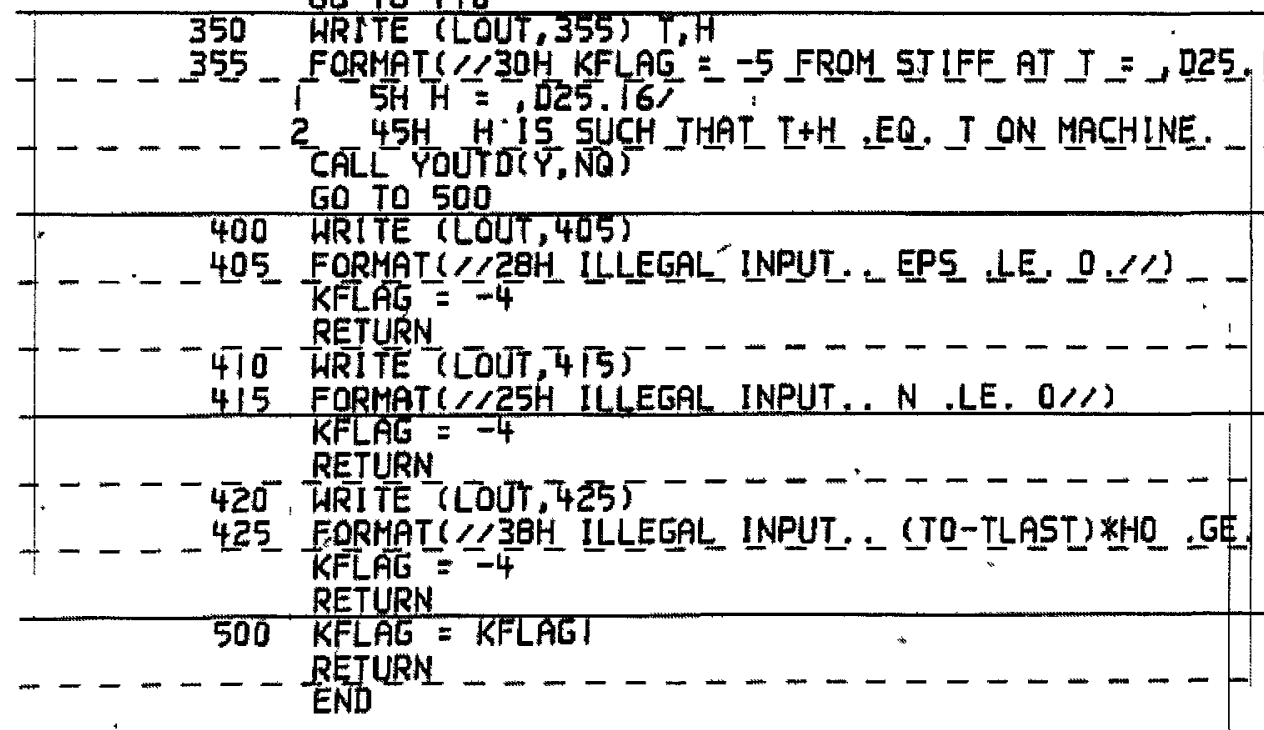

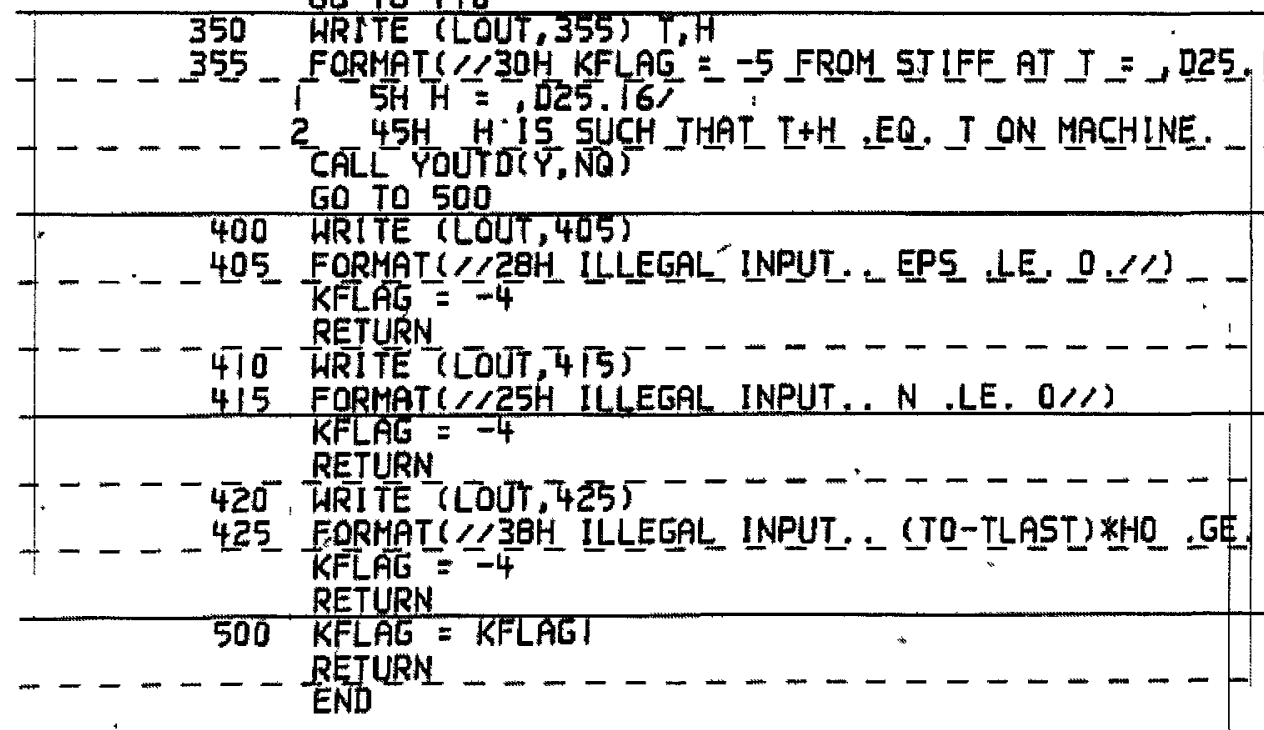

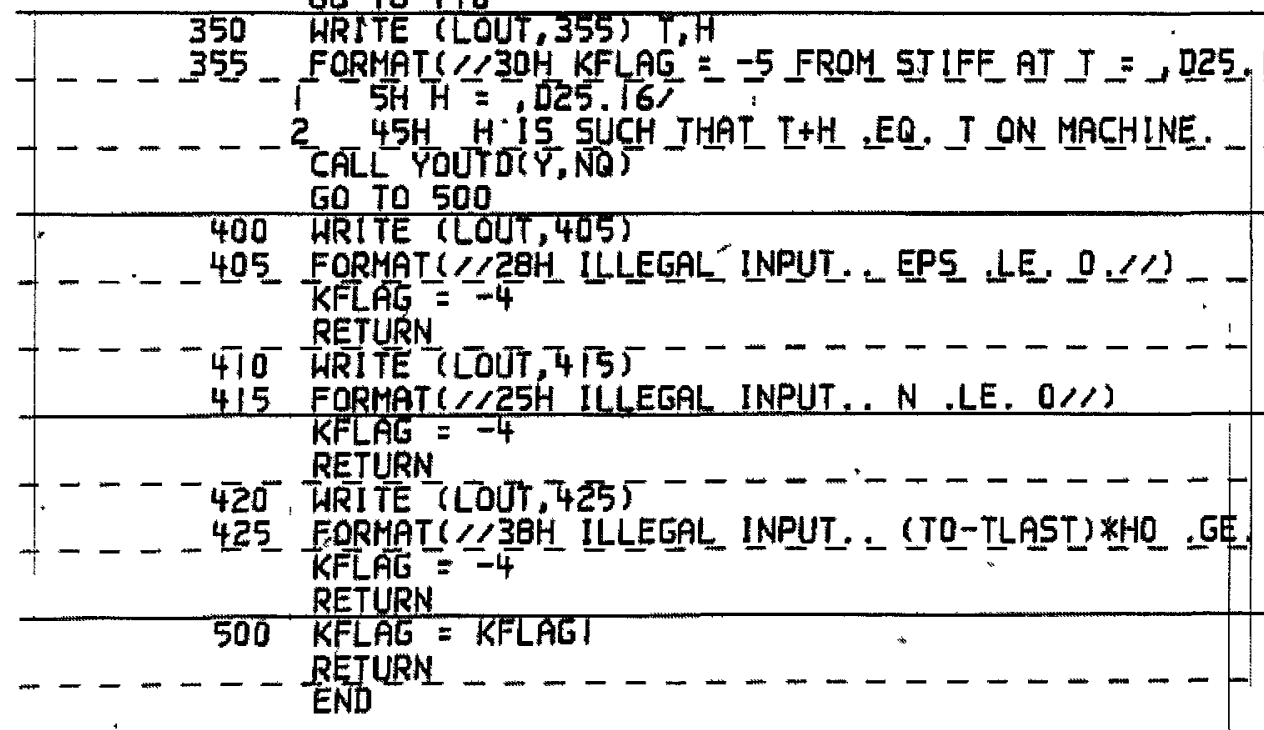

DRIUESB?

DRIVESE3

DRIUESBY

DRI UESB5

DRIUESBG

DRी UE SB?

DRIUESBB

DRIUESES

DRIUES9D

DRIUESS I

DRIUES92

DRI UES93

DRIUES94

DRIUES95

DRIUES96

DRाVES9?

DRIUE59日

DRाUES55

DRIUES O

DRTUES

DRIUES 2

DRIUES 4

DRIUES 5

DRIUES 6

DRIUES 7

DRIUES 8

DRIUES

DRIUESID

DRIVESI

DRIUESIE

DRTIUESIB

DRIUESI 4

DRIUEST 5

DRIUES IS

DRIUEST

DRIUESIO

DRIVESTS

DRIUESZD

DRT UES?

DRIUESZ2

DRT UES23

DRIUESZ4

DRIUES25

DRIUES26

DRIUESET 


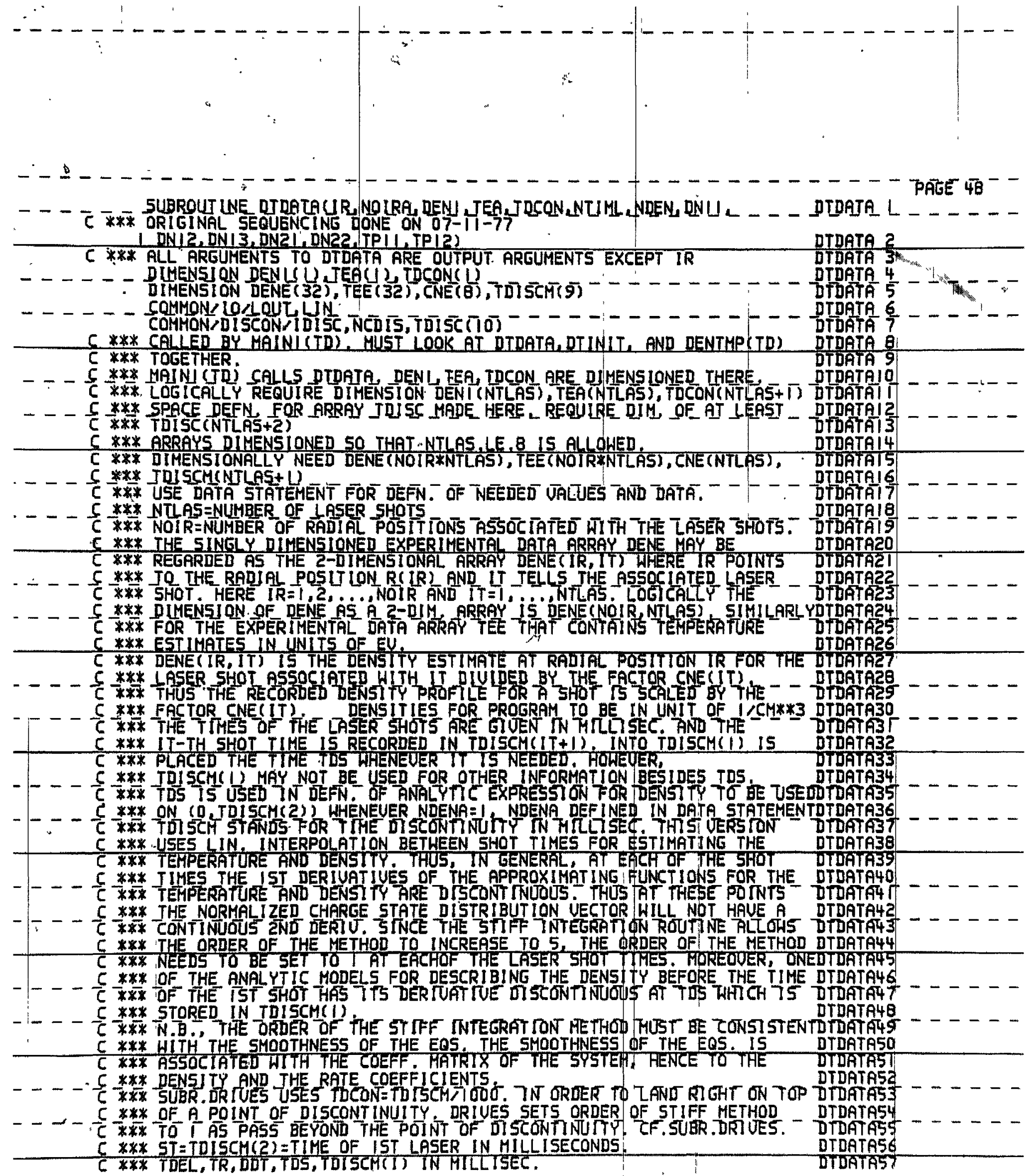

C *** TDEL, TR, DDT, TDS, TDISCM(T) IN HILLISEC. ITDATAST 
--5 * $*$ K* IDSS TDCON IN SES

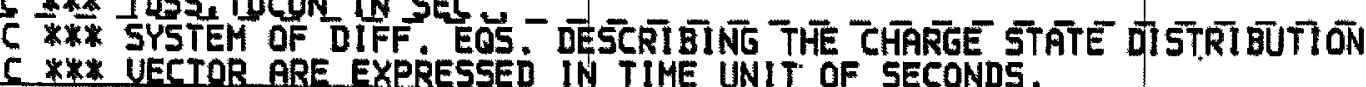
DATA TDEL/10.1.TR/10.1.DDT/5.

DATA DENE/5,

24 L L DATA CNE八. EI उ,T.EIẼ,T.EIT DATA TEE $/ 500 . .200 .10$.

\section{$1410 . .120 . .10 .$.}

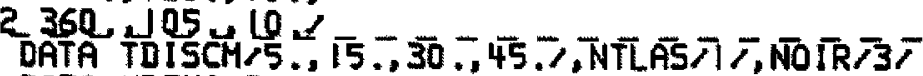

DATA NDENA 2

DATA TEO, DENO

C X* IR IS A LOOP ING INDEX AND IT IS EXPECTED TO RANGE OUER UALUES

DTDATA58

C *** $1 . .$. NOIRA=NOIR. NOTE THAT NOIRA 15 DEFINED HERE ON IST CALL TO DTBATA73 5 * D* DTDATA, MOREDUER, NOJR DETERMINES THE LOGICAL PARTI LIONING OF JHE DTDATA74

$C$ *XX ARRAYS TEE AND DENE.

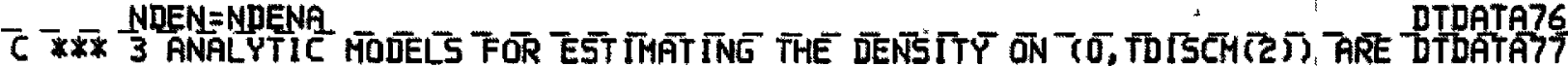

$C$ X** AUALLABLE. THE MODEL IS SELECTED BY THE UALUE OF THE PARA NDEN DTDATA79

C *** MODEL 1 , NDEN $=0$. HERE DENSITY AND TEMPERATURE ARE TTHE INDEPENEENTDTDATA79

5 *** FOR ALL JIME WITH UALLES GN 2 BY DENSI TY $=C N E$ (I) *DENE(IR) AND

C *** TEMPERATURE $=T E E(I R)$.

C *** MODEL IL NDEN=L DENSITY $(T)=C N E(1) * D E N E(I R S) * D I D * T / T D S 5+D$ HHERE DTDATABZ

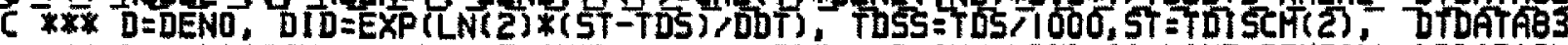

C *** TDS=TDISCHCH ON THE INTERUAL $(0$, TDS), D INCLUDED TO MAKE DENSITY DTDATAB4

C *** NONZERO. NEEDED IN SOME RATE COEFF. ROUTINES. ON THE INTERUAL

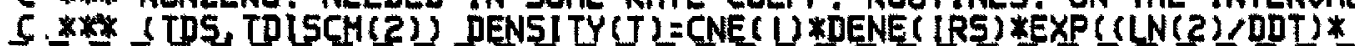

C * *

C *** MODEL II, NDEN=2 DENS ITY (T) =CNE (1)*DENE(IRS) $(1+(T D E L / S T) * * 2) *$

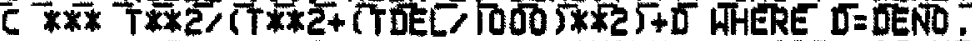

C *** WHEN NTLAS=1. THEN AN ANALYTIC MODEL IS USED FOR- LHOLE TIME

C *** INTEGRATION. THE ANALYTIC FORH THAT IS USED JUST PRIOR TO

DTDATAES

DTDATAB 6

DTDATAGT

C *** JDISCM(2) IS USED FOR LATER TIMES

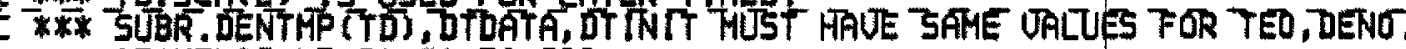

IF(NTLAS LE Q Q GO TO 200

50 FORMAT( 'O $* * * * *$ SUBR, DTDATA, REQUIRE NTLAS, LE, $\theta$ FOR STORAGE. HAUE ITLAS=' $12,2 X^{\prime}$ REDEFINEED NTLAS=E')

NTLAS=8

200 NOTRA=NOTR

NTIML $=$ NTLAS

$T R S=I R$

DO $\quad$ i $i=1$, NTLAS

TEA (1) $=$ TEE (IRS)

DENI (I) =CNE (I) $*$ DENE(IRS)

TRS =IRSTKOIR

5 * $*$ MAY HISH TO HRI TE OUT IHE EXPERIMENTAL_ DATA ASSOCIATED HITH IR. $M=N K L A 5+1$ DO $2 \quad I=1, M$

DTDATAEB

DTDATA90

DTUATAO

DTDATA92

DTDATAGI

DTDATAGS

DTDATAG5

DTDATA67

DTDATA68

DTDaTa70

DTDATA93

DTDATA94

DTDATAS

MDTDATA9G

DTUATR 97

DTDATA98

DTDATAgs

DTDATA D

Dtoatá i

DTDATA 2

DTuATR 3

DTDATA 4

DTDATA 5

DTDATA 6

DTDATE 7

DTDATA 8

C *** TIME UNIT OF DIFF. EOS. IN SECONDS, YET MANY OF DATA TIMES ARE

C *** GIUEN IN MILLISECONDS

2 TDCONN $(1)=T D$ TSCM(T), TDOOO.

TDS=TDISCM(1)

$S T=T D 15 C M(2)$

DID $=$ EXP(.693147*(ST-TDS)/DDT)

DTDATA 5

DTDATAIO

DTिATA ?

DTDATAI2

DTDATAT 3

DTDATA14

DTUATAT5 


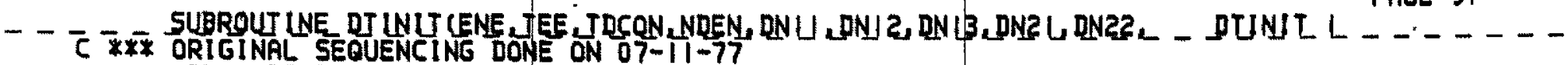

TPUITP(2,NTLAS)

DIMENSION ENE (1), TEE(1), TDCON(1)

COMMONOLOLAQULLUN

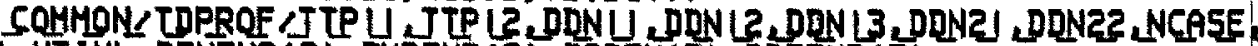

I NT IML, DENEXP (8), THPEXP (B), DDDEN $(7)$, DDTEMP( 7$)$

C *** CALLED BY MAINI (TD). HUST LOOK RT DTDATA. DTINIT, AND DENTMP(TD)

C *** TOGETHER

5 *** NCDLS POINTS TO NEXT DISCONUINUUTY OCCURS RT I=TDISC(NCDLC)

C *** SET TDISC (NTIML+2) $=1$. EIO SAYS LAST DISCONTINUITY RT TDISC(NTIML +1 JDTINITII

C *** JHIS UERSLON GENERATED ON $(3,22,72)$

C *** RECEIVES AND PROCESSES THE OATA TO

C *** NTLAS $=$ NO. OF LASER TIMES.

f $* *$ K JDCON $=$ (POSS LBLE) DISCONTINUITIES IN TIME UNITS OF SEC

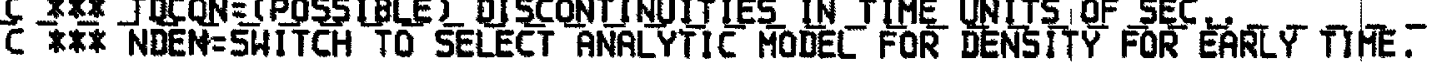

- - 5 *** NDENEQ MEANS NE AND JE ARE EACH CONSTANT

C $\times$ X DTINITIB

* * ENE(1) AND TEE(I) ARE THE EXPER.IMENTAL UALUES FOR THE DENSI TY ANDD DHINI fIS

C *** TEMPERATURE ASSOCIATED WITH THE LASER TIME RECORDED IN TDCON $(1+1)$, DTINITZO

$C$ *** SPACE IS RESERUED FOR TOSS IN TDCON(1)-EUEN HHEN NOT USED

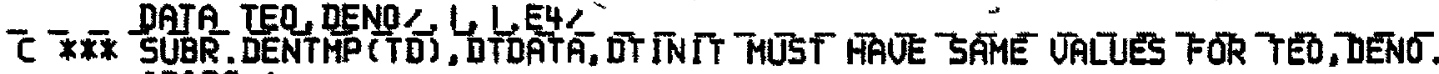

DTINTIZ

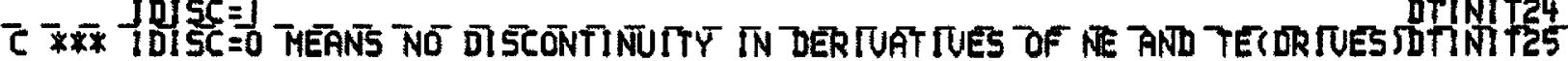
TDISC (1) =TDCON(1)

NTIML =NTLAS

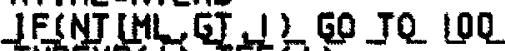

DTINIT26

TMPEXPT T =TE⿰त)

DENEXP (1) =ENE (1)

DTINIT27

DTINIT28

Drinitas

IFINDEN EE. 0 ' 50 to 7000

GO TO $(i, 2)$, NDEN

DTINIT30

NCASE $=1$

NCD 15 =1

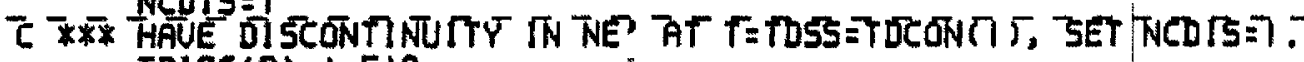

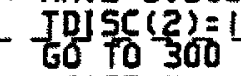

2 NCASE $=2$

IBISC $=0$

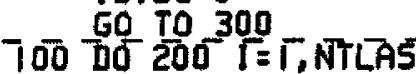

DENEXP(I)=ENE(I)

$200 \operatorname{TDISC}(1+1)=\operatorname{TDCON}(i+1)$

IF(NDEK.EO .0) 60 TO 500

TDISC $(N T L A S+2)=1 . E I 0$

$J=N \bar{T}$ AS-1

DINTH

DTINTT33

DTINIT34

onNT 35

DTINIT36

Drint37

DTINIT3B

oIINIT39

DTINIT40

DTini 74

DTINIT42

DTNI 7 3

DTINIT44

DTINIT45

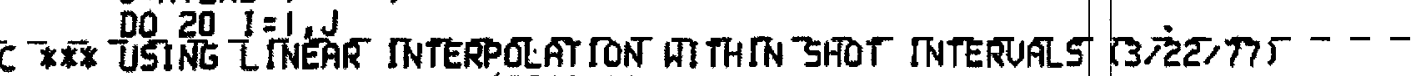
DEL $T=T D i s C(1+2)-T D(S C(1+1)$

DTINIT46

DกNT4 ?

DTINIT4E

DTNiT4

DDDEN $(1)=(D E N E X P(1+1)-D E N$ EXP (I)) DEECT

DTINIT50

20 DDTEMP $(1)=(T M P E X P(1+1)-T M P E X P(1))>D E L T$ GO TO $(1,1,12), N E E N$

DTINITSI

DTINIT52

NCASE $=3$

DTNT 53

NCDFS $=1$

G0 TO 300

DTINIT54

DTiNits

DTINIT56

12 NCASE $=4$

DाINTा5 


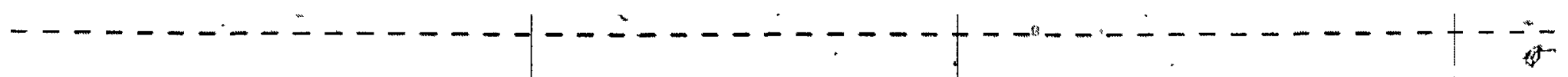

$-y_{-}-\ldots+\ldots$

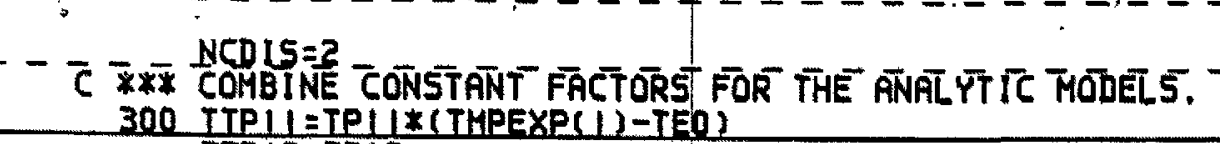

$T T P \mid z=T P 12$

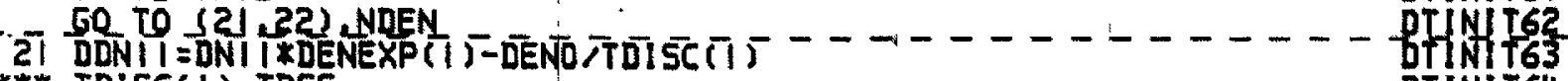

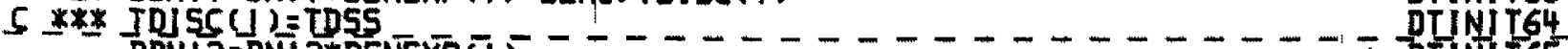

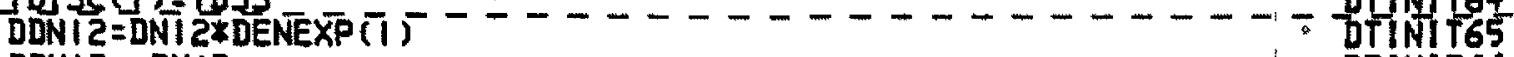
DONI $3=-\mathrm{DNIB}$

60 TO 400

22 DDN2 $=$ DNE L

400 RETURN

500 NCASE $=5$

C *** TE, DEN ARE CONSTANT FOR ALL TIME, $\operatorname{IDISC}=0$

END To 400

DTiNiT66

DTINIT58 Dink 55 DIINIT60 of N1t6

\section{PAGGE 52}


- - - - - - - - - - - - - - - - - - - - - - - - - - -

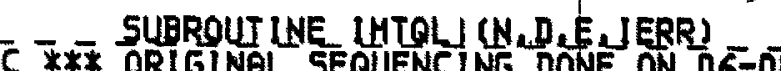
C XXX GHANGED FROH DOUBLE PRECISION TO SINCLE PRECISION $(5 / 2 / 277)$. REAL $D(N), E(N)$, HACHEP

5 - - IHIS SURROUUNE IS A TRANSLAT ION OF JHE ALGQL PROGEDURE JMTQLL

c - NUM MATH, $12,377-383(1968)$ BY MARTIN AND WILKINSDN.

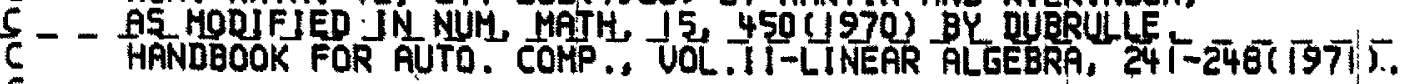

C THIS SUBROUTINE FINDS THE EIGENUALUES OF A SYMHETRIC

C - JRJDJAGONAL MAIRJX BY JHE JMPLJCIL QL MEJHOR

$--\frac{5}{C}--$ ON INPUL $-\ldots-\ldots$
NIS THE ORDER OF THE MATRIX:

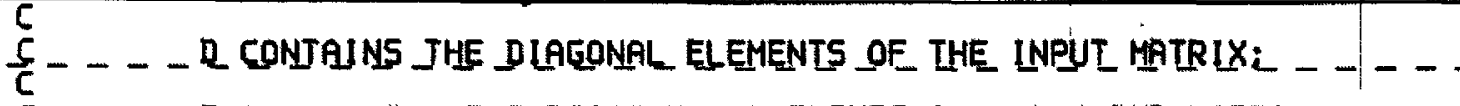

- - - $\frac{C}{C}---E$ CONTAINS THE SUBDLAGONAL ELEMENTS OF THE INPUT MATRIX $\ldots$ - -

- - - $\frac{C}{C}---E$ CONTAINS THE SUBDIAGONAL ELEMENTS OF THE INPUT MATRIX - - -

\section{ON OUTPUT:}

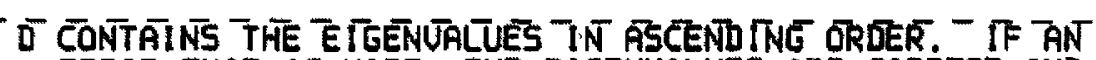
ERROR EXLT 15 MADE THE EI GENUALLIES ARE CORREC AND
ORDERED FOR INDICES I, $2, \ldots$ IERR-1, BUT MAY WOT BE THE SMALLEST EIGENUALLUES:

MTTQLI $\frac{2}{3}$

MTOL 45

IMTQL 16

IHTOLI 9

IMTQL 110

IATQLITI

IMTQL

IMTOL 114

IATOLIIS

IMTQL 116

MTQLU 10

INTOLTIS

IHTOLIZO

$\frac{c}{c}$

c

E HAS BEEN DESTROYED:

- IERR 15 SET TO

j

FOR TNORMAL RETURN

IF THE J-TH EIGENUALUE HAS NOT BEEN

|HTELTE|

IMTQL 122

IMTOL 124

INtál

IMTQL 126

IATOLT27

MTOL 128

$\frac{c}{c}$

DETERHINED AFTER 30 TIERATTONS.

IMTOL 130

IMTन 3 F

IMTOLI 32

, $\frac{c}{c}-$ QUEST TONS AND ZOMMENTS SHOULD BE DIRECTED TO E. Z S. GARBOW,

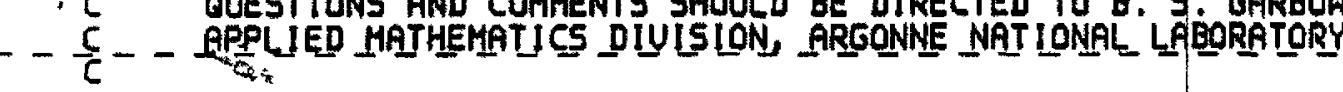

IMTOL 133

IMTOL 134

7HTिL 35

IHTOL 136

IHT⿰丿丶万阝 37

c

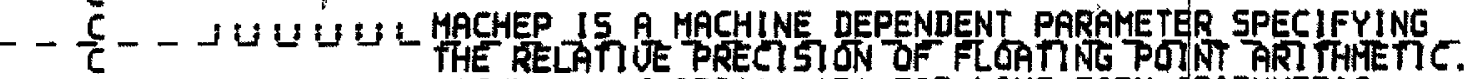

$C$ MACHEP $=16.0$ DO** $(-13)$ FOR LONG FORM ARI THMETIC

G1 $5360^{\circ}$.

$C$ C $\$$ MACHEP $=16 * 2 \times 5$ FOR SINGLE PREC, ON 1 BM 360 .

IMTOLI 44

$C$ *** MACHEP $=16 \% *-6 / 16 * *-1$ HHERE NUFERATOR INDICATES ERROR OF T IN LAST IHTOL 145

C *** HEX DIGIT. AND DENOHINATDR IS SMALLEST NORMALIZEQ FRACTION. - - 1 IMTOLI 46

DATA WACHEP $>23 C$ TOODOOO

C *\$* DATA KACHEP $/ 234$ 10000000000000/

IERR $=0$

IF (N .EQ. I) GO TO 1001

c -

Dó $\overline{0} 0^{-} \Gamma_{\overline{1}}=\overline{2}, \mathrm{~N}^{-}-\overline{x^{4}}$

$\tau^{100} E(1-J)=E(1)$

$E(N)=0.0$

7HTQLTT

IMTOL 148

गलTब 49

IMTOL 150

ITTELIST

IMTOL 152

imtol 55

IMTOL 154

तिनिं 55

IMTOL 156

c

INTOL 157 


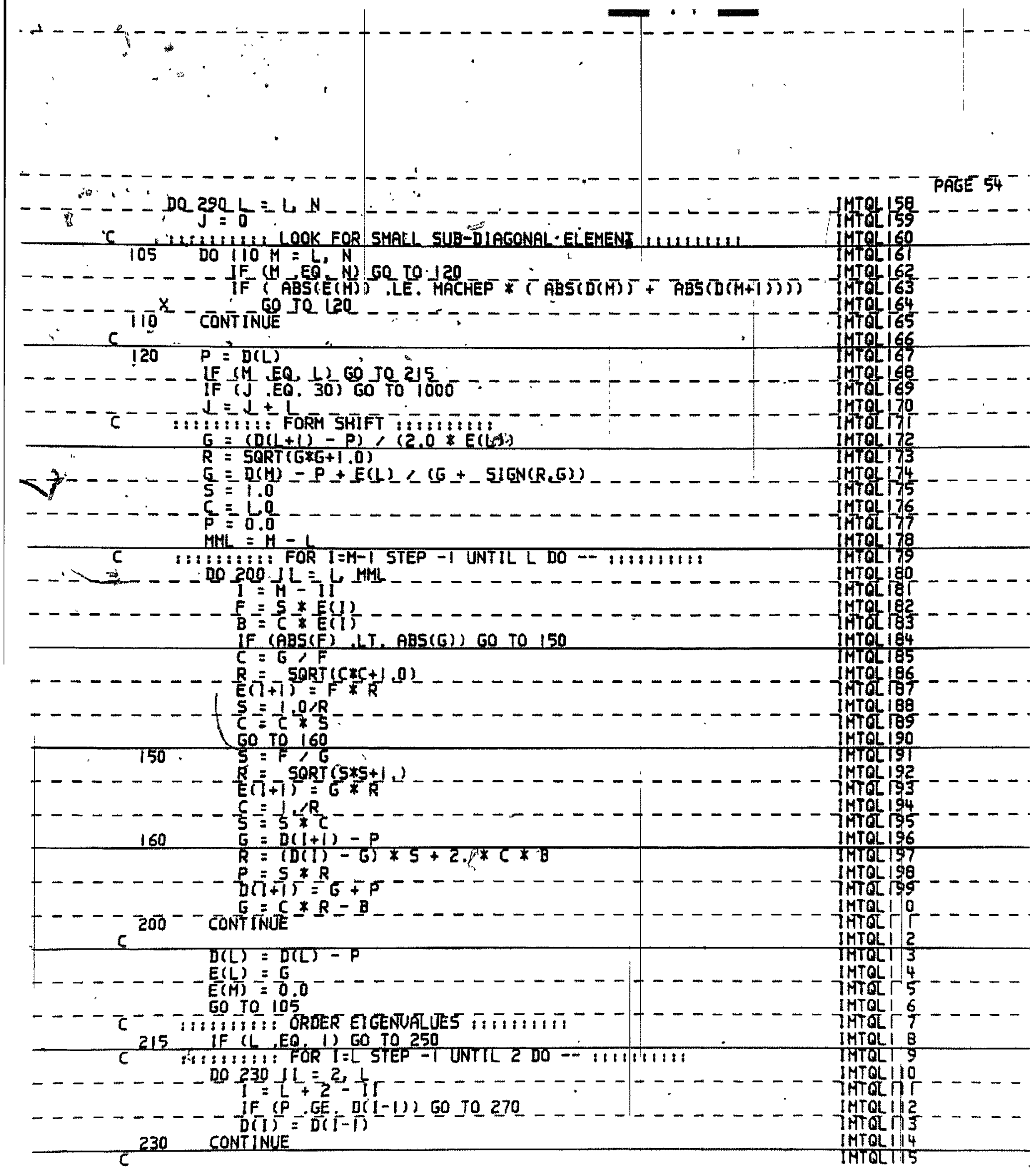

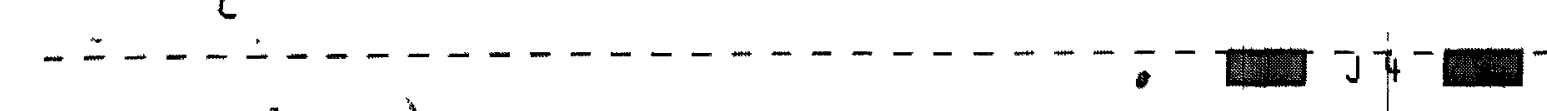




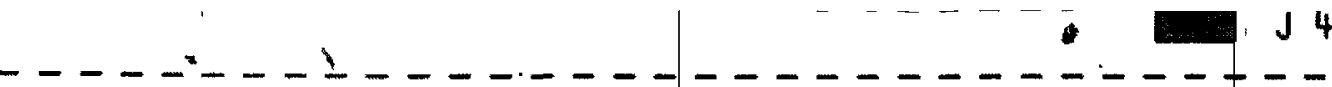

$$
-
$$

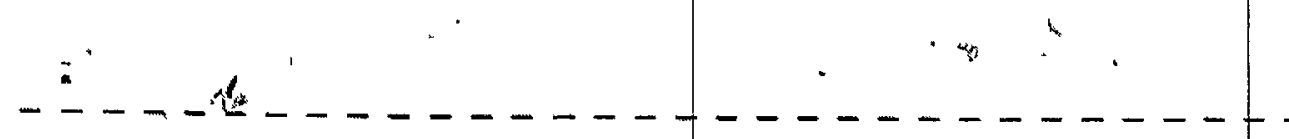

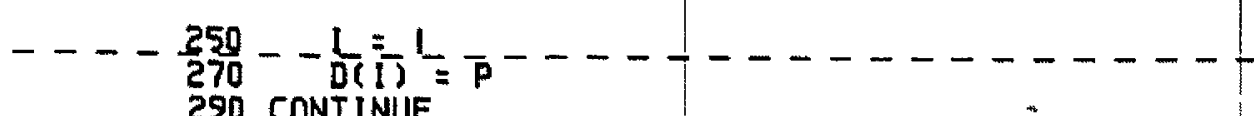
C 290 CONTINUE

$---\bar{C}-50$ TO $100 \mathrm{~L}$ SET ERROR = TO CONUERGENCE TO TN

$--5$

IDOO TERR $=\bar{L}$ IODI RETURN

: : : : : : : LAST CARD OF IHTOLI : : : :1:1:1: END EJ TENURLUE AFJER 3Q UTERAT LONS IUU UUL

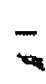

$\overline{4}=$

$----$

$--$

HTQL 119

IHTOL IIS

HTOLTIS

1 HTQL 120

IMTOL 122

IMTOL 123

IMTQL 124

IHTAL 125

IHTQL 126

PAGE $55^{-}$

- - - - - - - - - - - - - -

$+1.5$

K 4

$-\ldots-\cdots$

$-$ 


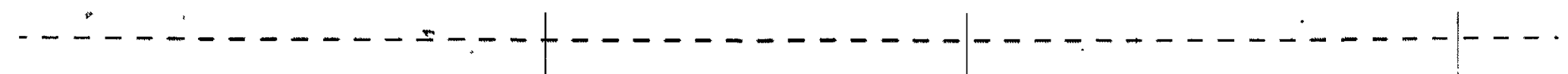

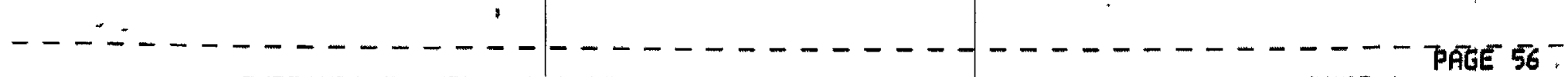

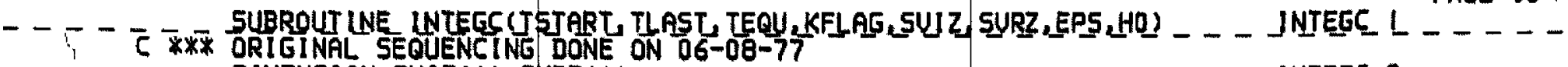
DIMENSION SUIZ(1), SURZ(1) COHMON/EPS $/ \mathrm{NCH}$, NEOU

- - - - - COMMON COHMON L L L

- - - - - COMMON COHMON L L L

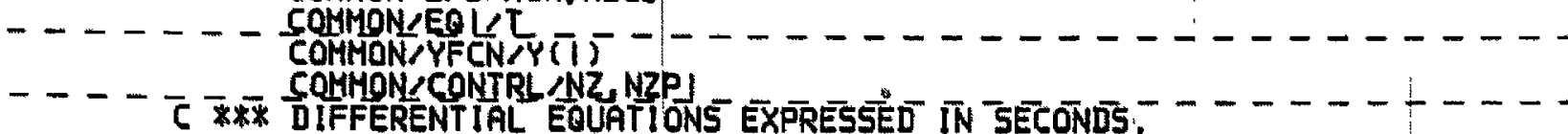

C *** EXTERNAL TIMES IN MULLISECONDS

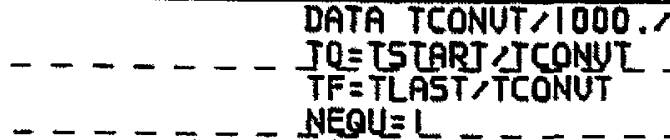

$----\bar{C} \bar{*}$ * NEQUU $N O=N Z P \mid$

$M F=21$

5 * * W USE SUIFF PART OF GEAR-HINDMARSH ODE PACKAGE

CALL DRIUES (NO, TO, TF, Y, HO, EPS, MF, KFLAG, SUIZ, SURZ)

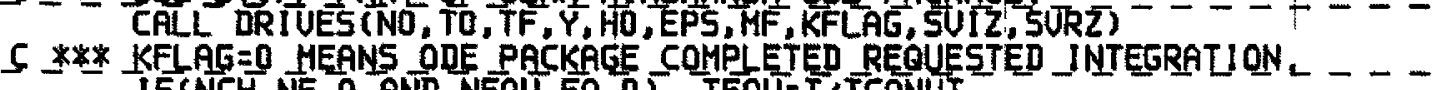
IFINCH.NE .O .AND .NEQU.EO.D T TEQUV T/TCONUT RETURN END

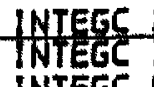

INTEGC 4

INTEGC $5-\cdots$

INTEEC 6

INTEGC

INTEGC T

INTEEC

INTEGC ?
INTEE
INTEGC 4

INTEECI5

INTEGC 6 
SUBROUT INE STRATG(Y. SUIZ, SURZ)

C X*X ORIGINAL SEQUENCING DONE ON $07-05-77$ DIMENSION $Y(1)$, SUIZ(1), SURZ(1)

COMMON/IO/LOUT, LIN

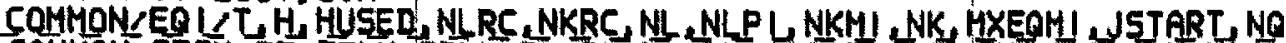

COMMON, STGY,TF, TFLN, TELN,FL, BL, DC, BOLOSS, BDLOSH, RDEC, TTDEL,NSTRT, UNBDEL NEOADD, NEQDEL NEODML BDDEL TSWJ T BDLSMH IPSTCY

COHMON/SHARE/TE, DEN

COHMON S STRAT CITINLB, NKKB, ISHSTR, IEOU, HH

COMMON CONTRLANZ, NZPI

5 *** STRATEGY U (2, LG/72

THIS IS STRATEGY DESCRIBED IN REPORT

5 *** JHE 0 -JH ELEMENL OF AN ARRAY IMMEDI ATEL T PRECEDES IHE ISI ELEMENT

C * ** INTEGRAL APPROX. US INE TRAPEZOI DAL RULE.

C * CONSIDERING ONLY ERRORS DUE TO USING A RESTRICTED SET OF EAS.

C *** BLEEST. OF CUMULATIUE LOSSES OUT BACK OF SYSTEY OF ACTIUE EOS..

5 *** BL = NTEGRAL FROM TSTARY TO I OF NE*I(K)*Y (K) WHERE L(NZ+1)=O

C *** FL=EST. OF CUMULATIUE LOSSES OUT FRONT OF $5 Y S T E M$ DF ACT IUE EOS.:

$C$ *** FL=INTEGRAL FROM TSTARI IO T OF NE*R $(L-1) * Y(L)$ WHERE R(O)=0

$C$ XXK DC=CUMULATIUE SUM OF ALL COMPONENTS DELETED IN TIME TNTEGRATION -

C $* * *$ FROM TSTART TO T

C *** COMPUTED COMPONENTS ARE HIGH BY AT ROST $F L+B L$ AND LOW BY AT MOST

C *** FL+BL+DC

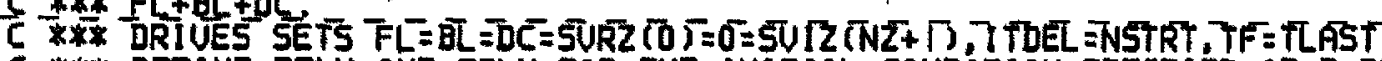

C *** DEF LNE TFLN AND TELN FOR IHE INIT IAL CONDITION SPECF]ED AL IETS.

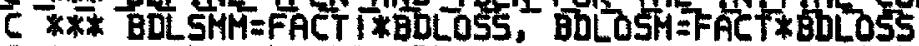

C *** TE, DEN $=$ TEMPERATURE AND DENSITY FOR TIME T

$C$ *** NZPI $=N Z+1$ WHERE NZ=MAX. CHAREE STATE FOR ELEMENT,

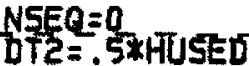

IF(NLEO I) EO TO 400

TFLOE=TFLN

TFLN=DEN*SURZ (NL-1)*Y(NL)

$F L=F L+D T C *(T F L O+T F L N)$

$400 J$ JEQ $=T B L N$

TELN=DEN*SU Z (NKT) FY (NK)

$B L=B L+D T Z *(T B L O+T B L N)$

$T F M T=T F-T$

TRMN $=$ TFLN + TBLN

$E R R=F L+B L+D C$

IF (T, GT. TSHIT) GO TO 401

IF (TRMNE( TSWIT-T) .LE. BDLSMA-ERR厂 LO To TOO

GO TO 402

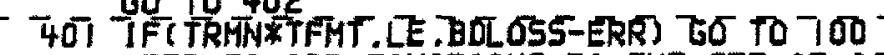

$C$ *** NEED TO ADD EOUATTIONS TO THE SET OF ACTIUE EQUATIONS.

402 NSEO $=1$

$N L M I=N L-1$

Go To $150 \%, 505,500,50 \Gamma, 7 P 5 T$ TY

500 WRI TE (LOUT, 299)

299 FORMATC ADO EOS. TSTRATES I

HRI TE (LQUT, 300) IT, NLMI, NK, T, HUSED, FL, BL, DC, TFLN, TQLN

300 FORHATC

$19 \times, 1 T=14$

$13,5,2 X^{\prime} H U S E D=' E 13,5$, ZX' $F L='$ 'EI3,5\%

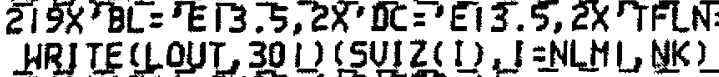

301 FORTAT SUTZ

HRITE(LOUT, 311$)(5 U R Z(1), I=N L M I, N K)$

311 FORHAT ' SURZ 'IPISE . 1
STRATG ?

STRATO

STRATG

STRATE 5

STRATG

STRATG

STRATS 5

STRATGIO

STRATGI

STRATGI2

STRATG।

STRATG 4

STRATGIS

STRATGI6

STRATGIT

STRATGIQ

STRÁTGIS

STRATGZO

STRATLC

STRATGZ2

STRATG24

STRATtCZS

STRATG26

STRATLZ

STRATG29

STRATLES

STRATG 30

STRATOSI

STRATG32

STRATLSS

STRATG 34

STRATO 35

STRATU36

STRATG3?

STRATG 38

5TRATU 35

STRATG40

STRATG4

STRATG42

STRATE4

STRATG 44

STRATO45

STRATG 46

5TRAT 447

STRATG4B

STRATG45

STRATG50

ISTRATGST

STRATG52

STRATG5

STRATG54

5TRATG5 5

STRATGSG

STRATEST 
HRI CE (LQUL 302) (YU) L LN NKL)

$30 \overline{2}$ FORMAT: Y Y IPIOE 12,4$)$

50L IF (TFLN,GI,TBLN) 50 IO 102

C *** ADD EOS, TO BACK, BUT IST SEE IF CAN DELETE FROH FRONT.

STRATG5:

PATEE 58

IF(UCNL GT BDDEL) GO 'JQ LOZ

5 I*ะ EUHIMATE EQ

SUM $=0$.

104 SUN $=5 U M+Y(N L)$

$Y(N L)=0$.

$M L=N L+1$

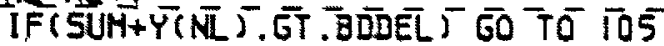

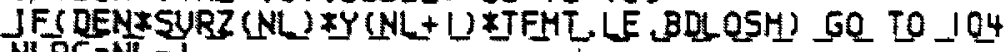

STRATG6O

STRATG6I

STRATG62

STRATG63

STRATG64

STRATE65

STRATE6E

STRRTG6

STRATG68

STRATU69

NLRC $=N L-1$

STRATG70

$\mathrm{NLPI}=\mathrm{NL}+1$

STRATEY

$D C=D C+5 U M$

STRATG72

STRATET3

103 KQL $=$ NKRL

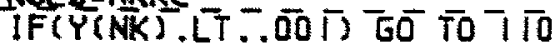

$N K=N K+1$

GO TO II

110 NK=HINO (NK+NEOADD, NZP I)

$111 \quad$ NKRC $=$ HINO $(N K, N Z)$

STRATE74

STRATG76

STRATGY

STRATG78

STRATG79

CALL SUIONZ (SUIZ, TE,DEN) _ _ . $\ldots \ldots \ldots$

CRLL SURECZ (SURZ, TE, DEN)

STRATEBI

JF(KOLD EQ NKRC) GO IQ 106

$K 5=K O L D+1$

107 IF(SUIZ(KS).LT,RDECKSUIZ(KOLD)) to To 108 KS=KS+1

JF(KS L L NKRC) EO TO 102

106 NKMI $=N K-1$
GO TO 109

100 NKMH $=$ KS

NKRC $=K 5$

NK= KS

Co TO 109

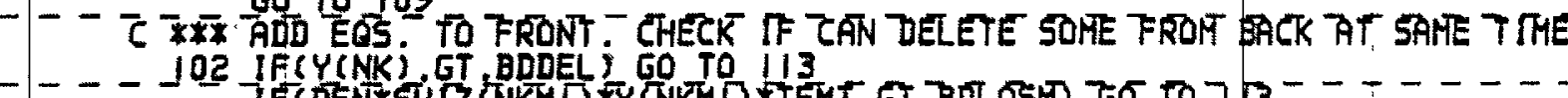

STRATGB?

STRATGB3

STRATGE 4

STRATLS5

5TRATGB 6

STRATGET

STRATGB

STRATGES

STRATG90

STRATGश

STRATG92

C $\times * *$ ELIMINATE EQ. K. SUH $=0$.

114 S4H $=5 U M+Y(N K)$

$Y(N K)=0$.

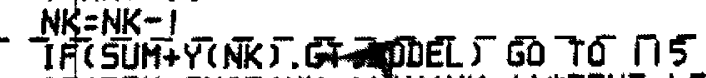

IF (DENXSUIZ (NK-1) KY (NK-1) *TFMT.LE. BDLOSM) GO TO TX4

115 NKRC =NK

$N K M I=N K-1$

$D C=\overline{D E}+S U M$

113 LOLD=NLRC

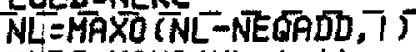

NLRC $=$ MAXO $(N L-1,1)$

CALL SUIONZ (SUT2, TE, DEN)

TTRAT693

STRATG94

STRATG95

STRATG96

STRATG97

STRATG98

STRATG9S

STRATG 0

STRATG

STRATG 2

STRATL 3

STRATG 4

STRATG 5

STRATG 6

STRATS T

STRATG 8

SALL SURECZ (SURZ, TE, DEN)

डTRATG 9

STRATGIO

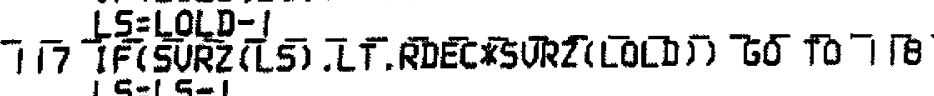
$L S=L 5-1$

IF(LS.GT. MLRC) GO TO 117

STRATG

STRATG 3

STRATG 14

STRATGI5 
$\ldots+\ldots 16$ NLPL $=N L+1$ GO TO 109

118 NLRC $=\angle 5$

$N L=L 5+1$

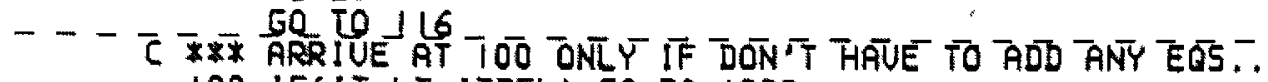

STRATGIG

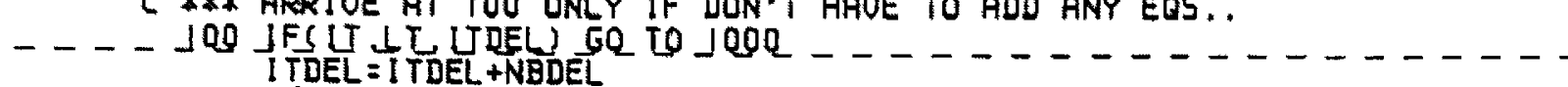
$N L M I=N L-1$

GO TO $(502,502,503,503)$, IPSTGY

503 HRJ TE(LOUL 290$)$

29Q FORHAT ( CHECK DEL. (STRATT)

HRI TE(LOUL 3OQ IL NLMI NK L HUSED, FL BL, DC IFLN, TBLN

HRI TE (LOUT, 301 ) (SUIZ(I), I =NLMI, NK)

WRITE (LOUT, 3| I) (SURZ $(1), I=N L M \mid$, NK)

HRI TE(LOUT, 302 ) ( $Y(1), I=N L, N K)$

5 TRATGI8

STRATUIS

STRATGZO

STRATEZI

STRATGZ2

STRATG23

STRATG24

STRATG25

STRATGZ6

STRATUZ7

STRATGZB

STRATگZ

STRATG30

F** CHECK JQ SEE IF CAN DELETE NEQDEL EQS \& FROH FRONT OF_ ACIIUE SYS -

$5025 \mathrm{SUM}=0$.

$\frac{L}{D O}=\frac{N L}{20}+N E O D M L, L$

200 SUM $=$ SUM + Y(1)

IF(SUM.GT.BDDEL) 60 TO 209

STRATL31

STRATG32

STRATG3

STRATG 34

STRATG

STRATG36

ZRM =DEN*SURZ (LS) *Y(LS+1)

- - - - - TFE ZRMKTFMT. GT. BDLOSM) GO TO $\overline{C O}$

STRATG37

$S$ \&** SET DELETED COMPONENTS $=0 . \ldots \ldots$

$201 Y(1)=0$

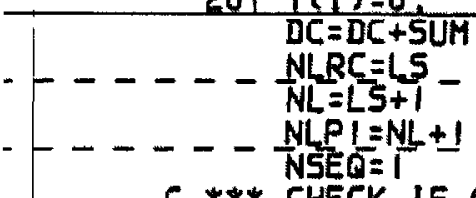

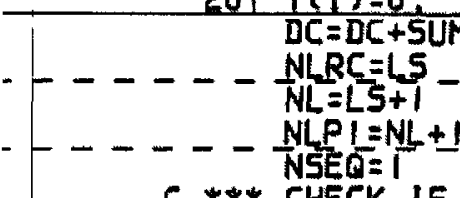

STRATG 38

STRATEZS

$C * * *$ CHECK IF CAN DELETE NEQDEL EQS. FROM BACK OF CURRENT SET,
209 SUM=0.

STRATG40

STRATE4

STRATG 42

STRATG43

STRATG44

STRATG45

STRATG46

LS=NK-NEODM!

$D 0^{-} 210^{-} \quad i=L 5, N K$

210 SUM $=5 U M+Y(1)$

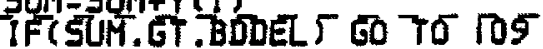

ZRM $=$ DEN $* S U I Z(L S-1) * Y(L S-1)$

IF(ZRMXTFHT. GT. BDLOSH) GO TO TOS

STRATG47

STRATG4E

STRATG4S

STRATG5O

STRATES

STRATG5Z

STRATG53

STRATG54

Do $202 \quad I=L 5$, NK

$\overline{202}$

(I) $=0$.

NSEQ $=1$

$\overline{D C}=\overline{D C}+5 \mathrm{UM}$

$N K=L 5-1$

NKRC $=$ NK

NKMI $=$ NK -1

STRATG55

STRATG56

STRATG57

STRATG5B

STRATE5S

STRATG 60

STRATGE

STRATG62

STRATG63

TO9 CONTINUE

STRATG 64

CONTINUE

IF(NSEO .EQ .0$) 7 \sigma$ T0 $100 \overline{1}$

STRATG65

C *** SET OF ACTIUE EQS.. ALTERED.

STRATG 66 JSTART $=0$

STRATG67

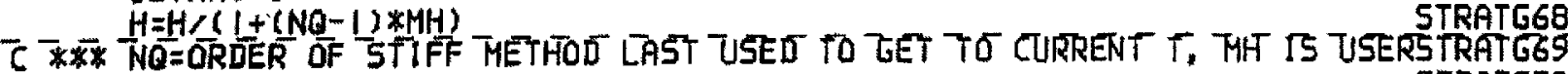

STRATG 68

C *** DEF INED

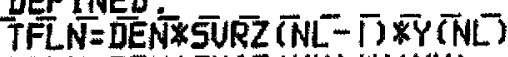

TBLN $=D E N * S U 1 Z(N K) \times Y(N K)$

TOOI RETURN

STRATG70

STRATG

STRATG72

STRATL73 


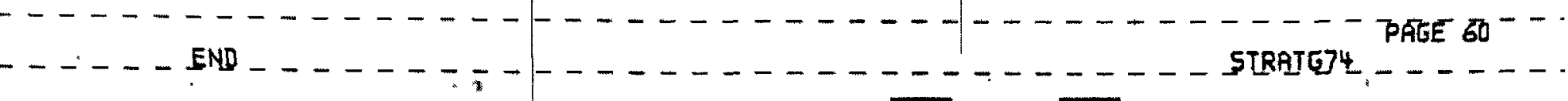

$1 P_{4}$

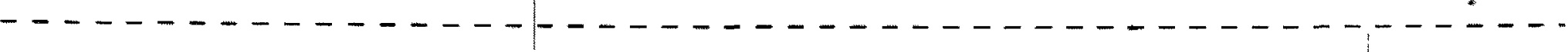

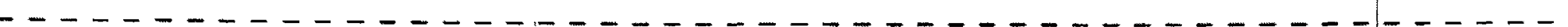

- - - - - - - - - - - - - - - - - - - - - - - - - - - - -

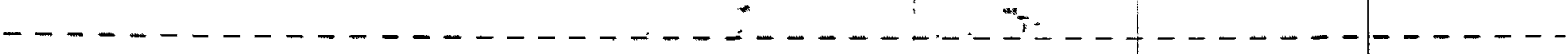

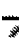

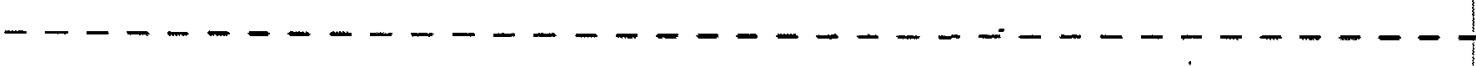

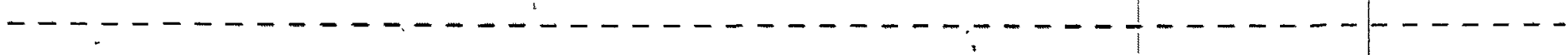

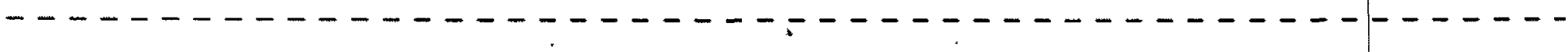

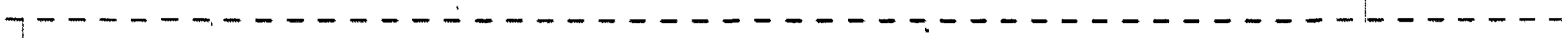

$:$

f- - - - - - - - - - - - - - - - - - - - - - - - - - - - - - - - - - - - - - - - - -

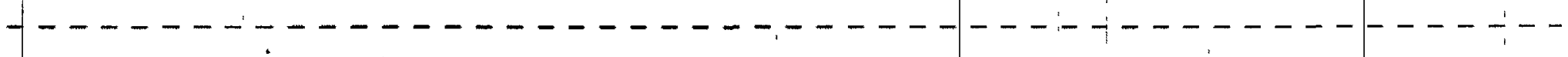

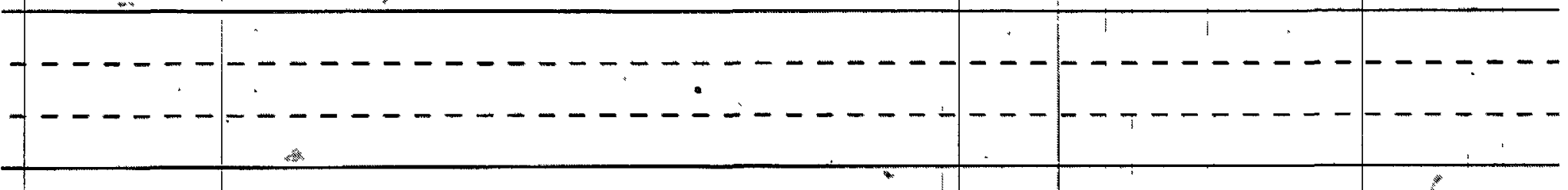

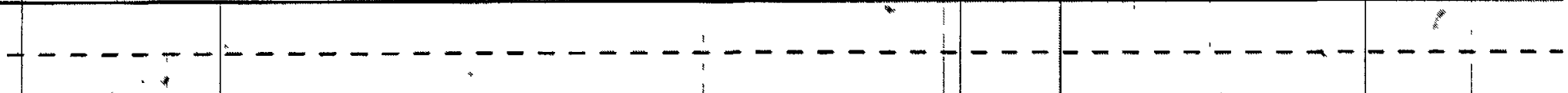

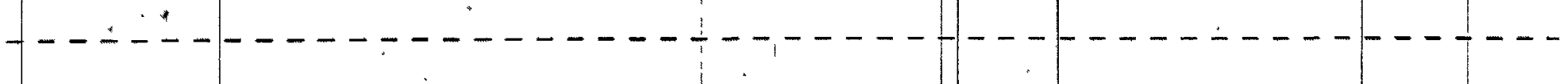

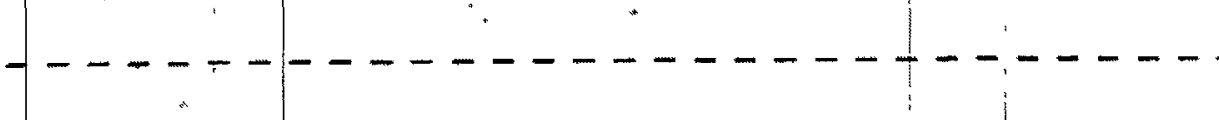

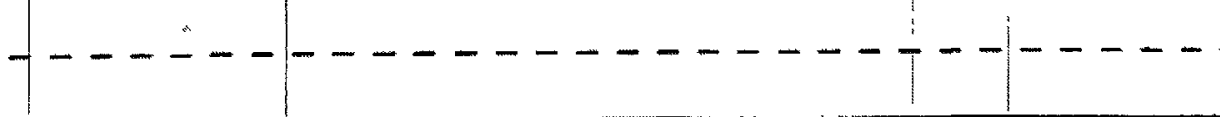

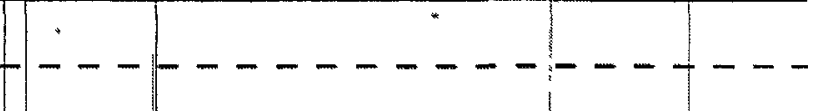

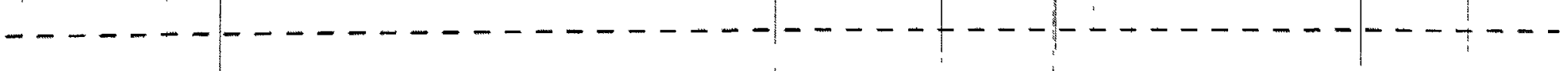

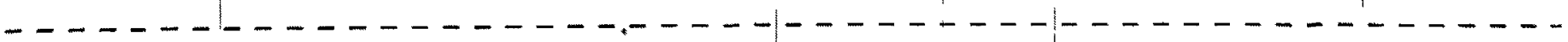

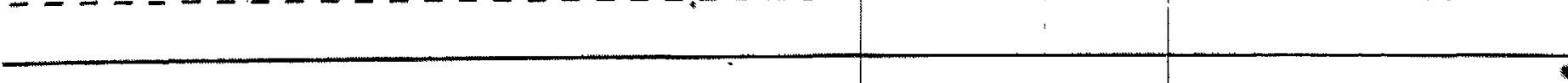

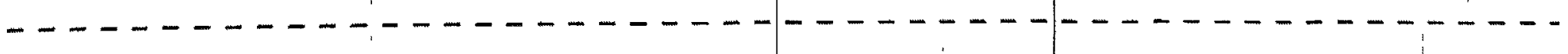





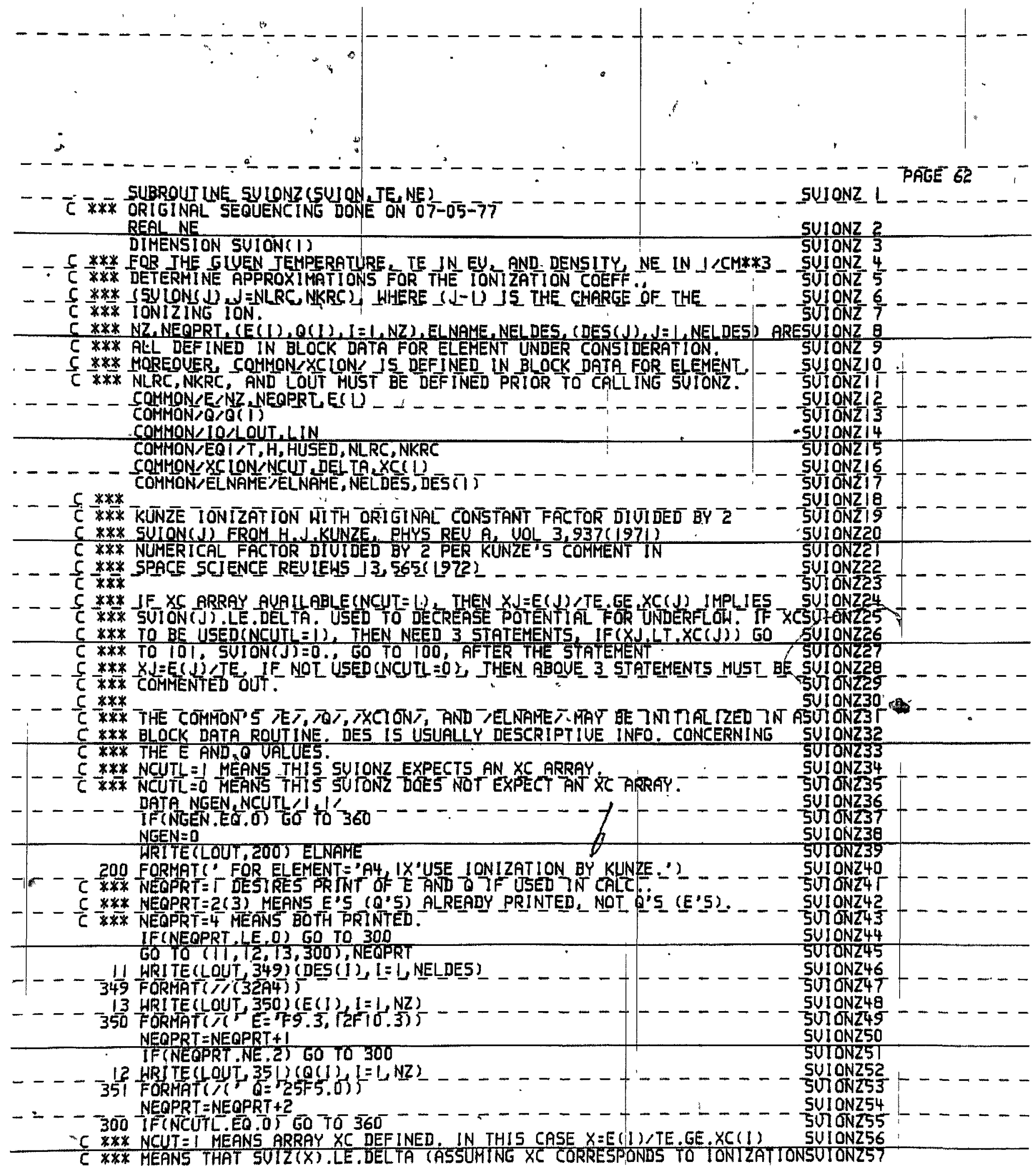

C X*K MEANS THAT SUIZ $(X)$.LE.DELTA (ASSUMING XC CORRESPONDS TO IONIZATIONSUIONZS7 


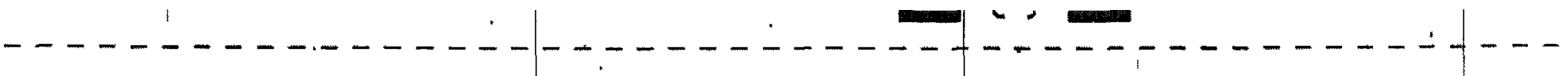

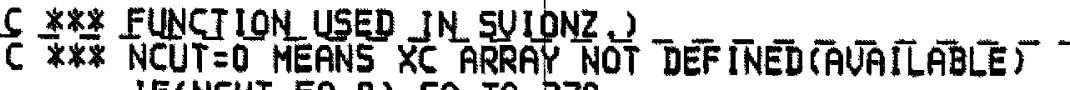
IF (NCUT $E Q$ O) 60 TO 370

IF(NEQPRT.GT.0) HRITECLOUT, 352) DELTA, $(X C(1), 1=1$, NZ)

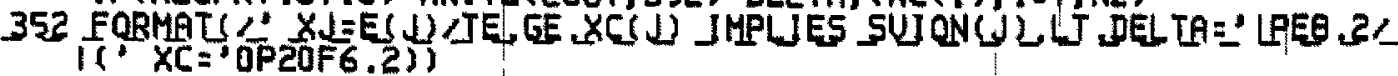

360 DQ 100 JENLRC N NKRC

$X J=E(J)<T E$

IF $(X, 1, L, x[(J))$ G0 TO 101

$5010 N(J)=0$.

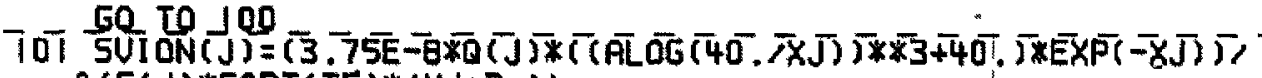

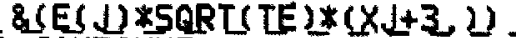

100 CONTINUE

380 RETURN

370 HRITE(LOUT, 353 )

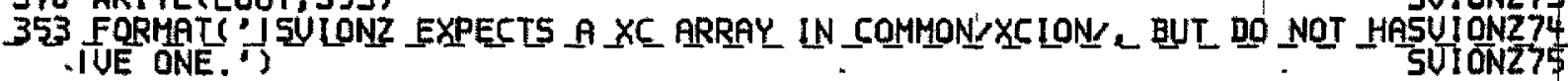
IUE ONE T

GAL TO EXUT END 


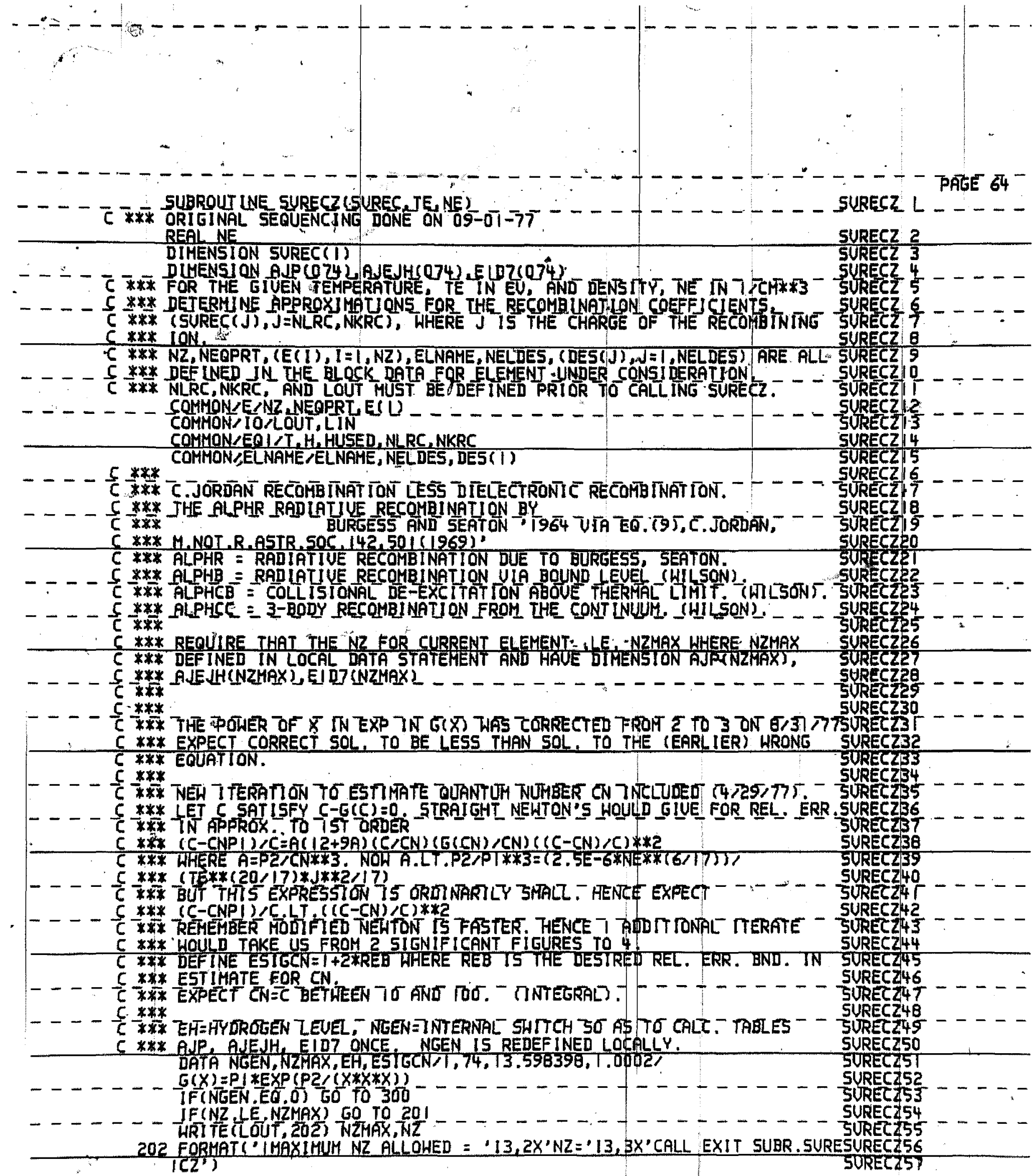




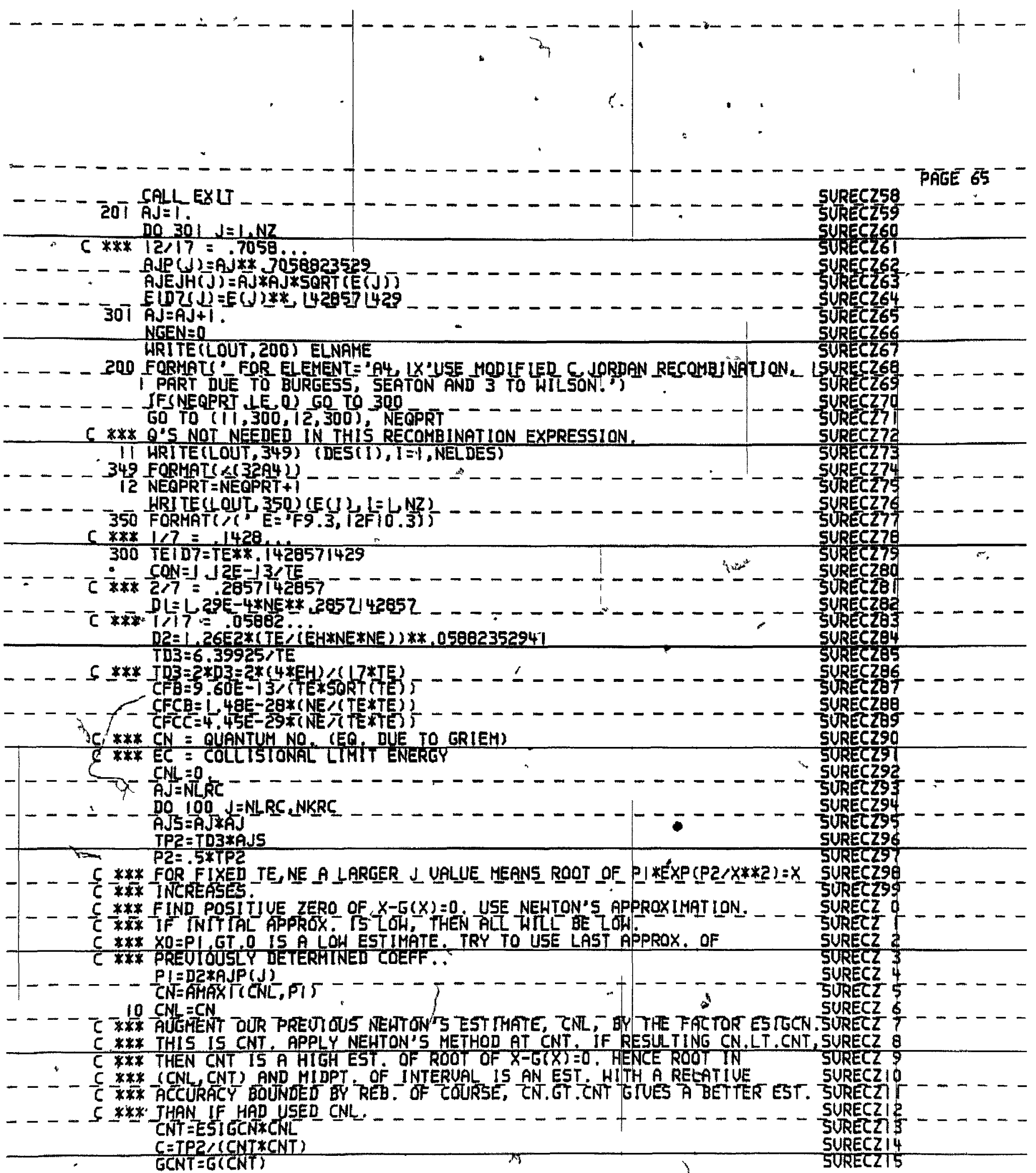
$G C N T=G(C N T)$

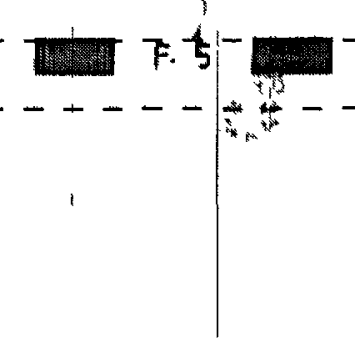




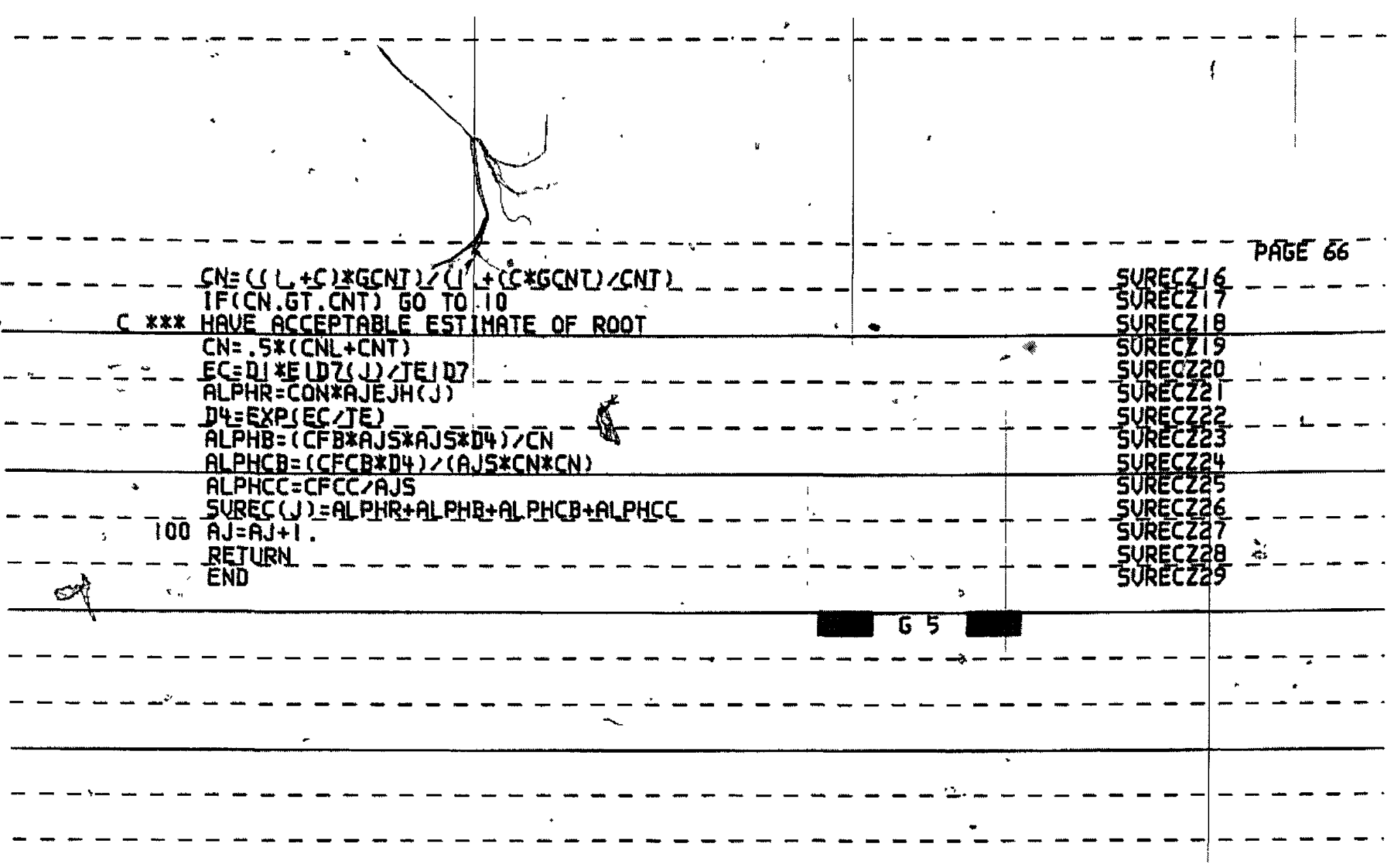

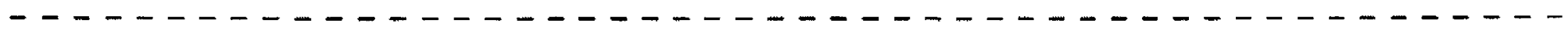

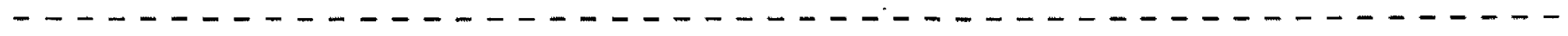
0

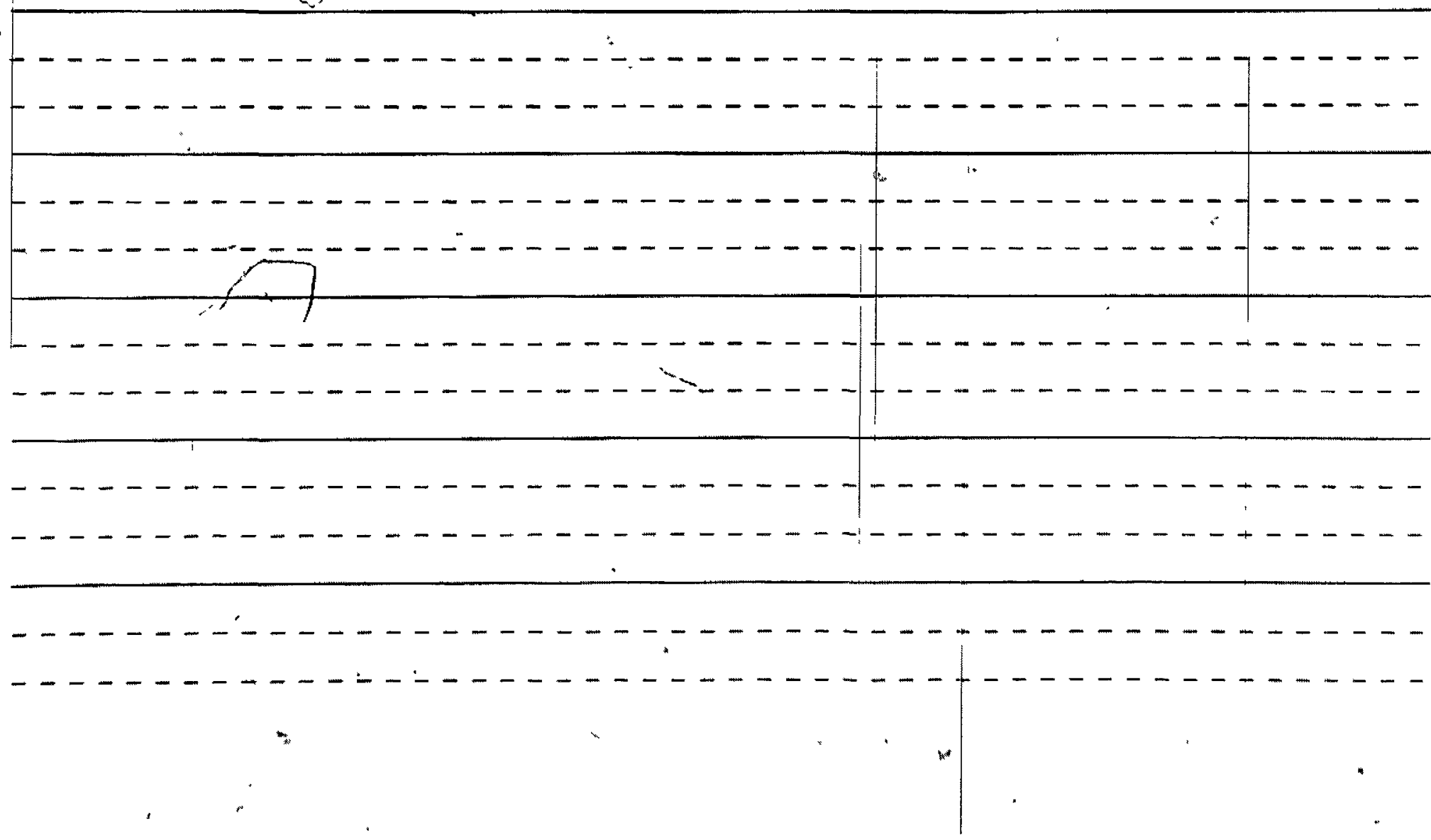




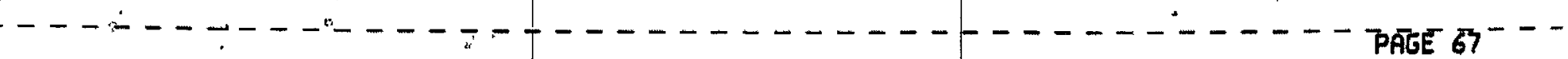

$\bar{C}$ ₹.F SURROUT LWE ZRUERG (ZRUE Y)

ORIGINAL SEOUENCING DONE ON $\overline{0} \overline{6}-\overline{0 B}-\overline{7} 7$

ZRUERG L $\ldots . . .-$

*** FORH THE AUERAGE $Z$ USING ONLY THE ACTIUE COMPONENTS NL. THRU NK DIMENSION $Y(1)$

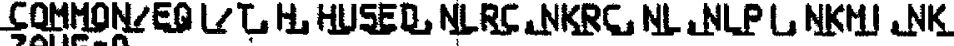

$2 A \cup 5=0$

AKHL $=\mathrm{NL}-\mathrm{J}$

$D O$ TOO $K=N \bar{L}, \overline{N K}$

ZAUG $=Z$ AUE $+A K M I K Y(K)$

700 AKMI $=$ AKH +1 .

RETURN

END
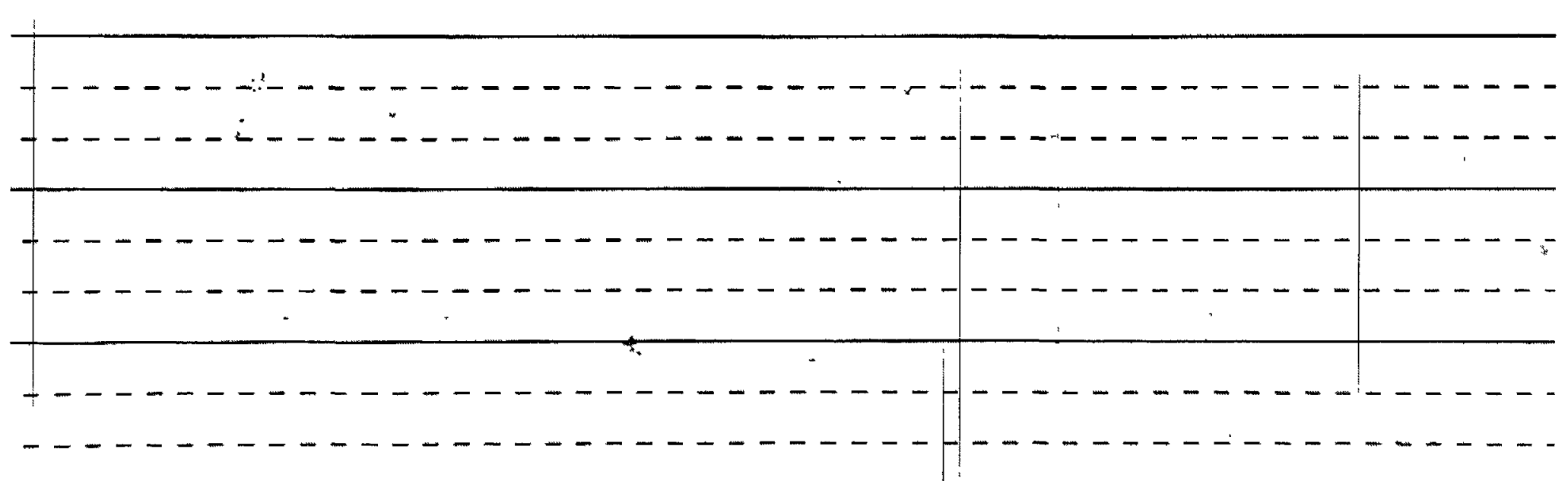


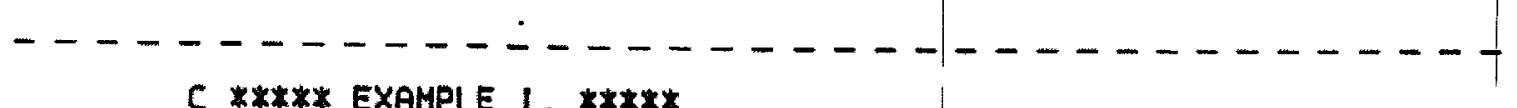

- - - - EXAMPLE ]- PAGE

C *** INEX I THE. TERT AND DEN. ARE T TME INDEPENDENT WI TH UALUES -

*** TE=5OOEU AND NE=DENEI E I3/CH*X3. IN EX I PROGTI IS USED TO FIND

Ex.t $-\frac{1}{2}$

*** (I) THE NORMALIZED, CHARGE-STATE, DISTRIBUTION UECTOR, (II) APPROXEX. 4

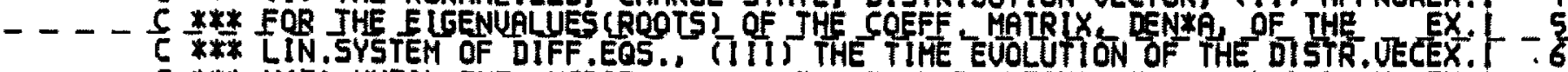

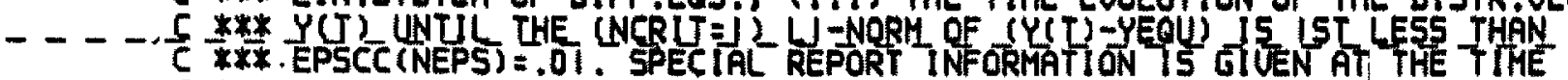

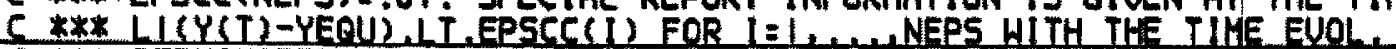

$C$ *** TERMINATED WHEN INEQ. HITH I INEPS IS IST SATISFIED. MOREOUER,

5 *** OTHER GENERAL REPORT UIMES RRE GIUEN THRU JHE ARRAYS TPRNL DTPRT

EX:-

C X** AND NPRNT AND THE URRIABLE NPRNTI THE GEN. REPORT INFORHAT ION AT EX

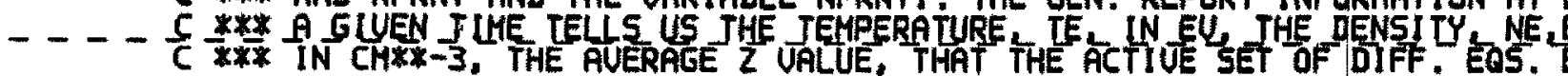

C X*X IN CMXX-3, THE RUERAGE Z UALUE, THAT THE ACTIUE SET OF DIFF EO EO

C N** PERFORMED TO ARRIUE AT THIS TIHE, THAT THE CURRENT OREER OF THE

5 X* SUFF J TEKRATION METHOD I5 NO THAT THE LAST STEPSIZE HAS HCSEC EX.

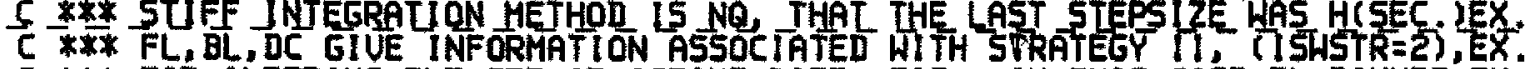

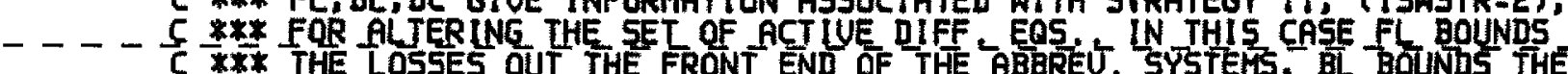

C $X \times *$ LOSSES OUT BACK END, AND DC BOLNADS SUM OF ALL COMPDNENTS DELETED

$C$ XFX FROM THE FRONT OR. THE BACK.

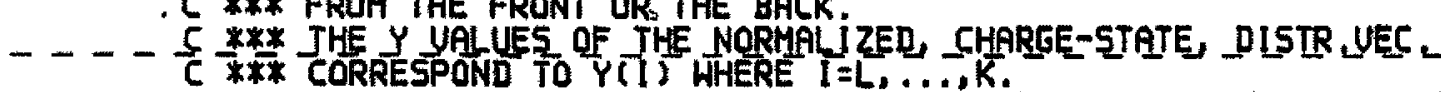

- - - 5 *** BELOH HE HAUE JHE BLOCK DATA BDPRAM FOR THIS EXAMPLE BUT

C *** HHE GENERAL PROGRAM USTINGS FOR THE DEFINITION OF THE UARIABLES

C *** THE GENERAL PROGRAM L 15

- - - - C $\frac{\text { *** }}{* * *}$ THE CPU TIME REGUIRED T6 RUN EXAMFLE $\Gamma$ ON THE 7 BN $36079 \Gamma$ AT DRNL

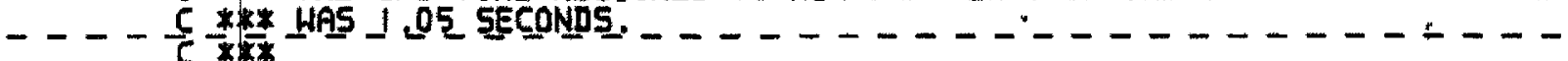

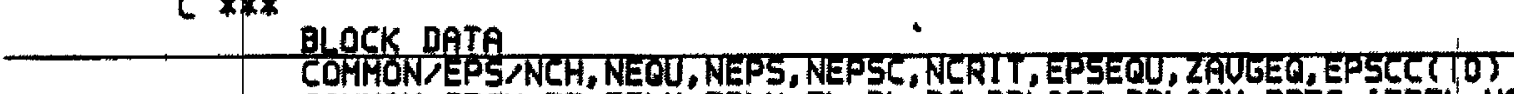

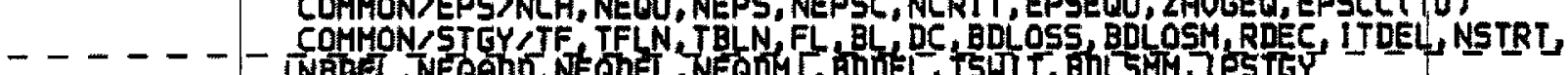

- - - - - - COMMON POR INT,TPRINT, TPRNT (5), DTPRT (5), NPRNT (5), NPRNTI, IPRNT I NPR COHHON 5 TRAT, IT

COHMON MAINBOJNTEFP, NUEENS, NLOG, NROOT'S, IPATR, TSTART, TLAST, TEL, DTE,

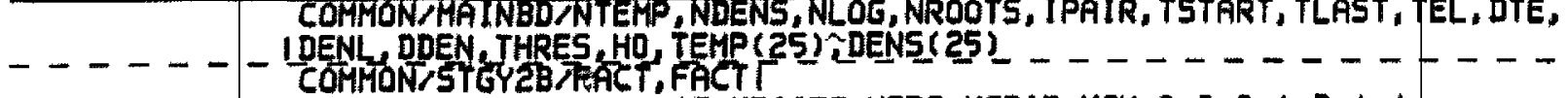

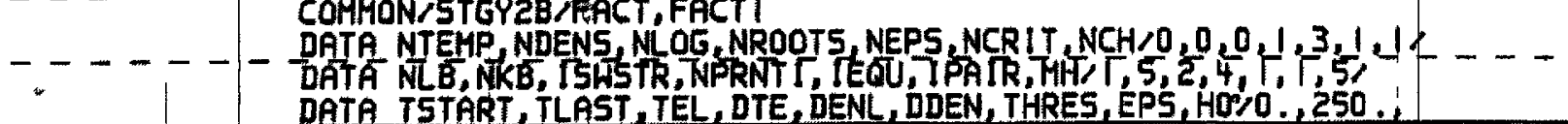

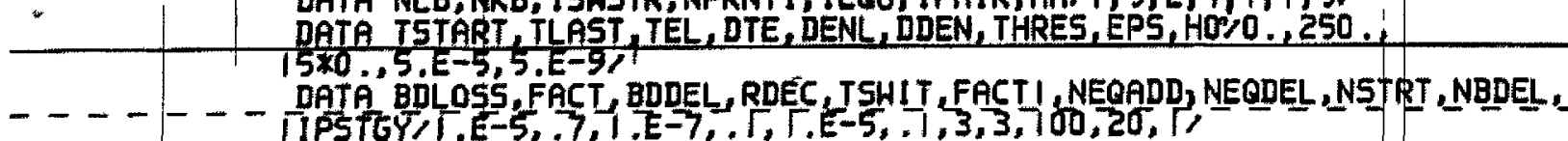

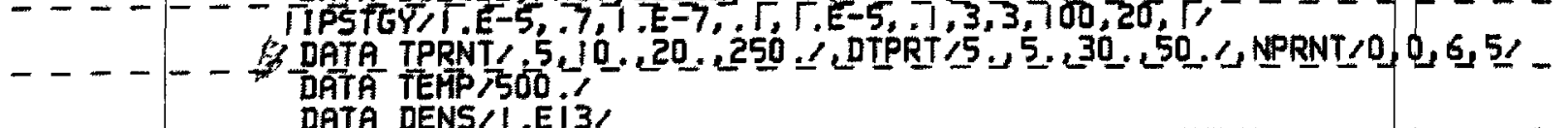
DATA DENS I.EI3,

DATA EPSCC $.5, .1, .01 /$

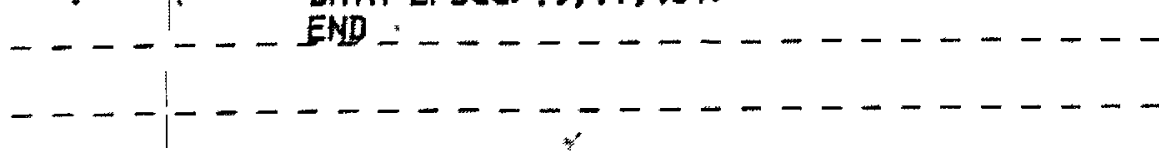


WVTEE PARHS L TSTART (MS) $=0$,

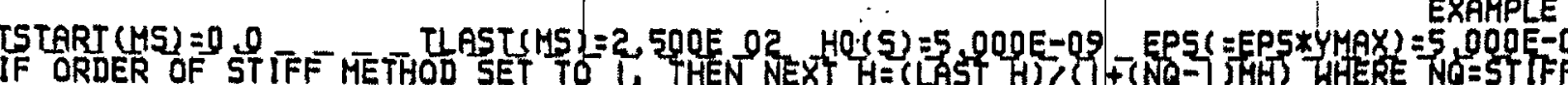

PACE - 2

STRATEGY II FOR ALTERING SET OF ACTIUE EQUATIONS (2/18/77)

- DESIRER BOUND. FOR ERROR DUE TO AL TERLWE SEL OF DLFF EQS =BDLOSS I OE-05

IN THE TIHE INTERUAL CTE AT ONCE TO BE LE. BDDEL= T.OE-OT

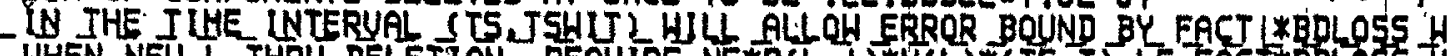

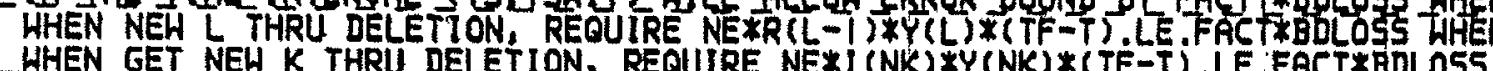

HILL ADD EQS. IN GROUPS OF AT MOST NEQADD 3 EOS.

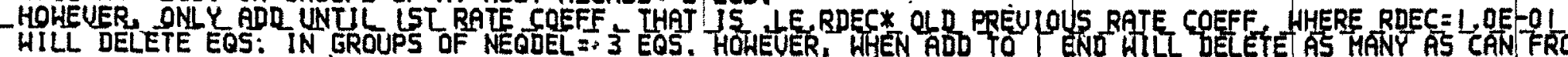

HIL

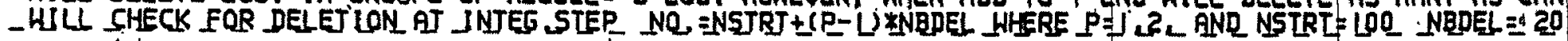

CALL YNA ÉT TSHS) = (TPRNT (1)+QEDTPRT(1)), $0=0$ TO NPRNT $(1), 1=1$ TO NPRNTI,

I TPRNT DTPRT NPRNT

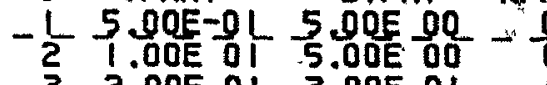

$-\frac{3}{4} \frac{2}{2} .50 E$ OL $\frac{3}{5.00 E}$ OL $-\frac{6}{5}-$

- INTEGRAT LON CONURG MEANS U -FOR ELEMENTEEE - YSE JONIZAT LON BY KUNZE.

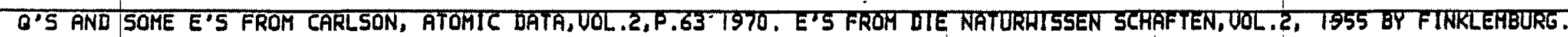

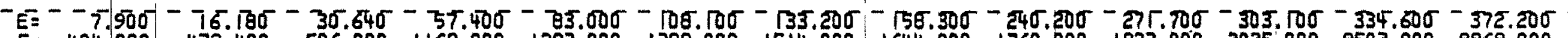

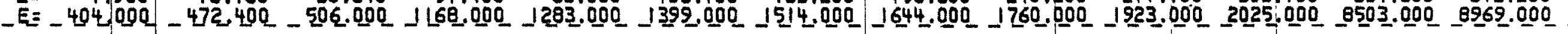

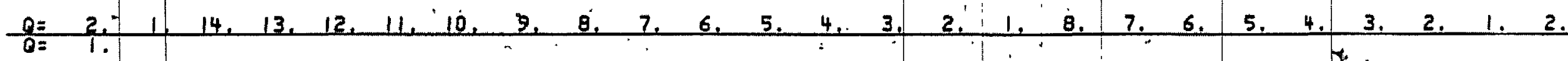

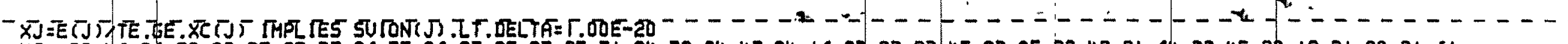

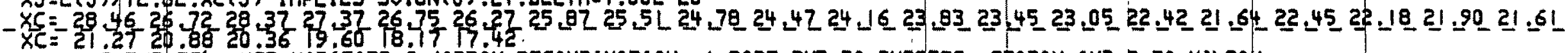
FOR ELEMENTEFE USE MODIFIED C.JORDAN RECOMBINATION, I PART DUE TO BUREESS, SEATON AND 3 TO WILSON.

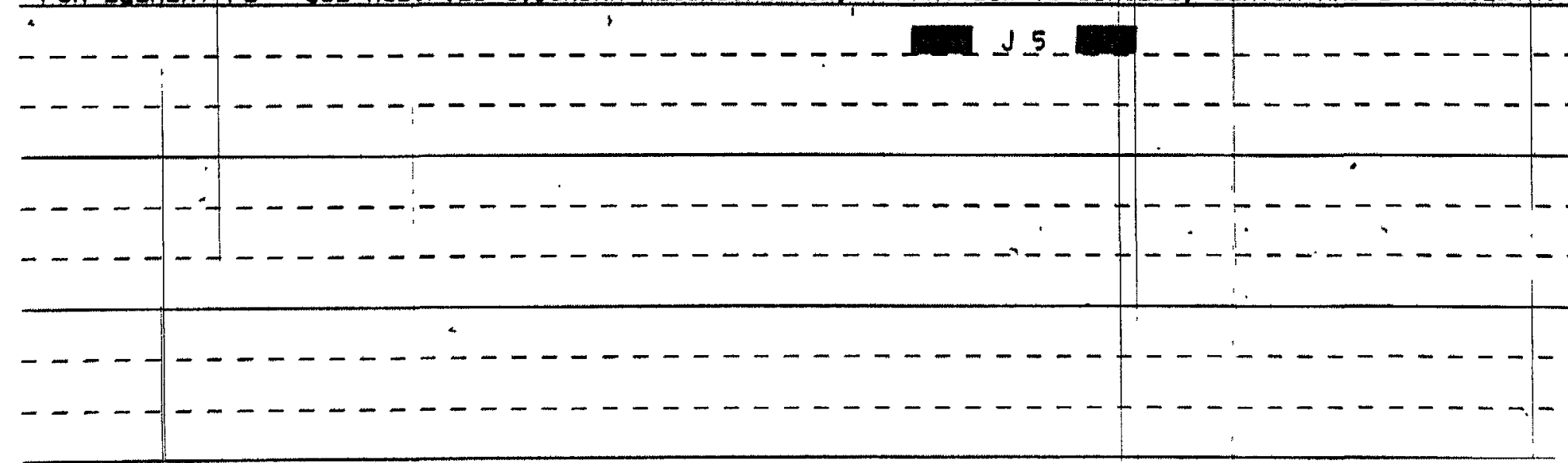


EXARPLE 7- PAGE

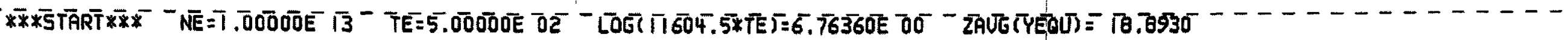

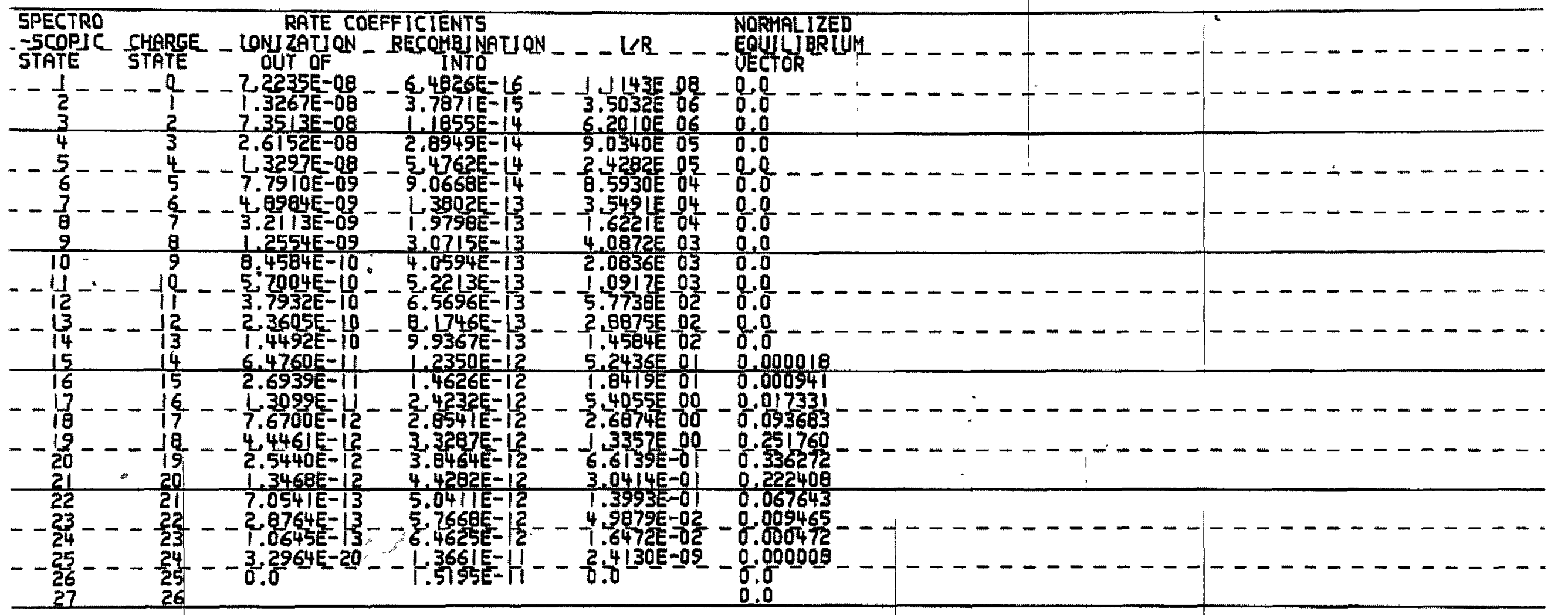

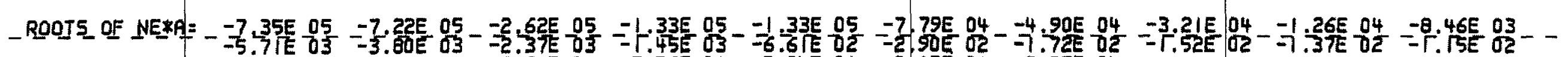

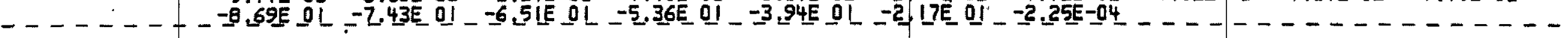
THE EXPONENT IAL ASSOCIATED HITH THE NEXT TO LAST ROOT =.1 AT TIME T(5)=1, IE-0I

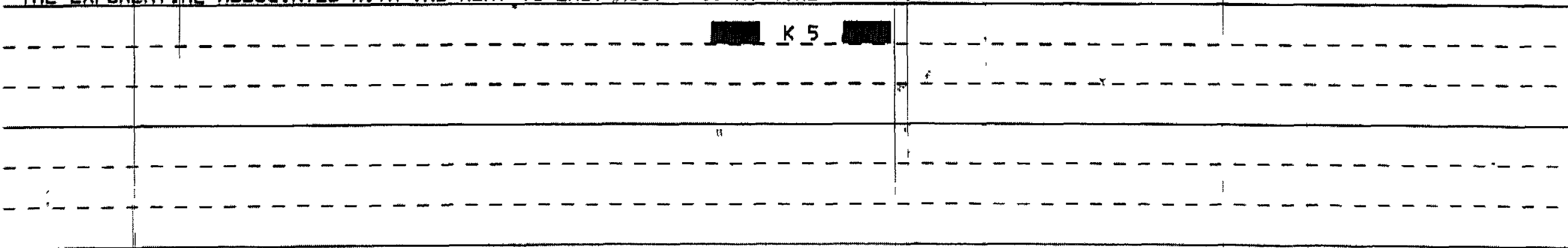


EXPAPLET - - PAGE $-\overline{4}$

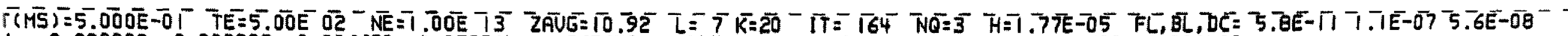
$=\begin{array}{lllllllllll}0.000000 & 0.000002 & 0.006620 & 0.079214 & 0.267632 & 0.357114 & 0.216705 & 0.061713 & 0.008528 & 0.000429\end{array}$

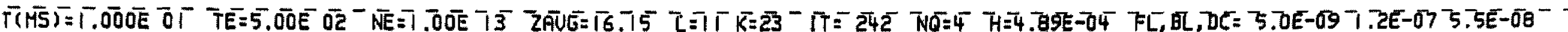

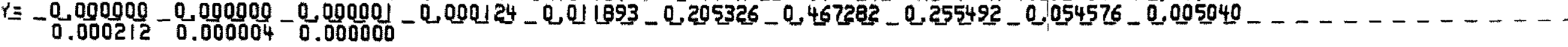

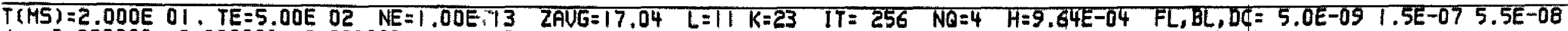

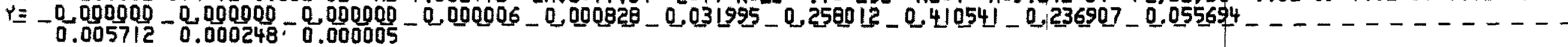

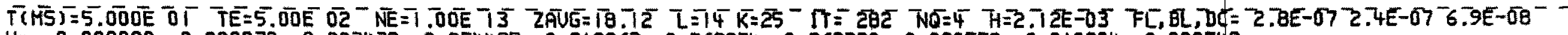
$Y=0.000000 \quad 0.000070 \quad 0.003438 \quad 0.054485 \quad 0.210963 \quad 0.369274 \quad 0.262390 \quad 0.080558 \quad 0.010204 \quad 0.000549$ $0.000010 \quad 0.000000$

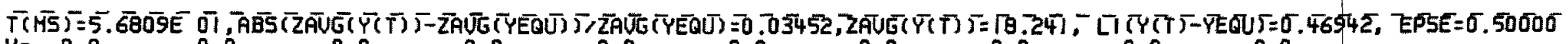

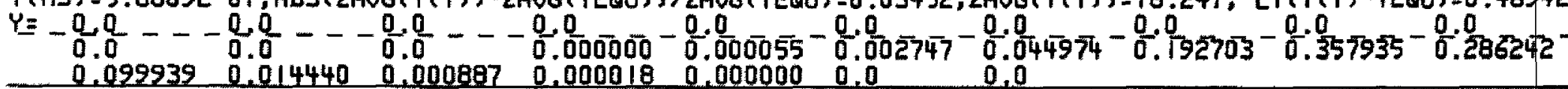

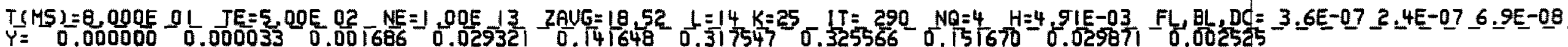
$-000072-000000$

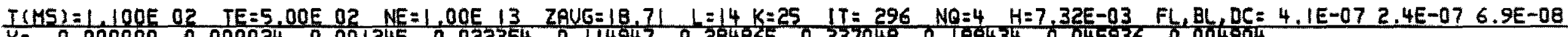
$Y=\begin{array}{llllllllllllll} & 0.000000 & 0.000024 & 0.001245 & 0.022354 & 0.114947 & 0.264865 & 0.337048 & 0.168434 & 0.045936 & 0.004904\end{array}$

$-0,00072$ - Q 000002

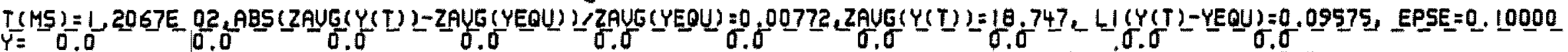

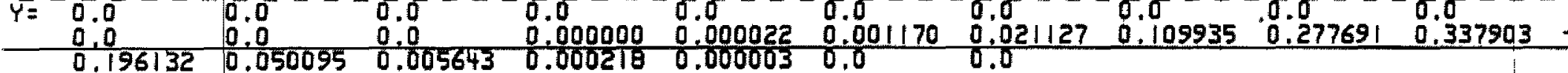

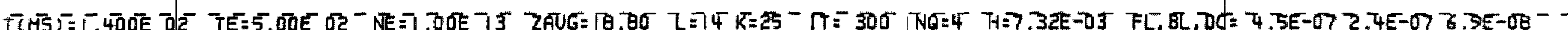

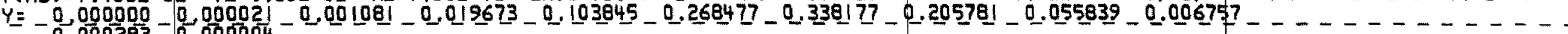
$0.000283-0.000004$

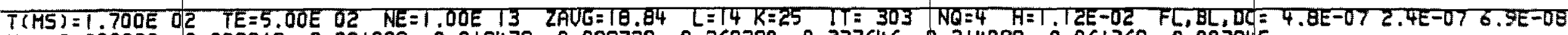
$y=-0.000000-0.000019-0.001009-0.018479-0.098728-0.260290-0.337646-0.214088-0.061368-0.007945$ $0.000360-0.000005$

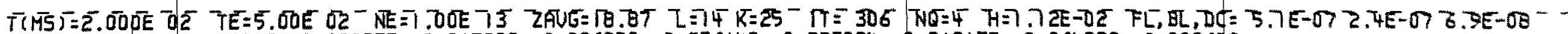

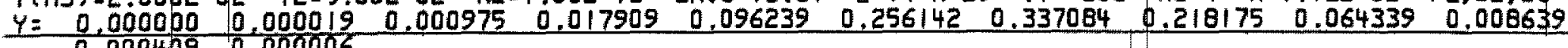
0.0004090 .000006

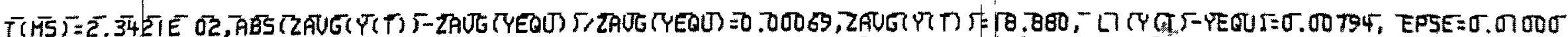

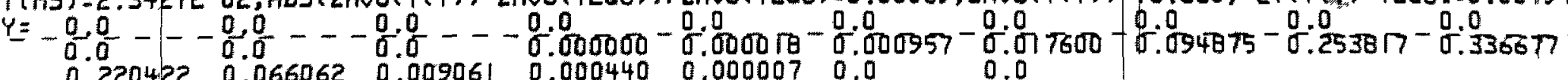


5 ***** EXAMPLE II ******

C *** IN EX.II THE FUNCTIONS TE AND DENENE UARY WTTH TI TE. PROETD 75

C *** USED TO DESCRIDE THE TIME EUOLUTION OF THE NORMAL IZED, CHAREE-

C *** 5TATE, DISTRIBUTION VECTOR, SEE EX. I DESCRIPTION FOR THE MEANIN

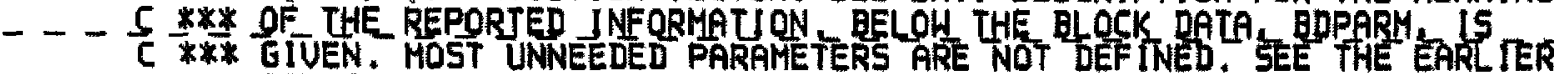

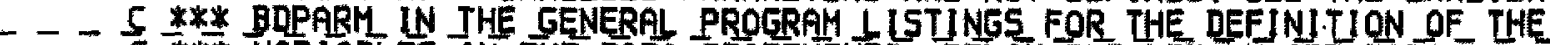
C *** UARIABLES IN THE DATA STATEMENTS. BELOH THE BDPARM ARE DATA

$C$ *** STATEMENTS THAT GO IN SUBR. DTDATA TO REPLACE CARDS DTDATASI THRU

6 *** DTDATA70.

- - - 5 XXX JHE SPU J LME REQULRED JQ RUN EXAHPLE U DN IHE LBM 36019I AT ORNL *** WAS 1.44 SECONDS.

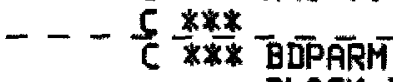

\section{BLOCK DATA}

COMHON/EPS/NCH, NEOU, NEPS, NEPSC, NCRI T, EPSEQU, ZAUGEQ, EPSCC C IO

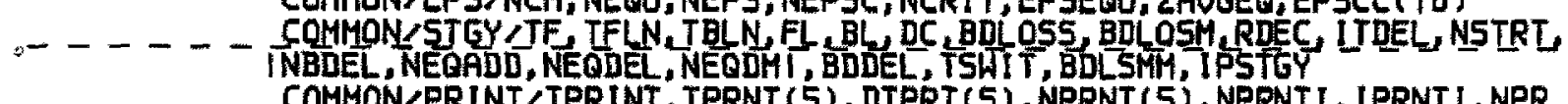

- - - - C COMMON COMHON/STRAT/IT, NLB. NKB ISHSTR, IEQU, MH

COMMON/MAINED NTEMP, NOENS, NLOK, NROOTS, IPAIR, TSTART, TLAST, TEL, DTE, CONL DDEN THRES HO, TEMP (25), DENS (25)

LDENL DDEN THRES HO, TEMP

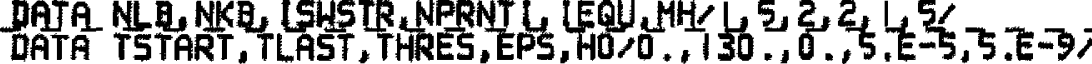

DATA BDLOSS FACT BDDEL RDEC TSHIT,FACT NEOAO NEODEL NSTRT NDDEL

IPSTGY $1 . E-5,7,1 . E-7,1,1, E-5,1,3,3,100,20,11$

- - - $\frac{C}{C} \frac{* * *}{* * *}$ DATA STATEMENTS THAT DO TNTO SUER.DTDATA.

DATA TR, DDT $/ 2,5,5,5,4,4,4,4,05,3,3,2,6,2.17$

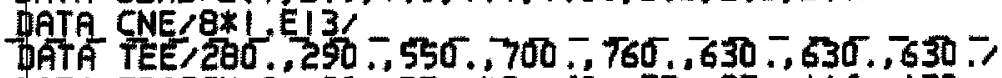
DATA TDISCH B

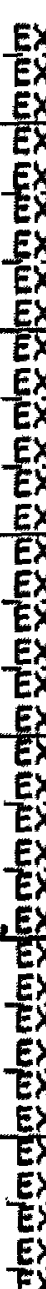

EXAPPLE IT PAEE 政 Ex.11 X.II Ex.II EX.H 13 EX.11 15 $x .116$ Ex. $\Pi$ Ex. II 19 (II 2 x. $\frac{2}{24}$

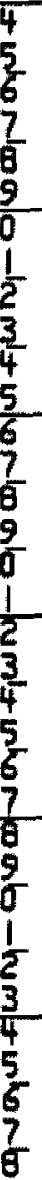




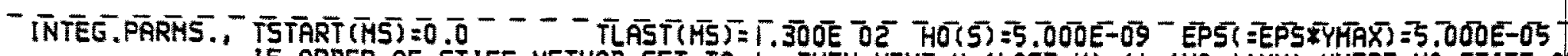
IF ORDER OF STIFF METHOD SET TO I. THEN NEXT HE(LAST H) $(1+(N O-1) M H)$ HHERE NOESTIFF ORDER LAST USED, MHE 5

\section{- STRBTEGY 1 L FOR ALTERING SET OF ACTIUE EOUATIONS $(2,18,77)$}

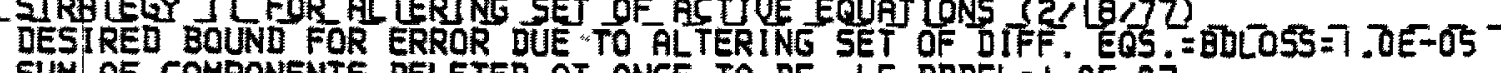

- SUM QF COMPONENTS DELETED AT ONCE TO BE LE BDDEL $=L$ LE 0 -0

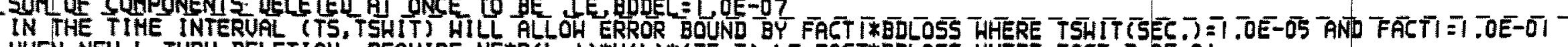

HHEN NEH L THRU DELETION, REOUIRE NEXR $(L-1) * Y(L) *(T F-T)$, LE, FACT*BDLOSS HHERE FACT=7,DE-01

WHEN GET NEH K THRU DELETION, REQUIRE NEXI(NK) XY(NK)*(TF-T).LE.FACTKEDLOSS.

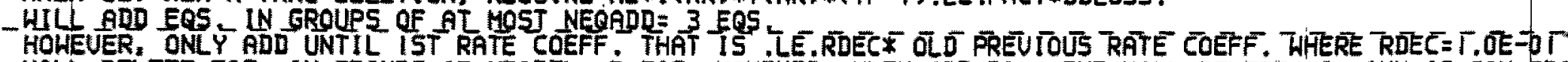

HILL DELEIE EQS. IN GROUPS OF NEODEL $=3$ EQS, HOWEUER WHEN ADD TO L END WILL DELETE AS MANY AS CAN FROM OTHER END HILL CHECK FOR DELETION AT INTEG.STEP NO. =NSTRT +(P-T) *NBDEL WHERE $P=1,2$, AND NSTRT=TOÓ NBDEL 20

\section{CALL YNA AT T(MS) $=$ (TPRNT(I)+QEDTPRT(I), $0=0$ TO NPRNT(I), $I=1$ TO NPRNTI.}

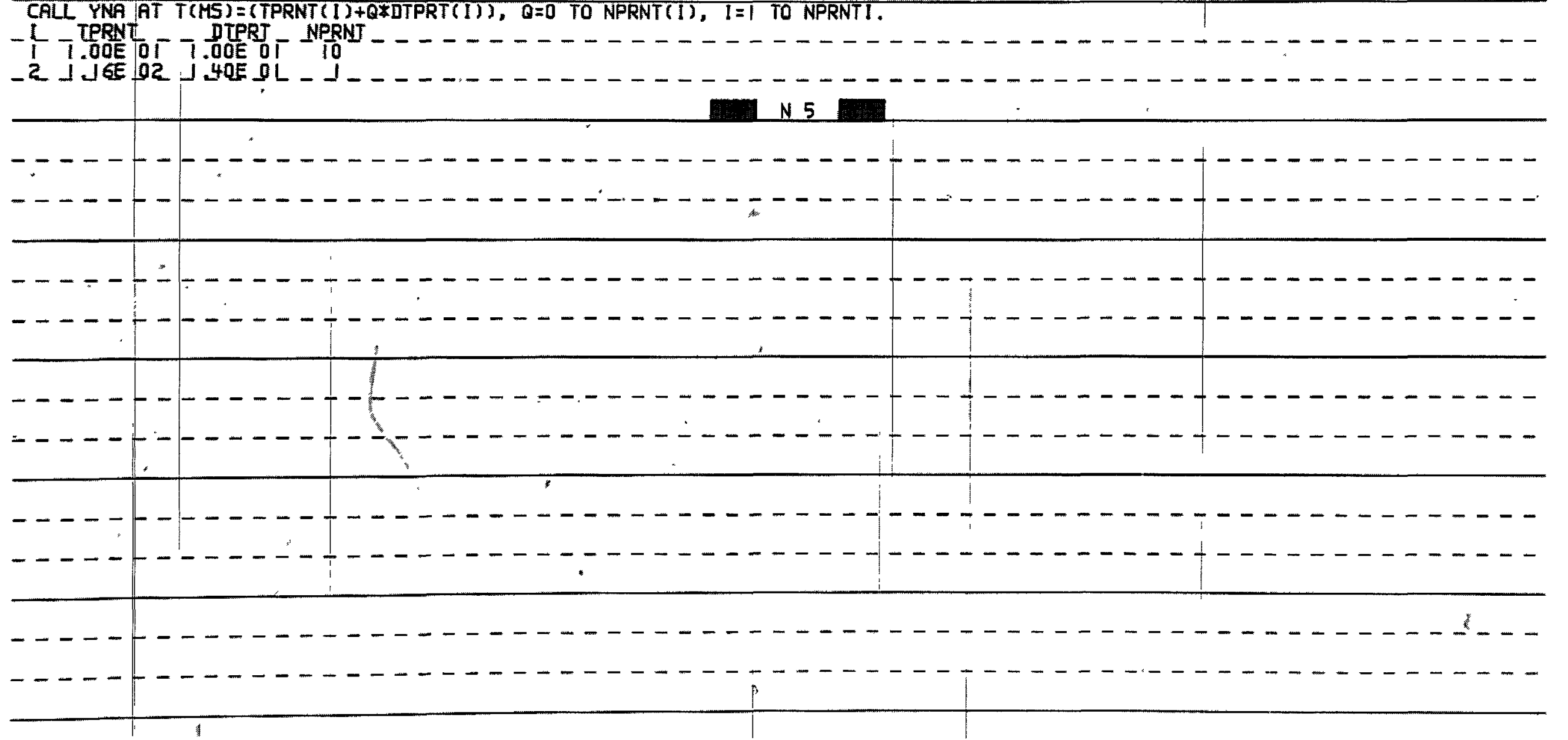




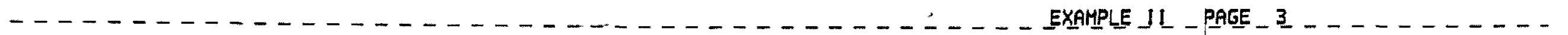

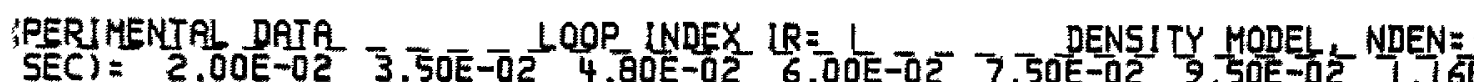
AN(T) $=2,70 E$ (3) $\frac{1}{(T)}=2.80 \mathrm{E}$ : $3.50 \mathrm{E}-02$ 4. $00 \mathrm{E}-02 \mathrm{2} 6.00 \mathrm{E}-02-7.50 \mathrm{E}-02$ 2.50E $13 \quad 4.50 E \quad 13$ $4.40 \mathrm{E}$ I3 $4.50 \mathrm{E}-029.50 \mathrm{E}-0 \mathrm{C}$

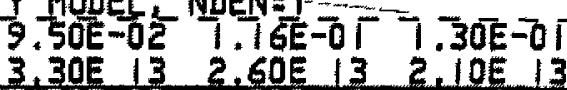

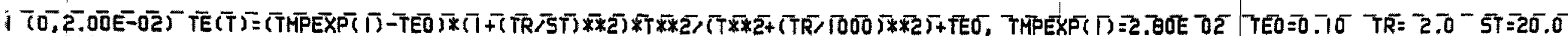

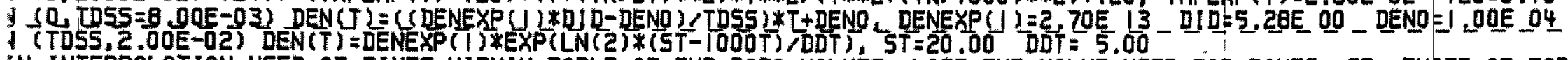
W. INTERPOLATION USED AT TIMES WITHIN TABLE OF EXP. DATA UALUES. LAST EXP. UALUE USED FOR TIMES GT, THOSE OF TABLE JR ELEMENT $=F E$ USE IONIZATION BY KUNZE.

- - - - - - - - - - - - - -

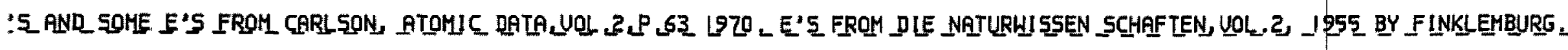

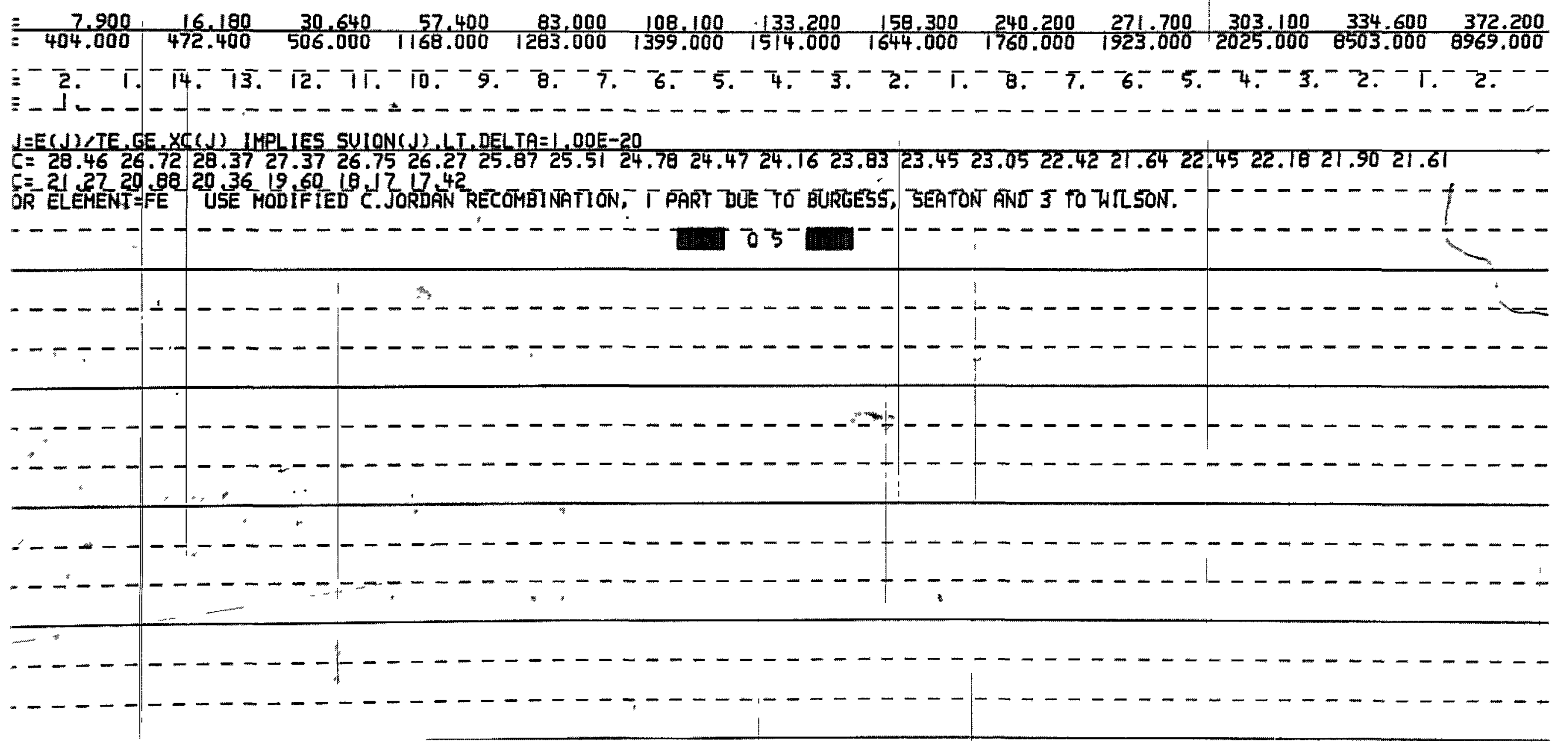


EXPMPLE 11

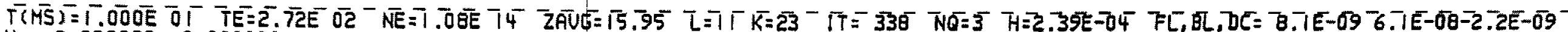

$y=\begin{array}{llllllllllllllllll}0.000000 & 0.000000 & 0.000009 & 0.000626 & 0.019818 & 0.194684 & 0.612674 & 0.157124 & 0.014511 & 0.000495\end{array}$

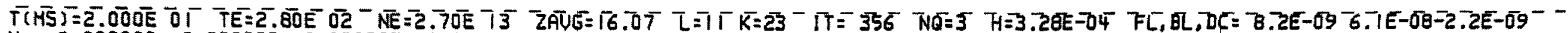
$Y=-0,000000-0,00000-000005-0000400-0.014265-0,160592-0.590622-0,204641-0.027842-0.001495$ $0.000032-0.000000-0.000000$

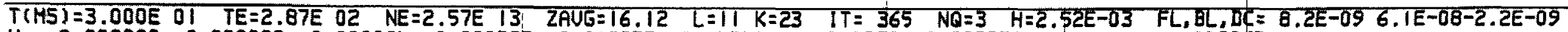

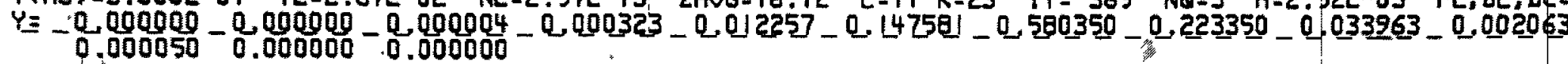

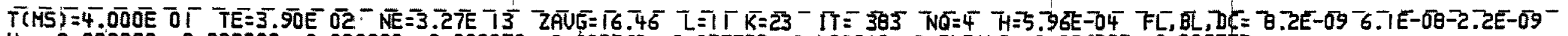
$y=\begin{array}{lllllllllllllll}0.000000 & 0.000000 & 0.000000 & 0.000050 & 0.003560 & 0.077733 & 0.480219 & 0.343142 & 0.086325 & 0.008553\end{array}$ $0.0003510 .000006 \quad 0.000000$

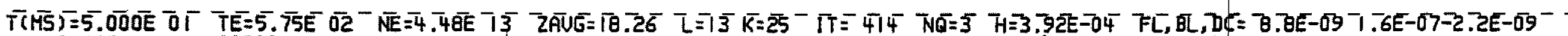
Y= $-0.00000000 .000000-0.000038-0.002249-0.038759-0.186923-0.366207-0.290418-0.098602-0.013891$

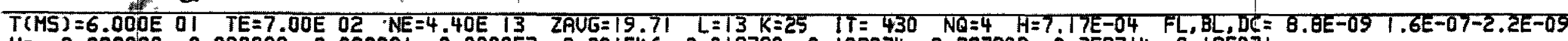
$. Y=-0.000000-0.000000-0.000001-0.00053-0.001546-0.010790-0.108034-0.292802-0.352714-0.185021$

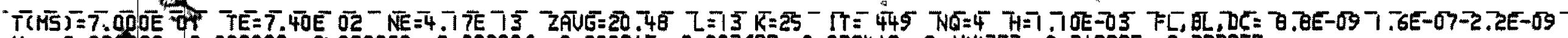
$Y=\begin{array}{llllllllllllllllllllll}0.000000 & 0.000000 & 0.000000 & 0.00006 & 0.000215 & 0.003685 & 0.032418 & 0.144357 & 0.319895 & 0.323855\end{array}$ 0.1492510 .0248920 .001351

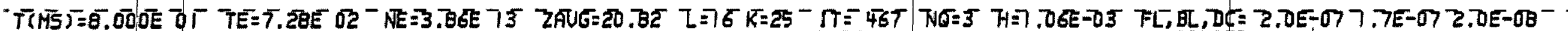

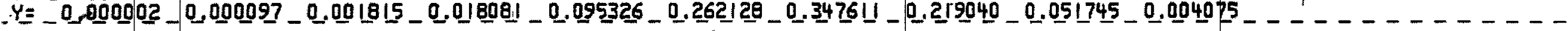

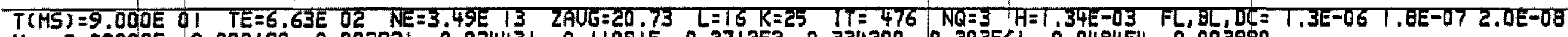
$Y=-0,00005-0,000190-0.002921-0.024431-0.110915-0.271252-0.334200-0.203561-0.048454-0.003990$

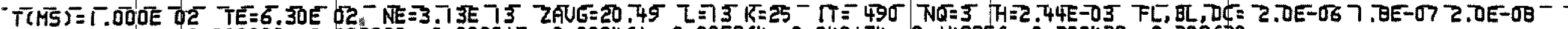
$Y=0.000000 \quad 0.000000 \quad 0.000000 \quad 0.000015 \quad 0.0004610 .005864 \quad 0.040174 \quad 0.149256 \quad 0.300438 \quad 0.308630$

$0.159617 \quad 0.033025 \quad 0.002436$

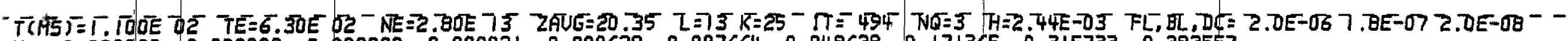

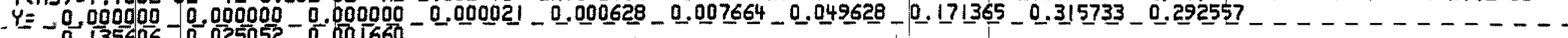
$0.135606-\frac{0.0025052}{0.0 .0001660}$

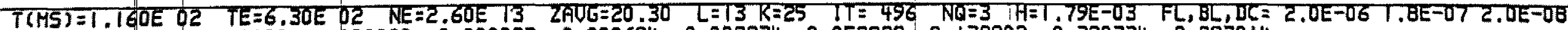
$.4=0.000000-0.000000-0.000000-0.000023-0.000684-0.008274-0.052829-0.178002-0.320734-0.287014$

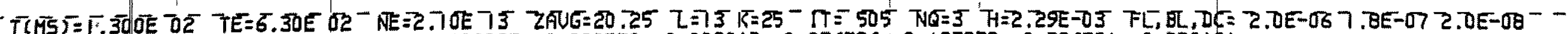
$y=0.000000 \quad 0.000000 \quad 0.000000 \quad 0.000025 \quad 0.000752 \quad 0.009013 \quad 0.056726: 0.107872 \quad 0.326791 \quad 0.280161$

$Y=\frac{0.000000}{0.118009} \quad 0.0019414 \quad 0.001130$

. $-\ldots .-17-\ldots$ 